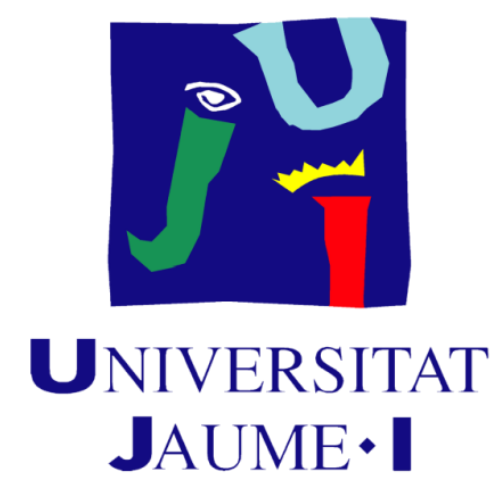

DOCTORAL THESIS

\title{
THE INFLUENCE OF NEW MARKETING APPROACHES ON THE EXPORT PERFORMANCE OF SPANISH FIRMS
}

AUTHOR:

Fernando González Ferriz

DIRECTORS:

Javier Sánchez García

Fernando José Garrigós Simón

Castellón de la Plana, June 2018 



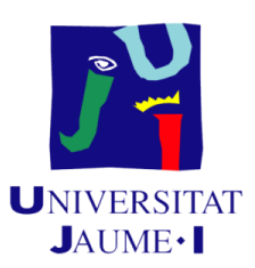

Programa de Doctorado en Economía y Empresa

Escuela de doctorado de la Universitat Jaume I

Título de la tesis:

La influencia de los nuevos enfoques de marketing

en el resultado exportador de las empresas españolas

Memoria presentada por Fernando González Ferriz

para optar al grado de doctor de la Universitat Jaume I

El doctorando:

Los directores:

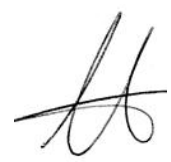

Fernando González Ferriz

Javier Sánchez García

Fernando J. Garrigós Simón

Castellón de la Plana, Junio de 2018 

To my wife Anna

and my daughter Paula 



\section{ACKNOWLEDGEMENTS}

First of all, I would like to thank all the companies and superiors who gave me the opportunity to grow as a professional throughout my working life, with a special mention to three particular persons: José Martínez from Curtidos Jomar, Jesús Martínez from Delfin Group and Iñigo Febrel from the Spanish Trade Commission in Hong Kong.

In the second place, I am extremely grateful to all the people who contributed to this investigation in one way or the other, especially to those who filled in the questionnaire, as they provided the necessary information for this research. Without them, this thesis would simply not have been possible. As a consequence, I would like to thank institutions like ICEX, IVACE, ASEPRI, AVECAL, ATEVAL or ANIEME for the information they elaborate and share, companies and particulars from different fashion sectors (Martín Espinosa, Martín Hernández, Carmen Sierra, Jorge Hernández, Pablo Amorós, Joaquín Marco, M. Angeles Ferrero, Borja Pastor or Eulogio Crespo, just to name a few) and colleagues in the export industry (Javier Navarro, José Bañón, Javier Soler, Electo Córdova, Ignacio Trigo and Jorge Guarner).

In the third place, I would like to express my gratitude to the directors of this thesis (Javier Sánchez García and Fernando José Garrigós Simón), and the Institutions they represent (Jaume I University of Castellón, and Polythecnic University of Valencia). Without their guidance and support, this research could not have been carried out.

And finally, last but not least, I would like to thank my family: my parents who always considered education as a preference, and both my daughter Paula and mi wife Anna, to whom I dedicate this thesis. 



\section{GENERAL INDEX}

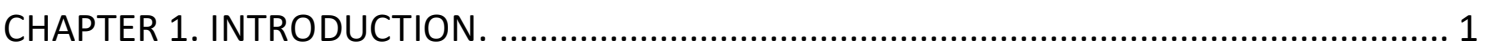

1.1. JUSTIFICATION OF THE INVESTIGATION .................................................. 1

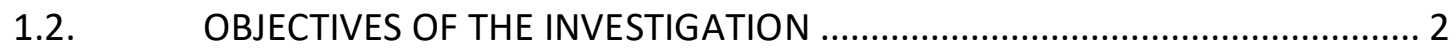

1.3. STRUCTURE OF THE INVESTIGATION ................................................... 7

CHAPTER 2. THE EVOLUTION OF INTERNATIONALIZATION THEORIES ............................ 9

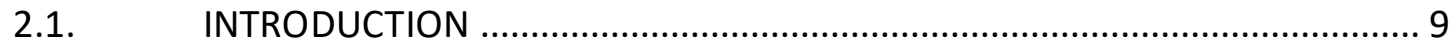

2.2. THE INTERNATIONALIZATION BACKGROUND IN SPAIN ......................... 10

2.3. THE MACROECONOMIC AND MNES PERSPECTIVE ................................... 13

2.3.1. Classical theory of International Trade and $\mathrm{H}-\mathrm{O}$ model ........................... 14

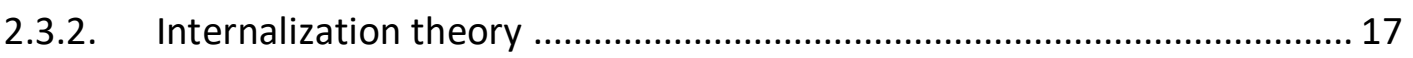

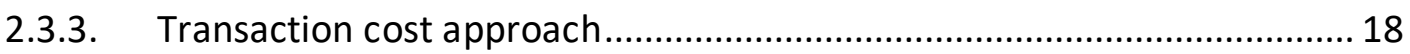

2.3.4. The eclectic paradigm theory (OLI) …....................................................... 18

2.3.5. The monopolistic advantage theory (industrial organization theory) ...... 19

2.3.6. The competitive advantage of nations (Porter) ..................................... 20

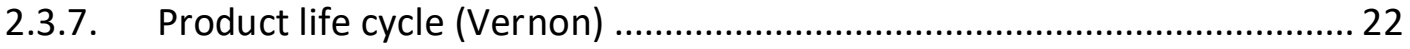

2.4. THE SMALL AND MEDIUM ENTERPRISES (SMES) PERSPECTIVE ................ 23

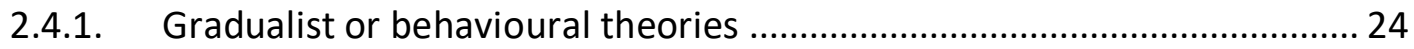

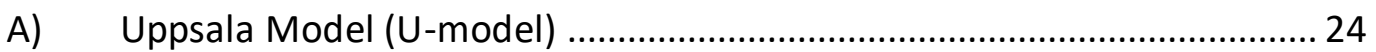

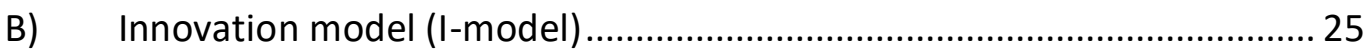




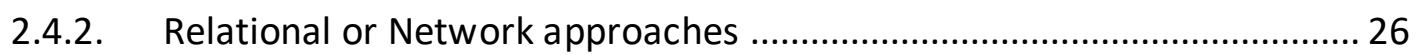

2.4.3. Resource based view (RBV) and dyna mic capabilities.............................. 27

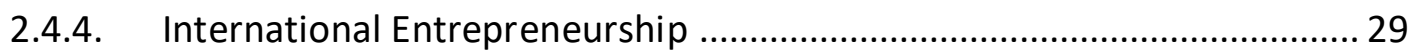

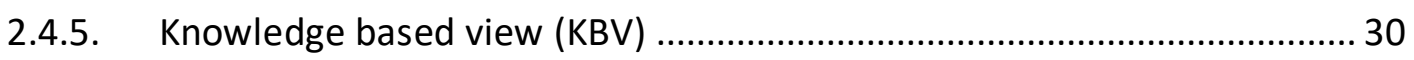

2.4.6. International New Ventures (INVs) and Born Globals (BGs) .................... 32

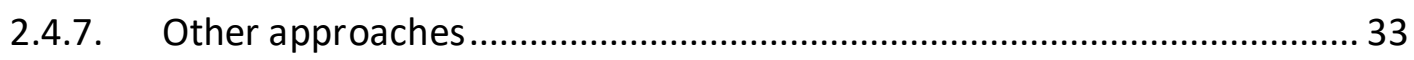

2.5. THE ANALYSIS OF EXPORT PERFORMANCE IN SMES .............................. 34

2.5.1. The determinants of export performance ................................................ 35

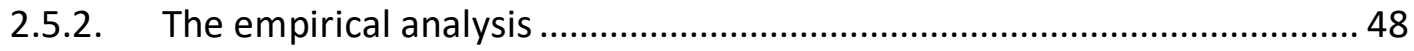

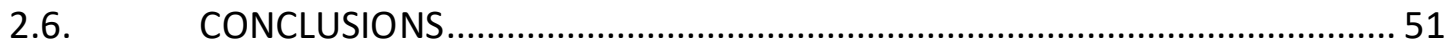

CHAPTER 3. THE EVOLUTION OF MARKETING APPROACHES ....................................... 53

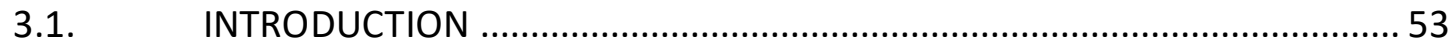

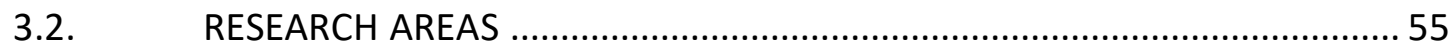

3.3. FROM CONSUMER GOODS MARKETING TO SERVICES MARKETING .........58

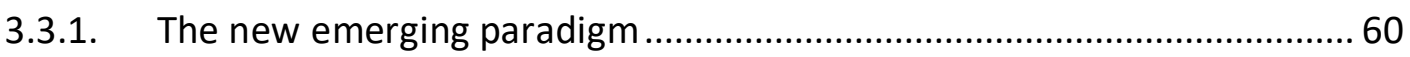

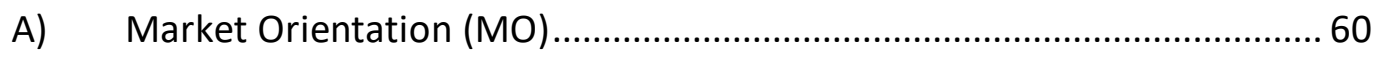

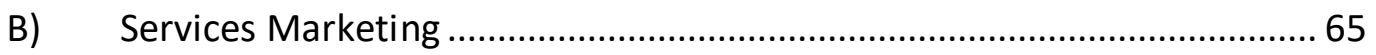

C) Relationship Marketing (RM) …......................................................... 70

D) Resource based view (RVB) and dynamic capabilities in marketing.......... 77

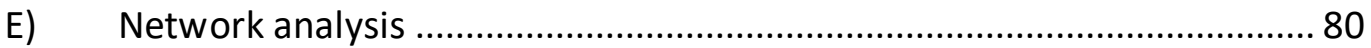

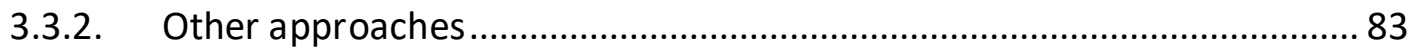

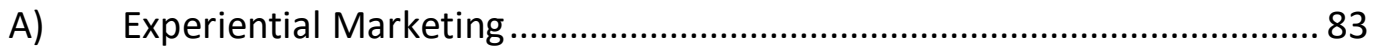

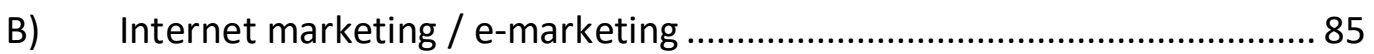

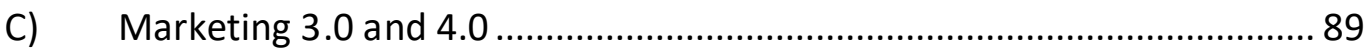

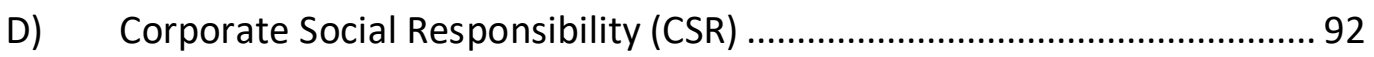

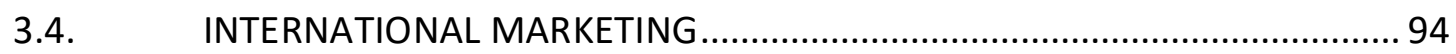




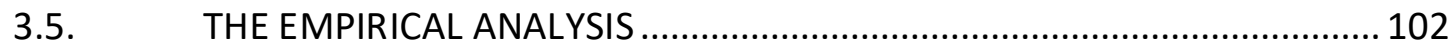

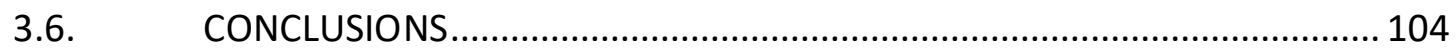

CHAPTER 4. THE EMSP MODEL OF INTERNATIONALIZATION ...................................... 107

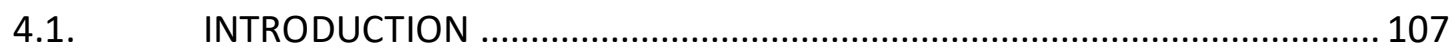

4.2. THE EMSP MODEL OF INTERNATIONALIZATION ...................................... 108

4.2.1. The determinants of export performance............................................ 109

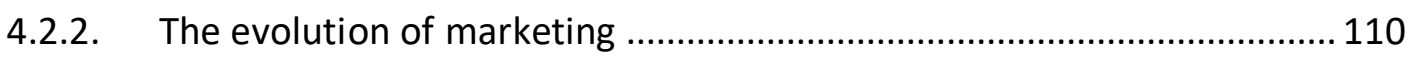

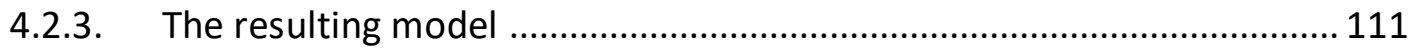

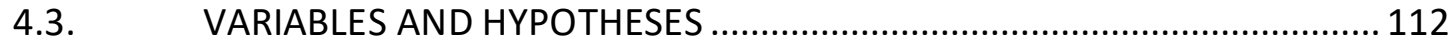

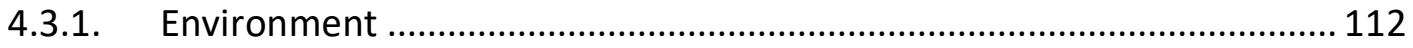

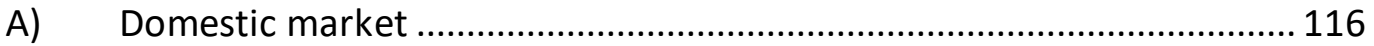

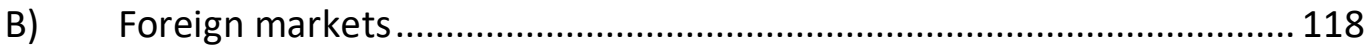

4.3.2. Firm characteristics and capabilities ..................................................... 120

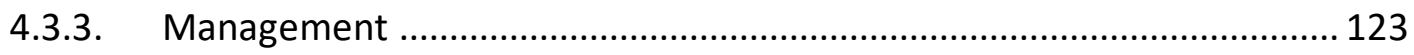

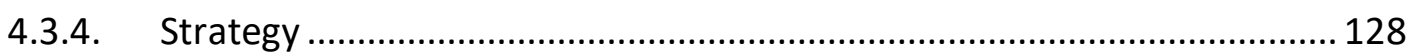

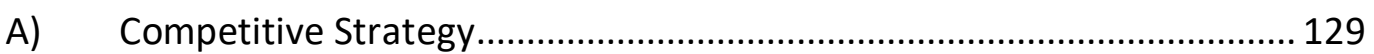

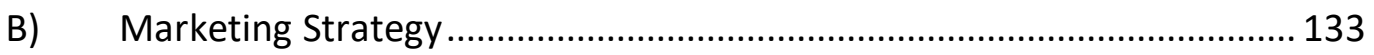

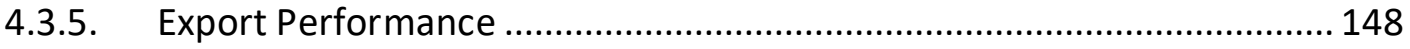

4.4. THE EMSP MODEL OF INTERNATIONALIZATION ..................................... 151

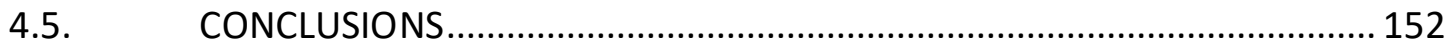

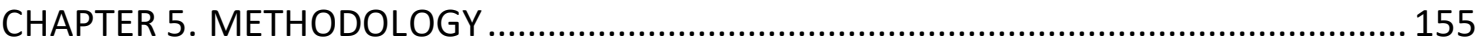

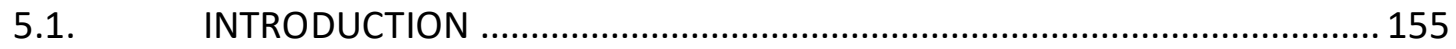

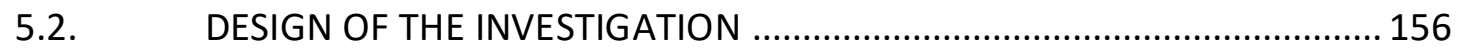

5.3. STRUCTURE OF THE QUESTIONNAIRE.................................................. 157

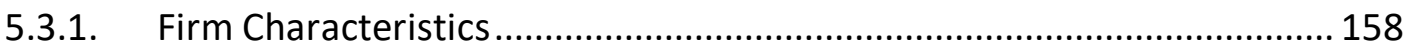

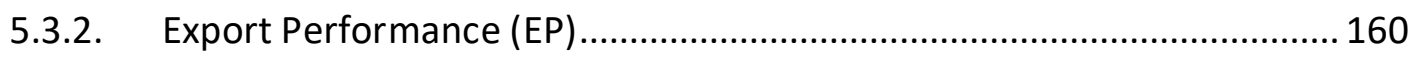




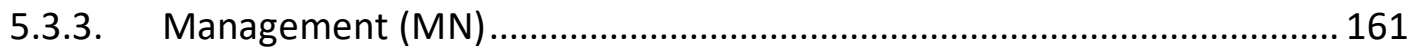

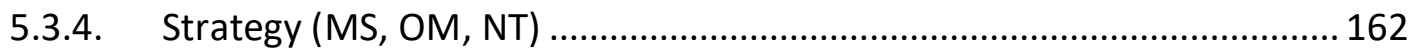

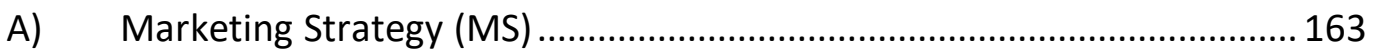

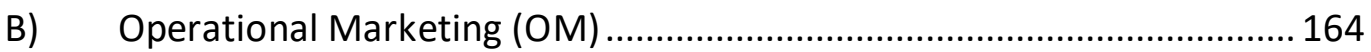

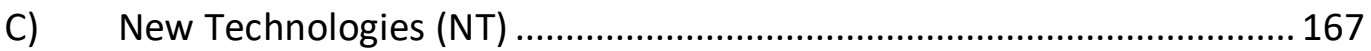

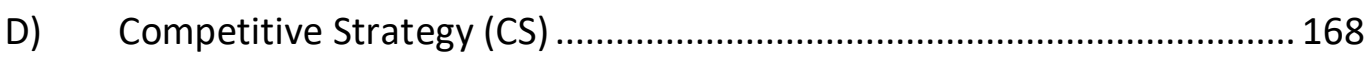

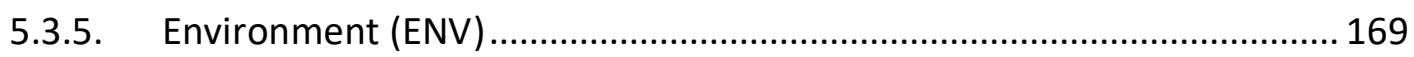

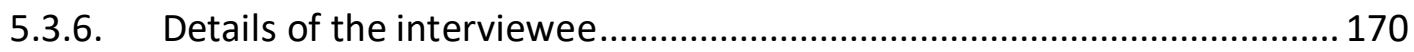

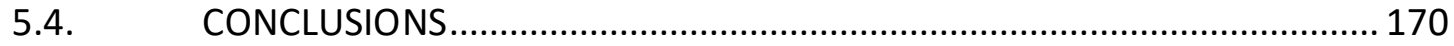

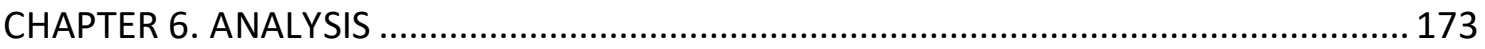

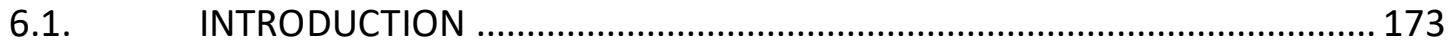

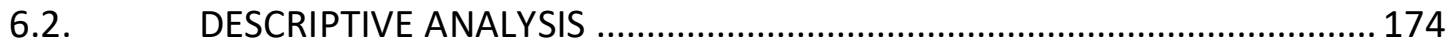

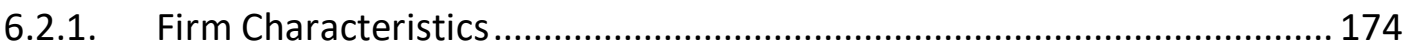

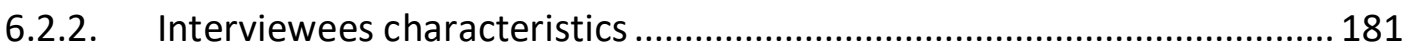

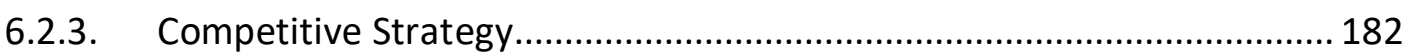

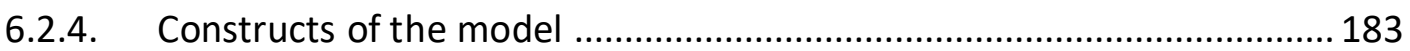

6.3. DIMENSIONALITY, RELIABILITY AND VALIDITY OF THE MODEL .............. 189

6.4. DETERMINATION OF CAUSAL RELATIONSHIPS ....................................... 199

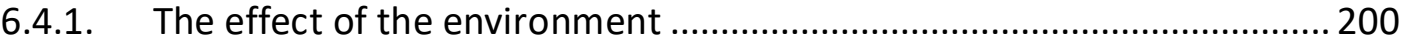

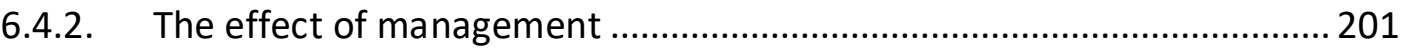

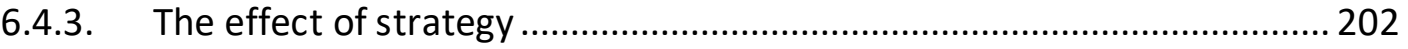

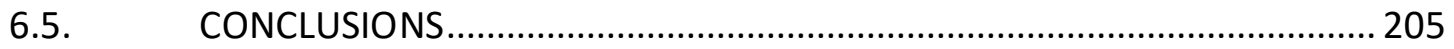

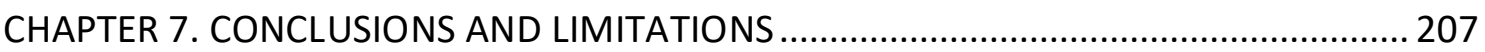

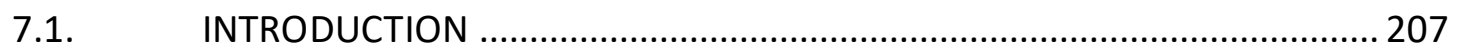

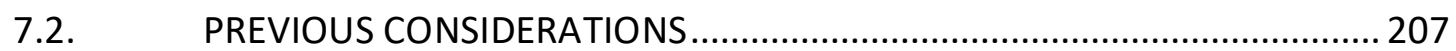

7.3. THE THEORETICAL BACKGROUND BEHIND THE EMSP MODEL ................. 209 


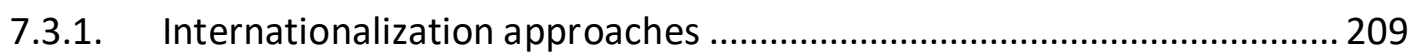

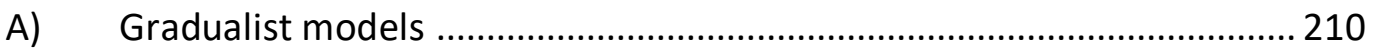

B) Resource Based View (RBV) and Dynamic Capabilities (DC) ................. 211

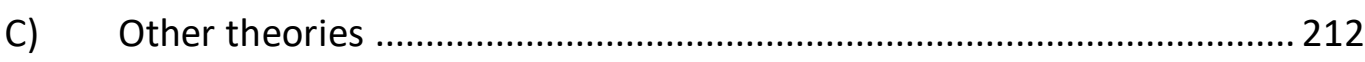

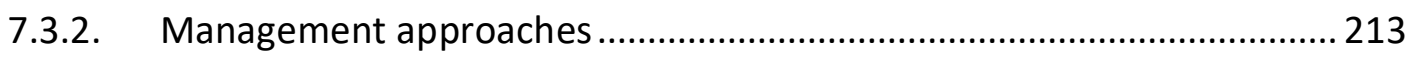

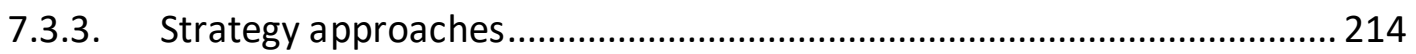

7.3.4. Marketing approaches .................................................................... 216

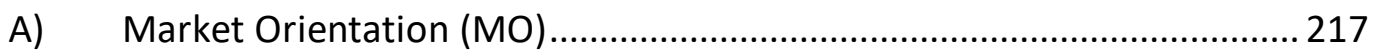

B) Relationship Marketing (RM) and Network Analysis............................ 217

C) RVB and the incorporation of New Technologies .................................218

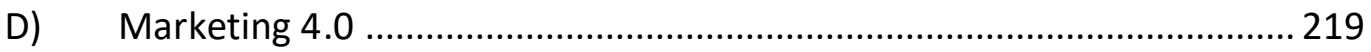

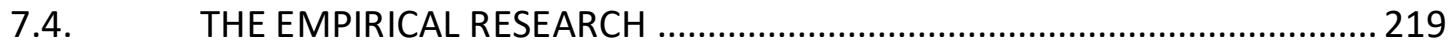

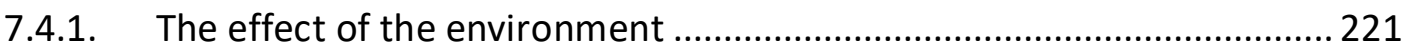

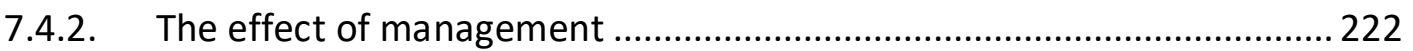

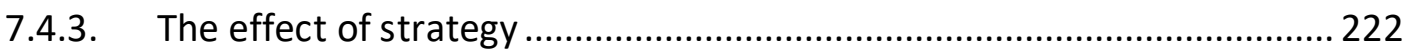

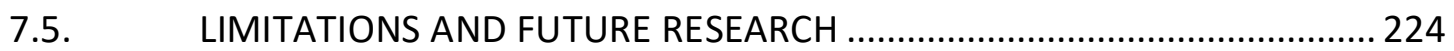

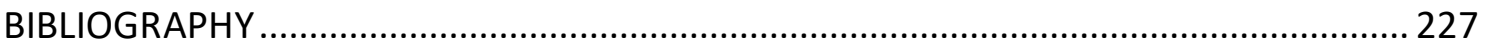

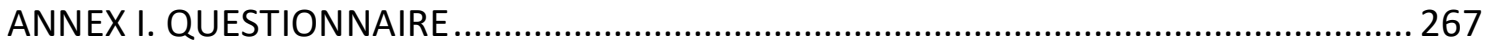




\section{INDEX OF FIGURES}

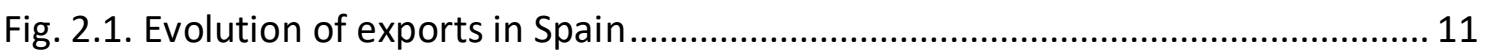

Fig. 2.2. Total exports in the European Union (2017) .................................................... 12

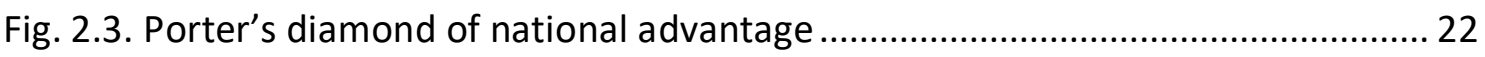

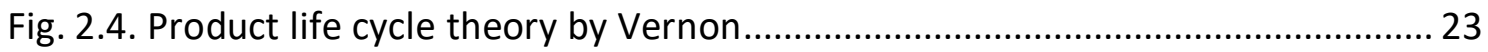

Fig. 2.5. The Uppsala model of internationalization ........................................................ 25

Fig. 2.6. Knowledge-based model of SME internationalization by Mejri and Unemoto 31

Fig. 2.7. Determinants of export performance according to Aaby and Slater ................ 37

Fig. 2.8. Determinants of export performance according to Zou and Stan .................... 38

Fig. 2.9. Determinants of export performance according to Sousa et al ........................ 39

Fig. 2.10. Conceptual framework of export marketing strategy and performance ........ 40

Fig. 2.11. Simplified export performance model ........................................................ 42

Fig. 2.12. Determinants of export performance according to Chen et al ...................... 44

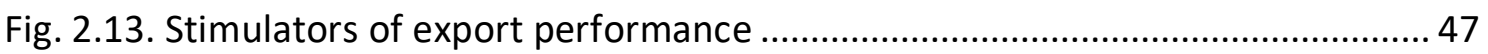

Fig. 3.1. Evolution of marketing research (1900-2016) ................................................. 59

Fig. 3.2. Market orientation according to Narver and Slater ....................................... 62

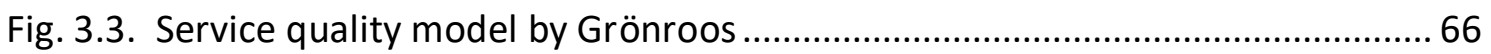

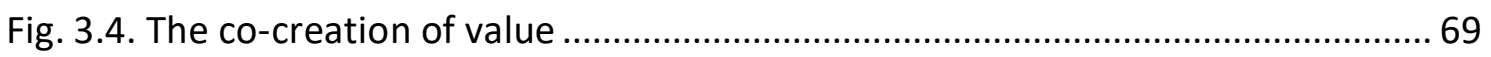

Fig. 3.5. Relationship Marketing according to Gummesson ....................................... 71

Fig. 3.6. Initial Marketing Mix Paradigm (left) and new RM Paradigm ........................... 72

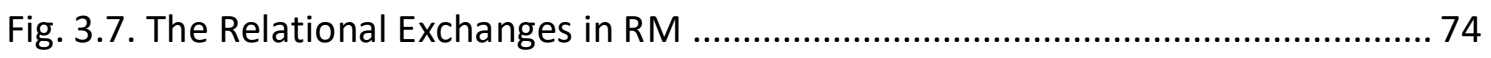

Fig. 3.8. The key mediating variable (KMV) model of RM .......................................... 75

Fig. 3.9. CRM model by Payne and Frow ....................................................................... 76 
Fig. 3.10. Conceptual model by Murray et al

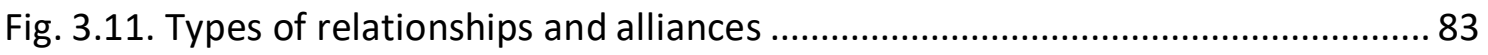

Fig. 3.12. E-business, e-commerce, e-marketing and internet marketing ..................... 86

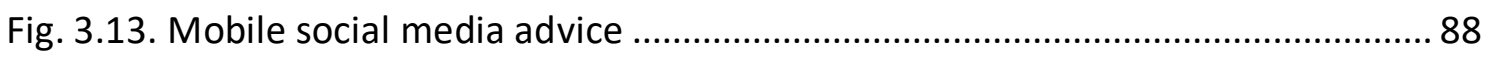

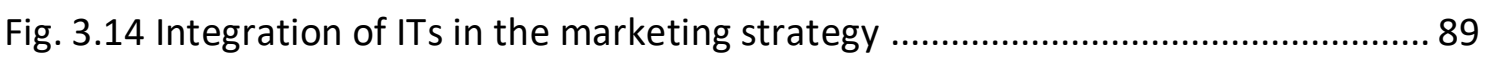

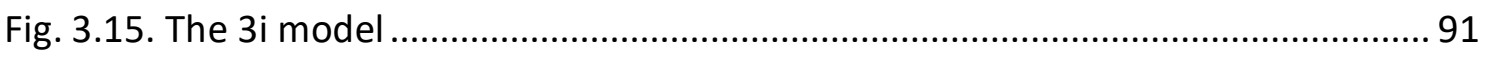

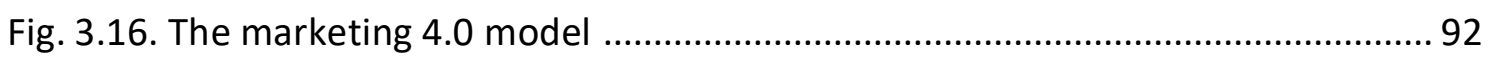

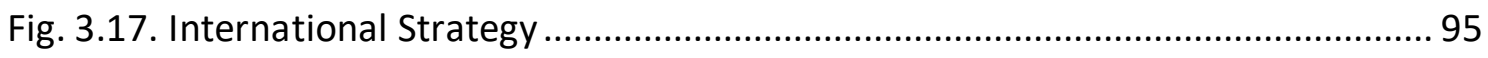

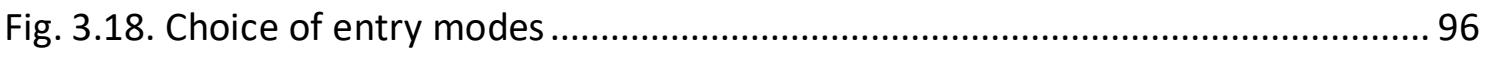

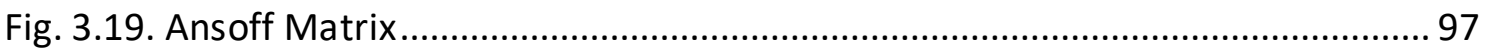

Fig. 3.20. The Global Marketing Strategy (GMS) model ................................................ 99

Fig. 3.21 Marketing capabilities in International Marketing ....................................... 100

Fig. 3.22. Strategic orientations and export marketing strategy ................................. 101

Fig. 4.1. The EMSP model of internationalization ..................................................... 108

Fig. 4.2. The EMSP model of Internationalization.................................................... 111

Fig. 4.3. Variables in the EMSP model of Internationalization .................................... 112

Fig. 4.4. Position of countries on the power distance and individualism scales.......... 115

Fig. 4.5. The five competitive forces that determine industry profitability .................. 130

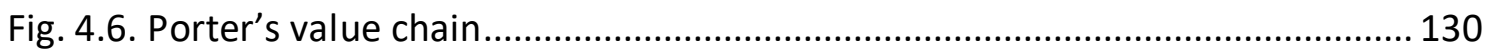

Fig. 4.7. Components of the Marketing Strategy Variable ......................................... 133

Fig. 4.8. Components of the Operational Marketing construct .................................... 141

Fig. 4.9. Hypotheses in the EMSP model of Internationalization ................................ 151

Fig. 6.1. EMSP model of internationalization with causal relationships ...................... 199 


\section{INDEX OF TABLES}

Table 2.1. Evolution of exports, imports and balance of trade in Spain (2000-2017) .... 10

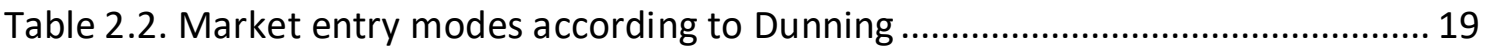

Table 2.3. Determinants of export performance (1980-2012 review) ........................... 43

Table 2.4. Determinants of export performance according to Chen et al ..................... 45

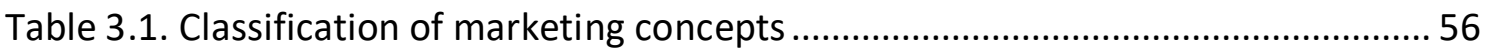

Table 3.2. Research Themes in Marketing (1978-2014) .................................................. 57

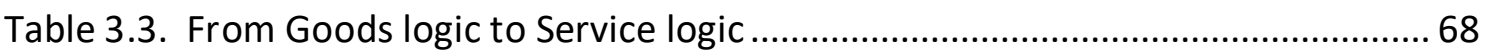

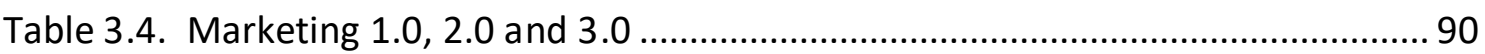

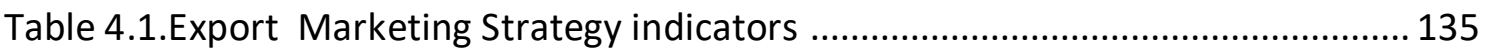

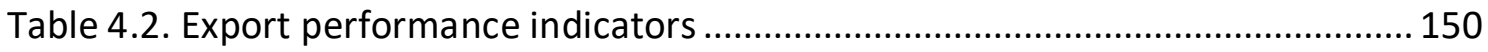

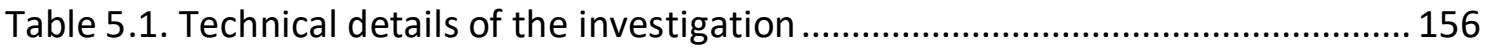

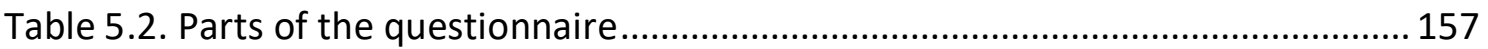

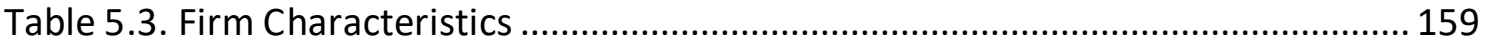

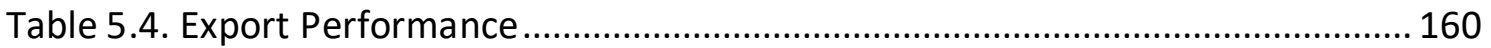

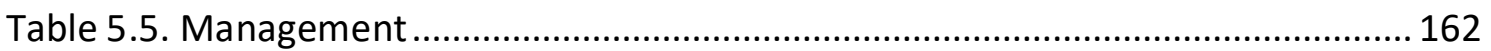

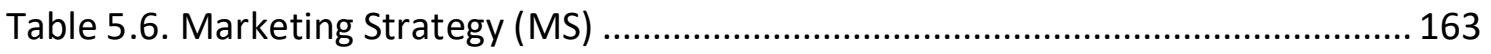

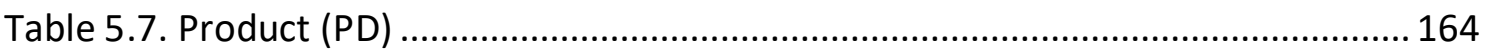

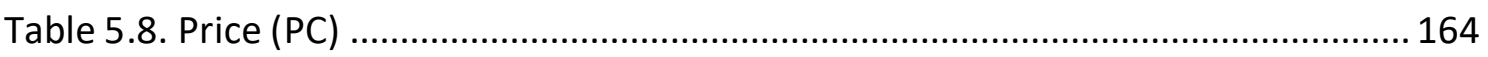

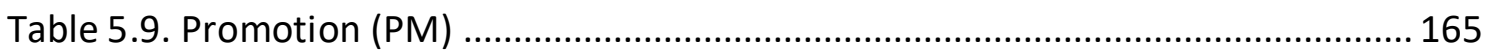

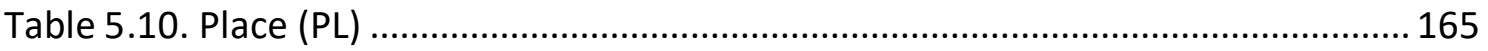

Table 5.11. Bibliography for Operational Marketing (OM) scales ................................. 166

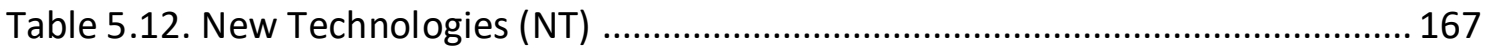




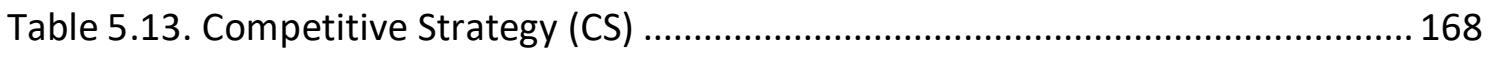

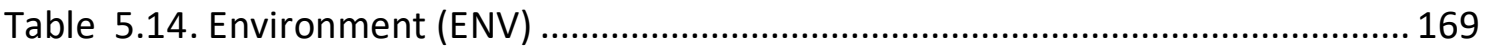

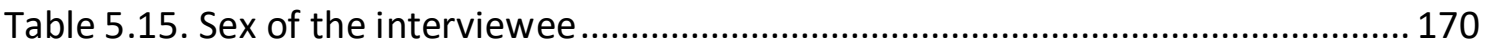

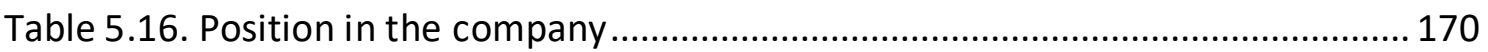

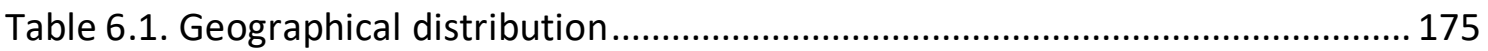

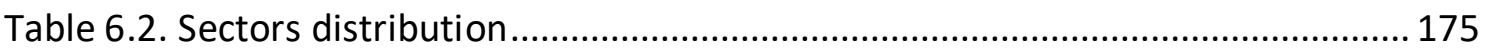

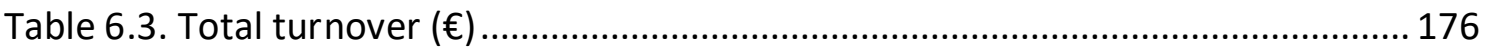

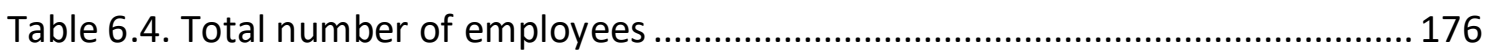

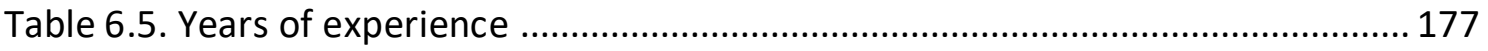

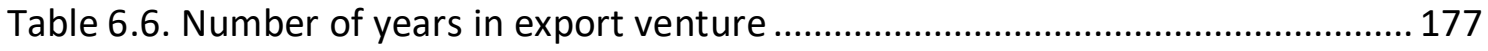

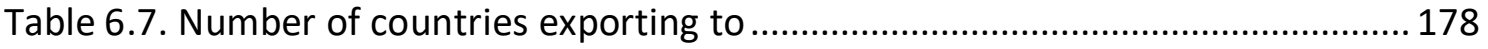

Table 6.8. Relation between Years in Exports and N. of countries exporting to. ......... 178

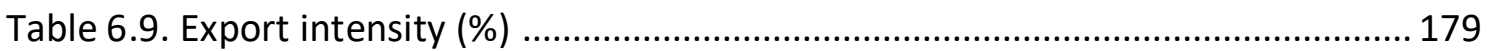

Table 6.10. Exports to EU / Total Exports (\%) .............................................................. 180

Table 6.11. Relation between Years in Exports and Exports to EU/Total Exports........ 180

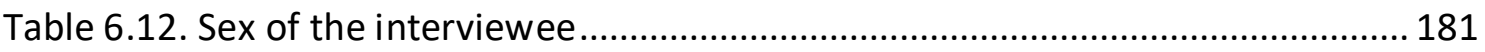

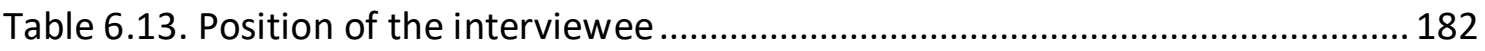

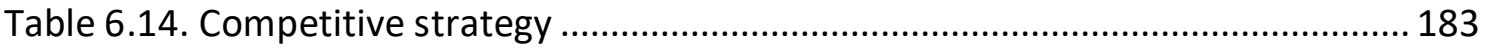

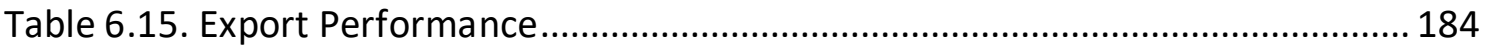

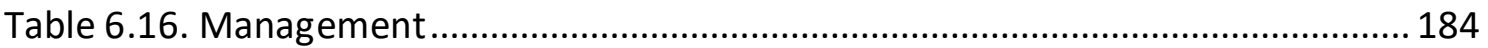

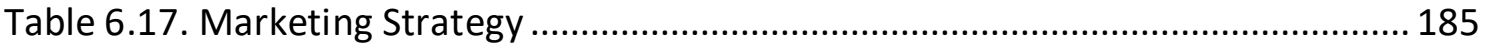

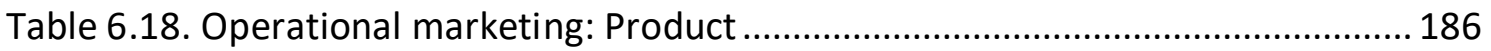

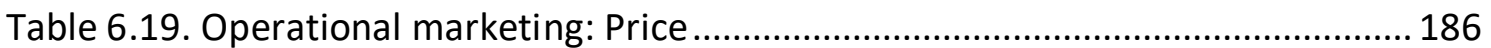

Table 6.20. Operational marketing: Promotion ........................................................... 187

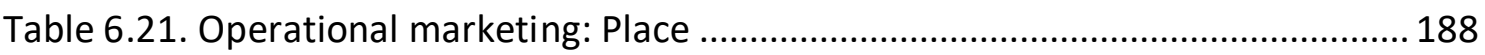

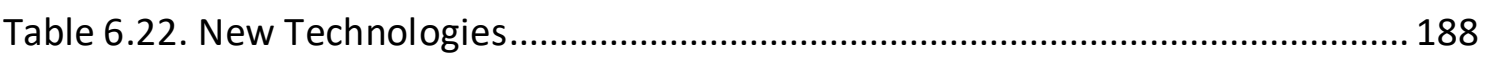


Table 6.23. Environment

Table 6.24. CFA for the Operational Marketing (OM) item parceling 191

Table 6.25. Analysis of the dimensionality, reliability and validity of OM 193

Table 6.26. Discriminant validity of the scales associated to OM 195

Table 6.27. Dimensionality, reliability and validity of the EMSP model. 196

Table 6.28. Discriminant validity of the scales associated to the EMSP model 198

Table 6.29. Causal relationships of the model 199

Table 6.30. Causal relationships for the Environment variable 200

Table 6.31. Causal relationships for the Management variable 201

Table 6.32. Causal relationships for the Marketing Strategy variable 203 


\section{CHAPTER 1. INTRODUCTION.}

\subsection{JUSTIFICATION OF THE INVESTIGATION}

International trade in general, and exports in particular, have attracted the attention of plenty of managers and researchers in the last years.

Spain is not a different a case, especially when exports (along with the touristic sector) have played a fundamental role in the recovery of the economy during the global crisis started in 2008.

If we go further, the figures of Spanish exports have presented a rising trend since the beginning of the century (see fig. 2.1 on chapter 2 for details), with the number of exporting companies growing year after year.

On the other hand, the industrial sector in our country is quite particular, with a big number of SMEs (small and medium enterprises) scattered all over the territory. These companies do not face internationalization processes the same way multinational enterprises do, as they present certain limitations.

This thesis pretends to analyze the way exporting companies in the fashion sector behave, how they develop their competitive strategy and what the factors determining the success or failure of their export ventures are. 
In order to do so, we have developed a theoretical model (the EMSP model of internationalization) with a certain number of variables that are supposed to have an effect on the performance of these companies. A later empirical analysis will help us to determine the actual relationship between these variables.

\subsection{OBJECTIVES OF THE INVESTIGATION}

In the present context of global markets and growing exports, companies are obliged to compete in many different environments. Some of them, especially multinational firms, are able to develop the necessary capabilities to detect the changes in the environment and adapt their competitive strategies, but some others, like SMEs and micro companies do not always have the chance.

This investigation pretends to offer a theoretical and practical framework for the study of the determinants of the export performance in those smaller companies where research is not always carried out.

The final objective is determining the variables that affect the behaviour of exporting companies from the fashion and design sector in Spain and the way they interact. And we do it by introducing the new approaches in the marketing discipline, which is fundamental to the development of a successful strategy.

The first step in the investigation is going through the previous research on the subject in order to determine a starting point. The process, however, leads us to a big number of disciplines and approaches.

As a result, we are able to conclude that the export performance analysis is influenced by four different disciplines: internationalization, management, strategy and marketing. These are the four pillars supporting the approaches behind our model and will be thoroughly developed throughout this thesis.

Additionally, the theoretical background will constitute the foundations of the model and determined by the evolution of different theories (Resouce Based View, 
Knwoledge Based View, Dynamic capabilities, Contingency theory ...) that will affect one or several disciplines.

The main contributions from the internationalization theory come from authors like Aaby and Slater (1989), Zou and Stan (1998), Leonidou et al (2002), Sousa et al (2008), Chugan and Singh (2014) or Chen et al (2016), who propose different models where the determinants of the export performance are clearly defined. However, the big number of variables resulting from this analysis takes us to a scenario with no consensus regarding the constructs to be considered in an empirical research, their measuring scales and the relationship among them.

The starting point for our theoretical model is the research carried out by Cavusgil and Zou (1994) where the marketing strategy construct plays a predominant central role in the determination of export performance. This approach was also developed by other authors like Katsikeas et al (2000), Leonidou et al (2002), Chugan and Singh (2014) and Chen et al (2016), considering the existence of an external variable (the environment) which cannot be controlled by the company, but influences internal characteristics (like management) and conditions the marketing strategy, which will, at the time, have an effect on the export performance of the company.

This analysis, which is approached from the Resource Based View theory, leads us to the basic structure of the EMSP model, considering the following variables: environment (ENV), management (MN), Marketing Strategy (MS) and export performance (EP) - the final dependent variable.

The theory on dynamic capabilities is also present throughout the investigation. Firm capabilities are fundamental to develop a series of intangible assets which result in the competitive strategy of the organization performance (Katsikeas et al, 2000; Barney, 1991; Prahalad and Hamel, 1990; Nelson, 1991; Penrose, 1959). In our case, the Management and Marketing Strategy constructs are considered from this perspective, and represent the way our companies develop their internal strategies in order to adapt to the constant changes in the environment. 
The theory on management plays a very important role in this thesis as well. Supported by other theoretical streams like Knowledge and Resource Based Views and dynamic capabilities, managers are fundamental to the success of internationalization process as they are able to analyze the environment and develop the necessary strategies to achieve a higher performance (Morgan and Katsikeas, 2012; Parnell et al, 2015; Fernandez and Alegre, 2015; Barney, 1991; Prahalad and Hamel, 1990; Nelson, 1991; Penrose, 1959; Teece, Pisano and Shuen, 1997; Shcumpeter, 2013; Bouncken et al, 2015).

On the other hand, the competitive strategy of the company, which is determined by its managers, as aforementioned, will show the way a particular organization pretends to differentiate from competitors and increase the profit. This can be done by developing a certain number of abilities coming from inputs like technology, innovation or marketing (Porter, 1980, 85; Camisón, Garrigós and Palacios, 2007; Lado et al, 2004)

Although our research places the focus on marketing, that does not mean that other capabilities (like technology or innovation) are not important. In our particular case, marketing policies are specially determinant because the companies in the fashion sector base their strategies on developing new products constantly, and they should meet their customer's requirements and needs. Marketing constitutes a capability which is very rarely outsourced, contrary to others like production or the development of new technology.

The described central role of marketing strategies leads us to the study of the main approaches in this discipline, with a clear conclusion: the marketing theory has evolved from traditional models based on marketing mix policies (product, price, promotion and place), to other models based on market orientation (companies focus on creating customer value in order to sustain competitive advantage), relationship marketing (how to develop long term relationships with customers in order to achieve customer loyalty), or the introducing of new technologies to the process.

Traditional and modern approaches are not exclusive, but inclusive and complimentary. As a consequence, the marketing strategy variable will be influenced by short term 
operational marketing policies and new technologies (Prasad et al, 1990, 2001; Parnell et al, 2015; Kotler, 2010, 2016; Vargo and Lusch, 2004), with the new approaches playing a fundamental role.

This thesis pretends to introduce a new model of internationalization which is based on the traditional theory regarding the determinants of the export performance. The variables affecting the success of export ventures are very clearly determined throughout the literature, and we are not going to incorporate any new developments. However, that analysis is not enough to explain the reality in the case of the specific sector we are considering.

The traditional analysis has ignored, in many cases, the way new marketing approaches affect theoretical and practical research. As a consequence, this is the point where we try to merge two disciplines (marketing and internationalization) which have usually moved in separate directions.

The marketing strategy has been analyzed in plenty of papers from a traditional point of view, and it is only in some recent studies, mainly incorporating the Resource Based View philosophy, that items like the development of social and ethical responsibility policies or the introduction of relational marketing approaches are being taken into consideration (Gadenne et al, 2009; Orlitzky et al, 2011; Antonietti and Marzucchi, 2014; Chen et al, 2016).

This is certainly a tipping point in the evolution of the internationalization theory, but even the researchers who have considered the subject from new perspectives, have neglected the combination of other decisive factors like the incorporation of new technologies to the marketing process.

From the theoretical perspective, the EMSP model of internationalization contributes to the analysis by considering the most determinant streams in the fields of marketing and internationalization in order to build an integrating model where they can offer an explanation to the internationalization of exporting companies in the fashion sector.

From the empirical perspective, our model pretends to pay a special attention to the development of the marketing strategy construct in order to incorporate, not only 
strategic and operational aspects, but also innovative processes which are analyzed from the introduction of new technologies (Prasad et al, 2001; Song et al, 2008; Parnell et al, 2015), fostering relationships with customers and other members from the distribution channel, something related to the marketing 3.0 and 4.0 approaches (Kotler, 2010, 2016).

Thanks to the development of the EMSP model of internationalization carried out throughout this investigation, the companies in the fashion sector will be able to know the way their competitors develop marketing strategies and how important the introduction of new technologies is supposed to be.

A descriptive analysis will focus on the characteristics of the exporting companies operating in the sector, the competitive strategies they develop, and the average results for every item describing the main variables of the model (Environment, Management, Strategic and Operational Marketing Strategies, New Technologies and Export Performance).

Additionally, a final analysis based on Structural Equations Modelling (SEM) will focus on the particular objectives of the research, which are referred to the way the previously described variables interact, and the way the causal relationships of the model are established (see chapter 4 for details).

In this direction, we will focus on the role of the environment as an external agent, considering that this variable has an effect on the characteristics of the management, on the implementation of the marketing strategy, and on the final export performance of the company.

Another particular objective will be the analysis of management capabilities as one of the key intangible assets that will contribute to the competitive advantage of the company. Managers are supposed to influence the way the marketing strategy is carried out and also to have an effect on the export performance.

And finally, a third sub-objective will focus on the importance of the marketing strategy construct, which should have a fundamental effect on the final efficiency of the company. At the same time, we will consider the influence of marketing mix 
policies and new technologies as determinants of the strategy construct, which plays the role of an intermediary variable.

\subsection{STRUCTURE OF THE INVESTIGATION}

The investigation carried out in this thesis has been structured along seven chapters with three different blocks. A first part develops the state of the art regarding the disciplines which are the basis for the theoretical development of the model. A second part refers to the definition of the model, containing the different constructs and items which are used in the empirical research. And finally, a third part presents the conclusions of the investigation.

Chapter 1 describes the motivations and the objectives of the investigation. It provides a general overview of the thesis and introduces the rest of chapters.

Chapter 2 develops the most important internationalization theories, firstly from a macroeconomic point of view and secondly from a microeconomic perspective, focusing on the variables that affect the export performance of a company, a crucial factor for the definition of the model.

Chapter 3 is devoted to marketing approaches, paying a special attention to the most important subjects of research in this discipline, and describing the evolution from a traditional marketing conception based on the product, to a present conception based on services and experiences. The introduction of new technologies in the marketing process and the interaction with the customer can also be considered as subjects of major interest.

Chapter 4 presents the variables of the model and the way they behave in other empirical studies. A first definition of the EMSP model of internationalization is introduced and the causal relationships among variables are established. 
Chapter 5 concentrates on methodology details and determines the structure of the questionnaire and the way all the items for the constructs were obtained. Measuring scales are also considered at this point.

Chapter 6 is related to the analysis of the model, which is carried out from two different angles: the descriptive analysis with details of the companies considered in the sample, and the confirmatory factor analysis that will determine the validity of the causal relationships in the model.

Chapter 7 introduces the conclusions of the investigation, paying a special attention to the acceptance or rejection of the predetermined hypotheses. This explains the way all the variables interact and finally affect the efficiency of the company, which is measured through the export performance construct.

Finally, bibliography is presented on a final annex. 


\section{CHAPTER 2. THE EVOLUTION OF INTERNATIONALIZATION THEORIES}

\subsection{INTRODUCTION}

As already mentioned on chapter 1 , the starting point for this investigation will be the study of the internationalization theories and their evolution in the last decades. This analysis will contribute to the determination of the variables in our model, both from theoretical and empirical perspectives.

A first part will focus on the characteristics of the foreign trade sector in Spain, and will show the behaviour of export figures in the last two decades, highlighting their important contribution to the economy.

A second part will determine the most important theoretical developments in the literature, starting from a macroeconomic perspective, based on nations and multinational companies, and continuing towards a microeconomic conception, which takes small and medium companies as the basic unit of analysis.

The most significant section of the chapter will consider the research on the determinants of the firm's export performance, which is fundamental to determine the basic structure of our model, together with the dependent and independent variables. The theory determines the existence of external (Environment) and internal (Management and Strategy) inputs that have an effect on the final export performance of the company. 
Finally, once the theory regarding the model is described, special attention will be paid to the empirical analysis, which is characterized by the great diversity of interpretations.

However the state of the art would not be complete without the introduction of the new approaches from the marketing theory, which add the differentiating factor to this research, and will be analyzed on chapter 3.

\subsection{THE INTERNATIONALIZATION BACKGROUND IN SPAIN}

As already specified on Chapter 1, internationalization has been the basis of plenty of research studies through the last years, and exports have been considered as a way to increase the efficiency and competitiveness of an economy.

In the case of Spain, since its entrance in the EU in 1986, exports have experienced a tremendous increase year after year. Table 2.1 shows the evolution of exports, imports and the balance of trade for the last seventeen years, and interesting conclusions can be obtained.

Table 2.1. Evolution of exports, imports and balance of trade in Spain (2000-2017)

\begin{tabular}{cccccc}
\hline Years & Exports & Imports & Balance & Coverage & Exports growth \\
\hline 2000 & 124.18 & 169.47 & -45.29 & 73.27 & - \\
2001 & 129.77 & 173.21 & -43.44 & 74.92 & $4.50 \%$ \\
2002 & 133.27 & 175.27 & -42.00 & 76.04 & $2.69 \%$ \\
2003 & 138.12 & 185.11 & -46.99 & 74.61 & $3.64 \%$ \\
2004 & 146.92 & 208.41 & -61.49 & 70.50 & $6.38 \%$ \\
2005 & 155.00 & 232.95 & -77.95 & 66.54 & $5.50 \%$ \\
2006 & 170.44 & 262.69 & -92.25 & 64.88 & $9.96 \%$ \\
2007 & 185.02 & 285.04 & -100.02 & 64.91 & $8.56 \%$ \\
2008 & 189.23 & 283.39 & -94.16 & 66.77 & $2.27 \%$ \\
2009 & 159.89 & 206.12 & -46.23 & 77.57 & $-15.50 \%$ \\
2010 & 186.78 & 240.06 & -53.28 & 77.81 & $16.82 \%$ \\
2011 & 215.23 & 263.14 & -47.91 & 81.79 & $15.23 \%$ \\
2012 & 226.11 & 257.95 & -31.83 & 87.66 & $5.06 \%$ \\
2013 & 235.81 & 252.35 & -16.53 & 93.45 & $4.29 \%$ \\
\hline
\end{tabular}




\begin{tabular}{llllll}
2014 & 240.58 & 265.56 & -24.97 & 90.60 & $2.02 \%$ \\
2015 & 249.79 & 274.77 & -24.98 & 90.91 & $3.83 \%$ \\
2016 & 256.39 & 273.78 & -17.39 & 93.65 & $2.64 \%$ \\
2017 & 277.13 & 301.87 & -24.74 & 91.80 & $8.09 \%$ \\
\hline
\end{tabular}

Source: Estacom

The descriptive analysis of export figures, shows a positive evolution of international sales in every single year, except for 2009 (-15.50\%), when commercial transactions in different countries suffered reductions higher than $25 \%$. Nevertheless, increases above $15 \%$ were achieved in the following two years, with a total rise of $74.2 \%$ in the next seven years. Moreover, according to trade statistics, Spanish exports have doubled the figure in fourteen years.

Even so, despite the increase in exports, the balance of trade has traditionally been negative (although it has been considerably reduced). In the same way, the coverage ratio (Exports/Imports) has moved to figures above $90 \%$ in the last five years. Exports are going up, but so are imports, and that makes it difficult to reduce the trade deficit.

Figure 2.1. shows a visual representation of the aforementioned evolution of exports and an important growth can be distinguished between 2009 and 2017.

Fig. 2.1. Evolution of exports in Spain

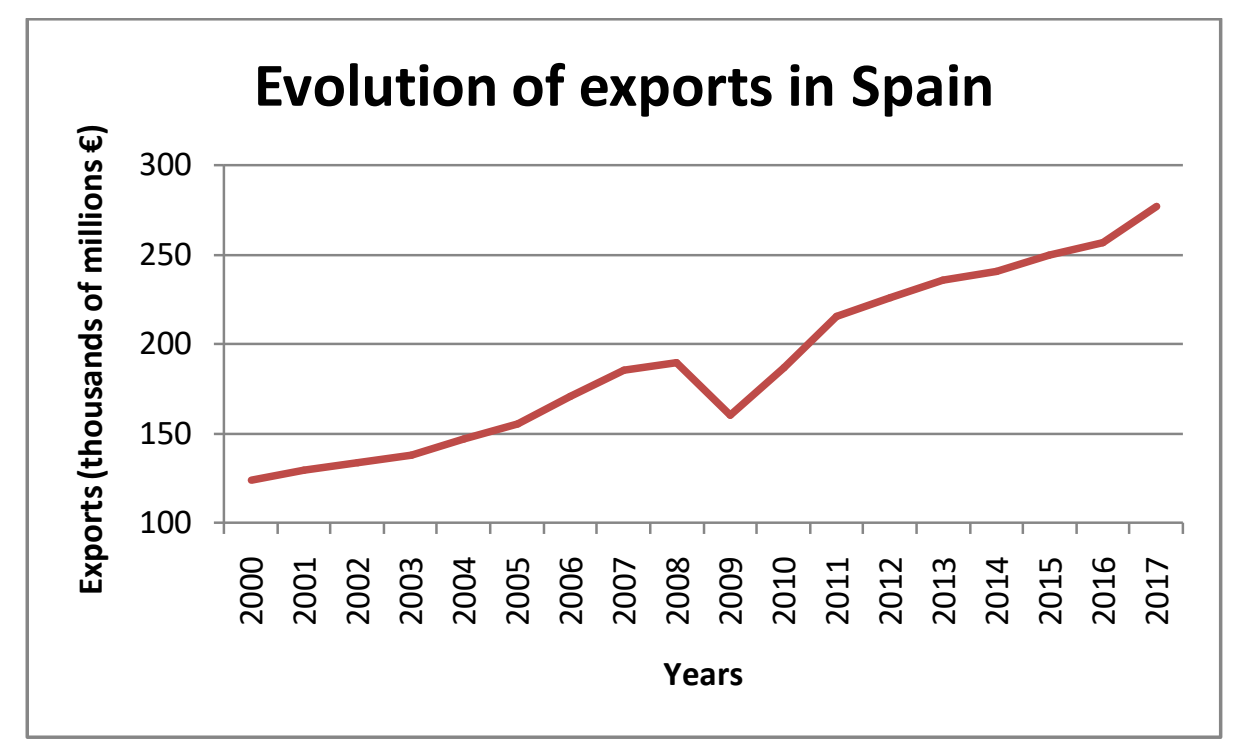

Source: Estacom 
Regarding the comparison of the evolution of exports in all European countries (figure 2.2), important differences can be found when analyzing the information. Germany is still the biggest exporting country, with figures doubling those of the Netherlands. France, Italy, United Kingdom and Belgium follow the ranking, and Spain can be found in the seventh position.

In the worldwide rankings developed by the $\mathrm{CIA}$, Spain can be found on a discreet fourteenth position, with China, Germany, USA, Japan and South Korea occupying the first places. Other rankings like the Observatory of Economic Complexity (OEC) describe Spain as the seventeenth largest export economy.

Fig. 2.2. Total exports in the European Union (2017)

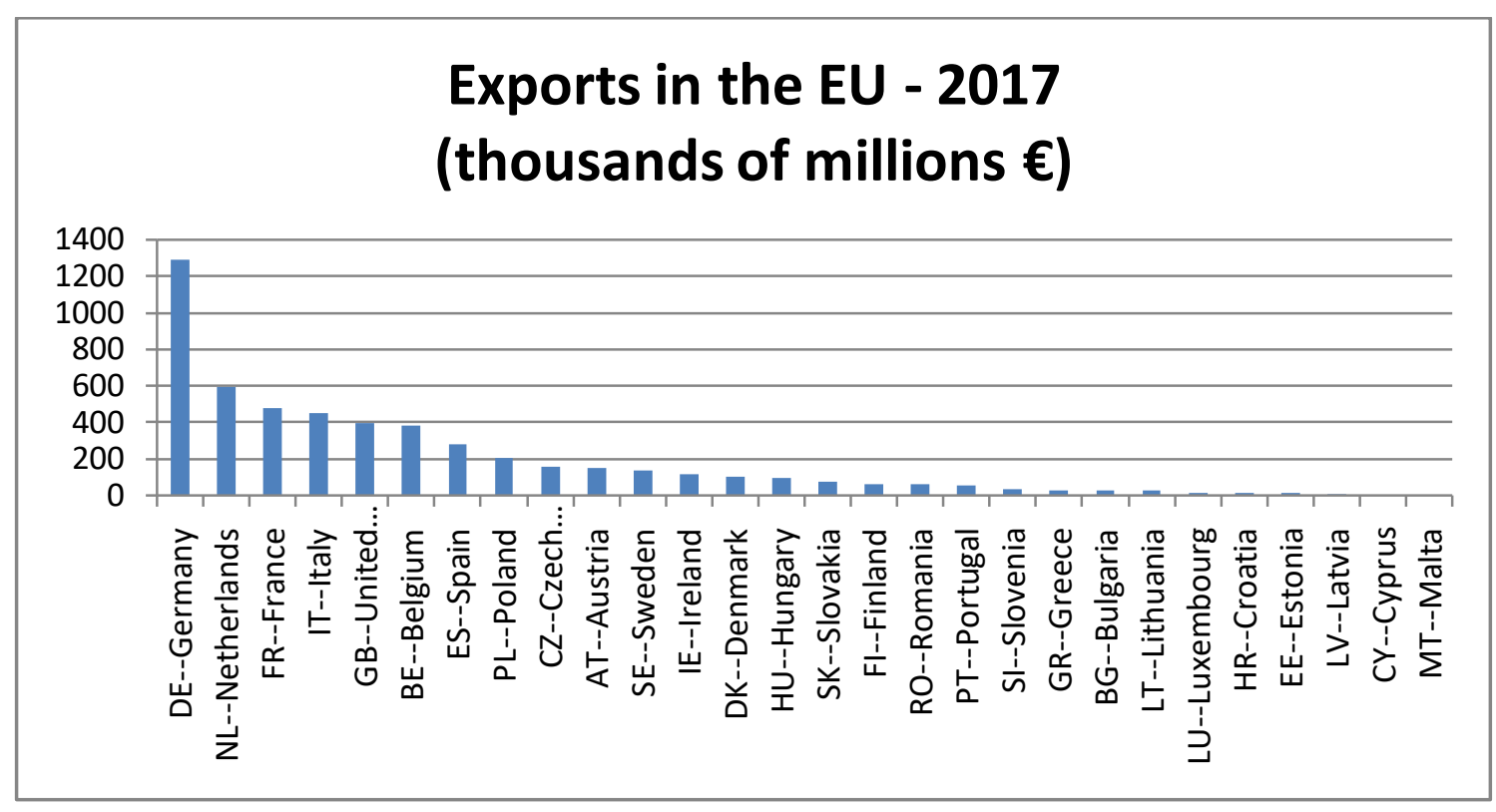

Source: Eurostacom

Despite the figures, there is still plenty of work to be done. When analyzing the exports to GDP ratio (according to the World Bank and OECD national account data files), Spain reaches a $23.8 \%$, still far away from Germany (46.1\%), the Euro area (45.8\%) or the average for all the countries in the European Union (44\%). The position in worldwide rankings comes down to the $80^{\text {th }}$ place when considering this ratio, which represents the relative importance of exports compared to the size of the national economy. 
Another peculiarity of Spanish exports is that they are still focused in European countries. Over $40 \%$ of international sales are carried out in France, Germany, Italy or United Kingdom. This means that an effort should be made to explore alternative faraway markets in order to diversify risks and increase efficiency.

On the other hand, although the number of exporting companies has increased over a $50 \%$ during the last years, the consideration of internationalization strategies is still a pending subject for a big number of SMEs in Spain.

With such a background, the focus for a further investigation, should be placed on the evolution of internationalization theories in order to determine the factors which have an influence on the performance of exporting companies, and that is the objective of this chapter.

Following the evolution of the literature in a chronological order, we will firstly analyze the macroeconomic and multinational enterprises perspective. Later on, we will concentrate on the small and medium enterprises perspective. And finally, the focus will be placed on the determinants of the export performance, which constitute one of the pillars (together with the marketing theories described on Chapter 3) for the theoretical model of our investigation.

\subsection{THE MACROECONOMIC AND MNES PERSPECTIVE}

When going through the theories of internationalization, we can find the first contributions from the parents of modern economy dating back from the $18^{\text {th }}$ century. The research carried out from authors like Adam Smith, David Ricardo or Stuart Mill can be considered as the basis for later developments introduced by researchers like Dunning, Hymer or Porter. However, all these approaches have one thing in common: they all consider internationalization from a macroeconomic point of view, placing multinational enterprises (MNEs) in the centre of the analysis.

The objective of the literature in these "early stages" of the internationalization theory is to determine why nations make the decision to produce a certain kind of products 
and sell them to other countries, which are sometimes far away from their original domestic marketplace.

Other streams consider the important contribution of MNEs to internationalization processes and centre their attention on how these organizations become global.

The following analysis will develop the most important theories and developments in this field of knowledge, and how they set the basis for a further investigation, which will involve the study of small and medium enterprises.

\subsubsection{Classical theory of International Trade and $\mathrm{H}-\mathrm{O}$ model}

The starting point of Internationalization comes from the "Classical Theory of International Trade" and is supported by Adam Smith, David Ricardo and John Stuart Mill. In general terms, this theory states that countries tend to specialize in manufacturing those goods or services with lower production costs. As a result, International Trade will promote the specialization of every country depending on their most efficient resources. That means that a country will produce and sell abroad the products which are manufactured in a more productive way and will import the products where no special efficiency is found.

The Classical Theory of International Trade is the basis of modern liberal economy and a consequence of the evolution in the following approaches:

a) Theory of absolute advantage (Adam Smith)

The Theory of Absolute Advantage (Adam Smith, The Wealth of Nations, 1776) determines that the division of labour leads to "the greatest improvement in the productive powers of labour". As a result of a more advanced division of labour, production is more efficient because more output can be produced with the same amount of labour. 
Production costs are-according to Smith-all those incurred by taking a product to a particular market. As a result, the direction of international trade is conditioned by production cost advantages in absolute terms, i.e., the costs that can be found in producing a good and carrying it to the market. So, different countries might present an "absolute advantage" in a particular good in different markets, when transport costs from the origin to the final marketplace are considered. (Schumacher, 2012)

Smith also determines an additional benefit coming from international trade as it is a way to transfer knowledge and technology between different nations. A rise in productivity leads to economic development and wealth improvement when new production techniques are adopted and used.

As a final conclusion, starting from the point that resources are generally scarce, countries will tend to produce and export the products with abundant domestic resources and will import those with limited ones.

b) Theory of comparative advantage (David Ricardo)

With the Theory of Comparative Advantage, David Ricardo (1817) shows that absolute differences in prices are not required to obtain an international specialization. Instead, countries should try to compare the opportunity costs of producing goods in different places, (relative differences in prices), which might come from differences in technology between sectors and countries.

With the Theory of Comparative Advantage, Ricardo is finding a solution to the problems raised by the Absolute Advantage approach, as countries with no specific absolute advantages might present relative advantages that would let them be competitive in International Trade.

Ricardo tried to explain the mechanisms of International Trade by considering it as "a competitive resource allocation in an international context", such in terms of trade as monetary exchange. (Fillis, 2001) 
c) The contributions of John Stuart Mill to the Theory of international trade

On "The Principles of Political Economy" (1848), Mill completed the Ricardian model by introducing the demand side, as Ricardo had only considered the supply side. In this way, according to Mill:

\footnotetext{
"The produce of a country exchanges for the produce of other countries, at such values as are required in order that the whole of her exports may exactly pay for the whole of her imports. ... So that supply and demand are but another expression for reciprocal demand: and to say that value will adjust itself so as to equalize demand with supply, is in fact to say that it will adjust itself so as to equalize the demand on one side with the demand on the other."
}

That means that the equilibrium terms of trade would be reached when the imports from a country equal the exports from the other. In the meantime, the prices of the goods should go up or down until a new equilibrium point is attained.

d) The Hecksher-Ohlin model $(\mathrm{H}-\mathrm{O})$

A refinement of the theory of comparative advantage, and consequently the classical theory of international trade, came from the neoclassical approach and the most important contribution was the Hecksher and Ohlin (1933) model, also known as the factor proportion theory.

According to $\mathrm{H}-\mathrm{O}$, the differences in the production cost structures, and therefore the prices of individual goods, which come out from the differences in national production factor endowments, formed the basis of trade among nations (Hill, 2004).

Unlike the Ricardian model of comparative advantage that considered efficiency in production as the basis of national advantage, the $\mathrm{H}-\mathrm{O}$ model considered national factor endowments as the basis of that advantage, which explains the concept of international trade (Mtigwe, 2006).

However, the theory based on factor proportions -like previous researches- presented serious limitations when coming to practice as it was based on the same fundamental 
assumptions of product and consumer homogeneity, as well as perfect competition, static costs and national advantage (Buckley and Brooke, 1992).

\subsubsection{Internalization theory}

The internalization approach to the theory of multinational companies is based on two premises: (1) Firms choose the location with the lowest cost for each activity they perform, and (2) firms grow by internalizing markets, and they get a profit when the benefits of further internalization are superior to the costs (Buckley, 1989).

These two premises are not independent, as globalization processes will introduce regulating factors like relocation to places with lower costs and this will also consider locations with lower taxes.

Internalization can involve a form of "vertical integration" bringing new activities and operations, previously developed in other intermediate markets, under the ow nership and control of the company, specially when natural markets are imperfect or missing. Internalization of transactions beyond national borders leads to the creation of the multinational enterprise. But before decisions on market internalization are made, research processes to gather information should be taken into consideration. That will lead to the best international expansion measures (Ruzzier et al, 2006).

In other words, Internalization theory holds that multinational enterprises (MNEs) exist because markets are not perfect, and these imperfections turn into the opportunity for firms to generate higher economic rents by internalizing the transfer of factor goods and services across international markets beyond their national boundaries (McDougall et al, 1994). 


\subsubsection{Transaction cost approach}

The transaction cost approach to the study of economic organization determines the transaction as the basic unit of analysis and holds that concentrating on economizing transaction costs is the key to the study of organizations.

\footnotetext{
"Economic approaches to the study of organization, transaction cost analysis included, generally focus on efficiency. To be sure, not every interesting organizational issue can be usefully addressed, except perhaps in a minor way, in efficiency terms. A surprisingly large number can, however, especially if transaction cost aspects are emphasized. This is accomplished by making the transaction -rather than commodities- the basic unit of analysis and by assessing governance structures, of which firms and markets are the leading alternatives, in terms of their capacities to economize on transaction costs (Williamson, 1981)".
}

According to some papers, internalization and transaction cost approaches can be considered as only one. Companies are seen as "a response to market failure". They are constantly looking for profit, and operations will be internalized when costs can be lowered by doing so. The difference between both theories is that, in the transaction cost approach, the final unit of analysis is the transaction itself (Ruzzier et al, 2006).

\subsubsection{The eclectic paradigm theory (OLI)}

The eclectic paradigm (or OLI Paradigm) is based on the internationalization theory and pretends to analyze the way companies determine how to produce in international markets and how to select a particular country for FDI (foreign direct investments). It was developed by John $\mathrm{H}$. Dunning and the objective is to merge several independent theories of international economics in one compiling approach.

According to Dunning (Dunning, 1980, 1981; Ruzzier et al, 2006), when trying to determine the internationalization of economic activity, there are three factors -apart from the structure of organizations- to be considered: 
1) Ownership advantages, which depend on every company, and are related to the development of intangible capabilities like product innovations or technology.

2) Location advantages, which can be found when the companies consider it is better to combine products manufactured in the domestic market with intermediate products and irremovable factors from a different location.

3) Internalization advantages, which are associated to the consolidation of foreign direct investments by integrating activities from the value-added chain into multinational structures.

Dunning also considers three ways to enter international markets (licensing, exports and FDI) and relates them to the OLI advantages as follows:

Table 2.2. Market entry modes according to Dunning

\begin{tabular}{llccc}
\hline & & \multicolumn{3}{c}{ Categories of advantages } \\
\cline { 4 - 5 } & & Ownership & Internalization & Locational \\
& & Advantages & advantages & advantages \\
Market & Licensing & $\mathrm{V}$ & $\mathrm{X}$ & $\mathrm{x}$ \\
entry & Export & $\mathrm{V}$ & $\mathrm{V}$ & $\mathrm{x}$ \\
modes & FDI & $\mathrm{V}$ & $\mathrm{V}$ & $\mathrm{V}$ \\
& & & & \\
\hline
\end{tabular}

Source: Compiled by the author based on Dunning, 1981

2.3.5. The monopolistic advantage theory (industrial organization theory)

The Monopolistic advantage theory states that the reason for the existence of multinational enterprises (MNEs) is that a company has "unique sources of superiority" when compared to other firms in international markets (Hymer, 1976). This kind of advantages are related to MNEs and are difficult to reach by other companies. 
"Superior ability" can be considered as one way of monopolistic advantage and has an effect on the improvement of the company performance. Hymer considered that MNEs are able to achieve "superior knowledge" by developing certain capacities in every functional part of the company: production, marketing, development of patents and new technology ... (McDougall et al, 1994).

So, according to the monopolistic advantage theory, once a firm has developed this "superior knowledge", the advantage can be exploited overseas at practically no additional cost if compared to the home market (Caves, 1971). That is why local companies at the destination market are unable to compete with foreign multinational firms despite their advantage in local market knowledge, and consequently foreign direct investment takes place (Caves, 1982).

Hymer's theory of the MNE brought the focus from the macroeconomic nation perspective to the company and holds that MNEs make the decision to internalize due to competition on markets for final competitive products. In other words, as firms compete with one another, they reduce the price consumers can be charged, and they finally give up their monopoly profits (Hennart, 2001).

\subsubsection{The competitive advantage of nations (Porter)}

"National prosperity is created, not inherited". Contrary to the belief of classical economists, that prosperity is not based on a nation's natural resources or the characteristics of its economy, which is determined by indicators like interest rates, the evolution of the labour market or the stability of its currency (Porter, 1990).

The competitiveness of a nation is based on the capacity to innovate and adapt to the constant changes in the environment. The companies within a country become more competitive and get advantage with respect to their competitors in other markets thanks to a situation of constant challenge and pressure.

As a consequence, nations play a fundamental role in a situation of escalating global competition, and their companies should concentrate on the creation and 
development of knowledge. Plenty of factors differ from one market to the other, and the ability to identify those differences in customs, values, cultural or political factors, constitute a way to adapt the strategy and determine competitive success.

In this context, the ability to gather information about other foreign markets is fundamental to determine the sources of competitiveness in different environments. According to Porter, a particular nation presents a competitive advantage in an industry because the local environment is specially dynamic and can be considered as the most appropriate one.

Porter (1990) determined the basis of his theory, also known as the diamond of national advantage, on "The competitive advantage of nations". According to him, we can find four particular attributes that determine the diamond of national advantage in a country (see fig. 2.3), and it can be applied not only to the nation, but also to the companies from every industry:

1) Factor conditions: regarding national production factors, like the structure of the labour force, which is basic to reach competitiveness.

2) Demand conditions: concerning the characteristics of the national demand in a particular industry for a product/service.

3) Related and supporting industries: the existence of globally competive supplier industries and other related industries.

4) Firm strategy, structure and rivalry: associated to the way companies are managed within a nation and the characteristics of domestic competitors.

"These determinants create the national envirornment in which companies are born and learn how to compete. When a national environment permits and supports the most rapid accumulation of specialized assets and skills (...), companies gain a competitive advantage (Porter, 1990). “ 
Fig. 2.3. Porter's diamond of national advantage

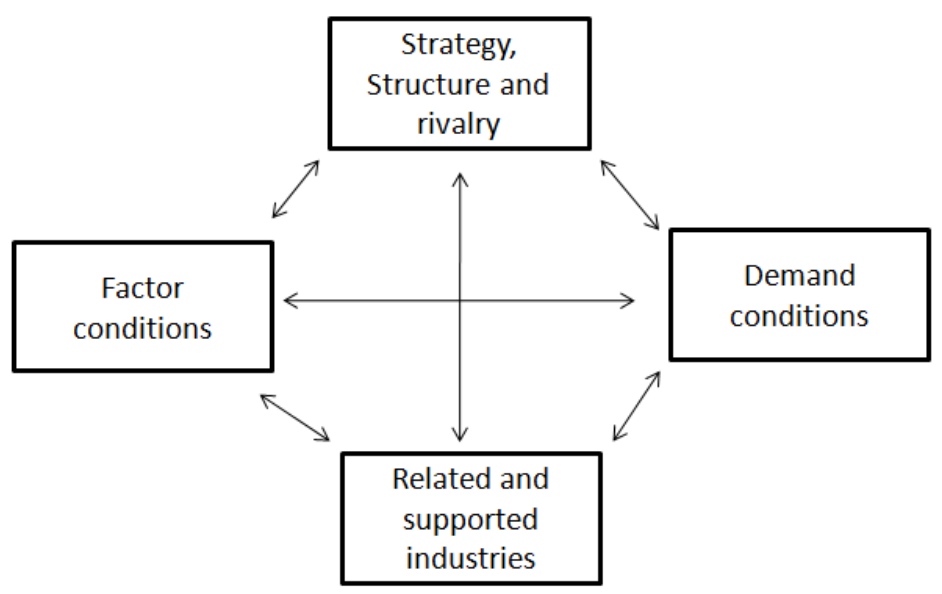

Source: Porter, 1990

\subsubsection{Product life cycle (Vernon)}

The product life cycle theory is an economic theory that was developed by Raymond Vernon after the Heckscher-Ohlin model was not able to provide an explanation to the observed pattern of international trade at the time.

This theory holds that the existence of MNEs is determined by the cycle of product development. According to that, companies make direct foreign investments as a second step to protect markets that were originally served through exports.

Anyhow, according to Vernon (1966), this decision should only be considered when the product has moved on to the maturity stage and the company's competitive strategy is based on cost reduction (see fig. 2.4). Foreign investment in other markets with lower costs of production, enables the foreign agent to compete with the local firms that pretend to rise their profit by going into exports.

On the other hand, although Vernon himself held that the predictive effectiveness of his theory has been reduced, it is still said to have an application on SMEs or other companies who have not developed important operations in foreign markets" (McDougall et al, 1994). 
Fig. 2.4. Product life cycle theory by Vernon

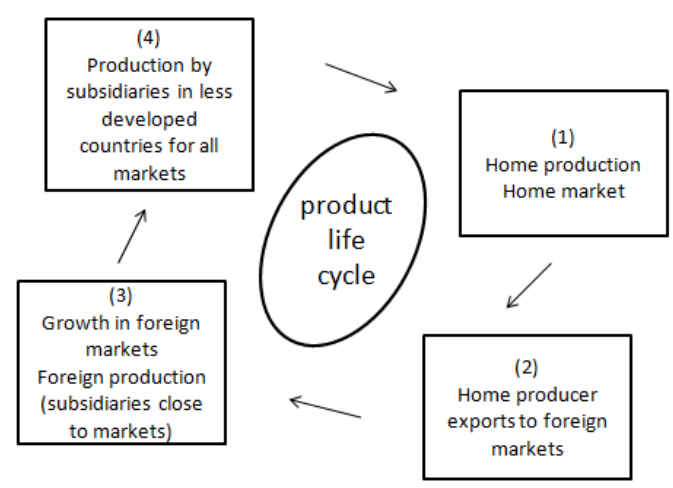

Source: Compiled by the author based on Vernon, 1966

\subsection{THE SMALL AND MEDIUM ENTERPRISES (SMES) PERSPECTIVE}

SMEs are considered as the central unit of analysis in our research and, consequently, the theoretical analysis is going to be considered from this point of view from now on.

It is not until the seventies and eighties when a big number of researchers start considering the importance of small and medium enterprises in the internationalization process of the economy. Streams like the Nordic school introduce gradualist models which consider the reasons for companies to become global and how that process is carried out gradually.

Other authors present approaches like Resource Based View or Knowledge Based View theories, where the objective is to determine the sources for a proper performance when SMEs consider the option of selling abroad, resulting in an important number of intangible resources.

Relational models, which concentrate on the importance of developing an appropriate network of relations, or contingency theory models, which introduce the inexistence of a general solution to the problem, are other examples of theoretical developments. 
At this point, we can appreciate that the literature on the subject is characterised by fragmentation and diversity, with plenty of different approaches that will be developed below in full detail.

\subsubsection{Gradualist or behavioural theories}

Gradualist theories (also known as stage models of internationalization) are behaviour related models that focus on the lack of experience and uncertainty as the main factors leading to a gradual learning process (Andersen, 1993). They were supported by authors like Johanson and Wiedersheim (1975) and Johanson and Vahlne (1977), and other nordic researchers in Sweden and Finland, a stream which is known as the Uppsala School (Ruzzier et al, 2006).

Although some researchers (Reid, 1981; Chetty, 1999; Andersson, 2000) have questioned the acceptance of these models on the basis of being too general, they are being very frequently used in empirical research to reinforce their theoretical backgrounds, especially to explain the internationalization of traditional SMEs (Mudalige et al, 2014).

The two gradualist models are: the Uppsala model (U-model) and the Innovation model (I-model).

A) Uppsala Model (U-model)

The Uppsala model determines that the internationalization process of a company starts by entering markets with least psychic distance and, gradually, once they get some more experience, seek to enter markets of greater psychic distance. The concept of psychic distance is defined by the Uppsala school as "factors preventing or disturbing the flow of information between firm and market, including factors such as 
differences in language, culture, political systems, level of education, or level of industrial development" (Johanson and Vahlne, 1977 p.24).

So, in this dynamic model, the internationalization of the company is considered as a process of increasing a firm's international compromise, which is the consequence of a learning procedure. It implies that firms increase their international performance step by step, starting with those markets in which they are already present. Firms will then consider the option of entering new markets at a greater "psychic distance", and the knowledge they have accumulated is supposed to have a positive influence on internationalization decisions like entry-mode or country-market selection (Ruzzier et al, 2006).

In the Uppsala model, the concept of foreign market commitment is composed of two factors: the degree of commitment and the amount of resources committed (see fig.2.5).

Fig. 2.5. The Uppsala model of internationalization

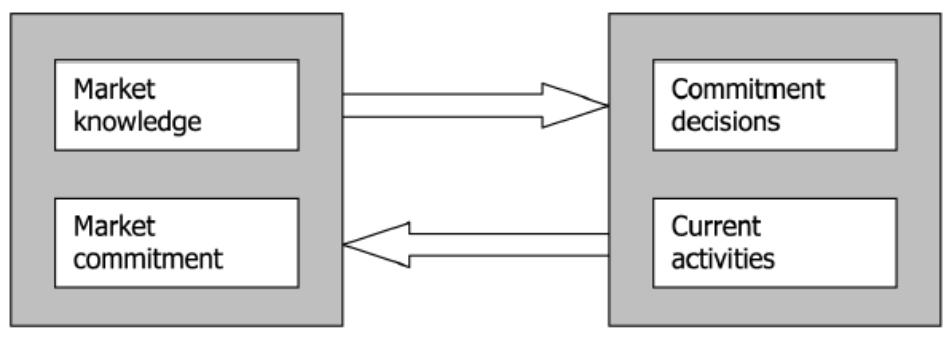

Source: Johanson and Vahlne (1977)

B) Innovation model (I-model)

The Innovation model is another gradualist explanation of internationalization where each consecutive step of the process is considered as an innovation for the firm. Therefore, Knowledge and experience are now related to innovation.

Leonidou and Kasitkeas (1996), noted in their review of the most important models at the time (Bilkey and Tesar, 1977; Cavusgil, 1980; Reid, 1981), that a number of fixed, 
sequential stages could be found in all of them -although the number of those stages changed considerably between models- ranging from as few as three to as many as six. They also identified three generic stages: "the pre-export stage; the initial export stage, and the advanced export stage" (Ruzzier et al, 2006).

Both the $U$ and the I models focus on the gradual incremental nature of internationalization processes, first in terms of activities and, second, in terms of resources - the basis of the behaviour of firms.

\subsubsection{Relational or Network approaches}

Based on the Uppsala model, some researchers (Johanson and Vahlne,1990; Johanson and Mattsson, 1993) continued and examination of the internationalization process by applying a network perspective.

The model is based on investing in networks that are new to the firm. Consequently, if the relationships between different companies are considered as a network, it can be determined that firms come into internationalization because other firms in their international network are doing so (Ruzzier et al, 2006).

According to Johanson and Mattsson (1993), firms get into the internationalization process when they "develop positions in relation to other counterparts in a foreign network". Companies get involved in a network which tends to be domestic in the first place, and develop further business relationships in international networks later on. The theory states that this process is achieved by establishing relationships in country networks that are new to the firm (international extension), by carrying on relationships in those networks (penetration) and by connecting networks in different countries (international integration). The importance of the theory behind this model lies in how the internationalization process is explained, rather than the existence of international firms.

The network model of internationalization does not only provide a theoretical framework for the development of networks in the company, but also extends to 
issues such as trust, control, resources and interdependency between firms. According to this, relationships have been thoroughly examined by scholars, both from an internationalization perspective and from a marketing point of view, as relationships have been considered the basis of relationship marketing -one of the main new emerging approaches of marketing -, which is fully developed in the next chapter. As already stated, marketing and internationalization theories have traditionally been studied separately, although they both present many points in common.

\subsubsection{Resource based view (RBV) and dynamic capabilities.}

Based on previous models, a resource-based perspective on internationalization is strongly emerging and being consolidated as one of the main approaches in the last years. The final objective of the stream is to develop an evolving dynamic theory based on resources and capabilities, something which is totally related to strategic management.

This approach -together with the latest relationship marketing trends- is specially important in the theoretical development of this thesis, as it is the cornerstone for the definition of the management and strategy constructs, key inputs to determine the final effect on the export performance of the firm. Although a thorough analysis of the model and its variables will be carried out on chapter 4 , it is important to keep the basis of this perspective in mind.

The main idea behind the RBV is that a firm has a unique combination of valuable tangible and intangible resources, and it is precisely these resources and capabilities that determine the company's competitive advantage and, as a final result, its performance (Katsikeas et al, 2000; Barney, 1991; Prahalad and Hamel, 1990; Nelson, 1991; Penrose, 1959; Teece, Pisano and Shuen, 1997; Wernerfelt, 1984, 1995).

The focus when considering the RVB approach is placed on the internal organization of firms. In this context, when companies possess resources which are unique and rare, 
they achieve "sustainable competitive advantage" because of the strategies they have implemented. Business models are, therefore, difficult to imitate by competitors.

In other words, Conner (1991) determined that a firm's ability to be competitive depends on the ability to exploit the fundamental resources in the company.

However, the RBV model has been extended to dynamic markets (Teece et al, 1997) in order to explain the way firms develop competitive advantage in situations of quick and unpredictable changes, and a new conception based on dynamic capabilities rather than resources has risen. Through dynamic capabilities, companies develop internal and external competencies to adapt the strategy to these rapidly changing environments, and special attention is paid to knowledge resources.

The RBV models tend to focus on the importance of intangible knowledge-based resources as a way to achieve competitive advantage. Not only the ownership of resources is important, but also the dynamic ability to acquire the necessary knowledge in the organization and develop new resources. It is considered as a dynamic theory that leads to a new dimension where the firms' diversification strategies play a very important role (Ruzzier et al, 2006).

Another important perspective from this approach is that capabilities are based on strategic and organizational processes that generate value for companies in dynamic markets (Eisenhardt et al, 2000). Consequently, processes like the development of new products, the definition of alliances and strategic decision making are fundamental and will be analyzed through the operational and strategic marketing strategy.

When attending the inherent nature of small firms, we can find there are plenty of difficulties trying to determine the critical resources needed for internationalization (Ruzzier et al, 2006). Due to their heterogeneity, researchers have identified plenty of different capabilities and resources: Barney (2000), for example, states that resources must be "valuable, rare and not substitutable", while Grant (1991) considers "they should represent durability, transparency, transferability and replicability".

Thanks to the study of the determinants of export performance and the analysis of the dynamic capabilities theory, we have been able to consider capabilities in our model 
from two points of view: the characteristics of management on one hand, and the analysis of the export marketing strategy on the other.

\subsubsection{International Entrepreneurship}

One more approach in the study of internationalization theories is the International Entrepreneurship stream, which is considered to develop a new research area in the fields of entrepreneurship and international business (McDougall and Oviatt, 2000a, 2000b; Antoncic and Hisrich, 2001).

According to Mc Dougall and Oviatt, international entrepreneurship can be defined as "a combination of innovative, risk-seeking behaviour that crosses national borders and is intended to create value in organization".

Some authors (Schumpeter, 2013; Alvarez and Busenitz, 2001; Rangone, 1999) established a certain number of connections between the RBV and entrepreneurship, considering entrepreneurs as one of the sources of sustained competitive advantage. Consequently, the focus of analysis of RBV was slightly changing from the firm to the individual level, but still within the context of abilities and resources.

These researchers hold that entrepreneurs possess individual resources which facilitate the recognition of new business opportunities and contribute to the set of company resources which are necessary for the export venture. Experience, entrepreneurial knowledge, relationships, training, judgement, and the ability to coordinate these and other resources are recognized as resources themselves. They are "socially complex" and add value to the company as they are not easy to copy or imitate by other firms (Ruzzier et al, 2006). So, the only way to be competitive is developing those resources, something which certainly takes time and money.

Other scholars, like Stevenson (1983), consider entrepreneurial management as "a set of opportunity-based management practices". Additionally, it may contribute to create value and help companies remain vital (Brown et al, 2001). 
At the heart of entrepreneurial activity we can find innovation. Schumpeter (1934) made a difference between invention and innovation: invention is considered the discovery of an opportunity, while innovation is supposed to be the exploitation of this opportunity. A successful international entrepreneurship venture requires not only the discovery of a valuable innovation, but also a proper way to take it into other foreign markets. According to Schumpeter's ideas, the internationalization process can be considered as a process to develop innovation, providing a new framework for the initiation and development of international activities, and recognizing the idea of innovation-related models (Ruzzier et al, 2006).

After going through the features of the model, it is remarkable that a very narrow relationship can also be found between the International Entrepreneurship and the Innovation gradualist model, as they both consider innovation playing a determinant role.

\subsubsection{Knowledge based view (KBV)}

Also starting from the basis of the RBV theory, and within the international entrepreneurship approach, an independent model -the knowledge-based view (KBV)was developed during the nineties. Various authors (Barney, 1991; Grant, 1996; Kogut \& Zander, 1992) consider knowledge as the primary resource that creates new value, heterogeneity and competitive advantages.

Consequently, knowledge, and not information is the basis for innovation. Knowledge and the way it is shared and spread has been found to be a critical process to generate innovation (Alguezaui and Filieri, 2014).

The KBV concentrates on the interaction of individuals and how they enrich their individual knowledge by cooperating with other partners abroad, something which turns into a positive a result as the whole resource of the company increases. In this way, the previous knowledge of individuals depends on their particular experiences, insights or skills that will be different from one to the other (Bouncken et al, 2015). 
The choice of a knowledge perspective is specially important in SMEs and was explained by mainly three reasons (Mejri and Unemoto, 2010):

1) SMEs compared with big firms have relatively less resources that makes knowledge very important for firm survival and growth (tangible resources should be compensated by intangible resources, ie. knowledge).

2) Knowledge has always been the core of human competences. Building on this, researchers perceive internationalization as a consequence of knowledge.

3) It has been found that knowledge is crucial for understanding SME internationalization.

According to Mejri and Unemoto, there are four different kind of knowledge (market knowledge, network knowledge, cultural knowledge and entrepreneurial knowledge) which can be found in the different stages of internationalization as shown on fig.2.6.

Fig. 2.6. Knowledge-based model of SME internationalization by Mejri and Unemoto

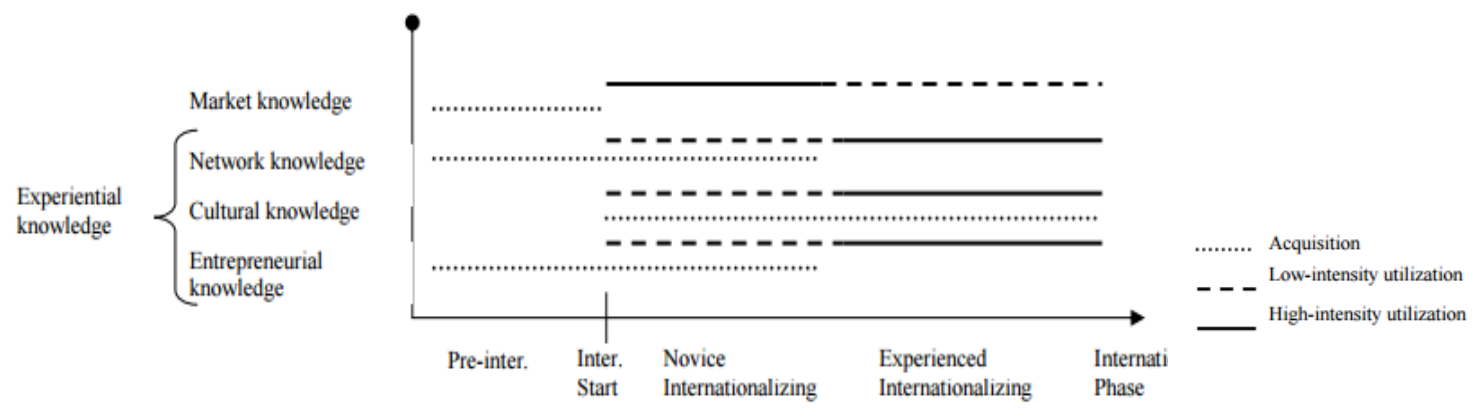

Source: Mejri and Unemoto, 2010

This new approach would also be introduced to explain the internationalization processes of International New Ventures and Born Global Companies. 


\subsubsection{International New Ventures (INVs) and Born Globals (BGs)}

According to traditional internationalization models, firms start operating in their domestic markets for a number of years and after that they start to expand their international business step by step. On the contrary, BGs and INVs develop a general and global vision of their markets from the first moment and develop the necessary capabilities to achieve their international goals (Knight and Cavusgil, 2004).

Born Globals (BGs) are defined by Knight and Cavusgil (2004) as "business organizations that, from or near their founding, seek superior international business performance from the application of knowledge-based resources to the sale of outputs in multiple countries". Therefore, the two basic resources in these rapid internationalization processes are knowledge and international networking.

Companies with a higher market knowledge (usually because of experience) present a higher propensity to develop learning skills that will result in a better adaptation to the new environment. Additionally, an international network helps the entrepreneurs in detecting new opportunities, establishing international relationships, and accessing information (Kalinic and Forza, 2012).

In a recent attempt to revisit their model, Johanson and Vahlne $(2003,2009)$ also noticed the importance of international networking. They consider that the major obstacle in internationalizing consist of "being or not being part of a network that makes difference", instead of the distance or the differences between the local and the foreign markets (Kalinic and Forza, 2012).

As stated by Bouncken et al (2015), seven reasons can be found to support the rapid internationalization of BGs:

1) Domestic market that is too small to achieve viability

2) Strong commitment by the firm's managers to the idea of internationalization

3) Personal networks that provide the basis for establishing partnerships and alliances

4) Unique technology that provides a source of competitive advantage 
5) Commitment to growth through partnerships and alliances with both suppliers and distribution partners

6) Adaptation of relationships over time in order to meet the changing needs of partners

7) The use of different entry modes depending on the market

\subsubsection{Other approaches}

Although most of recent studies have considered the resource-based view (RBV) as the underlying theoretical stream supporting their model, other approaches like the institutional-based view (IBV), the contingency theory and the organizational learning theory (OLT) are being taken into consideration and analyzed by the latest reviews, taking Chen et al (2016) as a reference.

The institutional-based view (IBV) is the consequence of the latest tendencies, where an increasing consideration of the Institutions is observed because of their influence on export marketing policies. The IBV determines the importance of the institutional environment as it has an influence on strategic management decisions and the final performance of the firm (Dacin et al, 2002; Peng et al, 2008; Lipuma et al, 2013; Chen et al, 2016). This line of research determines that institutions are particularly important in the case of exporting firms as they can provide assistance to these companies, and, therefore, a high quality of the institutional environment leads to a superior export performance.

On the other hand, the contingency theory highlights the positive relationship between strategic factors (where marketing strategies play a fundamental role) and the overall context. This theory considers that the "contingent compatibility" (which is different from one firm or export venture to the other) is associated to a superior export performance. An adequate export performance can be achieved through a combination of internal and external factors like marketing strategy, experience and a 
good knowledge of the environment. (Harrigan, 1983; Hultman et al, 2011; Chen et al, 2016).

The organization learning theory (OLT) establishes a relationship between "previous organizational operations" and a future performance. Export managers learn from the activities they have developed in the past, resulting in a better understanding of export strategies, that finally have a positive effect on export performance (Lages et al, 2008; Santos-Vijande et al, 2012; Wei et al, 2014). It is also held that the export marketing strategy of the company is influenced by the export performance during the learning process.

Other theories like behavioural theory, relationship marketing theory, or transaction cost theory, are also considered in the latest empirical studies. It seems that no single theory is appropriate to address the complexity of internationalization models and researchers tend to combine and integrate supplementary theories to support their analysis.

\subsection{THE ANALYSIS OF EXPORT PERFORMANCE IN SMES.}

The research on international theories has adopted different perspectives through the years. As we have already noticed, the first theories concentrated on a macro analysis and tried to explain how countries got involved in the international context and made the decision to intensify the production on the goods where they presented a certain kind of advantage.

Later on, the focus moved towards the framework of MNEs by developing theories that would offer an explanation to the way these companies started operating in foreign markets: the literature would concentrate on how the decision was made and how the process was carried out.

And finally, a new approach with a clear trend to consider SMEs as the final agents in the internationalization process has been identified in the last five decades, something 
which has led to a different conception where the most important subject of research is the determination of the variables affecting the export behaviour of these companies when developing their strategies in foreign markets.

The fact is that an increased globalization of trade has driven a growing number of companies to find new export markets with a higher growth, if compared to their traditional domestic markets. The final objective is not only to expand, but also to ensure their survival in many cases. As a consequence, the analysis of exports is playing a determinant role and the area of export performance has raised a tremendous interest among researchers and company managers (Sousa, 2004).

The following point in this chapter will concentrate on the determinants of the export performance in small and medium enterprises.

\subsubsection{The determinants of export performance}

Although the research on the determinants of export performance is an area which has attracted considerable attention since the early 1960s, the literature regarding the subject has been characterized by a big number of approaches, as already specified.

The result is that no common or standardized model has been found in order to merge the various empirical findings on the export performance of firms, despite the big amount of research effort on the area (Bilkey, 1978; Aaby and Slater, 1979; Leonidou and Kasitkeas, 1996, 1998, 2002, 2007, 2010; Sousa et al 2008, Chugan and Singh, 2014; Chen et al, 2016).

One more aspect of the research on the determinants of export performance is that the outline behind it has not changed much in the last 50 years. The variables affecting a firm's export behaviour were very clearly determined in the late seventies and early eighties and have remained basically the same through the years. Nevertheless, due to the interest on the subject, further research was carried out to analyze and quantify the relationship between these variables by introducing more sophisticated quantitative models and techniques. This resulted in plenty of empirical models that 
established different relations between constructs and, therefore, different theoretical approaches were considered.

The first attempt to reunite all the information in "an integrative model of export performance" comes from Bilkey (1978) and the conclusions -that might be considered as the basic facts for exports- can be summarized as follows:

- Exports are considered as a learning process with different stages, something which is totally consistent with the gradualist theories developed in this chapter. Besides, export success depends on the stage that the company is in.

- Exporting firms are generally more efficient and tend to have better management than non-exporting firms.

- The attitude of the managers towards export is fundamental for the success of the company in foreign markets.

- Exporting firms tend to perceive fewer obstacles to selling abroad than nonexporting firms.

- The most frequent obstacles for exports are: insufficient finances, export barriers and foreign government restrictions, insufficient knowledge about selling and marketing techniques, and the absence of foreign connections.

- Despite the unclear relation between exporting and firm size, bigger companies are usually more active regarding exports.

Aaby and Slater (1979) reached similar conclusions when analyzing the investigations carried out in the 1978-88 period and concluded that export knowledge was affected by two dimensions: the external environment level, and the company business strategy from the functional internal level. Anyway, despite the theoretical analysis, they would pay special attention to the second one and would disregard the influence of the environment as it could not be influenced by the individuals:

\footnotetext{
"The environmental level includes macro-economic, social, physical, cultural, and political aspects which influence export management, behaviour and performance. The individual exporter can only to a very limited extent influence this environment, and in most situations must consider the
} 
macro-parameters as given constraints. The business strategy level includes assessment of key business policies and capabilities within the firm's control that are required for successful export."

Their analysis would lead to the model on fig. 2.7 which establishes the relation between the dependent variable (export performance) and the different independent variables. The second group of variables would affect the export behaviour of the company through a series of constructs: Firm Characteristics, Competencies and Business Strategy.

The initial theoretical model of export performance developed by Aaby and Slater would be supported by other authors like Chetty and Hamilton (1993), determining the relative importance of every construct in the final result through the empirical analysis.

Fig. 2.7. Determinants of export performance according to Aaby and Slater

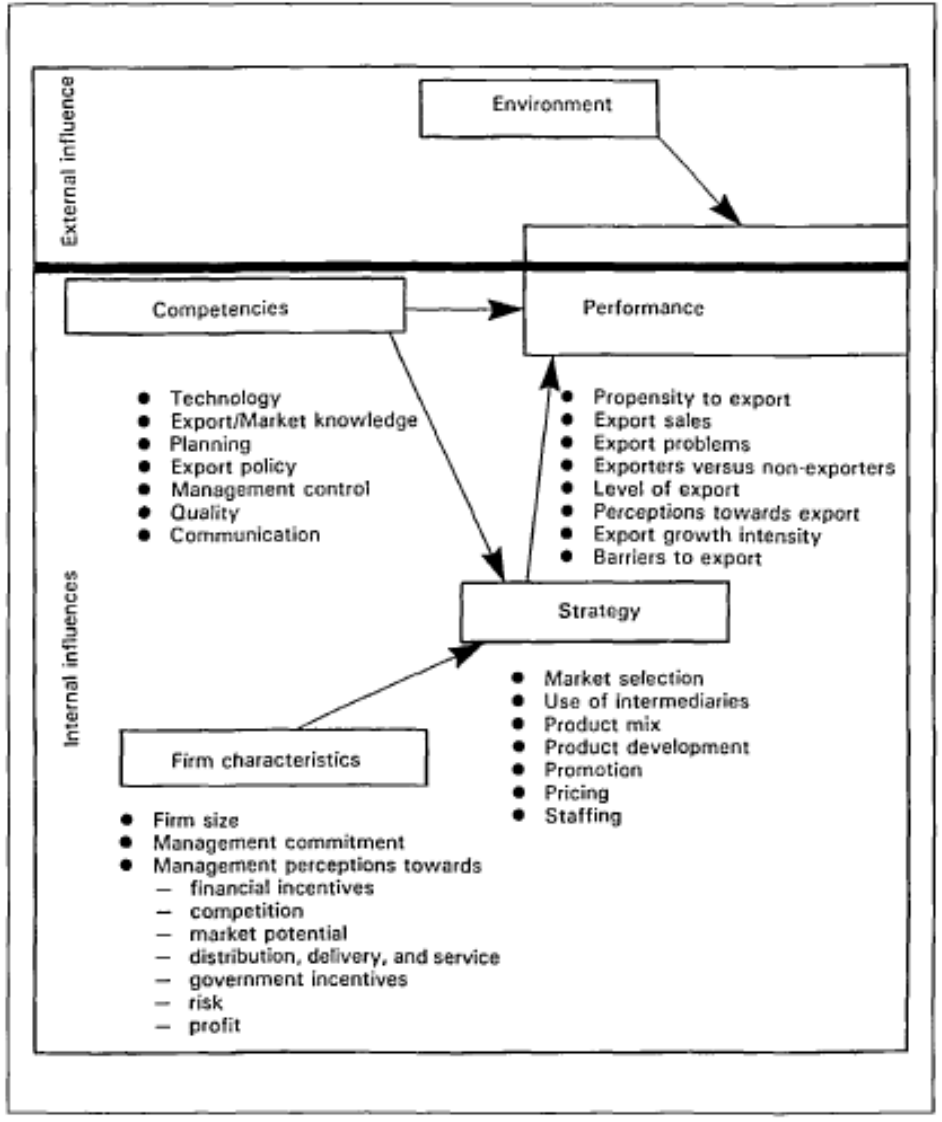

Source: Aaby and Slater, 1979 
The contribution of authors like Zou and Stan (1998) was also determinant to the evolution of the model, as they introduced a new approach by considering both internal and external factors as the determinants of export performance (see Fig. 2.8). By doing so, they pretended to overcome the weaknesses of the previous analyses and provide a wider perspective to the investigation.

Fig. 2.8. Determinants of export performance according to Zou and Stan

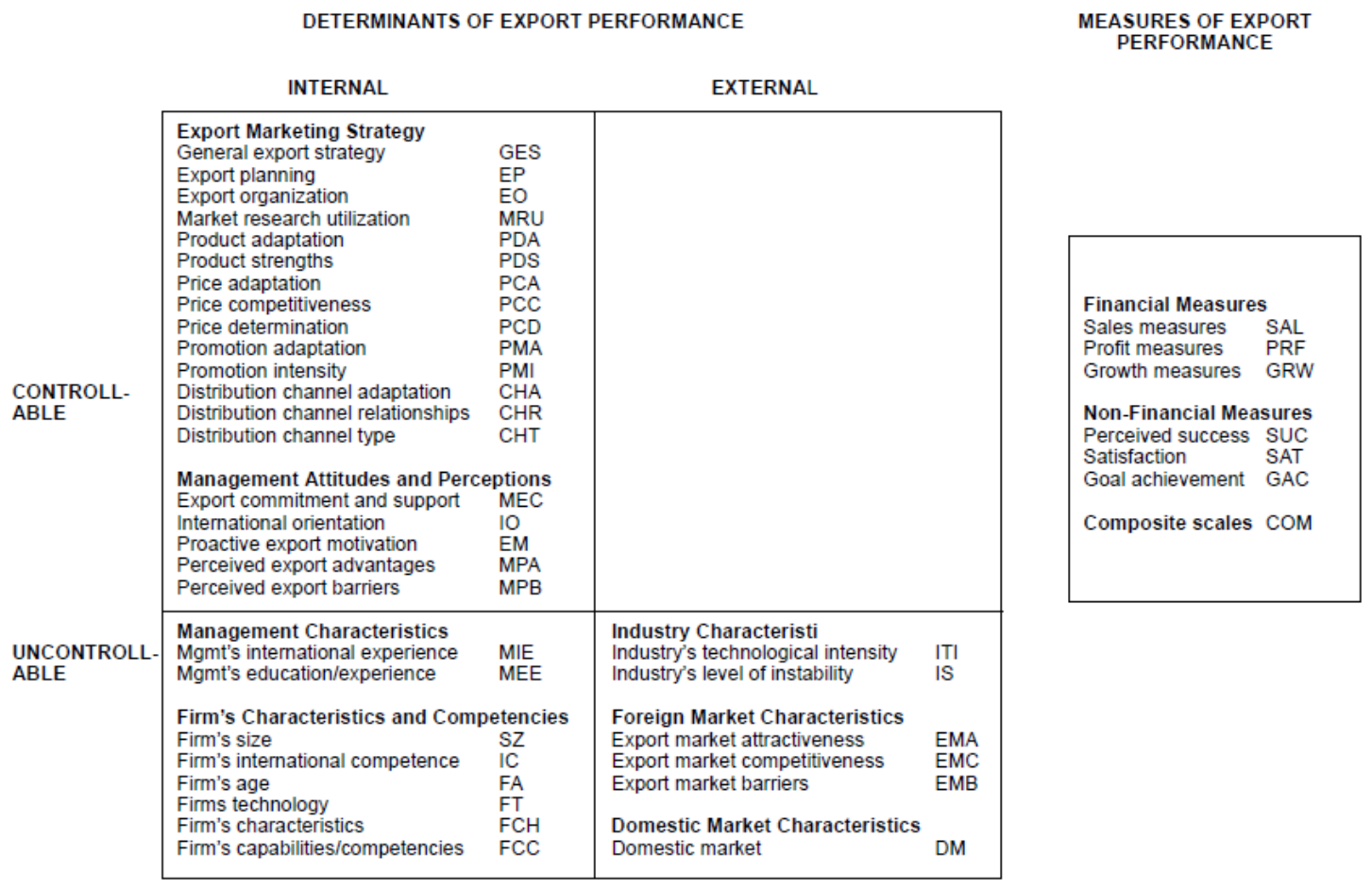

Source: Zou and Stan, 1998

Another major contribution to the evolution of the model is carried out by Sousa et al, 2008 (see fig. 2.9). In the attempt to provide a review of the research developed to the moment, they analyze the content of 52 articles published between 1998 and 2005, with the following conclusions:

- The investigation, which had traditionally been conducted in the USA, is now receiving contributions from other countries.

- The presence of studies analyzing the service sector is still a minority compared to the number of studies focusing on the manufacturing sector. 
- Most of the research continues to concentrate on small and medium-sized enterprises (SMEs)

- The size of the sample is continually increasing and the level of statistical analysis has improved.

- Also the use of control and moderating variables has increased, and a bigger number of investigations have started to consider the effect of the external environment -such in domestic as foreign markets- in their models.

- Finally, market orientation is being considered as a key determinant of export performance.

Fig. 2.9. Determinants of export performance according to Sousa et al

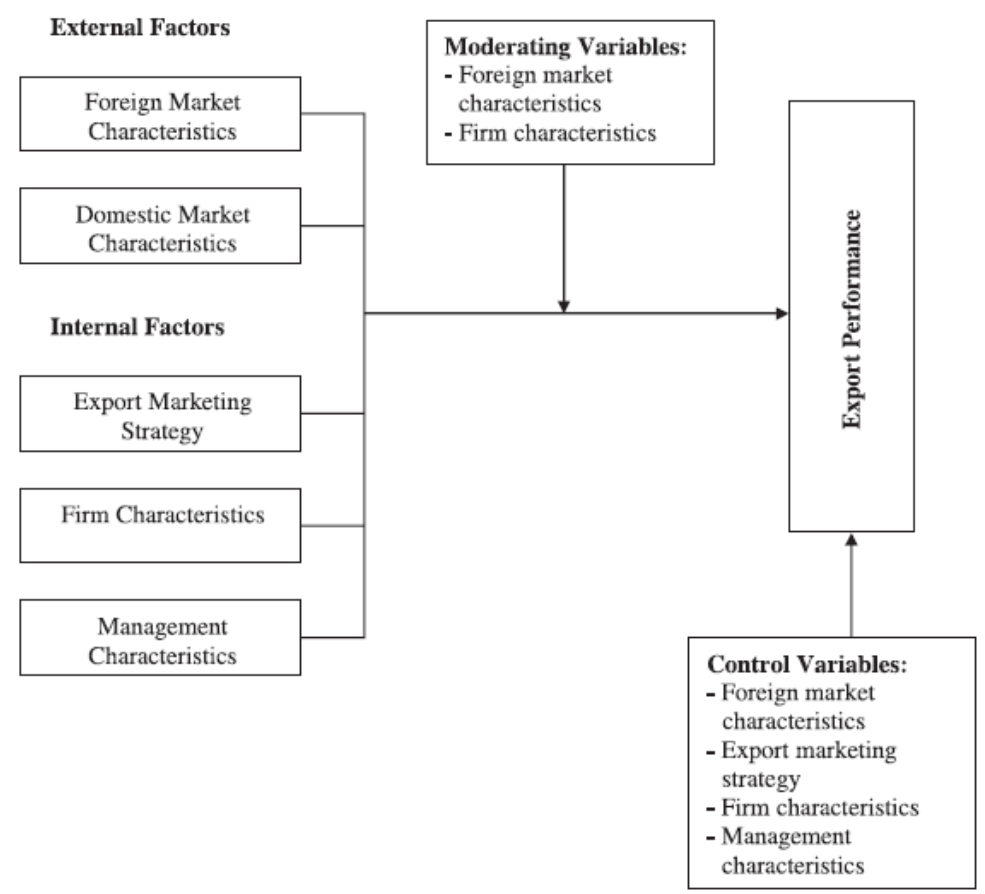

Source: Sousa et al, 2008

Up to this moment, the basis for the definition of variables was set up, but different approaches emerged when considering the relationship between these variables and constructs. A tipping point in the theoretical background was determined on the 
conceptual framework of Export marketing strategy model proposed by Cavusgil and Zou (1994) - also known as the simplified export performance model-, which is fundamental to our analysis.

According to them, "the framework postulates that marketing strategy in an export venture is determined by internal forces such as firm and product characteristics and external forces such as industry and export market characteristics (the environment). The performance of the export venture, in turn, is determined by export marketing strategy and firm characteristics (i.e. a firm's capability to implement the chosen strategy)".

Fig. 2.10. Conceptual framework of export marketing strategy and performance

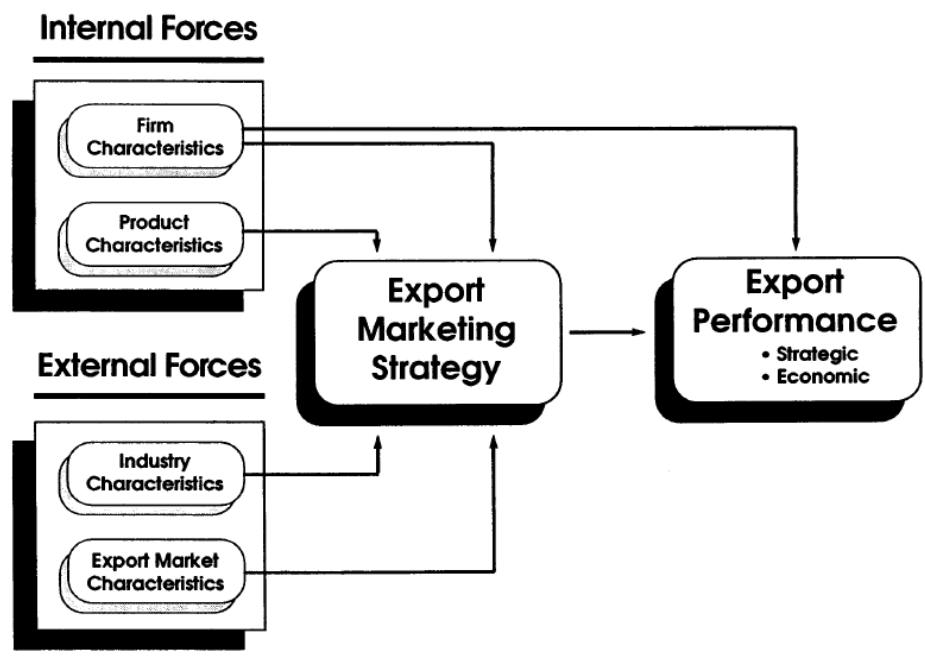

Source: Cavusgil and Zou (1994)

In contrast to previous exporting studies that postulate direct links from product, industry and export market characteristics to export performance, the Cavusgil and Zou model (see fig. 2.10) determines that these links are mediated by export marketing strategy, highlighting the central role of marketing strategy in determining performance. This is because export marketing strategy must be adapted depending on the environment in order to provide positive performance results. 
Other scholars like Katsikeas et al (2000) or Leonidou et al (2002), consider a very similar approach which is supported by complimentary literature (Gemünden, 1991; Holzmüller and Kasper, 1991; Axinn, 1994; da Rocha and Christensen, 1994). According to them, a group of variables (managerial, organizational and environmental forces), indirectly have an effect on export performance through a series of variables related to the company's export marketing strategy (i.e., targeting and marketing mix programs) that are directly linked to export performance.

In this way, Katsikeas et al (2000) introduce an intermediate variable (mainly the business strategy variable, where targeting and marketing policies play a determinant role) which is affected by the environment, the business organization and the management of the company (also known as background variables). At the same time, this intermediate variable -intervening variable as they call it- has a clear effect on the final variable (outcome variable in their theoretical model) which is the export performance.

Their main contribution, apart from providing support to the simplified export performance model started by Cavusgil and Zou, was the definition of the three different groups of variables considered in their model:

- Background variables: considering external factors (the influence of the environment), and the firm's internal characteristics (determined by organizational factors and managerial factors). In their model the environment affects the organization and the organization affects management.

- Intervening variables: comprising targeting factors and marketing strategy factors. As an intermediate variable they are affected by the background variables and, at the same time, have an effect on the final variable (outcome variable). They are considered the operating variables of the model.

- Outcome variable: considered as the final dependent variable in the model, export performance is consequently affected by intervening variables in the first place and by background variables in the second place. 
Fig. 2.11 represents, not only the variables in the Katsikeas et al (2000) model, but also the relationship among them. Environmental factors affect organizational and managerial factors at the time, and these background variables are fundamental to determine the marketing strategy, which results in a higher or lower export performance.

Fig. 2.11. Simplified export performance model

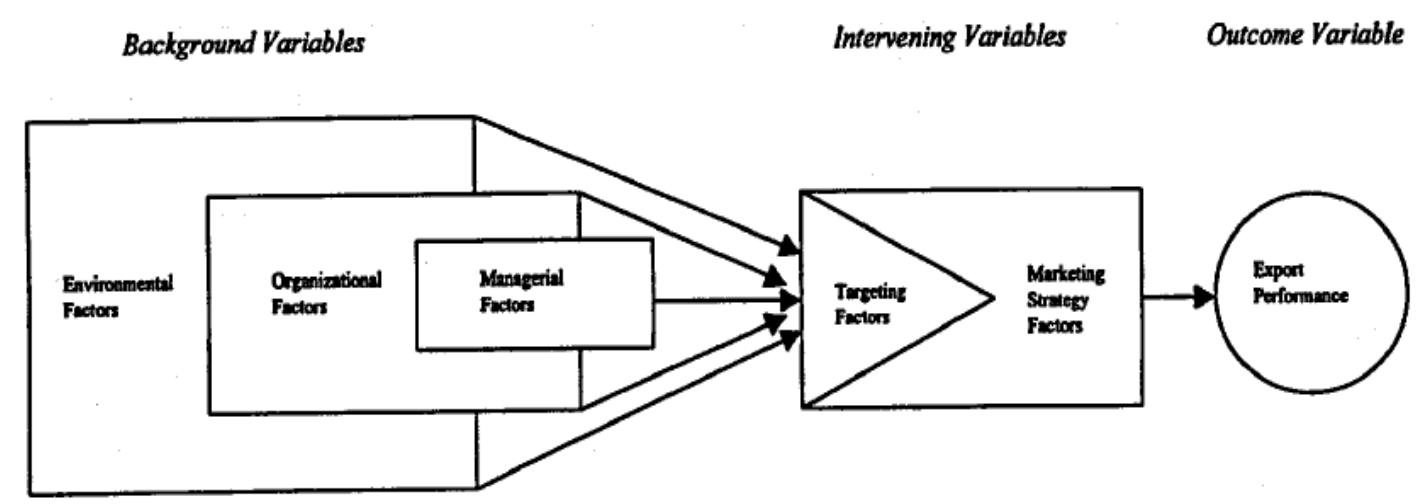

Source: Katsikeas et al (2000)

On the other hand, Chugan and Singh (2014) contribute to the analysis with a review of the literature from 1980 to 2012 and introduce a classification of variables in five different groups, attending to their internal or external characteristics (see table 2.3).

This classification is specially important for two reasons:

1) because it comes to summarize the determinants of export performance up to the present time, and

2) because it is considered by the author as the basis to the definition of variables and constructs within the theoretical model developed throughout this investigation. 
Table 2.3. Determinants of export performance (1980-2012 review)

\begin{tabular}{lc}
\hline INTERNAL VARIABLES & EXTERNAL VARIABLES \\
\hline Export Marketing Strategy & Foreign Market Characteristics \\
Product & Export market barriers \\
Pricing & Legal and political environment \\
Promotion/advertising & Socio-cultural environment \\
Distribution channel / channel relationship & \\
Strategic decision making & Domestic Market Characteristics \\
& Use of export assistance \\
Firm Characteristics & Export market barriers \\
Size & Legal and political environment \\
Age & \\
Technology innovation & \\
International experience & \\
Location/access to infrastructure/services & \\
Firm resources/capabilities & \\
Management Characteristics & \\
Export expertise & \\
Export commitment and attitude & \\
Corporate social responsibility & \\
Perceived export advantages & \\
Perceived export barriers &
\end{tabular}

Source: Chugan and Singh, 2014

Chen et al (2016), have also contributed to the analysis by developing a new review of the latest investigations and present a model with the marketing strategy as the intermediate variable. This variable, which has a clear effect on the export performance of the company, is also affected both by internal variables on one hand (mainly firm and management characteristics) and external variables on the other (industry-level and country-level characteristics).

These authors come to support not only the approach introduced by Cavusgil and Zou (1994) or Katsikeas et al (2000), but also the theoretical background considered in this investigation. In our model, the Strategy construct plays a fundamental role to determine the export performance of the company, but it is not the only input, as it is also affected by other variables (environment and firm capabilities). 
Another important contribution of Chen et al (2016) is the combination of two complementary factors: the variables affecting the export performance of the company, and the most important underlying theories, considered as the background to the development of the theoretical models behind the empirical analysis (see fig. 2.12).

Fig. 2.12. Determinants of export performance according to Chen et al

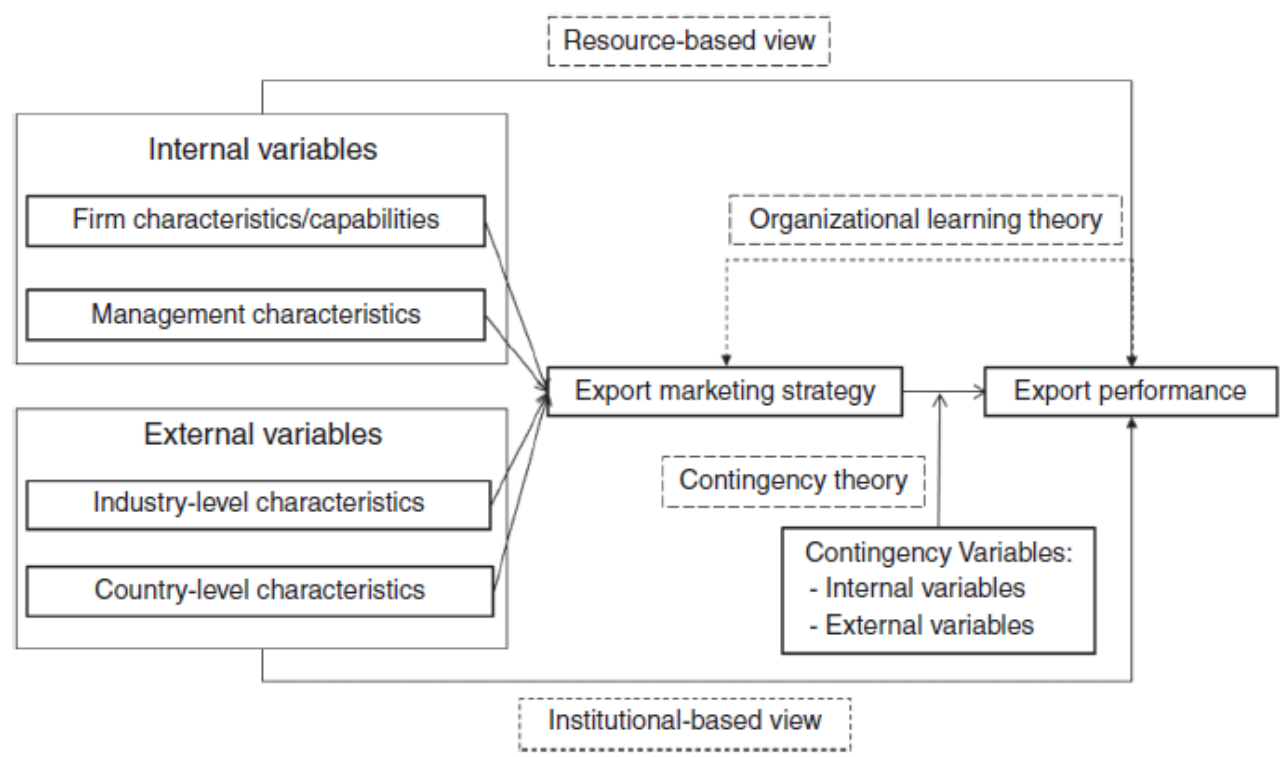

Source: Chen et al (2016)

When coming to the determinants of export performance, Chen et al (2016) identified a series of factors, which were classified in two big groups: internal characteristics coming from the firm side, and external characteristics coming from the environment (industry, domestic market and foreign markets). These determinants show the evolution of the discipline in the last decade, and a compilation of them, along with the most important items, is shown on Table 2.4. 
Table 2.4. Determinants of export performance according to Chen et al

\begin{tabular}{l} 
EXTERNAL FACTORS \\
\hline - Industry-level characteristics: \\
Technological turbulence \\
Degree of concentration \\
Technological environment \\
Industry export orientation \\
Kind of sector (products/services) \\
-..
\end{tabular}

Domestic demand

Quality of the infrastructures

Institutional environment

Quality of the legal system

- Foreign market characteristics:

Competitive intensity

Psychic distance

Market dynamism

Regulations

Cultural and geographical distance

Customer characteristics

Economic, cultural or political

environment

Export barriers
INTERNAL FACTORS

\section{- Export marketing strategy:}

Adaptation of the mktg mix policy

Cost leadership strategy

Differentiation strategy

Promotion strategy

Support to distribution channels

CSR (environmental, ethical policies)

Adaptation to customers

Branding strategy

Business strategy

Competitive positioning

Outsourcing strategies

Relationship marketing strategies

Internat. internet mktg strategies

...

- Firm Characteristics:

Firm size and firm age

Export experience

Export commitment

Financial resources

Degree of internationalization

Human capital resources

Competitive advantages

Knowledge-based resources

Relationship performance

Technological resources

Productivity

Tangible assets 
Sales Volume

$\cdots$

- Firm capabilities:

Market orientation

Network capability

Innovative capability

Expenditure on $\mathrm{R}+\mathrm{D}$

Information capability

Communication and coordination

Entrepreneurial orientation

Relationship and mktg capability

Technological capability

Market research and mktg planning

- Management characteristics:

International experience

Propensity to export and

internationalization processes

Education

Managerial commitment

Skills: languages, management ...

Risk taking

Source: Chen et al (2016)

Continuing with the analysis of the literature, apart from examining the determinants of export performance throughout different reviews $(2002,2014)$ Leonidou et al, also identified its stimulants (2007), classifying them as internal or external stimuli. According to them, most of external stimuli are reactive (R), and most of internal stimuli are proactive (P), as shown on fig. 2.13. 
Fig. 2.13. Stimulators of export performance

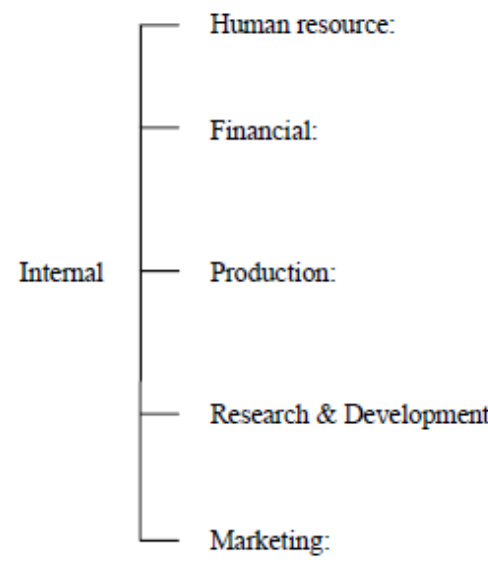

Special managerial interest/urge $(\mathrm{P})$

Utilisation of special managerial talent/skills/time (P)

Management trips overseas (P)

Stagnation/decline in domestic sales/profits (R)

Potential for extra sales/profits from exporting $(\mathrm{P})$

Potential for extra growth from exporting (P)

Possession of financial competitive advantage $(\mathrm{P})$

Accumulation of unsold inventory/overproduction $(R)$

Achievement of economies of scale $(\mathrm{P})$

Availability of unutilised production capacity $(R)$

Smoothing production of a seasonal product $(R)$

Possession of proprietary technical knowledge $(\mathrm{P})$

Possession of a unique/patented product $(\mathrm{P})$

Extending life-cycle of domestic products $(\mathrm{P})$

Possession of a marketing competitive advantage (P)

Ability to easily adapt marketing for foreign markets (P)

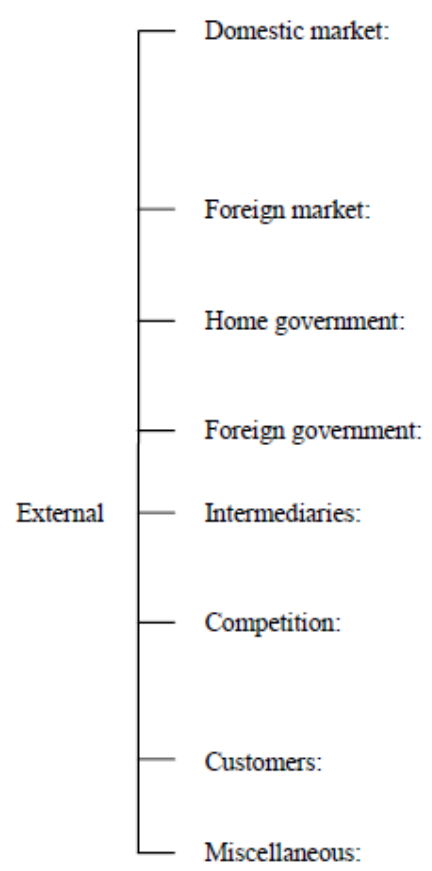

Saturation/shrinkage of domestic market (R)

Need to reduce dependence on and risk of domestic market $(R)$

Possibility of reducing the power of domestic customers (P)

Unfavourable state of domestic economy $(R)$

Favourable foreign exchange rates $(R)$

Possession of exclusive information on foreign markets $(\mathrm{P})$

Identification of better opportunities abroad (P)

Close physical proximity to foreign markets (R)

Government export assistance/incentives $(\mathrm{P})$

Ministry of Commerce/trade mission activity $(R)$

Encouragement by government agencies (R)

Relaxation of foreign rules and regulations in certain foreign markets (R)

Reduction of tariffs/non-tariffs in certain overseas countries (R)

Encouragement by industry, trade, and other associations (R)

Encouragement by banks/financial institutions (R)

Encouragement by brokers/agents/distributors (R)

Intense domestic competition $(R)$

Initiation of exports by domestic competitors $(R)$

Entry of a foreign competitor in the home market $(R)$

Gaining foreign expertise to improve domestic competitiveness $(\mathrm{P})$

Receipt of unsolicited orders from foreign customers (R)

Receipt of orders after participation in trade fairs $(R)$

Proximity to international ports/airports (R)

Patriotic duty of local firms (P)

Source: Leonidou et al (2007)

Finally, Leonidou et al (2010), in their review of five decades of export research, come to the conclusion that a majority of researchers (56\%) were located in North America (mainly in the U.S.), over a third (34.2\%) in Europe (mainly in the United Kingdom, Norway, Spain, Sweden, Netherlands, and Finland), and a continuously increasing $6.1 \%$ in Asia. This supports the findings from Sousa et al (2008) and reinforces the theory 
that European and Asian researchers are increasing their contribution to the investigation.

\subsubsection{The empirical analysis}

Once the theoretical analysis on the determinants of export performance has been carried out, we will focus on the empirical research. This analysis will result in a wide number of interpretations with different conclusions.

Gao et al (2010), for example analyzed the effect of three different perspectives (Resource-based view, Institutional-based view and Industry-based view) to determine the firm export performance. That leads us to the conclusion that it is extremely difficult to offer an explanation to the internationalization process from only one perspective.

Other authors, like Gashi et al (2014), Raymond and St Pierre (2013), Singh(2009), Yi et al (2013), Lages et al (2009), and so many others, have considered the Resource-based view and dynamic capabilities approaches, which are, probably, the most extended perspectives.

Singh (2009) determined that firm size, R+D expenditure, advertising expenditure and business group affiliation are the most important determinants of export performance. Gashi et al (2014), on the other hand, focused on the importance of human related factors (mainly the education of the workforce) and technology related factors (considered in terms of spending on $R+D$ or new products and new technology developments) to determine the export performance of the company.

In this context, Raymond and St. Pierre (2013), proposed an analysis of firm capabilities comprising product development capabilities (based on the $R+D$ budget), market development capabilities (based on market research and prospecting), network capabilities (based on the development of partnerships in every operational field), technological capabilities and Human Resources development capabilities. 
Continuing with this orientation, Yi et al (2013), considered that innovative capabilities have a positive effect on exports, but this relationship is conditioned by the institutional environment.

This analysis takes us to consider an important factor, which is the influence of the environment in general, and institutional support in particular, on the export performance of the company (Alvarez, 2004; Bonner and Mcguineess, 2007; Durmusoglu et al, 2012; Girma et al, 2009; Shamsuddoha and Ali, 2006; Singer and Czinkota, 1994). Lipuma et al (2013) determined that the role of institutions is more important for new and small firms, while Lee et al (2009) stated that quick changes in domestic markets (caused by reductions on demand and consumption) are linked to the effort of a company to increase exports. In this case post-crisis periods lead to an increase of international sales.

However, the analysis of the environment variable has been developed by plenty of researchers, who considered the construct from two perspectives:

- Domestic market characteristics: influenced by items like the existence of export assistance (already considered from the institutional-based view approach), the existence of export market barriers, and the legal and political characteristics of the environment (Ayan and Percin, 2005; Cameiro et al, 2011; O'Cass and Julian, 2003).

- Foreign market characteristics: basically determined by competitive intensity (one of the determinant factors) the existence of entry barriers, and the existence of legal, political and socio-cultural similarities (Ayan and Percin, 2005; Cadogan et al, 2012; Karelakis et al, 2008; Sousa and Bradley, 2008).

As aforementioned, plenty of factors play a fundamental role when considering the success of the internationalization processes from the resource and knowledge based view or the dynamic capabilities points of view. However, we will try to classify them into two big groups: firm characteristics (and capabilities) on one side, and 
management characteristics (this second group of variables deserves a separate analysis because of the importance of this intangible asset) on the other.

Regarding firm characteristics, firm size and age, along with international experience and the development of firm resources and capabilities (fundamentally intangible assets like the incorporation of technology or innovation to the processes of the company) have traditionally been determined as the most important factors to determine a superior export performance (Ayan and Percin, 2005; Brouthers et al, 2009; Contractor et al, 2005; Freeman et al, 2012; Gertner et al, 2006; Lages et al, 2009; Morgan et al, 2004).

As per management characteristics, the reviews by Chen et al (2016) and Chugan and Singh (2014) determined export commitment and attitude as one of the most important features linked to export performance, together with others like international expertise, education and a certain number of abilities (basically managerial, languages and communication skills).

Finally, another determinant variable considered in the empirical analysis of the subject is the export marketing strategy. This is the central intermediate construct in our model, which is influenced, at the time, by factors like the marketing mix policy and, more recently by other marketing approaches, like market orientation, relationship marketing or the introduction of new technologies in order to increase efficiency and boost long term relationships with consumers, leading to customer loyalty (Leonidou et al, 2002; Ayan and Percin, 2005; Ricci and Trionfetti, 2012; Boehe and Cruz, 2010).

Nevertheless, the effect of the Internet and new technologies on the marketing strategy variable has been neglected in most of recent studies. That is, without any kind of doubt, one of the weaknesses in the analysis of internationalization theories and the determinants of the export performance, but also one of the reasons for us to consider them as an input for our model. 
On the other hand, despite the introductory analysis of the determinant variables from our EMSP model of internationalization carried out in this chapter, full details of these constructs and they way they are connected, will be developed on chapters 4 and 5 .

We also dedicate chapter 3 to the study of the most important theories of the marketing discipline, as they are crucial in the conception of the marketing strategy construct.

\subsection{CONCLUSIONS}

The theory of internationalization has evolved through the years, with the focus moving from a macro-analysis, centered on the study of nations and MNEs, to a microanalysis, centered on the study of SMEs and the factors which determine their export performance.

As we could appreciate trough the chapter, the analysis of the determinants of the export performance has been (and still is) a subject of great interest in the last decades. However, one of the main critiques to this model comes from the side that the theory behind it has not evolved enough.

We can also observe from the previous examination that these determinants have remained the same for a number of years, and it is only the empirical analysis that considers different perspectives, with plenty of models and a lack of consensus to reach a common standardized background for the study of this particular discipline. Besides, the subject has been considered from many different approaches (gradualist models, RBV, KBV, contingency theory ...)

In our case, the theory developed on the chapter has led to determine four basic variables: environment (ENV), management (MN), marketing strategy (MS) and export performance (EP). Altogether, they will constitute the EMSP model of internationalization, which will be the basis for the empirical research carried out throughout this thesis. 
In this context, export performance (EP) will be the final dependant variable which will be affected by the rest of inputs. The marketing strategy (MS) construct will be analyzed separately on chapter 3 , as it is the most complex variable and will be affected by other marketing approaches.

The reason to do this is that the vast majority of investigations carried out so far, do not tend to introduce the latest approaches from the marketing discipline, especially regarding the use of new technologies, which are fundamental in the case of the fashion and design sector.

The final objective is getting to know the way all the variables and constructs interact to reach a final objective, which is the study of their effect on the export performance of the company. 


\section{CHAPTER 3. THE EVOLUTION OF MARKETING APPROACHES}

\subsection{INTRODUCTION}

Although the concept of marketing has been used for a long time with positive results, this is a discipline that has shown considerable development during the last years.

As a science with a very important social component, it has faced challenges to adapt to the new complex economic environment, deeply influenced by the incorporation of new technologies and profound changes in every single aspect of human and managerial activities.

Not in vain, Philip Kotler, the father of modern marketing stated that "marketing has been one of the most exciting subjects in the business world during the past six decades".

Apart from that, changes in the environment, resulting in a global market which is highly interconnected, has contributed to the development of new techniques and approaches in International Marketing. As a result, the companies operating in different countries tend to be more productive, with lower costs and higher profits.

Furthermore, "consumers are the greatest beneficiaries of all these changes". They are offered a wide choice of products which are available at lower prices. 
For the first time in history, the availability of international goods and services has become accessible to the masses, far from the previous belief than only those with a higher purchase power could have access to certain kind of products (Czinkota and Ronkainen, 2011).

However, it is important to remark that an evolution in the marketing discipline does not mean the traditional foundations of the discipline should be discarded. On the contrary, new approaches have been integrated in a traditional conception, resulting in a more complex and evolved theory of marketing.

If we take marketing mix theories as the basis of traditional operational marketing policies, the evolution towards a society based on services (and not so much on products, like some decades ago), has introduced new instruments based on subjects like customer relationship or new technologies that come to define a new era in marketing.

Philip Kotler $(2010,2016)$ describes this evolution in a very specific model which shows the evolution from a marketing 1.0 point of view, based on the product, to a marketing 3.0 and 4.0 framework where the focus in placed on customer experience and the use of new technologies.

Throughout this chapter, we will analyze the most important approaches in marketing and the evolution towards the new environment, based on a services perspective. These new approaches will help us to develop new constructs and items for the measuring variables, as described on chapters 4 and 5.

But just before considering the evolution of theoretical models, we will analyze the most important research areas in the marketing literature, something that will help us to define the subjects of interest and their relative importance with respect to a general context.

A detailed analysis is provided in the following section. 


\subsection{RESEARCH AREAS}

If we take a close look at specialized marketing literature, we can find a diversity of articles that analyze the subjects and trends in contemporary marketing research (HajiBasri 2012, Saleh 2016, Lehmann 2005, Yadav 2010).

The investigation carried out through the last years certainly helps us to know where we come from and where the marketing discipline is heading to. Only by getting to know the findings of these papers, shall we be able to understand how marketing research has evolved over last decades.

We should also note that the diversification of themes contributes not only to the development of marketing theory and practice, but also to the understanding of marketing itself (Haji-Basri 2012).

The business environment is rapidly changing, and - as a consequence- so are the trends of the research in marketing. Therefore, it is important to provide a continuous analysis of the overall content in the literature, so that "we know what is going on in research concerning the business world".

Besides, empirical generalizations in any subject, is a way to determine the "laws of marketing" and present future developments. That is, "the more complex the marketers' world gets, the more we have to understand the underlying trends which mark the direction of future developments" (Saleh 2016).

The study also concludes the rising interest on subjects like: marketing ethics and social corporate responsibility, international marketing, relational marketing, and competitive a nalysis.

\section{THE EVOLUTION OF MARKETING RESEARCH IN TIME}

Yadav (2010) and Lehmann (2005) carried out an intense research on the articles published in all the major marketing Journals at the time, comprising the 1978-2007 (30 years) and $1925-2004$ periods respectively. 
The findings show there is a clear lack of theory development in this field of investigation, which still remains, as Haji-Basri (2012) would also point out later. "While the findings show that the marketing practice is moving toward more rigorous research, there should be a balance between rigor and relevance of marketing research" (Yadav, 2010; Lehmann et al, 2011).

But Yadav also contributed to an interesting classification of the conceptual marketing articles as shown on table 3.1:

Table 3.1. Classification of marketing concepts

A) Marketing environment (21.36\%): Consumer behaviour Legal, political and economic issues Ethics and social responsibility

B) Marketing Functions (47.01\%): Management, planning and strategy Advertising

Product

Channels of distribution

Pricing

Personal selling

Sales management

Electronic Marketing

Physical distribution

Retailing

Sales Promotion
C) Special Marketing Applications (7.69\%): Services Industrial Nonprofit, political and social causes International and comparative

D) Marketing Research (21.36\%): Theory and philosophy of science Research methodology Information technology

E) Other Topics (2.58\%)

Educational and professional issues

Note: \% of articles developing each subject in the 30-year period in brackets

Source: Compiled by the author, based on Yadav (2010)

Haji-Basri (2012) performed a new research following the path started by Yadav and Lehmann, who had done basically the same kind of research on the same Journals, but in the period comprised between 2000 and 2009, with the following results:

\footnotetext{
"Based on a detailed analysis of the publications during these years the subject areas most often investigated were determined. The results indicate that Consumer Behaviour, Management, and Planning, Pricing, Market Function/Strategy, and New Product Development were the five most popular research themes within these years. The five themes consisted of approximately 45.4 percent of reviewed articled for this study. Consumer behaviour was a theme that attracted attention of most researchers." (Haji-Basri, 2012)
} 
The most recent study has been carried out by Saleh (2016), between 2010 and 2014, analysing articles from three of the main scientific marketing journals (Journal of Marketing Research, Journal of Marketing Science and Journal of Marketing) and demonstrating that:

1) Consumer behaviour presents the highest rates of interest from researchers, representing $22 \%$ of the marketing articles on all marketing themes.

2) The articles published in the e-marketing subject reached a $10 \%$ of all the published articles, with a high increase if compared with other periods of time.

3) Research on advertising, branding and research methods represented $7 \%$ each.

Consequently, we can reach the conclusions on table 3.2 when all the studies are compared:

Table 3.2. Research Themes in Marketing (1978-2014)

\begin{tabular}{|c|c|c|c|c|}
\hline \multirow[t]{2}{*}{ Themes } & \multicolumn{2}{|c|}{ Yadav } & \multirow{2}{*}{$\frac{\text { Haji-Basri }}{2000-2009}$} & \multirow{2}{*}{$\begin{array}{c}\text { Saleh } \\
2010-2014\end{array}$} \\
\hline & 1978-1987 & 1988-1997 & & \\
\hline Consumer behaviour & $11.3 \%$ & $3.75 \%$ & $12.1 \%$ & $22 \%$ \\
\hline Advertising & $7.83 \%$ & $5.0 \%$ & $4.3 \%$ & $7 \%$ \\
\hline Branding & - & - & $6.3 \%$ & $7 \%$ \\
\hline Research methods & $2.61 \%$ & $3.75 \%$ & $5.3 \%$ & $7 \%$ \\
\hline Product development & $5.22 \%$ & $3.75 \%$ & $6.9 \%$ & $5 \%$ \\
\hline Marketing management & $20.87 \%$ & $25.0 \%$ & $11.8 \%$ & $4 \%$ \\
\hline Sales and sales management & $4.35 \%$ & $1.25 \%$ & $7.2 \%$ & $2 \%$ \\
\hline Retailing & $0.87 \%$ & - & $1.0 \%$ & $2 \%$ \\
\hline Channels of distribution & $5.22 \%$ & $1.25 \%$ & $3.3 \%$ & $2 \%$ \\
\hline Customer relationship & - & - & - & $1 \%$ \\
\hline International marketing & - & - & $1.0 \%$ & $1 \%$ \\
\hline Social responsibility & $3.48 \%$ & $5.0 \%$ & - & $1 \%$ \\
\hline Customer loyalty & - & - & $1.6 \%$ & $1 \%$ \\
\hline Marketing ethics & - & - & $2.3 \%$ & $1 \%$ \\
\hline Theory and philosophy of science & $17.39 \%$ & $25.0 \%$ & $4.7 \%$ & - \\
\hline Legal, Political and economic issues & $11.3 \%$ & $7.5 \%$ & $2.6 \%$ & - \\
\hline Special Marketing Applications & $5.22 \%$ & $7.5 \%$ & - & - \\
\hline \multicolumn{5}{|c|}{ (Industrial, Social, International, Services) } \\
\hline Physical distribution & $0.87 \%$ & $1.25 \%$ & - & - \\
\hline Others & - & $5.0 \%$ & $6.5 \%$ & $7 \%$ \\
\hline
\end{tabular}

Source: Adapted from Yadav 2010, Haji-Basri 2012 and Saleh 2016 
Other scholars (Line and Runyan, 2012; Oh et al, 2004) carried out a similar investigation in the services and hospitality sectors with the following results classified by themes of research: Consumer behaviour/perceptions (28.1\%), management planning and strategy (19.7\%), employee behaviour/satisfaction (12.8\%), consumer characteristics (8.8\%), electronic marketing (6.9\%) and public relations (7.3\%).

We can see from the comparison that research areas are quite similar, but companies specialized in offering services pay a special attention to consumer and employee perceptions, and public relations is also an important variable to the detriment of traditional advertising.

\subsection{FROM CONSUMER GOODS MARKETING TO SERVICES MARKETING}

The formal study of marketing has suffered an evolution from the 1900 s up to the present time.

The initial research on marketing came from the so called "functional school", and its scholars paid special attention to the exchange and distribution of commodities and manufactured products (Marshall 1927; Shaw 1912; Smith 1904). Commodities were mass produced and there was a real need to "facilitate the exchange of goods through marketing institutions" (Vargo and Lusch, 2004).

However, by the early 1950s, a new approach known as the "marketing management school" was emerging. The focus was now being placed on a decision-making process to manage the marketing functions, and always keeping the attention on the customer (Drucker 1954; Levitt 1960, McKitterick 1957).

In the 1960s, scholars like McCarthy (1960) and Kotler (1967) defined marketing as "a decision-making activity directed at satisfying the customer at a profit by targeting a market and then making optimal decisions on the marketing mix", introducing the " $4 \mathrm{P}$ 's" concept that will remain until today: PRODUCT, PRICE, PROMOTION and PLACE. 
According to Kotler, "marketing management seeks to determine the settings of the company's objectives in the light of the expected behaviour of non-controllable demand variables"

This was a time when important contributions were made, considering marketing as a social discipline and developing a model that would explain the exchange and distribution of manufactured goods, from a microeconomic point of view.

Later on, during the eighties, other perspectives that were not based on the $4 \mathrm{P}^{\prime} \mathrm{s}$, became quite popular. Approaches as relationship management, quality management, market orientation, supply and value chain management, resource management and networks, contributed to the new "Services Marketing" subdiscipline and the concept of marketing became more fragmented. (details on fig. 3.1.)

From that moment, some researchers started questioning the existence of an alternative paradigm in marketing, leaving the "exchange of the goods" theory aside in order to consider services marketing as a separate area of study.

On the contrary, others determine that perhaps the marketing discipline is not that fragmented and is moving towards a new concept based on "the exchange of intangibles, specialized skills, knowledge and processes".

This new perspective would take us to a wider dominant logic that considers goods and services as an integrated pack, providing a richer base for the development of the marketing discipline, both in theory and practice (Vargo and Lusch, 2004).

Fig. 3.1. Evolution of marketing research (1900-2016)

Pre 1900:

Goods-Centered Model of Exchange

Based on:

Tangible goods

Manufacturing resources
Evolution from a product based (tangible) model

to a services based

(intangible)model $21^{\text {st }}$ Centruy:

Services-Centered Model of Exchange

Based on:

Intangible goods

Relationships

Exchange processes 
Classical and Neoclassical models:

(1800-1920)

Commodities

Marketing institutions

Marketing functions

Mktg management school of thought:

(1950-2000)

Customer orientation

Value determined in marketplace

Marketing to achieve optimal output

Social Marketing (2000-nowadays)

Market orientation

Services marketing

Quality management

Network management (relational mktg)

Resource management (RBV)

Source: Vargo and Lusch 2004

3.3.1. The new emerging paradigm

With the new emerging approach, marketing is considered as a social and economic discipline that pretends to focus on the importance of "operant resources". The marketplace lets organization learn about their operations in order to satisfy customer needs and, as a consequence, improve performance.

The new conception contributes to the development of additional literature from other areas like customer and marketing orientation, relationship marketing, resource management, and network analysis.

MAIN AREAS OF STUDY IN THE NEW EMERGING PARADIGM:

A) Market Orientation (MO) 
"A business that increases its market orientation will improve its market performance". This is a statement that had been continuously proclaimed by the marketing management school researchers from the 1960s.

But it was not until the 90s, when Narver and Slater on one side, and Kohli and Haworski on the other, presented valid scales for measuring marketing orientation and its influence on business performance, which would be considered the foundations of this approach and have been widely used by scholars for decades.

The findings in their studies suggest that "the market orientation of a business is an important determinant of its performance, regardless of the market turbulence, competitive intensity, or the technological turbulence of the environment in which it operates". (Jaworski and Kohli, 1993; Narver and Slater, 1990)

So, general managers should concentrate their efforts on how to improve the market orientation in their companies, in order to achieve higher levels of performance.

According to Narver and Slater, market orientation is the kind of philosophy within a company that generates the necessary actions to attain a higher value for customers and, as a consequence, a superior performance in time. That is what they called "sustainable competitive advantage" (SCA).

A company that promotes a market-oriented philosophy believes that, when the management generates additional benefits for the customers and reduce their "acquisition and use costs", new sources of sustainable competitive advantage (SCA) are developed.

As a result, a market-oriented activity will examine these "alternative sources of SCA" continuously to check how the business is able to create sustainable superior value for its present and future customers.

Apart from all this, the Market Orientation approach will set the basis for the new concept of relationship marketing, as they consider that a company should develop a long-term "mutually beneficial relationship" with its customers (see fig. 3.2). 
Accordingly, as Narver and Slater (1990) stated, a market-oriented seller will make decisions like determining how to share the generated superior value with its buyers.

The basic concepts of their scale (MKTOR scale) are taken from previous literature and determine that market orientation consists of:

- Three behavioural components:

1) customer orientation: understanding the customer's value chain and its evolution.

2) competitor orientation: understanding strengths, weaknesses, capabilities and strategies of potential competitors.

3) interfunctional coordination: business's efforts to generate superior value for customers.

- Two decision criteria:

4) long term focus

5) profitability

Fig. 3.2. Market orientation according to Narver and Slater

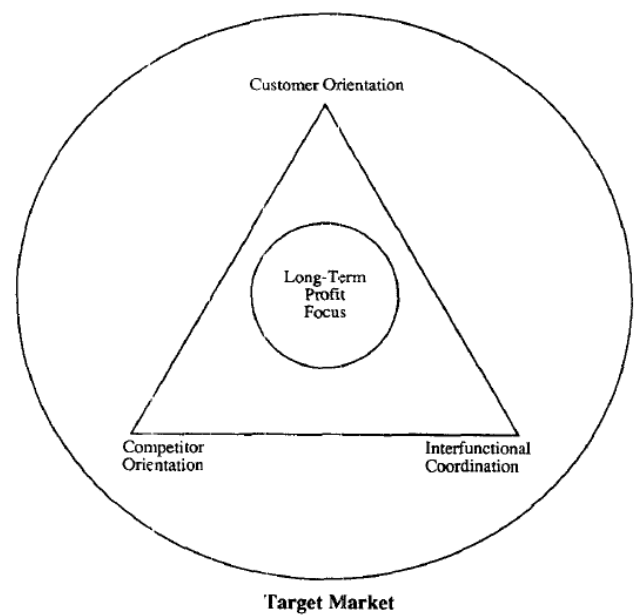

Source: Narver and Slater, 1990 
In the same decade, Kohli and Jaworski introduced their approach to Market Orientation (Kohli and Jaworski, 1990; Kohli et al, 1993; Jaworski and Kohli, 1993), providing a new scale to measure the incidence of market orientation on firm performance (the MARKOR scale).

For Kohli and Jaworski, market orientation results in "the implementation of the marketing concept". Hence, "a market-oriented business should represent the three basic pillars of the marketing concept: customer focus, coordinated marketing and profitability.

As a conclusion, they offer the following definition of market orientation:

"Market orientation is the organizationwide generation of market intelligence pertaining to current and future customer needs, dissemination of the intelligence across departments, and organizationwide responsiveness to it."

So, according to their definition, marketing orientation in a company is a three stage process with the following actions to be taken:

1) Generation of intelligence: detecting present and future customer needs.

2) Dissemination of intelligence: the generated intelligence must be spread across departments in the company.

3) Responsiveness to intelligence: the company must generate appropriate response to those customer needs and preferences.

That means that different organizations present different market orientations depending on the way they generate market intelligence, disseminate it internally and make decisions based on the previously generated intelligence.

Such Narver and Slater as Kohli and Jaworski reach very similar conclusions as they relate $\mathrm{MO}$ and business performance in a positive way. However, their conception is not exactly the same, as they use different ways to build their constructs and scales when considering the empirical research. Those discrepancies are based on two different conceptions: 
- For Kohli and Jaworski, MO is considered a way to process market information to detect and satisfy the needs of their customers.

- Nevertheless, Narver and Slater consider MO as the "interfunctional coordination" in a business to create and develop an added value for the customer.

The concept of $\mathrm{MO}$ has evolved during the last decades, and plenty of researchers have identified its role as "strategic contributors" to the improvement of the company performance (Chad, 2014; Balodi, 2014; Guo 2002; Pena et al, 2012; Shafei and Zohndi, 2014).

Market orientation does not only promote the exchange of information, but also develops a culture that encourages the use of communication within the company, developing relational capabilities that result in a series of valuable intangible resources (Wei et al, 2014; Shafei and Zohdi, 2014; Devece et al, 2017).

Consequently, market orientation can be considered as a way to achieve competitive advantage and create superior value, something which results in a higher performance. Companies should identify and analyze their markets in order to study the behaviour of potential customers, meeting the final goal of promoting customer loyalty (Fang et al, 2014; Jaworski and Kohli, 2017).

As a general rule, companies should focus on collecting as much information as possible on their customer's needs (Devece et al, 2017; Jaworski and Kohli, 2017). This sets the basis of a philosophy which contributes in an important way to the development of the items when determining the marketing strategy variable in our investigation.

But not only that, as the early MO theory constitutes the starting point for other approaches like relationship marketing, Resource based view or dynamic capabilities. Sometimes it is difficult to draw a line that separates one from the others. 
B) Services Marketing

When analyzing the literature on services marketing, three basic assumptions can be taken into consideration, according to Zeithaml et al (1985):

- The first one states that a number of inherent characteristics to services, inseparability of production and consumption, heterogeneity, intangibility and perishability (cannot be stored) - makes them different to tangible goods.

- The second one holds that these specific characteristics are the basis for the different problems that goods or services marketers will have to face.

- And the third assumption determines that "services marketing problems require services marketing solutions", as the strategies developed in the case of goods marketing are often incomplete.

Some of the problems arising when dealing with services marketing are:

- Unlike goods, services cannot be "mass-produced"

- It is difficult to control the quality of services

- Services cannot be stored, transported or accounted (perishability)

- They cannot be protected by patents

- The costs in the case of providing services are difficult to calculate

- Customers are very frequently involved in the process of creating the service

- The demand for services is not always the same, as it fluctuates

However, these problems are not perceived in the same way by companies within the services sector. Therefore plenty of different solutions can be provided.

On the other hand, Grönroos (1984), stated that, "in order to be able to develop service marketing models and service management models, one has to have a clear picture of what consumers in the marketplace really are looking for and what they are 
evaluating in the customer relation of service firms". In that case, a service quality model will be appropiate to satisfy customer needs.

According to Grönroos and his service quality model, the customers of a service firm get a perceived service quality when they hire a service, but that can be different to the expected service quality (depending on the expectations perceived by the customer, which may be influenced by marketing techniques).

So, when a services company pretends to introduce its image to new target markets, developing traditional marketing actions might be an effective way to achieve the goal.

Nevetheless, if there is not a technical and functional quality reflected in the process, the advertising campaigns could be counterproductive and should not be carried out.

In this context, all traditional marketing policies would have an impact on the customer's expectations, and that could result in disappointed customers, because of the existence of a gap between the expected service and the perceived service (see Fig.3.3).

Fig. 3.3. Service quality model by Grönroos

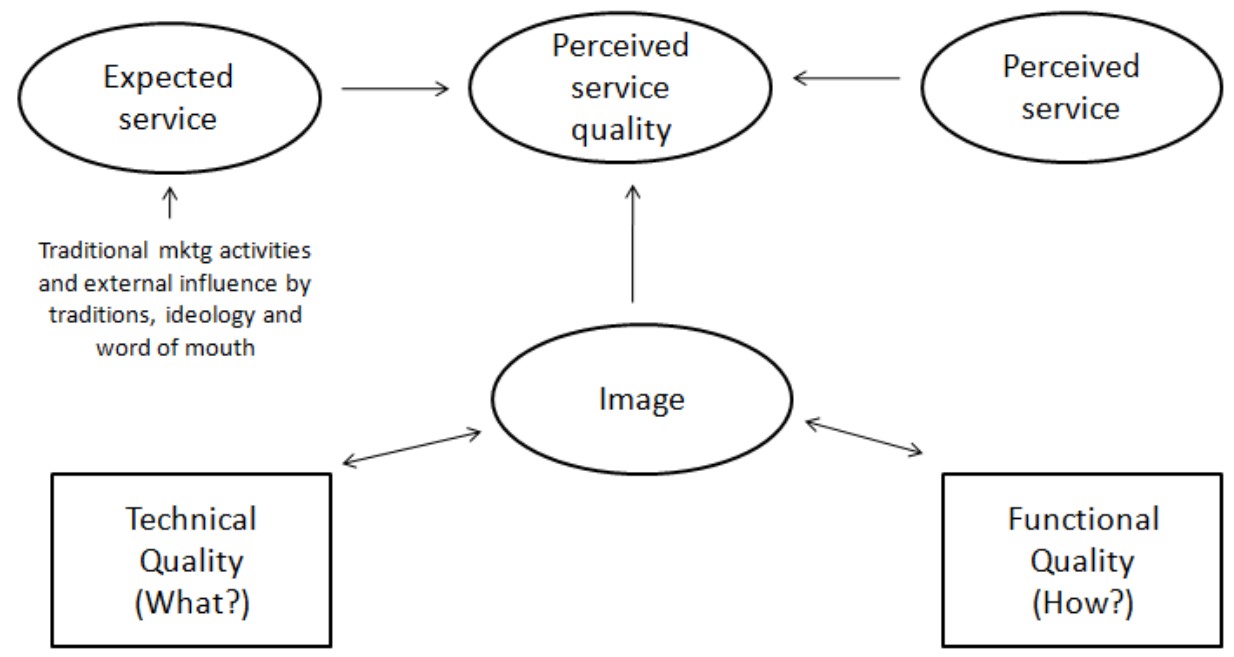

Source: Grönroos (1984)

But Grönroos also developed the customer relationship lifecycle model, originally called the "marketing circle". This theory would offer an explanation to the 
establishment of a long-term relationship between the company and its customers. Services marketing is therefore, narrowly linked to Relationship Marketing.

When analyzing the new services marketing stream, we can find two points of view that offer different explanations to the transition from goods to services:

- The first, "goods-dominant (G-D) logic", considers services as a kind of intangible goods and implies that the way these goods are produced and distributed should be changed in order to deal with the differences between traditional tangible goods and services.

- The second, "service-dominant (S-D) logic", focuses on services. In this context, services are considered as an economic exchange between companies and customers, and a way to use the company resources for a mutual benefit. Consequently, all marketing policies should be considered from a service-driven point of view (Vargo and Lusch, 2008a).

According to Vargo and Lusch, the basic foundational premises of the S-D emerging paradigm are as follows:

- Skills and knowledge are the fundamental unit of exchange

- Indirect exchange masks the fundamental unit of exchange

- Goods are distribution mechanisms for service provision

- Knowledge is the fundamental source of competitive advantage

- All economies are service economies

- The customer is always a co-producer

- The enterprise can only make value propositions

- A service-centered view is inherently customer oriented and relational 
These foundational premises, initially published in 2004 by Vargo and Lusch, were updated in 2008 and 2016 by the same authors, considering relational models and the effect of all social and economic factors as contributors to strategic benefit.

These foundational premises have become the framework of this new model focused on a service approach, which has been known through the years as the "service dominant logic" (see table 3.3).

In S-D logic, as already stated, services are considered as an exchange where competences (knowledge and skills) are applied to get a benefit for another party, obtaining a reciprocal service, which means that "service is exchanged for service".

Table 3.3. From Goods logic to Service logic

\begin{tabular}{|c|c|}
\hline Goods logic & Service logic \\
\hline $\begin{array}{l}\text { Making something } \\
\text { (goods or services) }\end{array}$ & $\begin{array}{l}\text { Assisting customers in their own } \\
\text { value-creation processes }\end{array}$ \\
\hline Value as produced & Value as co-created \\
\hline Customers as isolated entities & Customers in context of their own networks \\
\hline $\begin{array}{l}\text { Firms resources primarily } \\
\text { as operand }\end{array}$ & Firm resources primarily as operant \\
\hline Customers as targets & Customers as resources \\
\hline Primacy of efficiency & Efficiency through effectiveness \\
\hline
\end{tabular}

Source: Vargo and Lusch, 2008a

The S-D logic also considers that customers turn into "co-creators of value", something which reinforces a continuous development of customer-supplier relationships through interaction.

This new way to establish and develop relationships should be considered as a process of "learning together", as both parties are able to generate an added value through products or services which are now co-produced and, consequently, customized (Payne et al, 2008). 
According to Grönroos and Voima (2013), such the service provider as the customer should be seen like "co-creators of value".

In this scenario, the co-creation concept plays a very important role within the new marketing pagadigm. Not is vain, it was considered one of the foundational premises of the S-D logic, as defined by Vargo and Lusch (2004, 2008b, 2016).

Payne, Storbacka and Frow, presented a theoretical framework for the co-creation of value (see fig. 3.4) with three basic components:

- Customer value-creating processes: considered as the processes, resources and practices used by customers to manage the business and relationships developed with their suppliers.

- Supplier value-creating processes: the processes, resources and practices used by suppliers to manage the relationships they establish with their customers.

- Encounter processes: defined as the processes and practices behind the relationships established between customers and suppliers. They must be taken care of, so that co-creation opportunities can be successfully developed.

Fig. 3.4. The co-creation of value

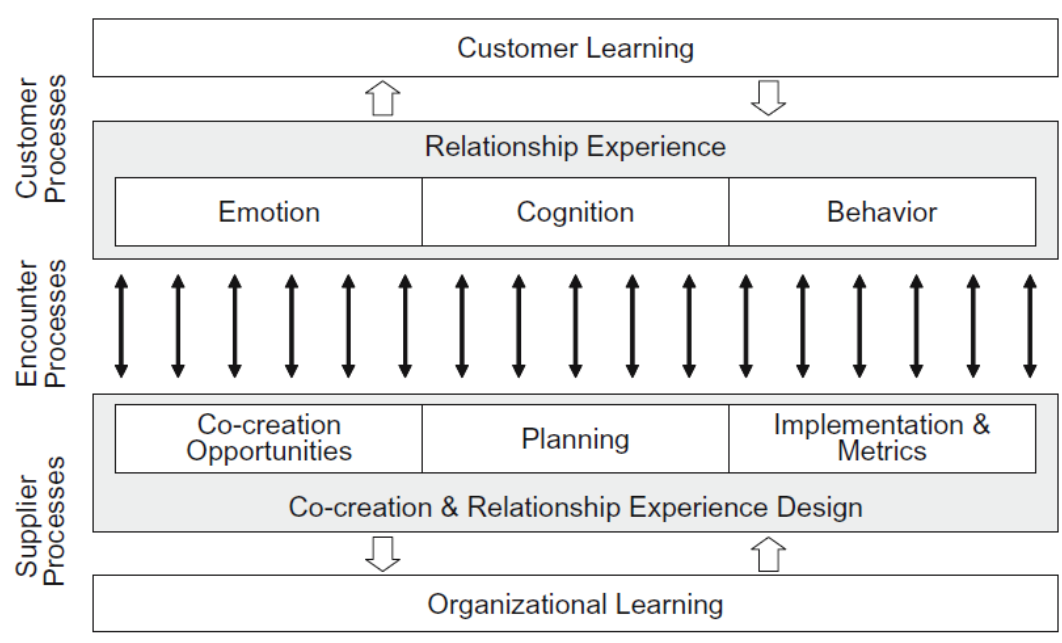

Source: Payne et al, 2008 
Grönroos and Voima (2013) present a very similar model with three "value creation spheres": the provider sphere, the customer sphere and, in between, the joint sphere where the customer participates as co-producer in the joint production process.

One additional concept within the Services Marketing approach is gamification, which is defined by Huotari and Hamari (2012) as "a process of enhancing a service with affordances for gameful experiences in order to support user's overall value creation".

Ever since the new Service Marketing approach, plenty of investigations have directed their research studies to this particular sector. More specific studies are being carried out, and particular problems in every sector are analyzed in order to find new solutions. If we take the hospitality marketing sector, for instance, we can find papers (Line and Runyan, 2012; Oh et al, 2004) where scholars analyze the trends in hospitality marketing.

Regarding our particular case, although the companies in the fashion sector are focused on the production and development of new products, they tend to incorporate certain aspects of the services marketing theory when developing their relational policies.

Offering an appropriate product is not enough, if the customer does not receive the best possible service. This is a way to improve the competitive advantage and create superior value, contributing to customer loyalty.

C) Relationship Marketing (RM)

Relationship marketing, which is one of the basic pillars in the theoretical model of this thesis, has also been considered as one of the most important approaches in the development of the marketing science. Not in vain, it has even been considered as a new paradigm for many scholars (Berry, 1983; Sheth and Parvatiyar, 2000; Gummesson, 1994a, 1994b, 2002; Payne and Frow, 2005). 
According to Gummersson (2002), relationship marketing is narrowly linked, not only to consumer goods, but also to services and business to business services. Besides, the new discipline could be considered as a general theory of marketing with networks, relationships and interactions as the basis of a new philosophy.

In one of the first definitions of the RM concept, Berry (1983) states that Relationship marketing is about "attracting, maintaining and developing customer relationships".

For Gummesoon, (1994a, 1994b) RM can be considered as the kind of marketing that pays a special attention to long term relationships and interaction, being the relationship between consumers and suppliers the basis to develop this activity. On the other hand, when these relationships become more frequent and more complex, they result in networks. RM promotes long term relationships with consumers and customer loyalty.

Gummesson contributed to the RM approach by broadening the concept when introducing two relatively new dimensions -nano relationships and mega relationships (fig.3.5) - in a model defined by 30 Rs (30 different kind of relationships to be considered within the company)-

Fig. 3.5. Relationship Marketing according to Gummesson

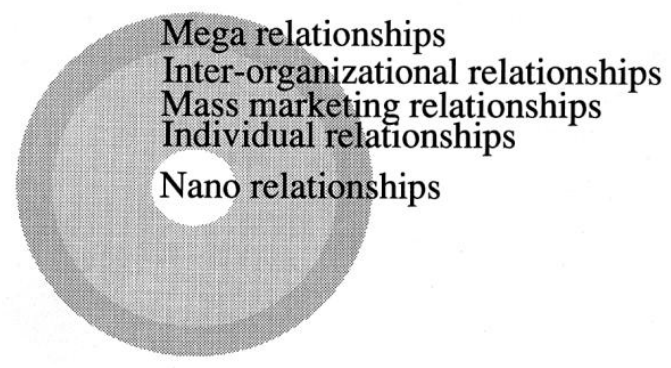

Source: Gummesson, 1994a

But he also considered that the initial Marketing Mix Paradigm (4Ps) could result into a new RM Paradigm by placing relationships (as previously defined by him) in the centre of the strategy and using the 4Ps and its extensions to achieve the necessary objectives (see fig. 3.6). 
Fig. 3.6. Initial Marketing Mix Paradigm (left) and new RM Paradigm

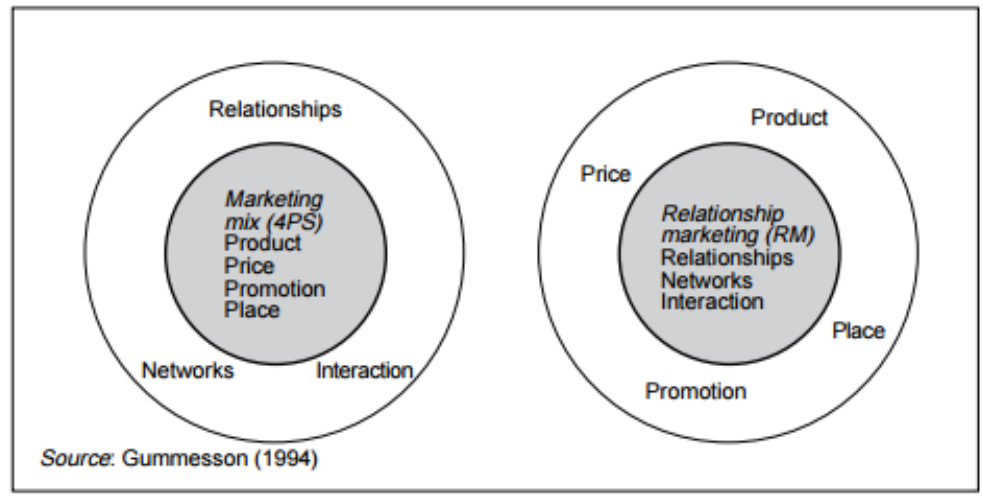

Source: Gummesson 1994b

In addition, Gummesson determines that companies need some basic security. Security is associated with words such as promises, honesty, reliability, predictability, stability, fear of being swindled or let down, reduction of uncertainty and reduction of risk.

In that way, security in the company can be reached from four sources: laws and regulations, knowledge, business culture and ethics, and relationships.

Authors like Duncan and Moriarty (1998) determine the existence of marketing models beyond the traditional conception of the marketing mix theory. They place communication in the centre of a new perspective where the objective is building long term relationships between firms and customers. This is, according to them, a more effective way develop marketing policies. Some of the basic points behind the new theoretical background can be summarized as follows:

- Companies are no longer interested in persuasion as the basis for a proper commercial relationship. Instead, they prefer building relationships with a clear focus on communication.

- Marketing mix policies are still determinant, but they are not considered as the only source of brand communication. 
- Feedback is considered as a basic tool in the new process, as it is fundamental for the establishment of a bidirectional communication relationship.

- Marketing policies in all sectors, but particularly in services, take a new dimension when an effective communication process is placed in the core of all marketing activities.

If we want to develop an effective theory of Relationship Marketing, it is fundamental getting to know what takes consumers to discard other market choices and engage in a particular "relational market behaviour".

As determined by sociologists, the reasons for consumers to engage in these commercial relationships are influenced by personal, social and institutional factors.

If we consider the personal aspect, by acting like this, consumers pretend to simplify the tasks involved in the buying process, reduce such the amount of information to be considered as perceived risks, and develop a state of psychological comfort.

Not only that. When focusing on the social and institutional perspective, consumers are also influenced by certain groups like family or society, and additional pressure can be placed through social norms, government policies, religious beliefs, employer influences or marketing policies.

Consequently, when both consumers and marketers are willing to engage in a proper commercial relationship, the result will be a greater marketing productivity. This mutual benefit, however will turn into a negative factor when "either consumers or marketers abuse the mutual interdependence and cooperation" (Sheth and Parvatiyar, 2000).

Morgan and Hunt (1994) identified 10 forms of RM as clearly shown on fig. 3.7. And they stated that relationships are based on trust and commitment. 
Fig. 3.7. The Relational Exchanges in RM

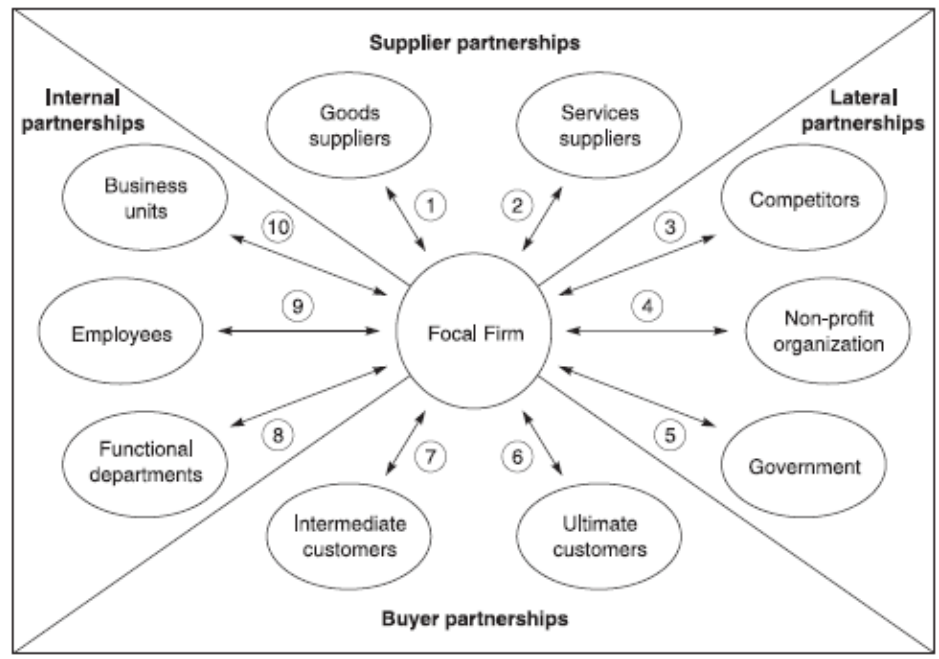

Source: Morgan and Hunt, 1994

According to them, commitment is a key element to relationship management, and defined it as "an enduring desire to maintain a valued relationship". Commitment exists in a relationship only when that interaction is important. In that context, "committed partners" pretend to keep that relationship in the long term and will do everything they can to achieve it.

On the other hand, trust is another important concept, which is defined as "the willingness to rely on an exchange partner in whom one has confidence".

With the key mediating variable (KMV) model of RM (see fig.3.8), they consider commitment and trust as key constructs in a model with five inputs (i.e., relationship termination costs, relationship benefits, shared values, communication, and opportunistic behaviour) and five outcomes (i.e., acquiescence, propensity to leave, cooperation, functional conflict, and decision-making uncertainty).

The conclusions from the study determine that trust is positively linked to commitment, as the second cannot be achieved without the first. Regarding the rest of variables, propensity to leave, uncertainty and opportunistic behaviour present the opposite effect, and the rest of antecedents and outcomes present a positive relation to trust or commitment. 
Fig. 3.8. The key mediating variable (KMV) model of RM

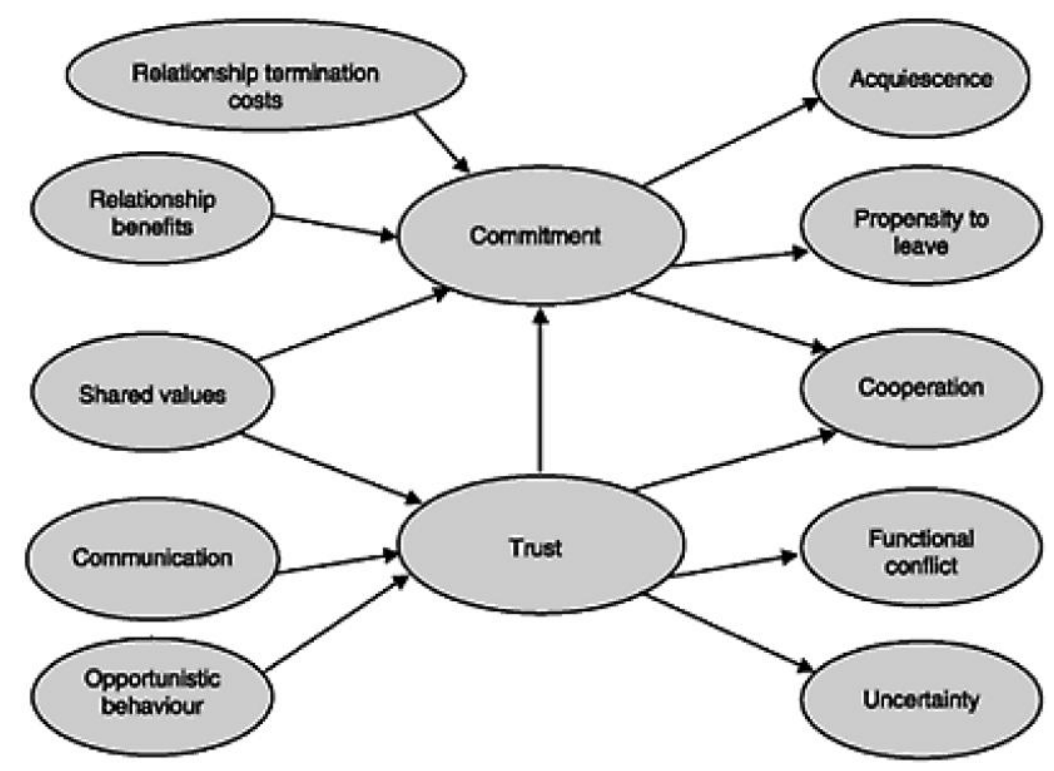

Source: Morgan and Hunt, 1994

Continuing with the analysis, a very important part of Relationship Marketing is Customer Relationship Management (CRM). Anyway, despite the increasing interest about this subject for nearly three decades, there is not a specific agreement about the consideration of CRM and how CRM strategy should be developed.

After examining the CRM literature, Payne and Frow (2005) offered the following definition that would provide the basis of their theoretical framework:

\footnotetext{
"CRM is a strategic approach that is concerned with creating improved shareholder value through the development of appropriate relationship with key customers and customer segments. CRM unites the potential of relationship marketing strategies and IT to create profitable, long-term relationships with customers and other key stakeholders. CRM provides enhanced opportunities to use data and information to both understand customers and cocreate value with them. This requires a cross-functional integration of processes, people, operations, and marketing capabilities that is enabled through information, technology and applications."
}

According to Payne and Frow $(2005,2009,2017)$, the CRM concept has suffered an evolution process, starting with the implementation of specific technology solution projects that result into the implementation of integrated solutions. This will, in turn, 
lead to a general process with a clear objective: managing long term customer relationships and create shareholder value.

As appreciated in fig. 3.9, they focus their model on creating customer and shareholder value through business and customer strategies, by introducing IT systems in a multichannel integration system.

Fig. 3.9. CRM model by Payne and Frow

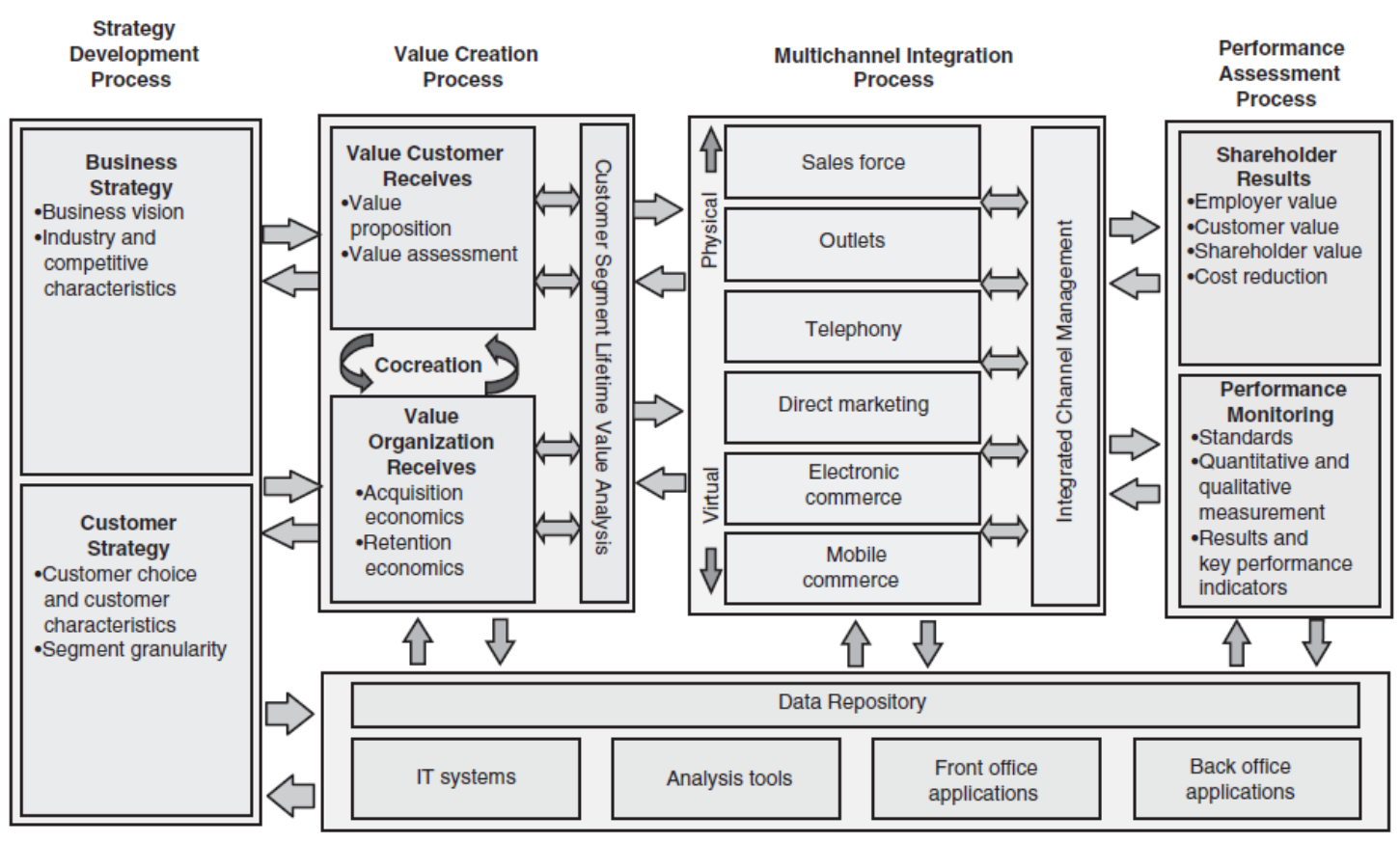

Source: Payne and Frow (2005)

Regarding the evolution of RM, Vivek et al (2012) show that pioneers in this approach (Berrry, 1983; Gronroos, 1990; Morgan and Hunt, 1994) proposed that the RM concept considers the fact of establishing relationships as a main objective.

However, the research on the subject focuses on retaining and maintaining existing relationships with customers, and not so much on attracting new customers.

In this context, when we concentrate on marketing policies, two different strategies can be found: offensive and defensive. Activities pretending to get additional 
consumers are offensive, while those devoted to reduce customer exit are defensive marketing strategies.

Finally, another key concept presented by Vivek is "Consumer Engagement" (CE), which is related to "the degree of connection and participation between individuals and organizations". Individuals can be current or potential customers, and CE may be present in different ways (cognitively, affectively, behaviourally or socially).

In this model, subjects like the involvement and participation of potential customers can be considered as inputs to achieve consumer engagement, while subjects like value, trust, loyalty, brand development or word of mouth can be considered as consequences.

Relationship marketing is one of the main streams of the marketing discipline, and a key element in the development of the theoretical model for this thesis. This approach, which has been considered by a big number of researchers (Chugan and Singh, 2014; Karelakis et al, 2008; Lages et al, 2009; Ricci and Trionfetti, 2012; Frow and Payne, 2009, Payne and Frow 2017) constitutes a fundamental tool to complement traditional marketing mix policies.

D) Resource based view (RVB) and dynamic capabilities in marketing

The previous approaches are very narrowly linked to the resource-based viewed (RBV) that was analyzed from an international perspective when developing internationalization theories on chapter 2.

As argued by Srivastava et al (1999), the execution of the processes in the marketing strategy, requires assets such as labour, knowledge and facilities. So, the RBV provides a conceptual framework to connect marketing and business management processes.

This RBV, which is focused on the development of capabilities according to the evolution of the market, considers that marketing strategy focuses on the development of intangible resources (like customer relationships, brand equity, 
technology or knowledge). The reason is that these kind of resources provide "sustainable competitive advantage" and a better performance (Srivastava et al, 1998; cited by Kozlenkova et al, 2014).

A resource-based view approach determines that, when a company has developed valuable resources that others do not have, competitive advantage can be obtained, especially if those resources are difficult to imitate (Barney and Hesterly, 2015).

According to Srivastava et al (2001), the RBV can also be applied to marketing in order to identify resources which are related to this discipline. However, the analysis will take us to consider other kind of resources as well, as they might have similar characteristics. Following the literature from other authors (Day, 1994; Fahey, 1999; Hunt and Morgan, 1995; Hunt, 2000), “assets, processes and capabilities" can be considered as the determinants of a RBV approach.

Assets refer to "organizational attributes that an organization can acquire and develop for both internal and external purposes" (Barney, 1991; Hunt and Morgan, 1995; Srivastava et al, 1998). According to Srivastava (2001), two types of market-based assets can be found: relational and intellectual.

- Relational assets: based on building customer relationships through marketing in order to develop factors like trust and reputation. These "intimate relations" with consumers are unique and extremely difficult for competitors to imitate.

- Intellectual market-based assets: focused on developing an appropriate knowledge of the company's competitive environment, something which is very closely linked to market orientation.

On the other hand, regarding processes, these business assets are supposed to be a fundamental part in the transformation process to turn inputs into products of services which are needed and desired by final customers, creating economic added value for the whole organization (Srivastava, 2001). Consequently, the role of marketing capabilities is crucial to connect processes and determine positive customer relationships. 
As already analyzed on chapter 2 , resources lead to dynamic capabilities when the constant changes in the environment are taken into consideration. This approach has been the theoretical support for a vast number of studies, and marketing capabilities have always been identified as basic inputs to develop competitive advantage.

Authors like Parnell et al (2015), Song et al (2008), Murray et al (2011) or Desarbo et al (2005), considered marketing and market linking capabilities capabilities as determinants of a higher performance.

The theoretical concepts and scales considered by these authors have been fundamental for the incorporation of marketing capabilities to the marketing strategy construct in our investigation. In this context, Murray et al (2011) develop a model (see fig. 3.10) that considers market orientation as an input for marketing capabilities, showing their effect on the company's competitive advantages and the final performance.

Fig. 3.10. Conceptual model by Murray et al

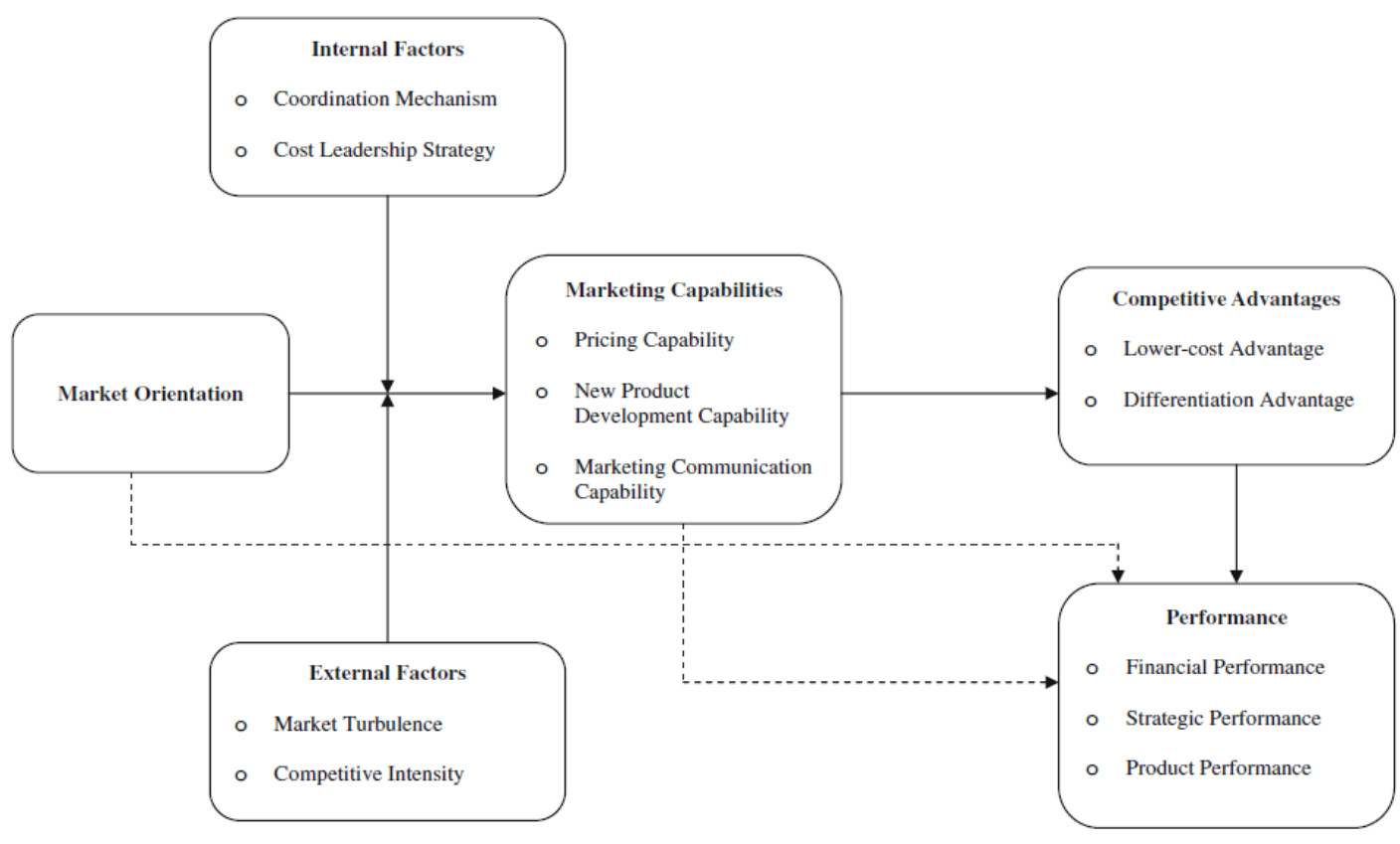

Source: Murray et al (2011) 
In the same direction, the papers by Chugan and Singh (2014) and Chen et al (2016) introduce a detailed number of items that influence the export performance from the firm resources and capabilities approach (see chapter 2 for details).

However, despite the important contribution of the RBV and dynamic capabilities perspectives to our model, one important critique might come from the omission of a key input in plenty of papers, which is the use of new technologies. The way to overcome this objection is considering internet marketing as an additional theoretical development that will set the basis for the introduction of a particular construct based on these factors.

E) Network analysis

As already noticed, the new approaches in the development of the marketing theory have contributed to important changes and the focus is no longer placed only on the traditional marketing mix activities (4Ps), but also on the development of networks and interactions based on relationships. The marketing practice has moved from firms and products to customers and values (Mele 2007).

In the 1990s, researchers from the nordic school (Johanson and Vahlne, 1990; Johanson an Mattson, 1993) are already conscious of the importance of the firm's relationships and networks. They consider that it is thanks to the relationships with important partners who are committed to developing the business through internationalization, that companies can expand their activities (Johanson and Vahlne, 2009).

By the end of the nineties, Achrol was able to predict that marketing environments in the coming century would be very turbulent and highly conditioned by knowledge. As a consequence, the traditional vertically integrated organization of the company, which had been so successful in previous decades, would be unlikely to survive under such circumstances. Instead, new forms of networks organizations, with "functionally 
specialized" companies, should exchange relationships to achieve efficiency (Achrol, 1997).

According to Achrol, a network organization is adequate when economic and managerial benefits are obtained from the "reciprocal exchange relationships" of the company. These relationships, at the time, are based on factors like commitment, trust or solidarity, which are the foundations of relationship marketing.

Finally, Achrol, identified four kinds of networks that present the characteristics of a "superorganization" (Achrol, 1997; Achrol and Kotler, 1999):

- Internal market network: a traditional company that has eliminated external boundaries and erradicated internal hierarchical control, making exchanges with other elements easier.

- Vertical market network: the conventional company that has transformed its operations by introducing technological, marketing or distribution components in the classic manufacturing process.

- Intermarket network: the establishment of all kind of economic and social alliances among all type of companies from other industries (financial, manufacturing or trading sectors, for instance).

- Opportunity network: a network that offers the possibility to match customer needs with customer solutions in a quick and efficient way.

Other authors, like Piercy and Cravens (1995) provided a different classification of network organizations, as follows:

- The hollow network: a transaction-based organizational form competing in highly volatile environments, being customer-focused and using transactional relationships to link customers with goods and services that meet their needs. It does not perform major research and development or production functions internally as technology is located with network members. 
- Flexible organization: encountered under conditions of high environment volatility, but has intra-network links that tend to be collaborative and long term. The network co-ordinator is likely to be an entrepreneur and manages an internal team which identifies customer needs, designs products, and establishes sources of supply to manufacture new products that satisfy a diversity of customer requirements.

- Value added networks: formed by companies which compete in markets where segments may be difficult to define and they may utilize a global network of suppliers coupled with substantial internal operations. Although the core organization in the value added network is responsible for innovation and product design, it may perform fewer value added functions than within a virtual network (it fits product-market situations where complex technologies and customized product offerings are not required).

- Virtual network: it is likely to be a reformed version of the traditional organization where the organization has a long-term organization and competes in markets with low levels of volatility. The network utilizes a substantial core competence in product innovation and production efficiency and the market encourages the formation of collaborative relationships with network members and customers.

Webster (1992), also contributed to the network theory with his own classification in the types of relationships and alliances, as can be appreciated on Fig. 3.11. From the initial stage of individual transactions to the final vertical integration, the author considers other intermediate options like repeated transactions, long-term relationships, partnerships, strategic alliances or network organizations. 
Fig. 3.11. Types of relationships and alliances

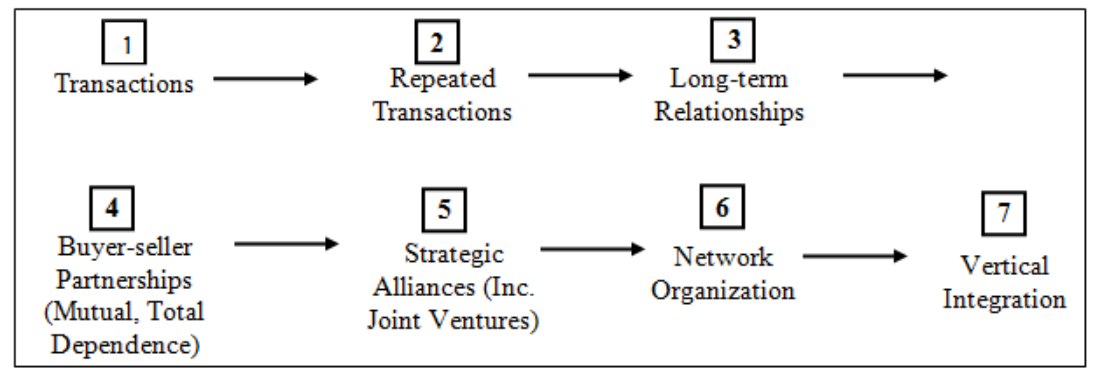

Source: Webster, 1992

However, the theory on the development of networks which are based on relationships, is still present in recent studies. Ebernhard and Craig (2013), for example, consider both interpersonal networks and interorganizational networks as one of the factors that boost internationalization processes, while Raymond and St. Pierre (2013) consider the development of networks as a firm capability (linking this approach to the RBV), resulting in the development of partnerships in every operational field of the company.

\subsubsection{Other approaches}

The aforementioned evolution of the theoretical approaches in the marketing discipline has led to a new conception of marketing. A big number of researchers have considered the new background in their studies and the result is a certain number of streams (mainly experiential marketing, internet marketing, and marketing $3.0+4.0$ ), which will be analyzed below.

\section{A) Experiential Marketing}

Pine and Gilmore (1999) determined that economic value within the company has gone through different stages, from a commodity based stage, to a manufacturing based stage, and into the service economy (directly associated to the new approach in 
marketing) of the twentieth century. But the economy is now entering a fourth stage, which they called "the experience economy", where the added economic value is no longer focused on products or services, but experiences.

Schmitt (2000), who is considered the initiator of experiential marketing, proposed that marketing activities of major companies had moved from "functional features and benefits marketing" towards "marketing experiences". He attributed this development to three marketing trends: the omnipresence of information technology, the supremacy of the brand and the ubiquity of communications, and entertainment.

Customers, he wrote, would take functional features and benefits, product quality and a positive brand image as a given. They demand products, services, communication processes and marketing campaigns that stimulate their senses, touch their hearts and stimulate their minds, that can be incorporated into their lifestyles and deliver an experience. Therefore, experiences would determine whether a brand will be successful in the global marketplace of the new era (Schmitt et al, 2014).

As we can check, the descriptions made by Schmitt (2000) seem pretty accurate, as the economy is increasingly dominated by information technologies, with businesses digitalizing operations, products and services, and connecting people through social media.

The next few years, however, are likely to launch yet another round of dramatic changes: the digital world will be connected with the physical, virtual realities may be created, there will be a bigger interaction with machines, and experiences will be the centre of these developments (Schmitt et al, 2014).

In this new context, experiential marketing is defined by Same and Larimo (2012) as a marketing planning tool concerned on tactical and operational level actions where the main question is how to create experiences and emotions to the customer.

While traditional marketing considers final consumers as rational human beings who make decisions based on the features and benefits that a certain product may offer, experiential marketing presents a different conception, considering consumers as 
rational and emotional individuals who pretend to achieve "pleasurable experiences" with the products and services they buy (Qader and Omar, 2013).

On the other hand, brand experience plays a very important role as it is considered the way final consumers respond to the impacts provoked by marketers through questions like brand design, packaging or promotion campaigns (Brakus et al, 2009). Brand experience, therefore, is the customer's response to experiential marketing.

Previous researchers considered the analysis of brand experience in relation to other variables like loyalty and satisfaction (Brakus et al, 2009). Nevertheless, scholars like Berry (2000) developed the brand experience concept in relation to brand equity by taking into consideration other constructs such as "customer's dominant perceptions of the brand" (Qader and Omar, 2013).

Finally, "brand equity" can be considered as one of the most important marketing concepts developed by researchers in the last thirty years (Atilgan et al, 2005). This can be explained by its determinant performance in the strategic management decisionmaking process. Firms which create brands with high equity provide a competitive advantage based on the creation of entry barriers for competitors (Farquhar, 1989).

B) Internet marketing / e-marketing

With the evolution of the Internet and the development of highly connected economies and markets, a new conception of marketing -known as Internet Marketing- has arrived. Although this new approach is not something new regarding commercial practices and activities, Internet marketing and e-commerce present a series of challenges to managers like: customer empowerment, new forms of communication, global operations, $24 / 7$ working hours, increase of market transparency, difficult to maintain competitive advantages ... (Constantinides, 2014).

An increasing number of companies have introduced new technologies and the Internet in their marketing policies in recent years. The incorporation of the Internet to the marketing process is so interesting because it provides such a way to increase sales 
as an additional distribution channel. The Internet can be considered as the access to a new market where buyers and sellers are able to contact each other. But not only that, as it also provides a way to develop and execute strategic business actions like marketing, sales and distribution (Farhoomand and Lovelock, 2001; cited by Ngai, 2003).

According to Ngai (2003), Electronic marketing is "the transfer of goods or services from seller to buyer that involves one or more electronic methods or media".

El Gohari (2010) describes electronic marketing (e-marketing) as a new philosophy, an innovative way to develop business through the determination of new marketing policies which are influenced by the internet and new technologies.

On the other hand, the literature on the subject, determines that the use of certain concepts like e-marketing is not clearly determined, as plenty of terms, like emarketing, internet-marketing, e-commerce or e-business, are frequently used in a similar context, while they have different meanings (El Gohari, 2010).

For instance, e-marketing denotes a broader extent than internet marketing, since internet marketing refers only to the part of e-marketing using the Internet and not any other instruments (like intranets, extranets, mobile phones ...). These differences can be appreciated in fig. 3.12.

Fig. 3.12. E-business, e-commerce, e-marketing and internet marketing

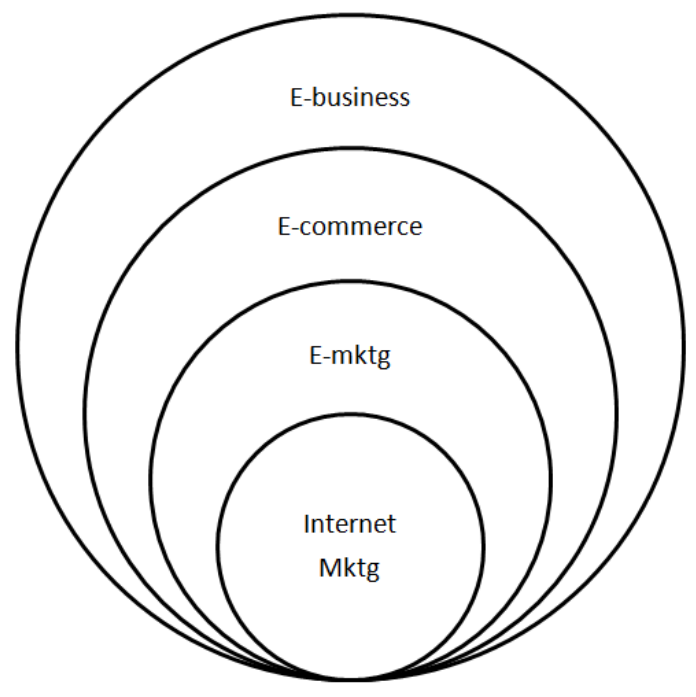

Source: El Gohari, 2010 
Some authors (Ngai, 2003; Hanson and Kalyanam, 2007; El Gohari, 2010) argued that internet marketing is the meeting point of three different disciplines: information technology \& information systems, economics, business \& management, and marketing.

El Gohari (2010) gathered the information in research studies from 2003 to 2010 and concluded that the main areas of interest were: electronic commerce (25.2\%), ebusiness (16.7\%), internet marketing (14.5\%) and mobile marketing (10.6\%).

According to Ngai (2003), the functions in internet marketing that arouse a bigger interest in the 2000s where: (1) management, planning and strategy, (2) channels of distribution, retailing and marketing structure, (3) advertising, and (4) pricing. This shows that there is not a big difference when compared to the traditional marketing research areas of interest, and therefore, Internet Marketing is considered as the instrument to support marketing strategies in the new information and communication technologies environment.

New web technology has also introduced a revolution in communication and advertising, making it simple for any company to create and share its own content thanks to social media. A blog post, tweet or youtube video can be displayed and viewed by thousands of potential customers almost for free. Social media comes in many forms and some of the most popular ones are: blogs, microblogs, social networks, media-sharing sites, analysis sites ... (Saravanakumar and SuganthaLakshmi, 2012).

Regarding mobile marketing (m-marketing), Andreas Kaplan (2012) defines it as "any marketing activity conducted through a ubiquitous network to which consumers are constantly connected using a personal mobile device" and pays special attention to social media, which can be managed in mobile marketing through a model with four basic points (see fig. 3.13.) 
Fig. 3.13. Mobile social media advice

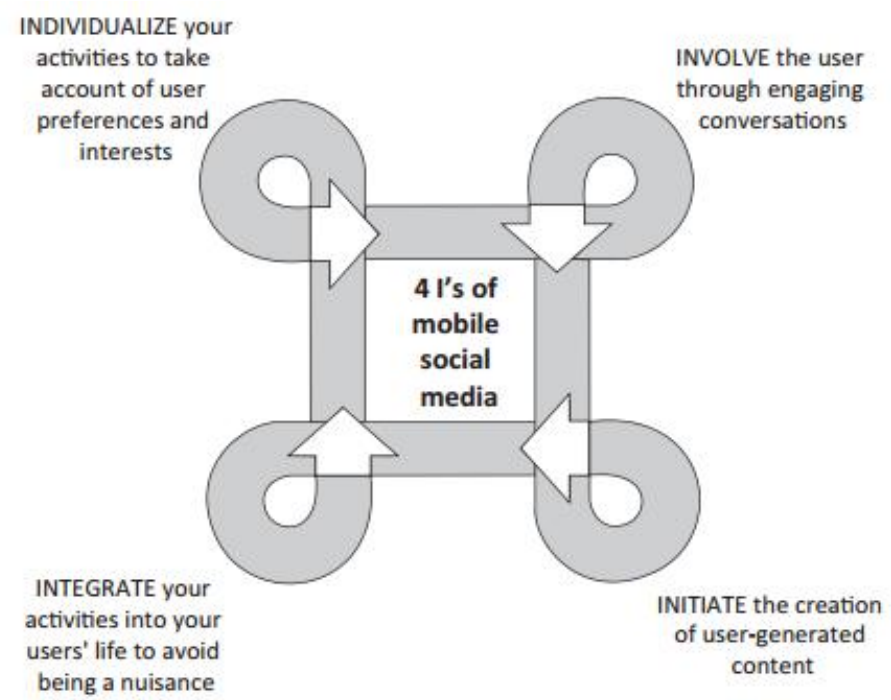

Source: Kaplan, 2012

Consequently, m-commerce, considered as an integrant part of m-marketing, consists of $\mathrm{B} 2 \mathrm{~B}$ (business to business), $\mathrm{B} 2 \mathrm{C}$ (business to consumer) and $\mathrm{C} 2 \mathrm{C}$ (consumer to consumer) developed through wireless devices like smart phones. It integrates all kind of services, like e-banking, e-commerce and information services (Yang and Huang, 2012), and is considered a very important part of Internet marketing due to the fact that the number of mobile devices among potential customers is constantly growing up.

Regarding the role of new technologies (basically the Internet) and the way they can be integrated in the marketing policy, the model by Prasad et al (2001) has been fundamental to our analysis (see fig. 3.14). The authors consider ITs as a basic component of marketing capabilities, which are also affected by market orientation policies. 
Fig. 3.14 Integration of ITs in the marketing strategy

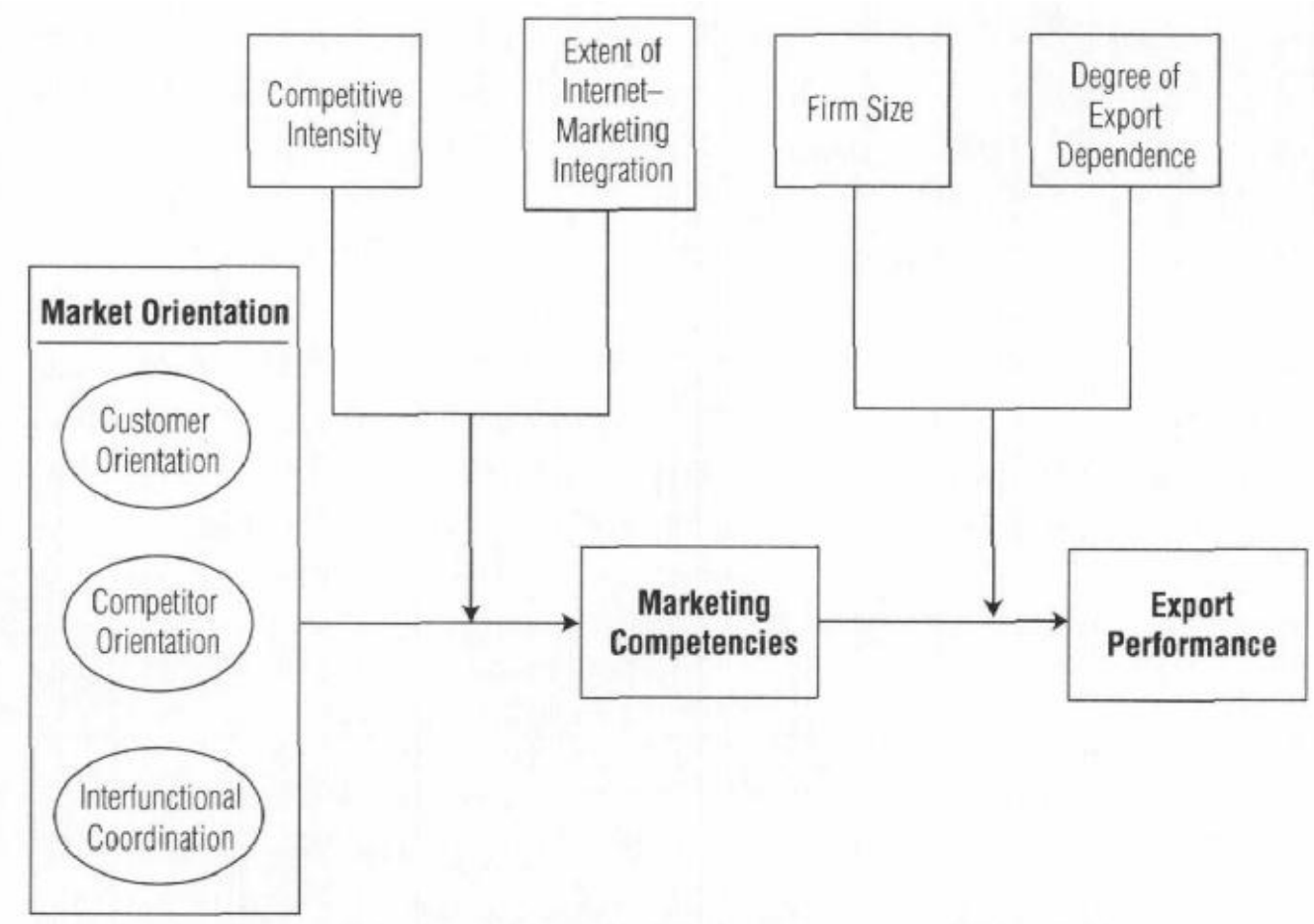

Source: Prasad et al (2001)

Other researchers which have approached the subject from the capabilities perspectives have been Parnell et al (2015), Morgan and Katsikeas (2012), or Song et al (2008). However, this is a field of study which demands a higher level of attention, and we will surely assist to a future development of both theory and practice.

C) Marketing 3.0 and 4.0

Marketing 3.0 is a modern approach within Marketing, whose principal defendant is Philip Kotler. In the book with the same name, Kotler et al (2010) develop the model and argue about the evolution from Marketing 1.0 to Marketing 3.0:

Long ago, during the industrial age-when the core technology was industrial machinerymarketing was about selling the factory's output of products to all who would buy them. The products were fairly basic and were designed to serve a mass market. The goal was to standardize and scale up to bring about the lowest possible costs of production so that these 
goods could be priced lower and made more affordable to more buyers. This was marketing 1.0 or the product-centric era.

Marketing 2.0 came out in today's information age-where the core is information technology. The job of marketing is no longer that simple. Consumers are well informed and can easily compare several similar product offerings. Consumers differ greatly in their preferences. The marketer must segment the market and develop a superior product for a specific target market. This is the view in marketing 2.0 or the customer-oriented era.

Now, we are witnessing the rise of marketing 3.0 or the values-driven era. Instead of treating people simply as consumers, marketers approach them as whole human beings with minds, hearts, and spirits. Increasingly, consumers are looking for solutions to their anxieties about making the globalized world a better place. In a world full of confusion, they search for companies that address their deepest needs for social, economic, and environmental justice in their mission, vision and values. They look for not only functional and emotional fulfilment but also human spirit fulfilment in the products or services they choose.

This evolution in marketing approaches can be easily appreciated on Table 3.4.

Table 3.4. Marketing 1.0, 2.0 and 3.0

\begin{tabular}{|c|c|c|c|}
\hline & $\begin{array}{l}\text { Marketing } 1.0 \\
\text { Product-centric } \\
\text { Marketing }\end{array}$ & $\begin{array}{l}\text { Marketing } 2.0 \\
\text { Consumer-oriented } \\
\text { Marketing }\end{array}$ & $\begin{array}{l}\text { Marketing } 3.0 \\
\text { Values-driven } \\
\text { Marketing }\end{array}$ \\
\hline Objective & Sell products & $\begin{array}{l}\text { Satisfy and retain the } \\
\text { consumers }\end{array}$ & $\begin{array}{l}\text { Make the world a better } \\
\text { place }\end{array}$ \\
\hline Enabling forces & Industrial Revolution & Information technology & New wave technology \\
\hline $\begin{array}{l}\text { How companies see the } \\
\text { market }\end{array}$ & $\begin{array}{l}\text { Mass buyers with physical } \\
\text { needs }\end{array}$ & $\begin{array}{l}\text { Smarter consumer with } \\
\text { mind and heart }\end{array}$ & $\begin{array}{l}\text { Whole human with mind, } \\
\text { heart, and spirit }\end{array}$ \\
\hline Key marketing concept & Product development & Differentiation & Values \\
\hline $\begin{array}{l}\text { Company marketing } \\
\text { guidelines }\end{array}$ & Product specification & $\begin{array}{l}\text { Corporate and product } \\
\text { positioning }\end{array}$ & $\begin{array}{l}\text { Corporate mission, vision, } \\
\text { and values }\end{array}$ \\
\hline Value propositions & Functional & Functional and emotional & $\begin{array}{l}\text { Functional, emotional, and } \\
\text { spiritual }\end{array}$ \\
\hline Interaction with consumers & One-to-many transaction & One-to-one relationship & Many-to-many collaboration \\
\hline
\end{tabular}

Source: Kotler et al, 2010

The evolution from Marketing 1.0 to 3.0 does not mean that the two first stages of the process are not relevant any more. The operational marketing policy is still related to segmentation, definition of targets and positioning, branding and marketing mix (through the development of the four Ps). However, marketing practices are in constant evolution due to the changes in the business environment, mainly recession, corporate social responsibility concerns, new social media, consumer empowerment, new technologies, and globalization (Kotler et al, 2010). 
According to Kotler et al, marketing should be considered as a triangle with three basic components: brand, positioning and differentiation. At a second stage, the triangle would include three additional elements (3i): brand identity, brand integrity, and brand image (see fig. 3.15)

Fig. 3.15. The 3i model

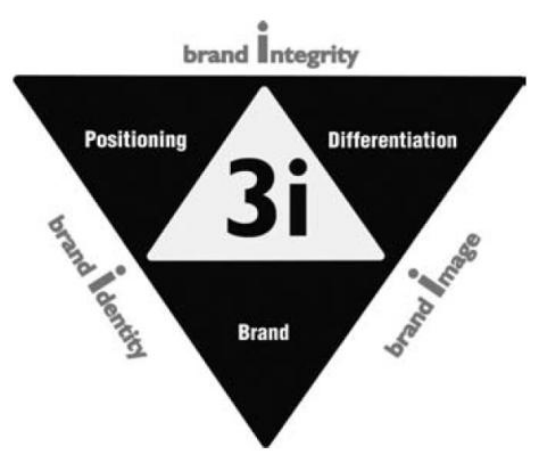

Source: Kotler et al, 2010

"The $3 \mathrm{i}$ model is also very relevant for marketing in the context of social media. In the era of consumer empowerment led by abundant information and networked communities, a consonant brand-positioning-differentiation is all you need."

As a conclusion, the marketing 3.0 approach is based on the following 3 premises:

1. Consumers do not act on their own. Instead, they are connected throughout communities (tribes) based on their likes and preferences.

2. Consumers look for certain kind of sensations when they feel connected to a particular brand.

3. Consumers are not only physical human beings, as they all have a soul. That means there is a need for spiritual marketing.

However, Kotler et al (2016) went a pace forward and introduced a new stage in the evolutions marketing, considering Marketing 4.0 as the customer experience era, which is based on brand-interaction (see fig. 3.16). In this context, consumers must be 
able to verify that the product they are about to buy meets their needs and the brand meets their expectations (not only from the product side, but also from the brand integrity and reputation side, taking factors like social responsibility into account).

Fig. 3.16. The marketing 4.0 model

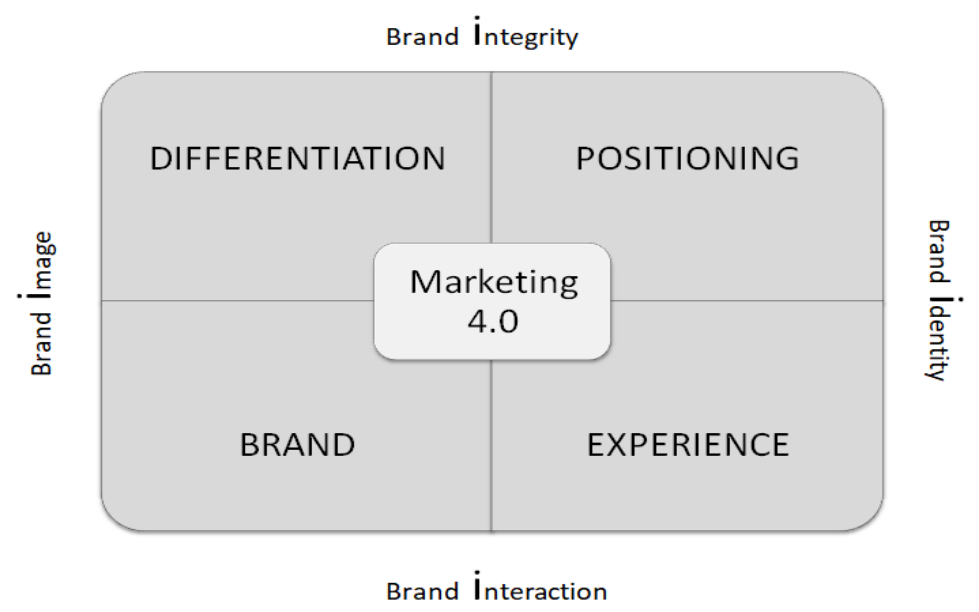

Source: Kotler et al (2016)

Marketing 4.0 is based on the participation of the customer with the final objective to create value. Consumers will help companies to build "brand reputation" through the use of new technologies. Social networks and any other instruments will increase customer relationship and will provide a powerful tool to develop brand awareness and transparency. Companies, on their side, should provide the tools for that interaction with the customer and be able to analyze the information they provide in the form of big data.

D) Corporate Social Responsibility (CSR)

The evolution towards Marketing 4.0, with consumers deeply interested in social, economic and environmental subjects, has driven scientific literature to develop new research areas, like corporate social responsibility (CSR). 
In a situation like this, multinational firms are increasingly pressured by numerous shareholders and consumers to engage in social and environmental responsibility. Thus, managers should be able to determine the way their organizations can turn "more socially responsible, ecologically sustainable, and economically competitive" (Orlitzky et al, 2011; Chen et al, 2016).

CSR is considered by literature as a variable with plenty of constructs, evolving from the four basic (philanthropic, ethical, legal and economic) responsibilities defined by Carrol (1991) to as it is related to subjects like community involvement, ethical programs, donations, implementation of green policies, and many other actions (Orlitzky et al, 2011).

The concept of CSR has been related to strategic management in the way that companies operate in a context of scarce resources and, as a consequence, they must be able to select actions that contribute to the increase of the welfare in the society because that reverts in the performance of the company (Friedman, 2007; White et al, 2017).

On the other hand, CSR policies contribute to the development of relational intangible assets, such as reputation and brand awareness, and constitute a way to adapt the company strategy to the market, increasing its competitive advantage (Zerbini, 2017; Ali et al, 2017).

Finally, Gadenne et al (2009) studied the effect of environmental awareness and practices in SMEs, and determined that, although they individually have, by definition, very limited operations, and therefore would not have the potential to impact the environment to the same degree as very large businesses, their total impact is high in countries where the total number of SMEs is high.

However, even though there have been plenty of research studies on the subject in the last years, scholars still find it difficult to quantify the effect of CSR practices in the final performance of the company. 


\subsection{INTERNATIONAL MARKETING}

When studying international marketing, an important group of scholars whose research has been focused mainly on this subject (Keegan, 2001; Aulakh and Johansson, 1997; Czinkota and Ronkanien, 2013) agree that the basis for both domestic and international marketing is quite similar. Nevertheless, specific questions that relate exclusively to the marketing in companies with activities beyond their home markets can be found, as these firms operate in very diverse environments with social, economic or legal differences.

Additionally, international marketing is very narrowly linked to international strategy, which can be considered as a relatively recent discipline that has received plenty of attention in the academic sector because of the influence on the final export performance of those companies which operate in international markets.

According to Eden et al (2010), international strategy is "the comprehensive set of commitments and decisions, and actions by firms to gain competitiveness internationally".

In this context, the way to enter foreign markets is directly related to the implementation of an internationalization strategy, which should take foreign factors into consideration. Eden et al focused on the relation among three different variables: international business (IB), international management (IM) and International Strategy (IS). That took them to conclusion that international strategy cannot be understood without considering strategic management.

According to Fig. 3.17, International Strategy (IS) is a part of International Management (IM), which is, at the same time, part of International Business (IB). The common aspect of the three disciplines is that they are integrated in an international environment. 
Fig. 3.17. International Strategy

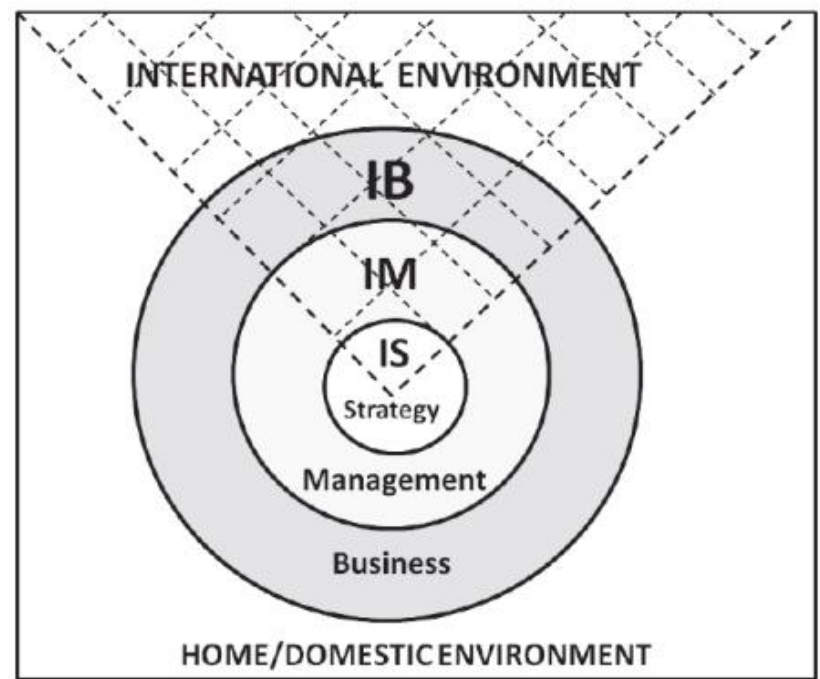

Source: Eden et al, 2010

How to enter international markets is one of the specific subjects of international marketing strategy that has received special attention. In the 1960s, some of the internationalization theories analyzed on chapter 2 (industrial organization theory, product life cycle) focused on the dichotomy FDI (foreign direct investment) vs exporting in multinational enterprises. In the 1970s the internationalization approach identified licensing, franchising and subcontracting as other strategic options. In the 1990s other scholars (Root, 1994; Buckley and Casson,1998; Pan and Tse, 2000) started considering investments in emerging "Psychic distant" economies with high costs and introduced alternatives like joint ventures or specific contracts considered (see fig. 3.18)

When referring to foreign market entry decisions, plenty of factors are considered to play an important role, and special attention should be paid to the classification by Buckley and Casson (1998) where the following items were identified: "location costs, internalization factors, financial variables, cultural factors-such as trust and psychic distances-, market structure and competitive strategy, adaptation costs to the local environment, and the cost of doing business abroad". 
Fig. 3.18. Choice of entry modes

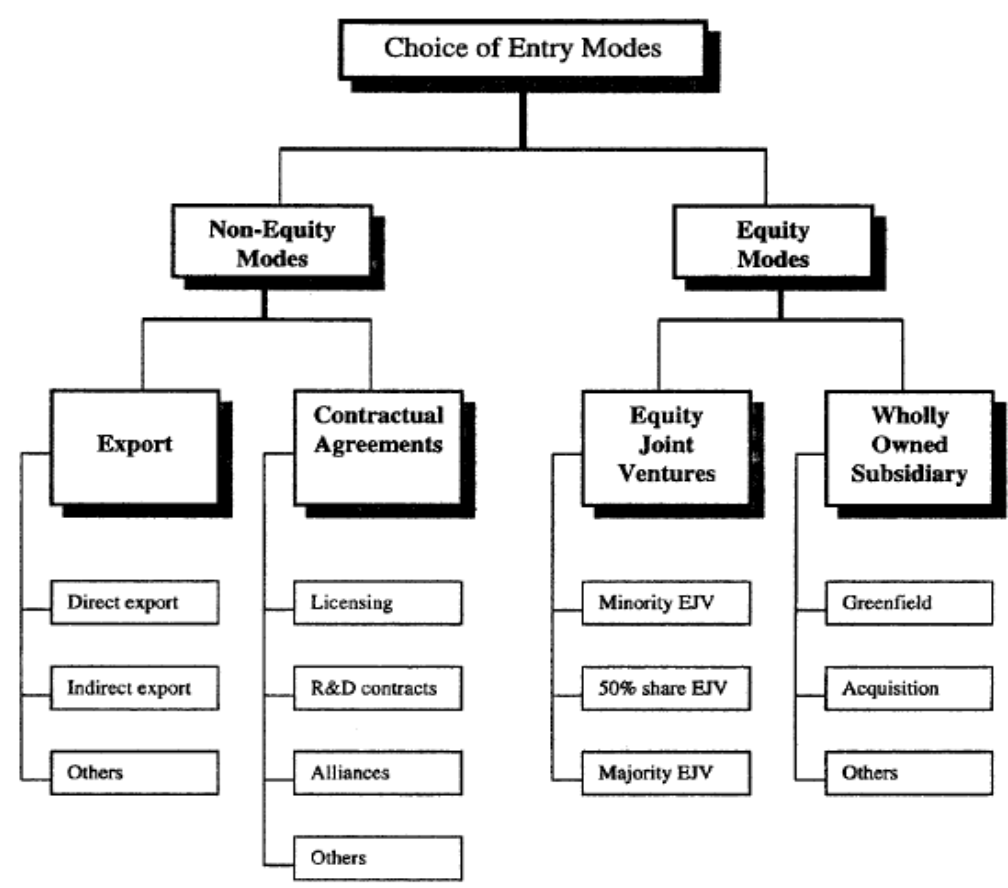

Source: Pan and Tse, 2000

With the approach from the Uppsala model, Johanson and Vahlne (1977) considered that an appropriate international marketing strategy should not only focus on which is the appropriate figure to enter new markets, but also on how to expand the business, analyzing their costs and risks based on market characteristics and taking into consideration their own resources. In a revision of the 1977 model, the business is now viewed as a web of relationships, rather than as a neoclassical market with many independent suppliers and customers, and two new variables - trust-building and knowledge creation - as determinants of relationship building are added to the model (Johanson and Vahlne, 2009). Therefore, the company should concentrate on finding the appropriate network of collaborators in every foreign market.

Regarding international marketing strategies, plenty of different approaches can be found throughout the theoretical analysis of the subject. In this way, an important contribution to the theory of international marketing strategies is the one by Ansoff (1965), who proposed two ways to increase the benefit of a company: developing new products, and entering new markets. 
The model (see fig. 3.19), which is still considered at present, was introduced by a strategy matrix using two variables -markets and products-, and two dimensions for them -new and already existing ones, resulting in the following four strategies:

- Market penetration: offering the existing products in current markets

- Market development: developing a new market for existing products or services

- Product development: developing or modifying products and offering them in the existing markets

- Diversification: developing new products in new markets

Fig. 3.19. Ansoff Matrix

\section{PRODUCTS}

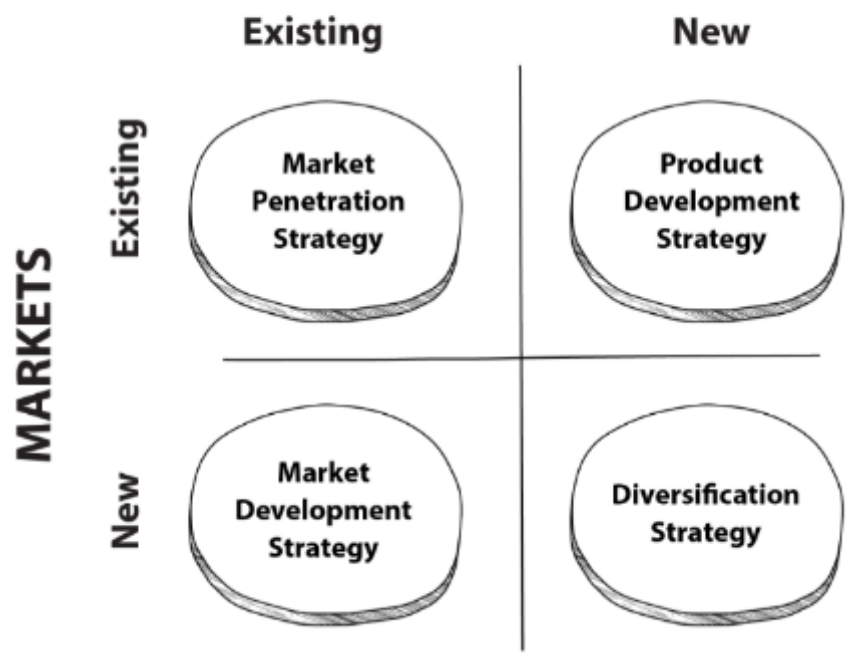

Source: Ansoff, 1965 
Continuing with the analysis, although there is not much agreement about the constituents of global marketing strategy, two major fields of study can be identified through the last years:

\section{1) Standardization vs adaptation policies}

The standardization perspective considers that companies tend to develop standard marketing programs across different foreign countries, that is, they carry on similar marketing mix policies for a group of countries. Acting like this, they focus on low-cost processes and economies of scales regarding production and marketing, and they are able to promote certain practices on a global scale. On the other hand, other authors support the idea that standardization is not always possible, and, as a result, companies should adapt their marketing strategies to each foreign country depending on customer needs.

\section{2) Concentration vs diversification policies}

In a market concentration strategy, the organization tends to concentrate its efforts on just a few markets (the most attractive ones), while a market diversification strategy, on the contrary, tends to consider a large number of markets. Both strategies can show positive results according to factors like the kind of company, the characteristics of the markets, and so on.

Zou and Cavulgil (2002) pretended to offer an integrative solution with their Global Marketing Strategy (GMS) model. They described the way a company develops different international strategies in different markets, trying to integrate all the possible alternatives, and how they interact in a global environment, contrary to domestic markets where only one strategy is carried out. (see fig. 3.20) 
Fig. 3.20. The Global Marketing Strategy (GMS) model

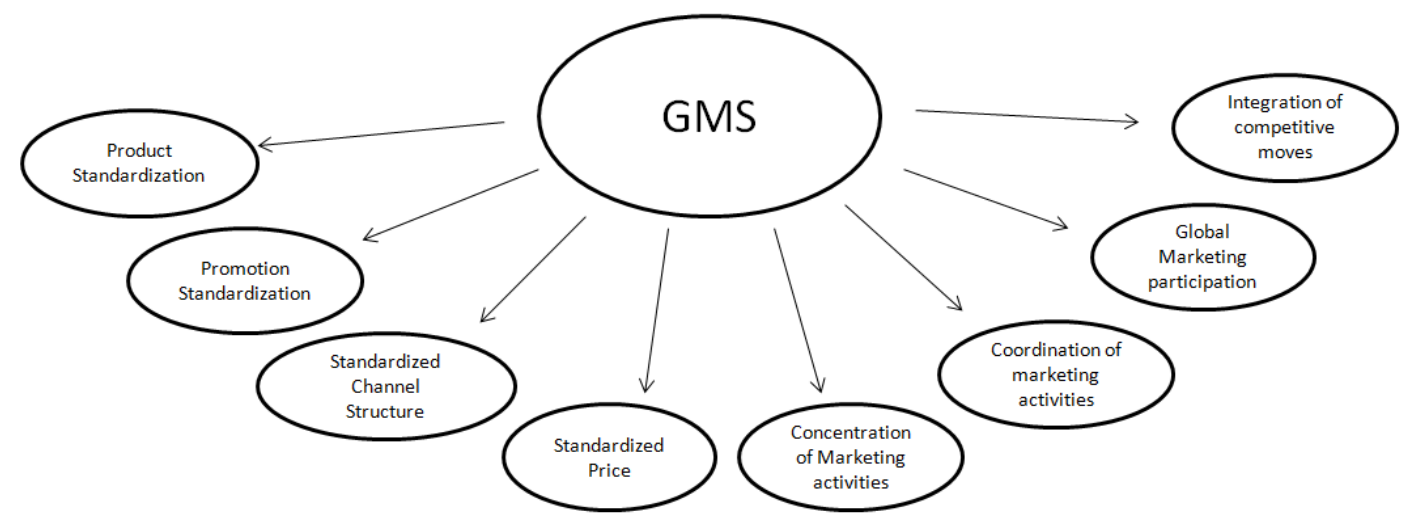

Source: Zou and Cavusgil, 2002

This analysis is totally consistent with the empirical research on the export performance of SMEs developed in the last 30 years and analyzed on chapter 2 (see Aaby and Slater, 1989; Zou and Stan, 1998; Leonidou et al, 2002; Sousa et al, 2008; Chugan and Singh, 2014; Chen et al, 2016, for review), presenting similar conclusions to other models presented by scholars like Doole and Lowe (2008).

The international marketing theory has also been considered from the resources and capabilities perspective by a big number of researchers. In this way, one of the most descriptive models (see fig. 3.21), which synthesises the research on marketing capabilities in international marketing, is the one by Morgan et al (2018).

The authors determine a series of factors (market orientation, international commitment, entrepreneurial orientation ...) that have an effect on the company's marketing capabilities. These are, at the time, influenced by other environmental aspects, and are fundamental to the implementation of the international strategy, that will result in a certain competitive advantage. 
Fig. 3.21 Marketing capabilities in International Marketing

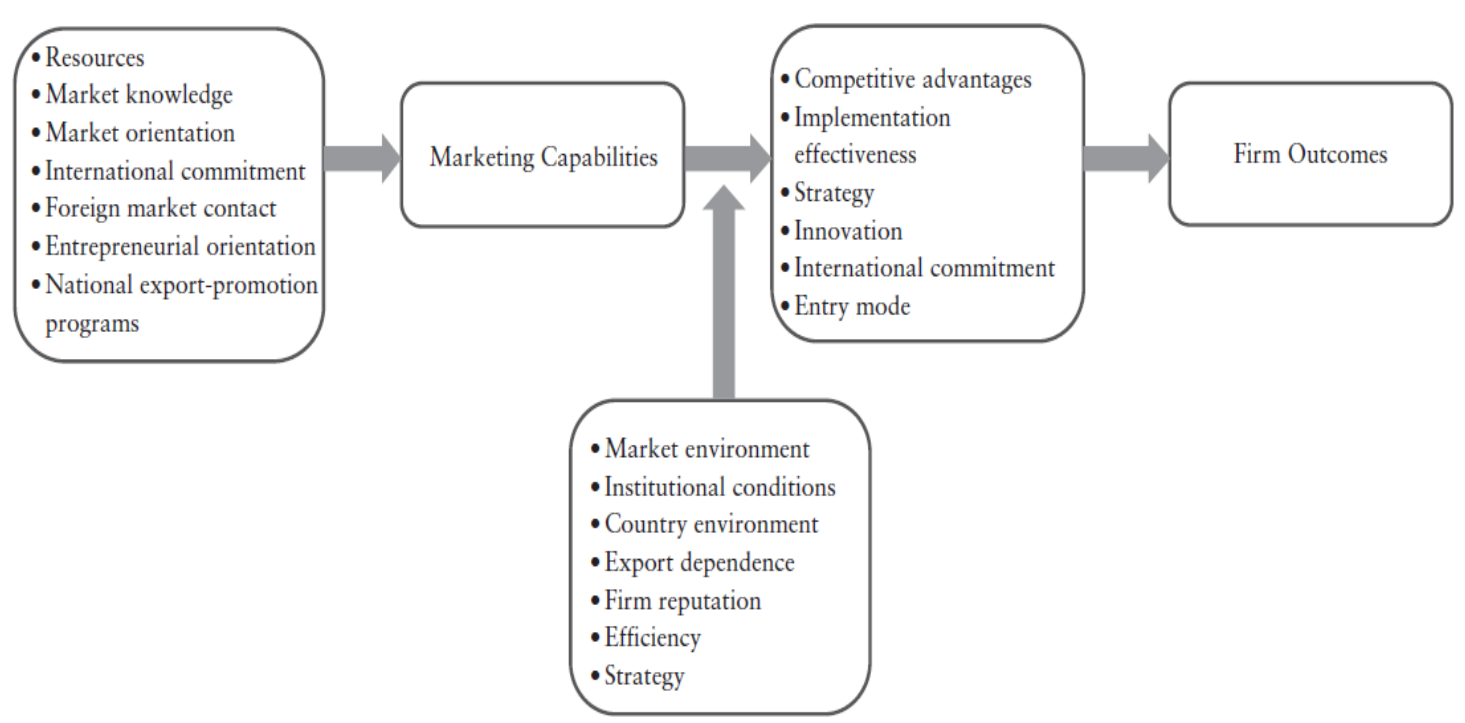

Source: Morgan et al (2018)

In the same context, Alonso and Donoso (2000), analyzed the performance of exporting firms in Spain, and determined that their strategy is affected by four dimensions: firm's competitive capabilities (competitive dimension), market opportunities (scope dimension), management attitudes and country's competitive advantages.

Asseraf and Shoham (2014) focused on the way dynamic capabilities contributed to the export marketing strategy. They stated that increasing performance through "strategic orientations" needs to develop certain "outside-in capabilities (marketing) and inside-out capabilities (technological)".

This will be determined by the marketing strategy, resulting in the standardization or adaption of processes in the organization (see fig.3.22). 
Fig. 3.22. Strategic orientations and export marketing strategy

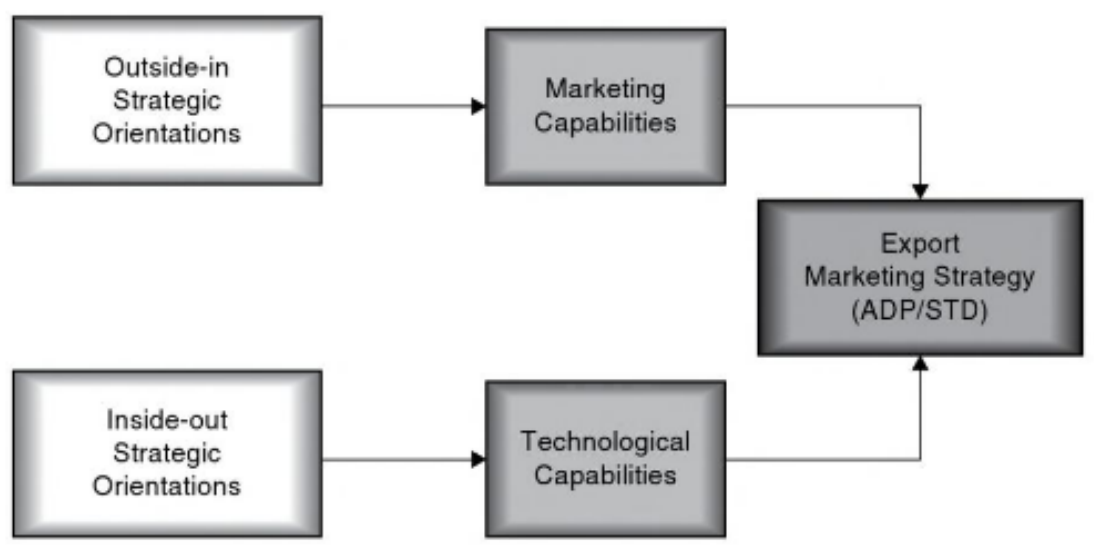

Source: Asseraf and Shoham, 2014

According to Asseraf and Shoham, companies should be able to identify the set of capabilities which are associated to a higher performance, and they could come from the marketing capabilities side, from the technological capabilities side, or from both of them.

If companies tend to focus on marketing capabilities, they should consider an "outsidein strategic orientation" that will be based on the analysis of the environment with the final objective to adapt the company to any important changes, resulting in the acquisition of new marketing capabilities.

On the contrary, if they tend to focus on technological capabilities, they should consider an "inside-out strategic orientation" that will be based on internal innovation processes, resulting in the development of new technological capabilities.

However a thorough study of the international marketing strategy is provided when considering the variables of our final model on Chapter 4. 


\subsection{THE EMPIRICAL ANALYSIS}

Following the structure on the previous chapter, once we have considered the evolution of the most important theories in the marketing discipline, we will concentrate on the empirical research.

To start with, we can observe that the change from a traditional conception of marketing (based on marketing mix policies) to a different scene (based on customer experience, relationships and new technologies) has also been incorporated to the evolution of the empirical analysis.

Ebernhard and Craig (2013), for example, consider that both interpersonal networks and interorganizational networks have a positive impact on the internationalization processes of SMEs, which is bigger in the case of non-family ownership. Fernández and Nieto (2006) reached similar conclusions by concluding that internationalization is negatively related to family ownership and positively linked to corporate ownership.

Ricci and Trionfetti (2012) demonstrated that firms are more likely to be successful in exports if they develop foreign, domestic and communication (email, internet) networks. Better network connections result in a higher probability to increase exports. The model considers not only the introduction of relational and network approaches, but also the incorporation of new technologies to these processes, something which is not very frequent.

In the same direction, Beise-Zee and Rammer (2006) stated that increasing local userproducer relationships lead to improve innovation and it results in an increase of the export performance.

Other authors like Girma et al (2009) or Bertrand (2011) considered the analysis by introducing changes in the product manufacturing and distribution policies and concluded that offshore outsourcing helps companies to reduce costs, increase flexibility and develop other capabilities (like market knowledge) that finally affects export performance in a positive way, adding the dynamic capabilities approach to the equation. 
In a similar context, authors like Anwar and Nguyen (2011), and Wengel and Rodríguez (2006), determined that the presence of foreign firms in emerging countries, and the existence of export-oriented sectors promote interfirm linkages that result in an increase of export figures.

Meanwhile other authors like Antonietti and Marzucchi (2014) considered that green strategies (which are related to the development of CSR policies) have a positive effect on intangible goods, which result in an increase of the export performance.

Other scholars followed a similar path and approached the analysis from a capabilities perspective (Raymond and St. Pierre, 2013; Yi et al, 2013; Singh, 2009; Gashi et al, 2014) reaching the conclusion that product development capabilities, market development capabilities, network capabilities, technological capabilities or human resources capabilities have a positive effect on the performance of the export venture.

However, the introduction of these new approaches does not mean that the traditional ones should be neglected. On the contrary, the literature is full of studies where the export marketing strategy is considered from two different aspects: strategic marketing decisions and operational marketing decisions (based on marketing mix policies).

Regarding strategic marketing, Chen et al (2016) and Chugan and Singh (2014) consider a series of factors which have an influence on the final performance of the company: strategic decision making, cost leadership strategies, differentiation strategies, marketing planning actions, adaptation to customers...

As per marketing mix policies, plenty of scholars have developed studies for each of the four Ps, being their adaptation to every market one of the most frequently considered. Market entry mode, the kind of promotions carried out, offering support to the distribution channels are other items which are also analyzed (Leonidou et al, 2002; Morgan et al, 2012; Ibeh, 2003; Cadogan et al, 2012; Okpara, 2009).

For Ayan and Percin (2005), the strategy based on marketing mix policies has a positive effect on export performance. Cadogan et al (2012), on their side, determined that 
high export market-oriented behaviours and high export experience levels have a bigger influence on the export performance.

Cavusgil and Zou (1994) concluded that product adaptation, support to foreign distributors and product uniqueness are basic determinants of export performance. Similarly, other authors like Boehe and Cruz (2010) or Higón and Driffield (2011), considered that product differentiation through innovation and CSR policies also have a positive influence on EP.

Regarding the intermediary role of the export strategy construct, authors like Katsikeas et al (2000), Shamsuddoha and Ali (2006) or Chen et al (2016) determined that this variable could be affected by export promotion programs, management perceptions of export markets, export knowledge and commitment, and was, at the same time, a fundamental determinant of export performance.

In a similar case, O'Cass and Julian (2003) considered that firm characteristics (like product uniqueness, international experience or the degree of commitment) and environmental characteristics (like competitive intensity or legal and political similarities) affect the marketing strategy (measured through adaptation vs standardization policies) and this is linked to export performance.

\subsection{CONCLUSIONS}

The research on the marketing theory in general, and export marketing strategy in particular, has evolved from the conception of a traditional marketing mix policy based on the study of product, price, promotion and place issues, to the consideration of a new paradigm, based on services and customer experience.

This new approach has been built thanks to the contributions of theories like relationship marketing, the use of new technologies and the internet, and marketing 3.0 and 4.0 models. 
The new streams in marketing do not mean that traditional models should be extinguished. On the contrary, the first ones should be built on the foundations of the other.

However, the existing empirical research is still on the way to the new conception, and the connection between marketing theory and internationalization models has not been seriously considered.

The objective of this investigation is to define an integrating model which can be applied to the analysis of the performance in the case of exporting companies from the fashion sector in Spain.

To do so, we have integrated conceptual internationalization and marketing approaches, mainly analyzed from the RBV, dynamic capabilities, relational and network marketing perspectives

In our particular case, this chapter has contributed to the development of the Marketing Strategy (MS) construct, which will be affected by two more variables: Operational Marketing (OM), which considers the marketing mix policy incorporating the relationship marketing theory, and New Technologies (NT).

The characteristics of the final model, known as the EMSP model of internationalization, and the variables that will constitute it, are described on the following chapter. 


\section{CHAPTER 4. THE EMSP MODEL OF INTERNATIONALIZATION}

\subsection{INTRODUCTION}

Chapter 4 plays a fundamental role in the structure of this thesis as it pretends to define the theoretical model of the investigation.

The EMSP model of internationalization takes its name from the four main variables (Environment, Management, Strategy and Performance) that constitutes the basis for a further development, and can be considered as the merge of different internationalization and marketing approaches.

The starting point is the study of the determinants of the export performance (considered on chapter 2), which helped us to introduce the dependent and independent variables. Although a considerable number of variables have been developed by the literature, we have focused on the ones that best define our particular case.

Another major contribution comes from the side of marketing theories, with two fundamental approaches: market orientation and relationship marketing on one hand, and the incorporation of new technologies on the other (see chapter 3 for complete details). 
The concept of marketing and its influence on the competitive strategy of the investigation is present throughout the investigation, being crucial to the construction of the marketing strategy variable. This variable will be composed of two more constructs: Operational Marketing and New Technologies.

The final stage will take us to the determination of the causal relationships of the model through a series of hypotheses that will be accepted or rejected by a later empirical research.

\subsection{THE EMSP MODEL OF INTERNATIONALIZATION}

The EMSP model has been developed on the basis of two different approaches: on one hand the analysis of the determinants of export performance and, on the other, the latest approaches of relationship marketing and the incorporation of IT to the marketing strategy (see fig. 4.1).

Fig. 4.1. The EMSP model of internationalization

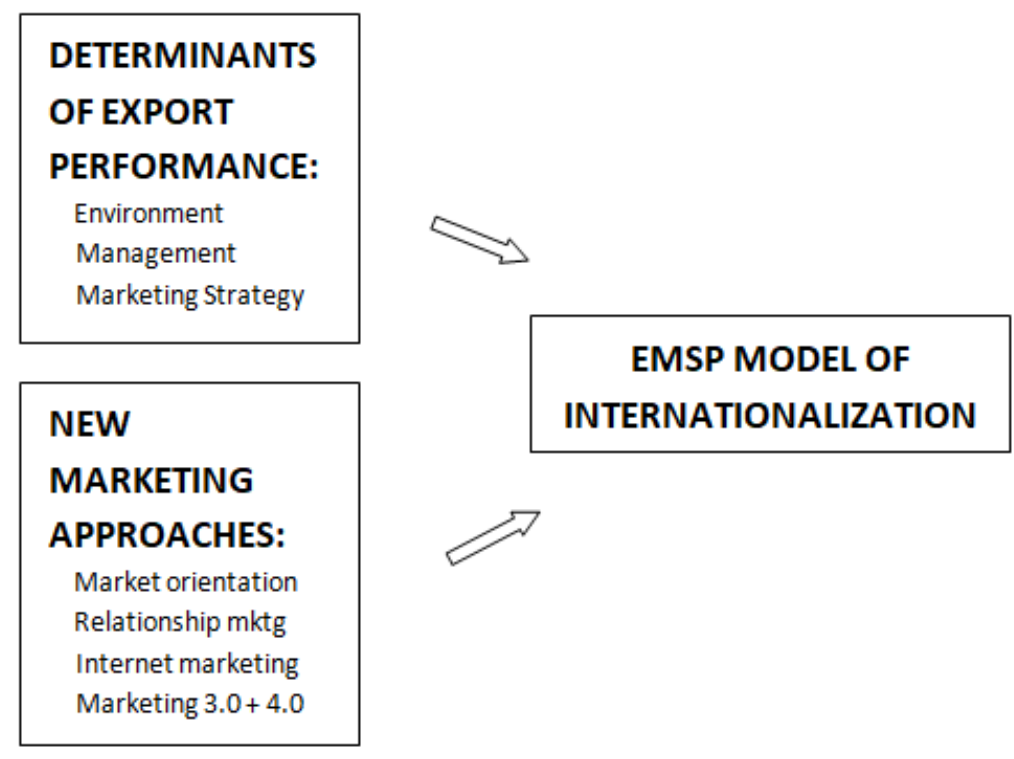

Source: Developed by the author 
In this way, due to the importance of marketing strategies throughout all the stages of the exporting process, a special focus has been placed on the evolution of the theories and approaches affecting the marketing discipline.

As a consequence, the EMSP model of internationalization is the merge of different theoretical approaches in an attempt to provide an integrative view of the existing literature. The new resulting model pretends to offer an alternative way to determine the final performance of an export venture.

\subsubsection{The determinants of export performance}

Two are the basic findings from "the determinants of export performance theory", that have been considered as the foundations for the development of the EMSP model of internationalization: on one hand the factors (both internal as external) that have an impact on the final export performance of the company, and on the other, how these variables interact to affect the final dependent variable.

Regarding the determinants of export performance, a detailed study of the literature on the subject (Aaby and Slater, 1989; Zou And Stan 1998; Leonidou et al, 2002; Sousa et al, 2008; Chugan and Singh, 2014; Chen et al, 2016), takes us to the conclusion that such determinants have been divided into two categories: 'Internal' and 'External' variables. Internal variables include 'Management Characteristics and Attitudes', 'Firm Characteristics and Competencies' and 'Export Marketing Strategy' while external variables include 'Foreign Market Characteristics' and 'Domestic Market Characteristics' (see Table 2.3 from chapter 2).

In our case, management characteristics (MN) and export marketing strategies (MS) are the two basic internal variables considered to determine the effect on the export performance, and environment (ENV), the external one. Firm characteristics have also been considered in the model, but only as a part of the descriptive analysis that summarizes the particularities of the sample for the empirical research (all companies present similar characteristics as they are all SMEs which operate in the same sector). 
Regarding the relationship between these variables, the marketing strategy (MS) is supposed to play the role of an intermediate variable, as determined in the models of Katsikeas et al (2000) and Leonidou et al (2002), among others (see fig. 2.11 from chapter 2).

\subsubsection{The evolution of marketing}

The basic lines from the "evolution of marketing" theory (developed on Chapter 3), that have been incorporated to the final EMSP model of internationalization, come to determine the importance of marketing mix policies and the need to complement them with new approaches, mainly market orientation and relationship marketing policies, as well as the incorporation of new technologies to the marketing process.

Market orientation actions pretend to increase added value for customers, and constitute a way to reach a superior competitive advantage (Narver and Slater, 1990; Jaworski and Kohli, 1993), which is directly linked to export performance.

Relationship marketing policies, on the other hand, sustain the importance of establishing a long term relationship with potential consumers that will lead to customer loyalty. Companies should focus on offering the kind of product or services that meet their customer needs, and that can only be achieved through market research and through a proper marketing planning activity (Gronroos, 1990; Morgan and Hunt, 1994; Payne and Frow, 2005).

The incorporation of new technologies to the process, on the other hand, has also become crucial, as they increase efficiency in the company (Prasad et al, 2001; Ngai, 2003; El Gohari, 2010; Kaplan, 2012) and let customers participate in the process of brand creation (see Marketing 3.0 and Marketing 4.0 theories from chapter 3; Kotler et al, 2010, 2016).

These are the reasons to consider new marketing approaches as fundamental to complement traditional marketing mix policies. They constitute, in fact, a basic input to the model and to the development of variables and measuring scales. 


\subsubsection{The resulting model}

The result when mixing these theoretical approaches is the EMSP model of internationalization that can be appreciated on fig. 4.2. The environment (ENV), acting as an external variable, together with Management characteristics (MN) and the Marketing Strategy (MS) developed by the company, constitute the basic determinants of export performance (EP).

Fig. 4.2. The EMSP model of Internationalization

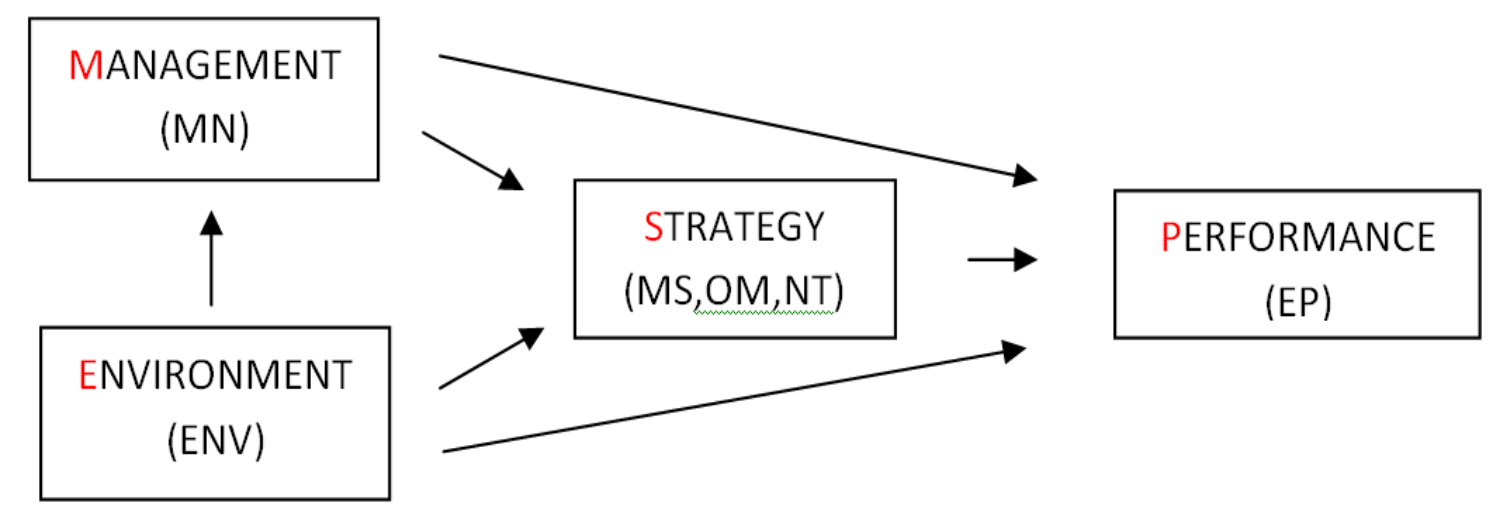

Legend: MS: Marketing Strategy, OM: Operational Marketing, NT: New Technologies

Source: Developed by the author

On the other hand, in order to define these relationships of dependence, different hypotheses will be considered throughout the chapter, and the vast empirical research on the study will contribute to provide the appropriate theoretical support for the model. 


\subsection{VARIABLES AND HYPOTHESES}

Keeping the general outline of all the variables affecting the EMSP model (see figs.4.2 and 4.3) in mind, and trying not to lose the general overview, will definitely help us to understand the relationship between all the constructs in the model in a much better way.

Fig. 4.3. Variables in the EMSP model of Internationalization

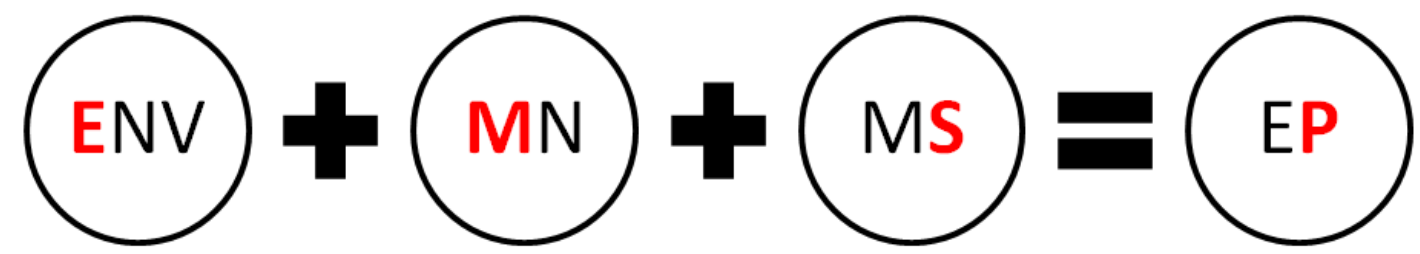

Source: Developed by the author

\subsubsection{Environment}

The environment variable has played a predominant role when analyzing the determinants of the export performance and has been present in every single model review from Aaby and Slater (1979) to Chen et al (2016).

The environment consists of external factors that cannot be controlled by the management. However, they have a major influence on the company, up to the point of conditioning the firm's capabilities and strategy that will result in a higher or lower export performance.

Environmental changes are usually difficult or impossible for companies to control, or even to predict. The analysis of the environment is important to develop a sustainable competitive advantage, and also a part of the strategic analysis carried out by all kind of enterprises (Lynch, 2009; Yüksel, 2012). 
Due to the effect of globalization and technological advances, the environment is changing very rapidly. People live in different locations, distances become smaller and so do cultural differences. National boundaries tend to lose their relative importance, especially in terms of economic activities. Goods and services are produced in markets which are different to the ones where they are supposed to be consumed.

In this scenario, the environment is one more variable to be taken into consideration within the strategic management of the company. Therefore, companies must be able to detect constant changes in order to adapt their marketing strategies and satisfy the new needs of their customers.

Approaches like the Ressource Based View (RBV) determine that the competitive advantage of an exporting firm is not only influenced by its resources, but also by external environmental forces (Peng et al, 2008; Chen et al, 2016).

When coming to practice, two kinds of environments must be considered:

1) micro environment: refers to the factors from the immediate environment that have an impact on the company (focusing on the analysis of customers, suppliers or competition)

2) macro environment: refers to non-controllable macroeconomic factors and their effect on the company's strategy (PESTEL analysis)

From an academic point of view, several attempts to determine the similarities and differences between "organizational cultures" have been made, being Hofstede's research one of the most important. According to Hofstede $(1980,1983)$ and Hofstede et al (1990), a national culture is determined by the common elements within a nation, and it does not describe the individuals. In this context, he introduces four dimensions to determine group of nations with similar characteristics: 
- Power distance: it indicates the way a society accepts that power in institutions and organizations is distributed unequally.

- Uncertainty avoidance: it indicates the extent to which a society feels threatened by uncertain and ambiguous situations. High uncertainty avoidance levels make people work harder.

- Individualism-collectivism: through individualism, people are supposed to take care of themselves and the immediate family (countries with higher income rates). Through collectivism, people belong to groups and present a sense of loyalty to them.

- Masculinity/feminity: it expresses the extent to which the dominant values in the society are masculine/feminine.

When comparing power distance and individualism indexes, for example, different groups can be established. In this case, countries like Spain, France, Belgium, Italy and South Africa would belong to the same group while Scandinavian countries, Germany, Austria or Switzerland would belong to a different one (see fig. 4.4 for details).

We can observe that countries with similarities in geographical, social, economic or political factors tend to present similar national cultures.

The analysis by Hostede is important because it introduces a model where different markets are compared according to a certain number of factors, something which is not very frequent in the literature. However, these factors are not very much in accordance with the reality of the exporting activity, and that is the reason to consider a deeper analysis which will be focused on such determinants. 
Fig. 4.4. Position of countries on the power distance and individualism scales

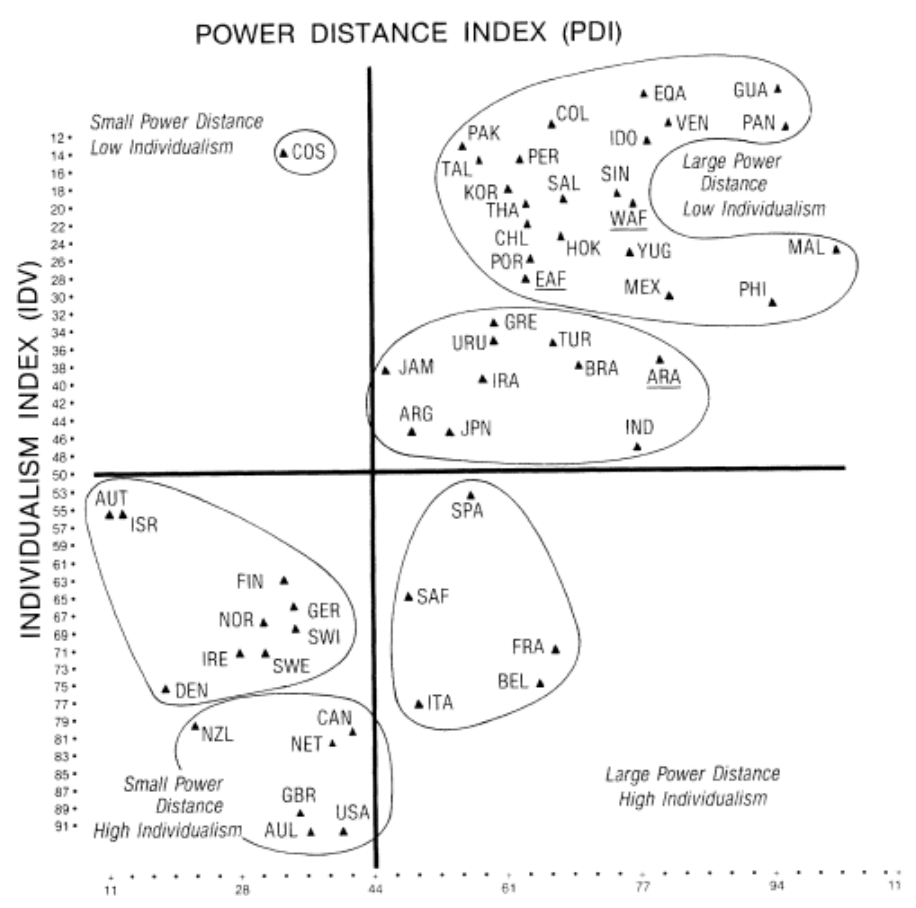

Source: Hofstede 1980, 1983

One of the tools to analyze the environment is the PESTEL model which takes into consideration political, economic, socio-cultural, technological, environmental and legal factors. This analysis fulfils two basic functions for a company: the identification of the environment in which the company operates, and the prediction of future situations by providing the necessary information from the former analysis.

The PESTEL analysis, together with the analysis of the specific factors conditioning the access to foreign markets in the export venture, will be the background for the determination of scales that will be developed in depth when defining the theoretical model of this investigation on chapter 5 .

However, when we consider the analysis of the environment variable from the exports point of view, external factors have been traditionally divided by scholars into national and foreign market characteristics, being the differences between one and the other the origin of opportunities for the companies involved in export ventures. (Sousa et al, 2008; Sousa and Novello, 2014). 
National and foreign market characteristics are different in essence and, therefore, the findings of both approaches will be different. The focus of this thesis will be placed on foreign market characteristics and not on the domestic market as all the companies in the empirical study are affected by the same conditions (they all operate in the same sector in Spain). Even so, details of the literature from both approaches will be exposed below:

A) Domestic market

According to Chen et al (2016), six factors are found to impact export performance in local markets: "domestic demand, export assistance, local market characteristics, infrastructure quality, legal quality and institutional environment".

Complementary, Chugan and Singh (2014), had previously reached the following conclusions:

- The use of export assistance provides a significant and positive association with export performance (Chugan, 1998; Singer and Czinkota, 1994; Alvarez, 2004; Gençturk and Kotabe, 2001; Shamsuddoha and Ali, 2006; Marandu, 1996; Francis and Collins-Dodd, 2004; Bonner and McGuinness, 2007; Durmusoglu et al, 2012).

- Export market barriers existing in the host country also impacts export performance negatively (Carneiro et al, 2011).

- Legal and political environment shows mixed results with positive association with export performance (O'Cass and Julian, 2003).

- As a higher competition is supposed to reduce profit margins, exporters operating in more competitive national environments can benefit most by entering new markets (Cadogan et al, 2012). 
Sousa et al (2008) state that basically two determinants of domestic market characteristics have an influence on export performance: export assistance and environmental hostility. The results in this case also suggest that firms generally perform better when they face a benign domestic environment, something totally consistent with the findings in the previous paragraph.

The existence of programs sponsored by government and nongovernment agencies designed to assist firms' export activities also contributes positively to the export performance of the firm (Alvarez 2004; Gençturk and Kotabe, 2001; Lages and Montgomery, 2005; Stöttinger and Holzmüller, 2001; Sousa et al, 2008). The final objective of these programs is to provide firms with the necessary knowledge to gain experience in foreign markets. Thanks to this assistance, firms get to improve their competitive advantage by implementing new policies -like the creation and development of international networks, or the development of much more sophisticated analysis of the foreign environment- resulting in bigger resources and marketing linking capabilities and contributing once more to the theory of the interconnectedness of resources and capabilities.

On the other hand, although the external uncontrollable factors did not receive much attention from researchers at the beginning (they had concentrated on the company as a whole and the decision to export), the trend changed and plenty of studies related the effects of these external uncontrollable factors on some of the export performance constructs such as export sales, profits or sales growth (Zou and Stan, 1998, Chugan and Singh, 2014; Chen et al, 2016).

Finally, Zou and Stan (1998) considered the effects of the company's industry characteristics on export performance, and their analysis concluded that the industry's technological intensity or manufacturing complexity showed a positive effect on export performance (Cavusgil and Zou, 1994; Holzmuller and Kasper, 1991; Holzmuller and Stottinger, 1996; Ito and Pucik, 1993; cited by Zou and Stan, 1998), something totally in accordance with the findings of the analysis from the technological capabilities point of view. 


\section{B) Foreign markets}

According to Chen et al (2016), when talking about foreign markets, competitive intensity attracts the most interest, although empirical studies show mixed results. Additionally, despite the earlier focus placed on the market distance and similarity, the literature on the subject shows a higher degree of attention being paid to psychic distance. In this way, empirical studies show psychic distance to be positively associated with marketing mix strategy adaptation but not significantly related to export performance (Sousa and Lengler, 2009; Sousa et al, 2010).

For Chugan and Singh (2014), one of the most important variables in this context is the export market barriers faced by local firms in foreign markets. These barriers are found to affect the firm's export performance in a negative way. In the same direction, the legal-political and the socio-cultural environment existing in foreign countries are also linked to export performance. The sign of this relationship, however, differs according to the type of environmental conditions.

In the same way, Sousa et al (2008) stated that foreign market characteristics -such as social or cultural similarity, market competitiveness, governmental regulations, etcalso present an influence on export performance. Legal and political factors and cultural similarity were the most cited determinants in this category, something totally consistent with the argument that socio-cultural and political factors determine the nature of the external environment. Furthermore, other empirical studies like Dean et al (2000), O'Cass and Julian (2003), White et al (1998), come to confirm the significant effect of trade barriers on the export performance of the firm.

The theory that cultural similarity is positively related to export performance assumes that "similarities are easier for firms to manage than dissimilarities", making it easier for firms to succeed in markets with certain similarities. In this context, culturally similar markets tend to reduce the perceived risk of failure, encouraging companies with a limited presence in foreign countries to expand their business and start trading in that area. 
On the other hand, environmental conditions can vary so much from one country to the other, that there has been a lack of agreement regarding the items that should be considered to measure cultural differences between countries.

Regarding the effect of market competitiveness on export performance, Sousa et al (2008) report that mixed results were obtained. O'Cass and Julian (2003) determined that the lack of competition in the market has a positive effect on the export performance of the firm, while Morgan et al (2004) found that competitive intensity is not significantly associated with it. In contrast, Lages and Montgomery (2005) reported competition in foreign markets to be positively linked to export performance. One possible explanation for this is that less competitive markets tend to be associated with less developed countries where the economic instability is higher and the possibilities to succeed in exports considerably lower. Another reason to illustrate why firms might perform better in more competitive environments could be that easier to operate markets lead firms to an excessive relaxation.

Finally, environmental hostility, channel accessibility, customer exposure and economic similarity were also considered by Sousa et al (2008) as variables defining foreign market characteristics. The literature suggests that export performance is positively related to non-hostile environments (Balababnis and Katsikea, 2003) and to economically similar markets (Balababnis and Katsikea, 2003; Brouthers and Xu, 2002). Likewise, customer relationship, and the accessibility to distribution channels, also seem to have a positive effect on the final performance of the exporting company (O'Cass and Julian, 2003).

Zou and Stan (1998) also contribute to the analysis by stating that only one study in their review (Cavusgil and Zou, 1994) found a significant effect of market competitiveness on export performance. Export market attractiveness, on the other hand, showed mixed effects when studied as a determinant of export performance. And most studies reported that export market barriers (trade barriers, physical and psychological distance) are not a significant predictor of export performance. In this context, firms could always overcome such barriers by carrying out effective marketing strategies. 
The analysis of the determinants of the environment analysis is not only important to demonstrate they have an effect on the final dependent variable (export performance), but also to consider a series of items that will be the basis for the definitive environment construct on chapter 5 .

Finally, just before determining the hypotheses for the environment variable, we should also note that this construct can affect the model in different ways. According to the research of authors like Katsikeas et al (2000), Leonidou et al (2002), Gemünden (1991), Holzmüller and Kasper (1991), Axinn (1994), da Rocha and Christensen (1994), the environment was considered as a background variable that could not be controlled by the company, but affected internal factors like management and functional operations like marketing strategy.

Those are the reasons that take us to consider three different hypotheses:

$\mathrm{H}_{1}$ : The environment in foreign markets affects the management of the company.

$\mathrm{H}_{3}$ : The environment in foreign markets has an effect on the marketing strategy of the company.

$\mathrm{H}_{7}$ : The environment in foreign markets directly affects the final performance of the export venture.

\subsubsection{Firm characteristics and capabilities}

In order to support the relationship between the variables in the model, a number of studies have suggested links between organizational capabilities and business strategies (Parnell et al, 2015; Pandzda and Thorpe, 2009; Vivas López, 2005; Hoque, 2004; Bowman and Ambrosini, 2003; Hussey, 2002; Campbell-Hunt, 2000).

On the other hand, the literature also supports a relationship between strategic capabilities and performance (Ruiz-Ortega and García-Villaverde, 2007; Shamsie et al, 2004; Boulding and Christen, 2001; Nadler and Tushman, 1997; Mitchell, 1991). 
In the same direction, according to Chen et al (2016), there is a trend in recent studies to consider that the relationship between export marketing strategy and export performance depends on a diverse number of company resources (Bertrand, 2011; Lipuma et al, 2013), something which strengthens the premises of our model in two ways: on one hand by determining that the set of capabilities developed by the company affects the strategy, and on the other by considering the strategy as a link to performance. Furthermore, these findings are consistent with those of previous reviews (Aaby and Slater, 1989; Zou and Stan, 1998; Sousa et al, 2008; Chugan and Singh, 2014).

Other studies have examined the relationship between strategic types, distinctive competencies, and organizational performance (Miles and Snow, 1978; Snow and Hrebiniak, 1980; Hambrick, 1983; Smith et al, 1986; McDaniel and Kolari, 1987; Conant et al, 1990), finding that the different strategic types differ in functional strategy expertise, competencies, and performance.

Bowman and Catignon (1995) highlighted the positive influence of marketing and technical capabilities on performance, and the development of various strategic capabilities is also believed to have a positive influence on business performance (Desarbo et al, 2005; Pandza and Thorpe, 2009; Wu, 2006; Zhu et al, 2013).

Additionally, empirical studies in the analysis of the variables affecting export performance, have traditionally concentrated on two aspects of the organizational structure of the company: firm characteristics and firm capabilities.

Regarding firm characteristics, export size and firm export experience are the most commonly studied variables, and empirical evidence widely supports the positive impact of these two variables on export performance.

According to Chen et al (2016), apart from analyzing the relationship between firm characteristics and export performance, recent studies consider that the relationship between export marketing strategy and export performance depends on the company's resources (Bertrand, 2011; Lipuma et al, 2013). Bertrand (2011), for instance, determines that export experience shows a positive effect on export 
performance. In global markets, strategic export marketing decisions are conditioned by firm characteristics and linked to export performance (Lipuma et al, 2013).

The firm's experience in foreign markets has also been considered as an important determinant of export performance. The export activity is characterized by a high degree of uncertainty, which comes from the lack of information and knowledge on international markets. This knowledge, however, can be obtained through experience when operating abroad, and the marketing strategy can be adapted to meet the requirement of other foreign markets with different environmental conditions (Uppsala model). Different empirical studies were able to confirm this relationship (Zou and Stan, 1998; Sousa et al, 2008; Chugan and Singh, 2014).

The size of the firm is another independent variable that has been considered in plenty of papers (Aaby and Slater, 1989; Zou and Stan, 1998; Sousa et al, 2008; Chen et al, 2016). Bigger companies are supposed to achieve a higher export performance as they possess more resources, something which results in higher levels of economies of scales and reduces the levels of risk in foreign markets. Nevertheless, some studies did not show a significant relationship (Wolf and Pett, 2000; Contractor et al, 2005), implying that results could be different depending on the criteria and measurement scales developed in the process (Sousa et al, 2008).

However, firm characteristics have only been taken into consideration as a way to describe the sample in our case, because all the companies in our study present similar conditions. They are SMEs in its vast majority with similar experience in international markets. That is why this information will be considered only on the descriptive analysis and not through any of the variables from the empirical analysis.

Regarding firm capabilities, they have been a central theme of international business research, which are recognized as one of the key elements to get sustainable competitive advantage and achieve a proper export performance (Barney et al, 2001; Lages et al, 2009).

In this way, Ling-yee and Ogunmokun (2001) looked at firm's financial resources and supply chain management capabilities as positive contributors towards firm export 
performance. Similarly, Morgan et al (2004) assert that firm resources and capabilities affect competitive strategy and positional advantage which in turn influences the performance of export venture (Chugan and Singh, 2014).

Other important capabilities and competencies that have an influence on the export performance of the firm are: resource commitment, customer relationship, product uniqueness and quality, quickness and flexibility to respond to market change, patents and knowledge (Sousa et al, 2008).

In our case, firm capabilities have been considered from two different sides:

1) Management

2) Marketing strategy

\subsubsection{Management}

The management variable has been considered not only as one of the key elements to determine export performance, but also as an input to the marketing strategy of the company. Managers, in fact, are considered as a way to direct a group of people towards planned objectives and have existed since the earth was populated by the first human beings (Kwok, 2014).

That is why the concept of management has been a widely studied subject in all times and plenty of publications have reflected the evolution of the literature from the early theories of traditional management to the modern approaches of global economies.

If we go back in time, Adam Smith and David Ricardo were defenders of the division of labour and reaching efficiency through specialization. Later on, traditional management theories considered the formal relationships among departments in a company, and the way efficiency and productivity could be reached through the clear definition of tasks and processes.

Traditional management theories can be divided into three main streams: 
1) Bureaucratic management: based on a rigid structure with a hierarachy and details procedures (Max Weber). It is more efficient in organizations where customer needs are known, technology is stable and products or services are standard.

2) Administrative management: concerned with the way the organization is run and determines the basic functions of a manager (Henri Fayol).

3) Scientific management: introduces observation and analysis as a way to improve work methods. Financial incentives are introduced to motivate workers with production levels above the standard, there is a higher level of cooperation among workers and managers, and the division of work is more egalitarian (F.W. Taylor, The Gilbreths, Henry Gantt ...).

Behavioural theories, on the other hand, do not only focus on production, technology and science, but also on the way people can be impacted and the way they behave and could react to coming events. Special attention is paid to questions like human motivation, leadership style, communication and teamwork. It is also believed that organizations would increase performance if workers prosper along with the company. This approach is also known as the human relations school of management, with theorists like Elton Mayo, Abraham Maslow, Douglas McGregor, Rensis Likert or Frederick Herzberg.

Douglas McGregor (1960), for instance, introduced the theory $X$ and theory $Y$ assumptions where he considered two kinds of workers: theory $X$ describes the average person who has to be controlled because he/she dislikes work and avoids it, while theory $Y$ presents a motivated worker who is committed to the goals established by the organization.

Abraham Maslow also contributed to the research by presenting the famous pyramid with the basic needs of human beings and how they had to be satisfied in a certain order. 
Other contemporary approaches like the system theory considers the company as a system where certain inputs are incorporated to the production process to obtain a final product, also known as output. This theory has incorporated a new perspective where managers determine the different parts of the organization and the way they are connected. The company is analyzed from a broader perspective, and it must be considered as a whole system with different departments that are interconnected. The way the whole system is managed will determine the final performance.

Finally, other researchers focus on the present changing environment and the way managers should adapt their organizations to them. In this way, the contingency theory determines that when managers make a decision, they should consider the situation at that particular moment and the best management style depends on a determinate situation. Successful companies determine strategies as a response to a number of variables (contingencies), and that means there is not "one best way". Different strategies may be successful in similar organizations. The chaos theory, correspondingly, states that organizations are as chaotic and random as the present environment, and events are rarely controlled. That leads to a higher complexity and a bigger structure is required to keep stability (Fiedler, 2006; Levy, 1994).

When coming to exports, management factors, that will be explained through management capabilities, are also fundamental to business success. In this way, "export managers make decisions and strategies to enhance and expand the overseas market, which inevitably influence the firm's export performance" (Katsikeas et al, 2000).

The managers' international experience has been widely explored in the literature and considered as one of the key determinant of export performance. According to Chugan and Singh (2014), several researchers in their investigations suggest that export performance is positively influenced by the degree of export experience the managers has acquired (Ayan and Percin, 2005; Cadogan et al, 2012; Alvarez, 2004; O'Cass and Julian, 2003; Gençturk and Kotabe, 2001).

The level of commitment and attitude of the managers towards exports is another fundamental variable showing a positive relationship with export performance, as 
stated by authors like Axinn and Thach (1990), Cavusgil and Zou (1994), Singer and Czinkota (1994), Gençturk and Kotabe (2001), Ayan and Percin (2005), and Shamsuddoha and Ali (2006).

According to authors like Ling-yee and Ogunmokun (2001), Zou et al (2003), and Karelakis et al (2008), perceived export advantages also reflect significant degree of positive association with export performance. On the contrary, perceived export barriers show a negative relationship, as remarked by Diamantopoulos and Schlegelmilch (1994).

Management's perceived export advantages can be seen as a proper way to predict export sales, profits, and growth, whereas management's perceived export barriers (e.g. perceived risks, costs or complexity of exporting) do not seem to be significant predictors of export performance. These findings suggest that it is important for the management to focus on the advantages rather than barriers to exporting, and keep a positive attitude toward the outlook of export operations (Zou and Stan, 1998).

According to other authors like Chen et al (2016), Sousa et al (2008) or Zou and Stan (1998), the most important managerial characteristics as possible determinants of export performance are: export commitment and support, level of education, international experience, and innovativeness.

Among these managerial characteristics, commitment and support was the most common determinant. Besides, this result is consistent with previous reviews (Zou and Stan, 1998) and therefore, management commitment in exporting appears to be a necessary organizational ingredient to determine export success. The explanation behind the statement is that, when managers are committed, they are able to develop the necessary financial and managerial resources. As a result, the final marketing strategy is effectively implemented, and uncertainty goes down, taking the company to better performance results (Sousa et al,2008).

Other variables included in this category were educational background and innovative and professional experience. Previous research in this area report that bettereducated managers, with a good command of foreign languages and extensive 
professional experience, are more successful in exporting. However mixed results were obtained for the impact of the manager's international experience on the export performance of the firm. While Lages and Montgomery (2005) found a positive relationship, Contractor et al (2005) found no support for it (Sousa et al, 2008).

According to Zou and Stan (1998), about a third of the studies in their papers showed a positive effect of the levels of formal education and general business experience on export performance.

For other authors like Drucker (1993), Knowledge is considered to be one of the most important intangible assets and capabilities which have a direct effect on the export performance of the company. The development of these capabilities provides a determinant tool to identify the characteristics of the foreign markets where the company operates, contributing to the implementation of marketing strategies, which results in a higher export performance (Cavusgil and Zou, 1994; Parnell et al, 2015; Morgan and Katsikeas, 2012; Song et al, 2008; Desarbo et al, 2005).

Similar conclusions were reached by Sousa et al (2008) when stating that Knowledge and its acquisition and exploitation, has been declared as the key resource to create sustainable competitive advantages. In the new era of global competition, firms succeed not only because of their superior control over scarce resources, but also because of their ability to use this learning more efficiently than their competitors. Given the complexity and uncertainty surrounding export decisions, information acquisition is viewed as a primary means of minimizing the likelihood of negative consequences in the international marketplace.

This analysis comes to demonstrate the importance of the management construct, as it is very narrowly related to knowledge capabilities, which are basic in the process of developing unique resources within the company. Managers, through the incorporation of intangible knowledge capabilities constitute a way to increase the company competitiveness, something which is supported by the RBV approach.

In this point, the only remaining question is the definition of the hypotheses for this variable, and we will consider that it affects the export performance in two ways, both 
directly, and through the export marketing strategy, which is determined by the directors of the company. Consequently:

$\mathrm{H}_{2}$ : Management has a direct effect on the export marketing strategy of the company. $\mathrm{H}_{8}$ : Management also influences the export performance of the company.

\subsubsection{Strategy}

The strategy construct plays a determinant role in the structure of this investigation. As an intermediate variable, the overall strategy of the company is affected by external uncontrollable factors (the environment) and by other internal characteristics (management), but it also has an effect on the final performance of the export venture.

The study of this variable will be carried out in two parts: first, we will consider the analysis of the competitive strategy, and later on, the analysis of the marketing strategy.

The competitive strategy of the company is a really important issue because it determines the priorities of the organization. However, this input is not considered as a variable itself in our model, although it will be included in the questionnaire as a way to determine if the companies in the sample will follow marketing-based strategies, innovation and differentiation-based strategies or no particular strategies.

As a consequence, a higher exposure to marketing-based strategies will revert in a bigger influence of the marketing strategy, which is the only construct finally considered.

Once this clarification has been made, the next step will take us to the theoretical analysis of both dimensions from a separate point of view. 
A) Competitive Strategy

The strategic orientation of the firms, which leads to a determined competitive strategy, has also been considered to influence the performance of exporting companies. As stated by Sousa et al (2008), several authors (Francis and Collins-Dodd, 2000; Lado et al, 2004) introduced the "proactive/reactive" dichotomy in their researches to determine the strategic orientation of the firm.

Proactiveness plays an important role within the firm by boosting the search of new business opportunities as a consequence of the analysis of a changing environment. This will lead to the logical conclusion that, "in an exporting context, a proactive orientation is positively associated with the export performance of the firm".

On the other hand, contrary to proactive firms, those companies with a reactive behaviour, are not so much aware of internal and external conditions, presenting informational disadvantages that will certainly lead to lower levels of performance.

One of the most important contributions to the analysis of the competitive strategy comes from Porter $(1980,1985)$, who defined it as "the search for a favourable competitive position in an industry". So, competition determines the implementation of a certain strategy, which has a consequence on the performance of the company.

On Competitive Strategy (1980) Porter introduced three generic strategies, based on overall cost leadership, differentiation, or focusing on a specific market niche.

Another important concept in the theory of competitive strategy is the introduction of five forces that have an influence on the market: existing competitors (industry rivalry), the negotiation power of buyers and suppliers, and the threat of new products and new competitors (see fig. 4.5). This set of forces leads a company to adopt defensive or offensive strategies. 
Fig. 4.5. The five competitive forces that determine industry profitability

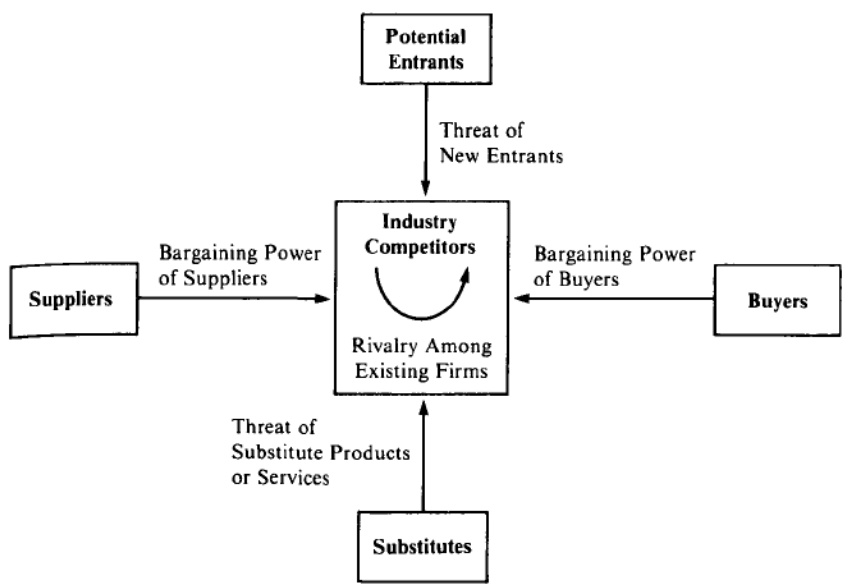

Source: Porter (1980)

A final concept developed by Porter (1985) is the definition of the value chain in a company. According to the author, all the primary activities of an organization (design and development of products, marketing, delivering and logistics) contribute to develop a sense of differentiation, which is the basis for competitive advantage (see fig. 4.6). Besides, these primary activities can be influenced by other activities (support activities) like the development of other intangible assets (technology, human resources, structure of the company ...).

The final objective of the value chain is to divide the structure of the organization into a number of strategic activities, in order to determine the way they contribute to the final performance.

Fig. 4.6. Porter's value chain

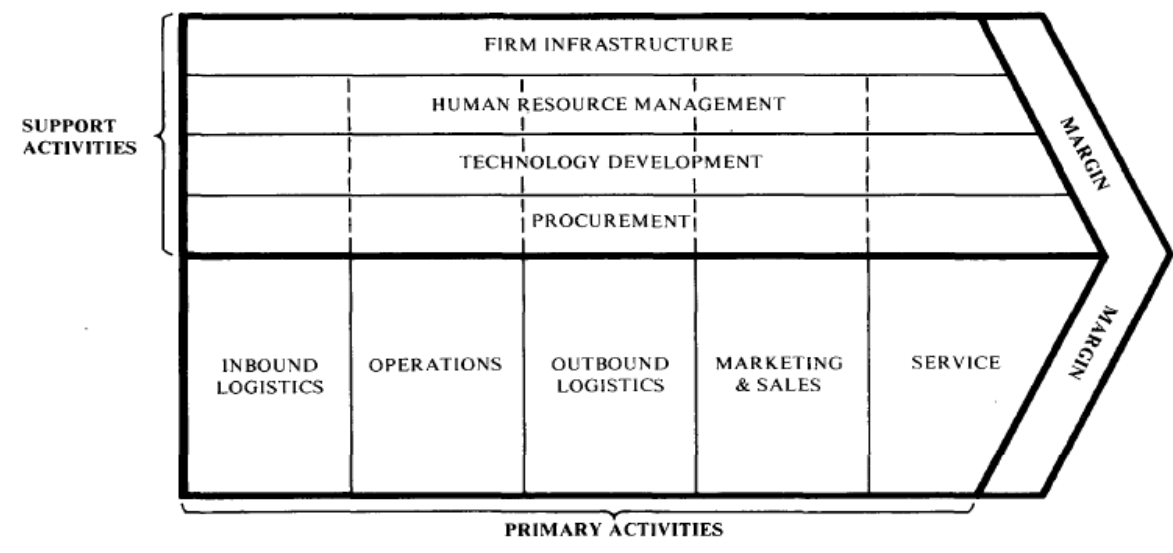

Source: Porter (1985) 
The theory developed by Porter is so important to our investigation because it sets the foundations for future theoretical approaches, like the Resource Based View (the company performance depends on a series of capabilities and the way they are connected), dynamic capabilities (these capabilities are not static, as they must adapt to the changing environment) or the contingency theory (there is not a universal strategy which can be implemented in any company at any time).

Taking Porter's (1980) generic strategies as the starting point for his empirical study, Namiki (1988) reached the conclusion that exporting SMEs generally adopt four types of competitive strategies:

- marketing differentiation: based on competitive pricing, brand development, control over distribution, advertising and innovation in terms of marketing techniques.

- segmentation differentiation: based on the ability to offer specialized products to specific customer groups.

- innovation differentiation: based on the ability to offer new and technologically superior products.

- Products/services differentiation: based on the quality of the products and services provided to customers.

According to the author, the firms that achieved the best performance, both in terms of profitability and export growth, adopted segmentation or innovation differentiation strategies.

In a similar way, Robinson and Pearce (1988), examined the influence of planning strategies on the performance of the firm by using a 22 -item-scale and came out with five groups of companies according to their strategic orientation:

- Efficiency and service orientation: simultaneously emphasizes efficiency (strict quality control, lowest cost per unit, trained personnel, innovation in the manufacturing process...) and service strategies (customer service, high-price segmentation ...). 
- Brand and service orientation: companies focus on building brand identification in order to influence distribution channels through marketing, and customer service to avoid price competition.

- Product development and innovation orientation: major emphasis on innovation, $R+D$, but also on service.

- Brand identification and efficiency orientation: presents a strong and balanced focus between two complementary strategies -brand identification/channel influence and efficiency- , trying to avoid competitive methods.

- No clear strategic orientation: reflects indecision and confusion by not adopting a clear strategic orientation.

According to the research, "strategic orientations emphasizing product innovation or incorporating efficiency and differentiation patterns of strategic behaviour were associated with higher performance levels".

Other authors like Mintzberg (1988) or Campbell-Hunt (2000) show very similar results when identifying different kind of competitive strategies, and scholars like Camisón et al (2007) have contributed to a new validation of the scale.

As cited by Julien and Ramangalahy (2003), another interesting approach to the competitive strategy of the firm, is the analysis by Denis (1990), who identified sixteen competitive factors taken into consideration by small companies, establishing a very narrow link between competitive strategies and marketing strategies:

\footnotetext{
"six of them relate to product strategy (adaptation, scope of product line, exclusivity, technological intensity, maturity, and size of orders); five to distribution strategy (similarity and number of models, intensity of contacts, and marketing coordination with intermediaries); three to price strategy (differentiation, lower export price, pricing according to local situation); and the last two factors relate to promotion strategy (scope of promotional efforts and participation in trade fairs)."
}

Another classical -yet widely considered, even up to the present moment -approach is the one by Miles and Snow (1978), in which four different kind of competitive 
strategies were determined: prospectors, analyzers, defenders and reactors. These four types of strategy have very much in common with the proactive/reactive dichotomy analyzed by Sousa et al (2008), as prospectors, analyzers and defenders play a much more proactive role compared to reactors.

As already mentioned, the competitive strategy is not going to be considered as a variable itself in our model, but a question has been introduced in the questionnaire to analyze the extent to which marketing is considered as an important issue within the strategy of the companies in the research. The results will be duly exposed in the descriptive analysis from the next chapter.

B) Marketing Strategy

We have already described the role of the Strategy (which, in our case, is represented by the Marketing Strategy) as an intermediary variable. However, from a marketing point of view, the marketing strategy (MS) construct is also influenced by two more variables: operational marketing strategies (OM) and the use of new technologies (NT) in marketing processes (see fig. 4.7).

Fig. 4.7. Components of the Marketing Strategy Variable

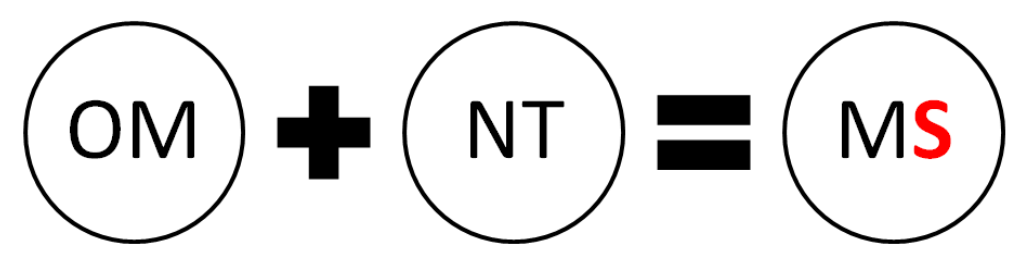

Source: Developed by the author

According to the official definition of the American Marketing Association (AMA), marketing is "the activity, set of institutions, and processes for creating, 
communicating, delivering, and exchanging offerings that have value for customers, clients, partners and society at large".

On the other hand, the marketing strategy can be considered as the way an organization achieves marketing objectives through a series of actions and decisions that pretend to create customer value.

Therefore, the marketing strategy concept is related to decisions on subjects like "market segmentation and targeting, and the development of a positioning strategy based on product, price, promotion and distribution decisions" (Slater and Olson, 2001; cited by Varadarajan, 2010).

The former statement implies that the marketing strategy is composed of two different kinds of decisions: strategic decisions on one hand, and tactical decisions on the other. This conception can be considered as the basis for the analysis of the export marketing strategy construct, which will be considered from the following two perspectives.

- From a strategic point of view, the marketing strategy is considered from the firm capabilities perspective. In this way, questions like the ability to segment and target markets, the knowledge of customers and competitors, or the skills to develop relationships are considered inherent components of the marketing strategy construct, as they constitute an intangible asset for the company.

- From an operational point of view, the marketing strategy results in the execution of the marketing mix policy (product, price, promotion and distribution). However, as already analyzed on chapter 3 , this is not the only tool to be considered and should be complemented with other instruments coming from the relationship marketing approach and the introduction of the Internet and New Technologies.

The export marketing strategy has been one of the most frequently analyzed internal variables as a determinant of the export performance in traditional models, although 
its role as an intermediate variable determines that it is also affected by other inputs like firm and management characteristics, the external environment, or even some technological firm capabilities (Katsikeas et al, 2006; Chugan and Singh, 2014; Chen et al, 2016)

The attitude from the top management contributes to improve export profit by introducing flexibility and reinforcing export policies, something which leads to new organizational and strategic possibilities (Ibeh, 2003; Cadogan et al, 2012; Okpara, 2009; Chugan and Singh, 2014), and the relationship between management capabilities and strategy $\left(\mathrm{H}_{2}\right)$, as well as the positive effect on export performance $\left(\mathrm{H}_{8}\right)$ is now proven from a new conceptual perspective.

The starting point for this analysis is based on the analysis of the export marketing strategy indicators (see Table 4.1), developed by Leonidou et al (2002), that will be complemented by the contributions of two theoretical streams: the Dynamic capabilities theory (based on the RBV), and the contingency theory.

Table 4.1.Export Marketing Strategy indicators

\begin{tabular}{lllll}
\hline Export strategy area & Product & Price & Promotion & Distribution \\
\hline Market concentration & Design & Price method & Advertising & Distributors / agents \\
Market spreading & Quality & Pricing strategy & Sales promotion & Sales reps / office \\
Market segmentation & Branding & Price competitiveness & Personal selling & Merchants \\
& Packaging / Labeling & Sales terms & Trade fairs & Direct buying \\
& Customer service & Credit policy & Personal visits & Delivery time \\
& Warranty & Currency strategy & Promotion adaptation & Distribution adaptation \\
& Product Advantage & Price adaptation & & \\
& New / Unique product & & & \\
& Product/brand mix & & & \\
& Product adaptation & & & \\
\hline
\end{tabular}

Source: Leonidou et al, 2002

The dynamic capabilities theory suggests that the basis for an effective implementation of the marketing strategy, are the capabilities developed by the firm. They are used to analyze the environment and determine the necessary tactics (operational marketing policies) that will lead to the correct execution of the 
marketing strategy (Morgan et al, 2012). The implementation of operational marketing policies will, therefore, have an effect on the long term marketing strategy.

Besides, prior research has suggested that "different marketing capabilities may be most valuable to firms in combination, as they interact in ways that help firms achieve superior performance" (Srivastava et al, 1999; Ramaswami et al, 2009; Vorhies and Morgan; 2005; Morgan et al, 2012).

Consequently, the fact of introducing the firm's capabilities approach implies a broader overview of the situation, and incorporates a new factor to the equation (economies of scale), that can generate additional benefits by connecting the different kind of assets (Grant 1996; Teece et al, 1997) and contribute to the dynamism of the model. Moreover, the existing relationship between capabilities results in a different model for each organization, which is difficult for competitors to copy, and leads them to compete in a different, more efficient, way (Helfat, 1997; Morgan et al, 2009).

In the same direction, the contingency theory highlights the importance of strategic factors, which are highly influenced by capabilities. These factors, however, are not static due to the effect of the changing environment, and the way they are combined determine the performance of the company. That takes us to the conclusion that a certain strategy may be appropriate for a determinate company in a certain moment, and inappropriate for other companies or different moments. (Harrigan, 1983; Hultman et al, 2011; Chen et al, 2016).

The approach from the contingency theory is a new evidence that all capabilities are interconnected and boosts the findings that the environment plays a crucial role, not only as a determinant of export performance, but also as a provider of the dynamic component to the set of capabilities in the company.

The underlying premise is that a firm's performance is determined mainly through two sets of precedents: the characteristics of the company's markets that determine the competitive intensity the firm faces (the environment), and the firm's capability to achieve and sustain positional advantages through the efficient execution of planned competitive and marketing strategy (Morgan et al, 2004). 
Therefore, strategic marketing decisions are affected by a firm's internal resources and capabilities, its manager's characteristics, and the external environment (Katsikeas et al, 2006). But besides the strategy itself, strategic implementation effectiveness (measured through the effectiveness of the marketing mix policies in our model) and strategic fit are also key determinants of export performance. (Chen et al, 2016).

Although neglected by many traditional studies, these inputs, based on marketing capabilities, are now taken into consideration in this thesis, and the theory behind them, which has been described above, comes to support the relationship between marketing strategy and export performance.

The analysis of the Export Marketing Strategy will be determined by three particular constructs:

1) Marketing Strategy (MS), which considers strategic marketing capabilities

2) Operational Marketing (OM), which considers marketing mix policies

3) New Technologies (NT), which considers the use of the Internet.

MARKETING STRATEGY (MS)

Leonidou et al (2002) determined export targeting and market segmentation as the key instruments in the export marketing strategy. Export targeting is associated to the number of international markets selected by a firm, while segmentation is related to the identification of groups of potential consumers with similar characteristics.

Export expansion has been very narrowly linked to export targeting, and considered in the literature through the implementation of market concentration or market spreading strategies, depending on the number of markets the company exported to. In any case, the use of one strategy or the other, were positively linked to export performance (Leonidou et al, 2002). 
A positive relationship between export performance and segmentation is also supported, despite the fact that this subject has received a more limited attention than market expansion strategies.

Another determinant to be considered is marketing research, which can be identified as the way to get information about the changes in the environment. This will enable the company to determine an effective marketing strategy oriented to the improvement of export performance, and several empirical studies have distinguished marketing research as an important element in the firm's foreign success (Hart and Tzokas, 1999; Ling-Yee, 2004; Yeoh 2000).

In the same direction, when analyzing the export marketing strategy, Zou and Stan (1998) concluded that export planning is proven to be a consistent and key determinant for export sales, which are at the time a way to quantify export performance, and an indicator of export profits and export growth. An appropriate export organization seems to show positive results in terms of sales, profits and satisfaction. According to a number of studies when a company tends to develop international marketing research policies, a positive effect on export sales, growth, and export performance is shown, although other papers reported non significant effects. Market research, general export strategy, innovation, risk taking and control were other determinants positively linked to export performance, as specified in the review by Sousa et al (2008).

As previously stated, a crucial element in the development of this thesis is the incorporation of new marketing approaches, basically market orientation and relationship marketing, which have been linked to the analysis of capabilities by a group of researchers. Details are shown below.

Authors like Chen et al (2016), Sousa (2008) or Day (1994) specified that, with respect to firm capabilities, export market orientation has been identified as an emerging key determinant of export performance in the last years, despite the fact that it is still in an early stage of development. 
The term market (or marketing orientation) has been defined as "the organizational culture that most effectively and efficiently creates the necessary behaviours for the creation of superior value for buyers, and, thus, continuous superior performance for the business" (Narver and Slater, 1990). Therefore, market-oriented firms are those which collect information about their market environments (e.g. customer needs), disseminate this information and then act on it to meet the needs of their counterparts (Cadogan et al, 2002b; Ruekert, 1992; Sousa et al, 2008).

The growing importance of this determinant in the literature is explained by the fact that market orientation provides an integrated perspective for determining export performance by enabling the organization to predict changes in the environment and act accordingly (Sousa et al, 2008).

It has been found that those firms that are market oriented are better able to recognize and respond to global changes and opportunities in today's competitive environment (Rose and Shoham, 2002). They are able to satisfy customer needs and to predict future requirements, which is a way to fight competitors (Cadogan et al, 2002a).

Chugan and Singh (2014) also contributed to highlight the importance of channel relationship, as they reported studies (Karelakis et al, 2008; Ibeh, 2003; Lages et al, 2005, 2009) where a positive implication for export performance was shown, providing even a higher consistency to the relation between marketing linking capabilities, export distribution and, therefore, export performance.

Market linking capabilities are a way to increase competitiveness within the company by analyzing the changes in the environment, in order to develop long lasting links with customers and channel members, like wholesalers and retailers. (Day, 1994).

According to Ellis (2007), three streams of market orientation research can be defined when considering exports:

- Researchers investigating the link between overall market orientation and performance (Jaworoski and Kohli, 1993; Narver and Slater, 1990). 
- Scholars who have examined the link between market orientation and export performance (Rose and Shoham, 2002; Thirkell and Dau,1998).

- Researchers who examined the influence of market orientations on export markets (Akyol and Akenhurst, 2003; Cadogan et al, 2002 a,b; 2003).

In all cases, the results of empirical studies indicate that both market orientation and export market orientation are related to the export performance of the firm in a positive way (Sousa et al, 2008).

Relationship marketing implies the creation of strong long-term relationships, not only with customers, but also with suppliers or other value-chain partners of a firm, and is based on two axioms: mutual cooperation and mutual interdependence. The development of those relationships based on mutual trust can be considered as an intangible asset, which will result in an increase of the company's competitive advantage, especially in foreign markets. (Zhang et al, 2003; Sousa et al, 2008).

In this regard, one of factors which have not been thoroughly considered is the level of corporate social responsibility carried out by the firm managers. Authors like Boehe and Cruz (2010) contribute to the literature by showing how CSR-based product differentiation may result in a higher export performance (Chugan and Singh, 2014).

Chen et al (2016) also state that some researchers have focused on the importance of "environmentally oriented strategic behaviour" (in accordance with social responsibility programs) as a way to develop sustainable long term marketing strategies, finding a positive relationship between the implementation of these policies and export performance (Antonietti and Marzucchi, 2014; Zeriti et al, 2014).

Plenty of empirical studies including scales have been developed regarding marketing linking capabilities and market orientation in the last years, showing the increasing interest for this subject: Murray et al (2009), Zou et al (2003), Morgan et al (2009), Martin and Javalgi (2015), Wilden et al (2015), Vorhies and Harker (2000), Chen et al (2013). 
They all associate the development of these marketing capabilities to an increase of export performance, which leads us to the consideration of the following hypothesis:

$\mathrm{H}_{6}$ : The export marketing strategy (which is influenced by operational marketing policies and the introduction of New Technologies) has an effect on the export performance of the company.

OPERATIONAL MARKETING (OM)

Commonly used strategies of marketing capabilities in traditional models include product, pricing or promotion adaptation policies, distribution strategy/channel relationships, and strategic decision making by the managers in the company, among others (Chugan and Singh, 2014).

In our case, we will consider that operational marketing strategies are based on marketing mix policies including product, price, promotion and place variables (see fig. 4.8). However, contrary to other traditional models, we will introduce market orientation and relationship management approaches that will result in the final items described on chapter 5 .

Fig. 4.8. Components of the Operational Marketing construct

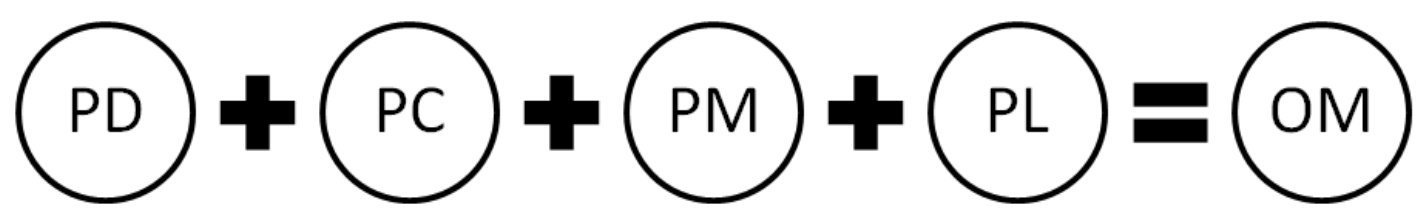

Source: Developed by the author 
According to Sousa et al (2008), the most frequently cited subjects regarding export marketing strategy are the marketing mix variables, with product receiving the most research attention, followed by price, promotion and distribution.

As stated by Chugan and Singh (2014), and Chen et al (2016), the components of the marketing mix strategy (i.e., product, pricing, promotion, and distribution) are related to the export marketing strategy, which has been widely tested in plenty of studies with positive implications for firm export performance in most of them.

This contributes to support the causal relationship established by $\mathrm{H}_{4}$ :

$\mathrm{H}_{4}$ : Operational marketing policies have an influence on the export marketing strategy of the company

The degree of adaptation or standardization of the four elements of the marketing mix policies throughout different foreign markets has been the main subject in a number of studies, although different conclusions have been reached.

A possible interpretation could imply that, not only the marketing strategy itself results in a higher performance for the company, but also the way the strategy fits the specific context, which is often affected by the external environment and firm organizational characteristics. (Cavusgil and Zou, 1994; Zou and Stan, 1998; Katsikeas et al, 2006; Sousa et al, 2008; Morgan et al, 2012; Chen et al, 2016).

This seems to be consistent with the findings of O'Cass and Julian (2003) which did not link the adaptation of the marketing mix variables to export performance. According to them, some companies could perform better by carrying out a standardization strategy, while others could achieve better results following an adaptation strategy. Consequently, different industries present different contexts and this leads to different strategies.

This approach stating that "no strategy can be effective in all contexts" is also considered the starting point of the contingency theory, deeply analyzed in the review 
by Chen et al (2016). According to them, the final performance of exporting firms depends on the context where they operate, and their effectiveness depends on the appropriate mix of organizational factors that will let the company adapt to its surrounding (Zeithaml et al, 1988; Sousa et al, 2008).

In the same direction, authors like Katsikeas et al, 2006 or Morgan et al, 2012 state that, apart from strategy itself, the effectiveness of the strategy implementation (marketing mix policies) and strategic fit are also determinant factors of the export performance.

Although neglected by many studies, we have considered both strategy and its implementation as inputs in the EMSP model of international, as their contribution to the final performance of the company has been widely demonstrated by an important number of researchers in the last decades and specially recognized by the contingency theory, coming to support the scientific foundations of the new model.

If we concentrate on the four elements of the marketing mix policy separately, we can reach the conclusions described below:

\section{PRODUCT}

Regarding product policy, there are two questions which are usually analyzed by the literature: product adaptation and product strength. In this way, different studies in Zou and Stan's review (1998) stated that these two factors are important determinants of export performance and profits within the company. This conclusion might be explained because of the fact that adapting a product can meet foreign consumers' needs and preferences in a better way, and consequently the adapted product enables the firm to sell it more easily in foreign markets. However, other studies stated non significant effects of product adaptation and product strength, while just a few resulted in negative effects (Zou and Stan, 1998).

For Leonidou et al (2002), product design and style, product quality, branding, customer service, the provision of a warranty, product-related advantages, export 
product uniqueness and the firm's ability to offer a complete product or brand mix in export markets, are all components of the product policy positively correlated with export performance. Packaging and labelling, on the contrary, were the only product variables that had no effect on export performance. And product adaptation, which is the most widely researched issue in the extant literature, was also correlated with superior export performance.

O'Cass and Julian (2003) considered that factors like "product uniqueness" affected the marketing strategy, which was analyzed from the adaptation/standardization side, while Chen et al (2016), Boehe and Cruz (2010) or Gashi et al (2014) associated the ability to develop new products to firm capabilities, having an effect on the final performance of the company.

\section{PRICE}

When studying price policies, price adaptation is also widely considered and is proven to positively influence export sales, export profits, and export growth in most of the studies, although it is insignificant in others. According to Zou and Stan (1998), the effect of price competitiveness is mostly insignificant, with the exception of some particular studies, and the price determination method was not a significant factor either. Nevertheless, the uncertain and non-concluding findings of Zou and Stan on pricing are in contrast with the positive effect size found by Chetty and Hamilton (1993).

Leonidou et al (2002) found a positive relation between export performance and variables like pricing method (the firm sets export prices according to customer demand and competitive practices), the adoption of a price penetration strategy with low prices, a prestige pricing approach, a competitive credit policy, a currency strategy (trying to adapt prices to the currency in the export country) and the effect of price adjustment (according to economic, political or legal conditions). Sales terms, by contrast, were not found to influence export performance. 
For Karelakis et al (2008), price competition influenced channel relationships, and these had a positive effect on the final dependent variable. In the same direction, Chen et al (2016) considered cost leadership (very narrowly linked to the price strategy) as one of determinants factors of success.

\section{PROMOTION}

When analyzing promotion policies, the effects of promotion adaptation on export performance seem to be mixed on one side, while promotion intensity conclude positive effects on export sales, export profits, and satisfaction with export on the other. A possible explanation for these results is that the focus of researchers was placed on measuring the extent of promotion adaption, instead of measuring the level of satisfaction provided by the adapted promotion to foreign consumers' preferences (Zou and Stan, 1998).

For Leonidou et al (2002), advertising, personal selling, trade fairs and promotion adaptation play a positive role when influencing export performance. Anyway, personal selling and the assistance to trade fairs, should be view with caution because of the limited number of studies analyzing this relationship.

Chugan and Singh (2014) and Chen et al (2016) also considered the adaptation of promotion and the promotion strategy as two of the most important inputs when considering the strategy from the marketing mix policy approach.

\section{DISTRIBUTION}

Regarding distribution policies, while the effects of channel adaptation and channel type on export performance are also mixed, channel relationship, generally expressed as motivation, involvement and support to dealers and distributors emerges as a key determinant of export sales, profits, and growth (Karelakis et al, 2008; Ibeh, 2003; Lages et al, 2005, 2009), something totally consistent with the relationship marketing 
and marketing orientation approaches of marketing and deeply considered on the marketing linking capabilities.

Finally, Leonidou et al (2002) determined that the relationship between the type of export channel intermediary and export performance does not always show consistent results. A possible explanation is that distribution channels are not static, as they depend largely on changing market conditions like the economic background, the structure of distribution channels or the difference in commercial practices. Consequently, distribution policies are also affected by these changes, a fact that supports the necessity to consider the firm's marketing strategy not only as an operative tool, but also as a dynamic capability.

Dealer support policies (in order to develop long term productive business relationships), efficiency in meeting the agreed export delivery terms, and the requirement to adapt distribution to foreign markets, on the contrary, resulted in a clear positive relationship when associated to export performance. Besides, it has been considered in plenty of empirical studies (Karelakis et al, 2008; Lages et al, 2009; Raymond and St. Pierre, 2013).

\section{NEW TECHNOLOGIES (NT)}

New Internet technologies are usually considered to be fundamental in changing the business paradigm. As a consequence, they are increasingly integrated into the marketing strategy (Prasad et al, 2001). Even so, there has not been a significant amount of research in this subject from the "determinants of export performance" side, and most of the literature has been developed from the "dynamic capabilities theory" point of view.

According to classical approaches, "a firm active in product development must be able to gather technical and market information effectively and disseminate it throughout the organization" (Jaworski and Kohli, 1993; Kohli and Jaworski, 1990; Narver and Slater, 1990). 
In a context like this, IT capabilities contribute to develop "internal communication" and "cross-functional integration" (Song et al, 2008). Besides, a correct use of IT is associated with a bigger flexibility in strategic questions and, which results in a better performance (Bharadwaj, Bharadwaj and Konsynski, 1999; Swanson, 1994; cited by Song et al, 2008).

According to Day (1994), a creative way in the use of IT should result in a better export performance, while other scholars state that effective products and services are obtained when a better transmission of information across the departments in the company is carried out (Griffin and Hauser 1992, 1993, 1996; Gupta Raj, and Wilemon; 1986; Moenaert and Souder, 1996; cited by Song et al, 2008).

In the same direction, Karavdic and Gregory (2005) determine that the relation between export marketing strategy and export performance is strengthened by the development of e-commerce. Internet technologies, consequently, have an influence on the relationship between strategy and performance in a contingency model proposing that the introduction of the Internet in the export marketing strategy can significantly improve a firms' efficiency and profitability in export ventures.

Prasad et al (2001) contribute to the analysis through a theoretical model where they pay special attention to the way market orientation, marketing competencies and export performance are linked, trying to determinate the role of the internet technology in these relationships. They find that the integration of internet technologies into the firm's marketing actions generally promotes the influence of market orientation on the firms' marketing strategies, which is proven to result in a positive impact on their export performance. Furthermore, they develop the following literature and concepts:

\footnotetext{
"Both in business-to-business and consumer marketing domains, the Internet affects activities that occur through three types of marketing channels: (1) communication channels, whose primary functions are to inform buyers and prospective buyers about availability and attributes of a seller's products/services and to enable buyers and prospective buyers to communicate with sellers; (2) transaction channels, whose primary function is to facilitate economic exchanges between buyers and sellers; and (3) distribution channels, whose primary function is to facilitate
} 
physical exchanges. Among the several ways in which the Internet is expected to transform the marketing functions are disintermediation, customer relations management, mass customization, sales force automation, marketing decision support information, and collaboration and coordination."

Nevertheless, in spite of some researchers' effort to conceptualize and develop this new approach which is proven to introduce a positive effect on export performance through the export marketing strategy, the number of studies evaluating the Internet's impact on international market growth remains still surprisingly limited. Some of them, which introduce measuring scales and support for our $\mathrm{H}_{5}$ hypothesis (NT $\rightarrow$ MS) enclosed below, are: Asikhia, 2009; Mathews et al, 2016; Gregory et al, 2007; Oh et al, 2012; Sinkovics et al, 2013; Bianchi and Mathews, 2016.

Finally, Kotler (2010, 2016) also contributed to the analysis by introducing the concepts of marketing 3.0 and 4.0, where the Internet plays a fundamental role, as it is a way to foster the relationship with the customer and let him participate in the process of adding value by developing the brand concept.

As a consequence:

$\mathrm{H}_{5}$ : The use of New Technologies in marketing processes has a positive result on the export marketing strategy of the company

\subsubsection{Export Performance}

Export performance is defined by Cavusgil and Zou (1994) as "the extent to which a firm's objectives, both economic and strategic, (...) are achieved through planning and execution of export marketing strategy".

Export performance is a crucial construct in the study of export marketing and, therefore, plenty of studies have considered it as the final dependent variable to explain how effective the determinants of an export venture are supposed to be. 
When considering the research on the export performance variable, a lack of uniformity -such in the conceptualization as in the operationalization of the constructcan be found despite the incredibly big number of investigations in the subject. (Cavusgil and Zou, 1994; Sousa et al, 2008; Chugan and Singh, 2014).

Consequently, this leads to a big amount of different names and definitions regarding export performance measures, resulting in a limitation to the empirical analysis of the literature, as it is difficult to compare the conclusions from different studies (Zou and Stan, 1998).

However, a considerable effort in this regard, was made by Zou et al (1998), as they managed to develop the EXPERF scale, a way to conceptualize and measure export performance which was globally accepted and considered up to the present time (Chugan et al, 2014).

This scale considers three basic components of export performance: financial export performance, strategic export performance and satisfaction with export venture.

Another important contribution to the study of the different export performance measures was made by Sousa (2004). He classified the different export performance indicators into objective (based mainly on absolute values) and subjective (measuring the perceptual or attitudinal performance) indicators, introducing both quantitative and qualitative components.

Sousa reached the conclusion that, in spite of the large number of different export performance measures, only a few were frequently utilized, such as export intensity (export to total sales ratio), export sales growth, export profitability, export market share, satisfaction with overall export performance, and perceived export success.

Other measures, such as return on investment, customer satisfaction or satisfaction with product/service quality were not so frequently studied (Sousa, 2004). See table 4.2 for complete details. 
Table 4.2. Export performance indicators

\begin{tabular}{|c|c|c|c|}
\hline PERFORMANCE & FREQ. OF USE & PERFORMANCE & FREQ. OF \\
\hline MEASURE & & MEASURE & USE \\
\hline OBJECTIVE MEASURES & & SUBJECTIVE MEASURES & \\
\hline Sales related & & Sales related & \\
\hline Export intensity & 16 & Export sales growth & 14 \\
\hline Export sales growth & 12 & Export sales volume & 9 \\
\hline Export sales volume & 8 & Export sales growth $(*)$ & 5 \\
\hline Export intensity growth & 5 & Export intensity & 4 \\
\hline Export sales efficiency & 2 & Export intensity growth & 4 \\
\hline Profit related & & Export sales volume $\left({ }^{*}\right)$ & 3 \\
\hline Export profit margin & 3 & Profit related & \\
\hline Export profitability & 2 & Export profitability & 18 \\
\hline Market related & & Export profit margin & 6 \\
\hline Export market share & 2 & Export profit margin growth & 4 \\
\hline \multirow[t]{12}{*}{ Export market share growth } & 2 & Export profitability $(*)$ & 4 \\
\hline & & Market related & \\
\hline & & Export market share & 11 \\
\hline & & Export market share growth & 7 \\
\hline & & Export market share $(*)$ & 4 \\
\hline & & Rate of new market entry & 4 \\
\hline & & Market diversification & 3 \\
\hline & & General & \\
\hline & & Overall export performance & 12 \\
\hline & & Strategic export performance & 7 \\
\hline & & Export success & 6 \\
\hline & & Meeting expectations & 4 \\
\hline
\end{tabular}

Source: Sousa (2004)

Finally, Chen et al (2016) followed the same path by identifying the most important indicators when measuring export performance, coming to the conclusion that the EXPERF scale is still considered by an important number of researchers. Regarding other indicators, they highlighted the following ones: export satisfaction, export growth, export intensity, export sales and export sales growth, market share and market share growth, and a series of financial indicators (like profit margins, profitability, productivity, ROI, ROA). 
In our model, the export performance of the company will be determined by the marketing strategy, the management and the environment, as already specified through the hypotheses described in the chapter.

\subsection{THE EMSP MODEL OF INTERNATIONALIZATION}

The objective of this chapter is providing a theoretical model which is consistent with the literature. In order to do so, we have introduced a series of variables and causal relationships that offer an explanation to the internationalization process of our companies through the analysis of their export performance.

Fig. 4.9 shows the EMSP model of internationalization and the relationships among its variables.

Fig. 4.9. Hypotheses in the EMSP model of Internationalization

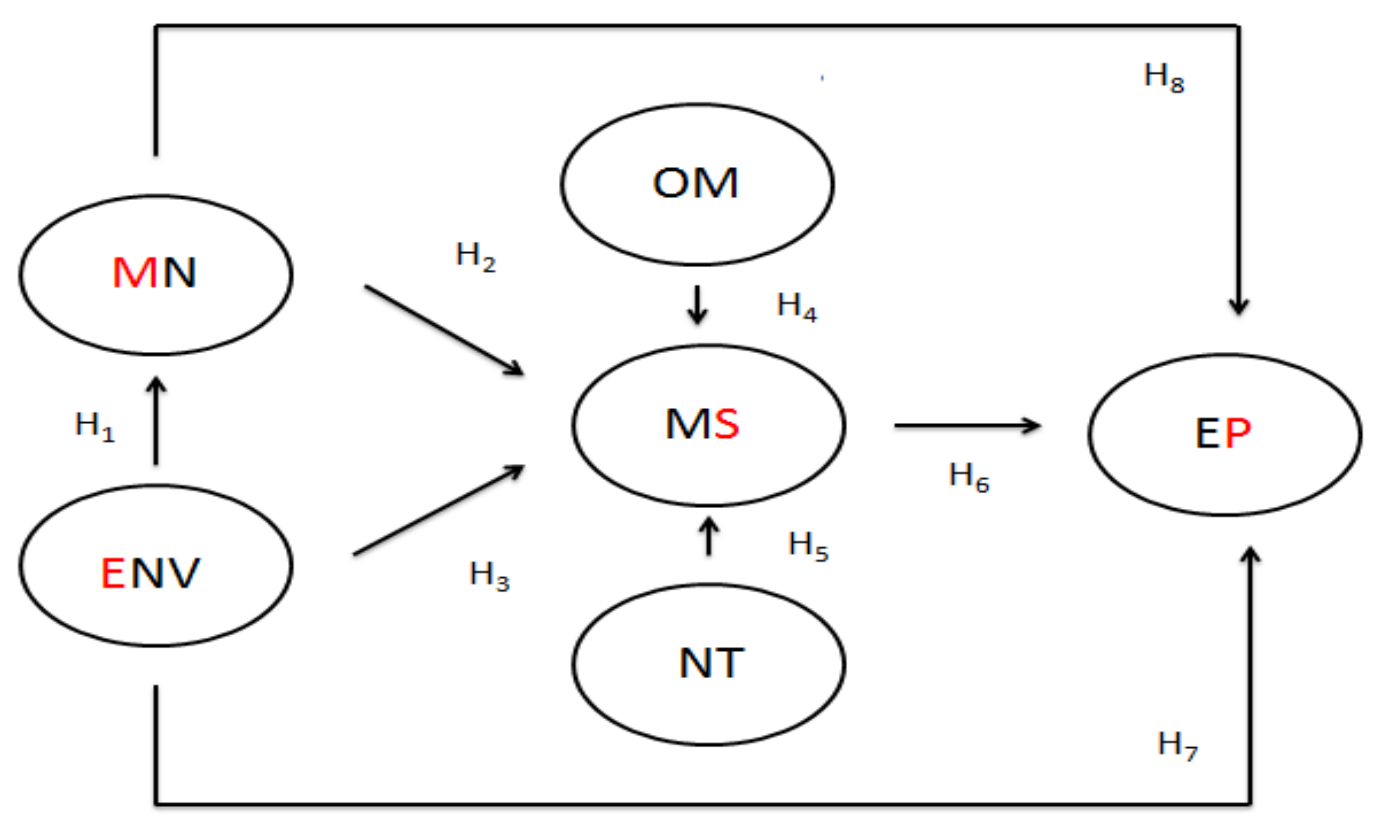

Source: Developed by the author 
Finally, the hypotheses to be contrasted in the following chapters can be described as follows:

$\mathrm{H}_{1}$ : The environment in foreign markets affects the management of the company.

$\mathrm{H}_{2}$ : Management has a direct effect on the export marketing strategy of the company.

$\mathrm{H}_{3}$ : The environment in foreign markets has an effect on the marketing strategy of the company.

$\mathrm{H}_{4}$ : Operational marketing policies have an influence on the export marketing strategy of the company

$\mathrm{H}_{5}$ : The use of New Technologies in marketing processes has a positive result on the export marketing strategy of the company

$\mathrm{H}_{6}$ : The export marketing strategy has an effect on the export performance of the company.

$\mathrm{H}_{7}$ : The environment in foreign markets directly affects the final performance of the export venture.

$\mathrm{H}_{8}$ : Management also influences the export performance of the company.

\subsection{CONCLUSIONS}

Our model pretends to integrate a different number of approaches in order to offer an explanation to the internationalization processes of the Spanish companies from the fashion sector. 
Consequently, the EMSP model of internationalization can be considered as the combination of two complementary disciplines: the theory regarding the determinants of the export performance, and the latest approaches in marketing, which come to support and develop the marketing strategy construct.

The result is a theoretical model with the following constructs: Environment (ENV), Management (MN), Marketing Strategy (MS) and Export Performance (EP).

The environment is an external variable that is supposed to have an influence on the rest of variables. The management construct, which is considered as an intangible resource of the company, is directly related to the implementation of the marketing strategy, and this plays the role of a central variable, which has a final effect on the export performance of the company.

At the same time, the marketing strategy (MS) depends on operational marketing (OM) policies and the use of new technologies (NT).

The model could not be understood without the incorporation of relational theories. These contribute to develop long term relationships with customers that lead to the improvement of customer loyalty.

Finally, other theoretical approaches which support the investigation come from the Resource Based View and its subsequent theories (Knowledge based view, dynamic capabilities or contingency theory). As a result, the Management (MN) and Marketing Strategy (MS) constructs are considered as firm capabilities, intangible assets, which contribute to the improvement of the competitive advantage in every moment.

The following chapters will introduce the empirical analysis. Thanks to the development of scales and the distribution of a questionnaire, we will get the necessary information for hypotheses contrast, and that will help us to determine the final structure of the model. 


\section{CHAPTER 5. METHODOLOGY}

\subsection{INTRODUCTION}

Once the theoretical model and the research hypotheses have been duly analyzed and defined in the previous chapter, the focus of the investigation will be placed on the characteristics of the empirical research.

To do so, we will develop the methodology of the study, that will be carried out in two basic steps:

- a first part will focus on the design of the investigation and will describe the tools and technical details of the analysis, mainly a questionnaire that will be distributed to representative companies in the fashion sector through the Internet.

- a second part will pay a special attention to the analysis of the items that will constitute the basis to measure the constructs in the model. Most of those items have been previously considered by other researchers, something which provides an additional scientific support, and will be adapted to our particular situation.

When the items of the questionnaire are finally settled, a deep statistical analysis will be considered on chapter 6 . 


\subsection{DESIGN OF THE INVESTIGATION}

The investigation is based on quantitative techniques, consisting of a questionnaire which was delivered to a selection of exporting companies in the fashion sector (mainly clothing, footwear, complements and home decoration) throughout Spain, paying a special attention to the Eastern Region (Comunidad Valenciana and Murcia), as those are activities with a determining role in the area.

According to the ORBIS databases, a total of 43,464 companies in Spain and 8,494 in the Eastern Region can be found when filtering by NACE codes Rev. 2 (13, 14, 15, 16, 31 and 32). If we consider approximately a 5\% of regular exporters, that leads to a total universe of 2,173 companies in these sectors in the whole country.

After several email contacts and direct calls presenting a questionnaire of structured closed questions with a 7 point Likert scale, a total number of 74 complete questionnaires were received. Google Forms and a digital Word Template were the basic tools used in the data collection procedure.

The technical details of the investigation can be appreciated on Table 5.1

Table 5.1. Technical details of the investigation

\section{TECHNICAL DETAILS OF THE INVESTIGATION}

\begin{tabular}{|c|c|}
\hline Universe & $\begin{array}{l}\text { 2,173 exporting companies } \\
\text { (NACE codes: } 13,14,15,16,31 \text { and } 32 \text { ) }\end{array}$ \\
\hline Sample size & 74 \\
\hline Sample selection & Quota sampling \\
\hline Data collection procedure & $\begin{array}{l}\text { Mailing with structured questionnaire using Google Forms } \\
\text { and a digital Word Template }\end{array}$ \\
\hline Questionnaire & Structured closed questions with a 7 point Likert scale \\
\hline Date of the fieldwork & November and December 2017 \\
\hline
\end{tabular}

Source: Developed by the author 


\subsection{STRUCTURE OF THE QUESTIONNAIRE}

When considering the structure of the questionnaire (enclosed in Annex I), a division of five different blocks has been taken into consideration (see Table 5.2). This division has been made attending mainly to the different constructs in the model which are related to different fields of knowledge. Besides, a logical order has been followed, so that it was easier for the interviewee to fill in the survey. Details of the structure are enclosed below:

Table 5.2. Parts of the questionnaire

\begin{tabular}{ll}
\hline Part 1 & Firm Characteristics and perceptions on export performance \\
Part 2 & Management \\
Part 3 & $\begin{array}{l}\text { Strategy: comprising Marketing Strategy, Operational Marketing } \\
\text { Strategy (4 Ps) and New Technologies }\end{array}$ \\
Part 4 & Environment \\
Part 5 & Information about the interviewee \\
\hline
\end{tabular}

The first three parts of the survey pretend to analyze internal factors of the company, part 4 focuses on external factors which cannot be controlled by the firm, but have an effect on the final performance, and part 5 concentrates on the basic information about the respondent .

In Part 1, "Firm characteristics" are decisive to the descriptive analysis in order to provide details about the sample. Perceptions on export performance (EP), on the other hand, are fundamental to determine the behaviour of the final dependent variable, which is analyzed from the interviewee's point of view.

Part 2 concentrates on the "Management" (MN) construct and pretends to analyze the way managers are influenced by the international environment and how they conceive the export activity. 
Part 3 develops the Strategy construct, which is analyzed in full detail and comprises the longest part of the questionnaire. Strategy is approached from the marketing side, which is the main field of study in this thesis (together with the determinants of export performance) and includes three more variables:

1) Marketing strategy (MS), which analyzes the strategic marketing policy in the long term.

2) Operational Marketing (OM), which considers the marketing mix policies in the short term.

3) New Technologies (NT), which determines the way new technologies are incorporated to the marketing process.

In this context, the interviewee who fills in the survey (classification questions considered in Part 5), plays a determinant role in the acquisition of information process, as he/she is providing not only objective information when needed, but also subjective criteria to determine other variables that would be impossible to estimate otherwise.

Additionally, in order to provide a coherent measuring scale, a seven-point Likert scale has been introduced throughout the questionnaire where possible.

As a last remark, the order considered in the questionnaire will be the one established all along the empirical analysis process, and the name of variables and items (which will be shown in detail below), along with their abbreviations, will also follow the same structure throughout this thesis.

\subsubsection{Firm Characteristics}

Firm characteristics (Table 5.3) have been considered on the first place, attending to the general information required in this group of questions. As a result, the questionnaire must provide information about the overall structure of the company and the way it is performing in international markets. 
Details of the company, its geographical situation, the sector they operate in, and quantitative indicators of their experience, total sales and total exports will be requested. Although this information will not be considered as a variable itself, it will be extremely useful to determine the characteristics of the sample in the descriptive analysis.

As already specified throughout this thesis, the general structure of the firms from the selected sample should not differ in great manner as they all belong to the same industrial sector (design and fashion) and they could be classified as SMEs in its vast majority.

Table 5.3. Firm Characteristics

\begin{tabular}{ll}
\hline Corporate name & \\
City & \\
Province / Area & $\square$ home \\
Fashion sector & $\square$ clothing industry \\
& $\square$ footwear \\
& $\square$ complements \\
& $\square$ others
\end{tabular}

Total turnover $(€)$

Number of employees

Year of establishment

N. of years in export venture

N. of countries selling to

Export intensity: exports / total sales (\%)

Exports to EU / Total exports (\%)

Items like firm size (number of employees) and firm age (years in business), and concepts like export intensity, number of markets served or years of international operations have been widely developed in the literature. In addition, scales were found in the papers from White et al (1998), Francis and Collins-Dodd (2004) or Baldauf et al (2000) that contributed to the final selection of items related to firm characteristics. 


\subsubsection{Export Performance (EP)}

The export performance variable (EP) pretends to evaluate the behaviour of the company in international markets and will contribute to the analyses of the final " $\mathrm{P}$ " (for Performance) in the EMSP model. Export performance is the final dependent variable which will be affected by other variables like Environment (ENV), Management (MN) or Marketing Strategy (MS).

Although the export performance of the company could have been quantified through indicators like export intensity (exports/total sales), or simply exports, we preferred to do it through a seven point Likert scale. The scale evaluates the level of satisfaction with different aspects of the international activity (see Table 5.4) in the company in the last three years, being 1 very unsatisfied and 7 very satisfied. By doing so, we were able to collect information about profit margins, degree of diversification, the evolution of exports or the satisfaction with that evolution, something which would have been really difficult otherwise.

Table 5.4. Export Performance

\begin{tabular}{ll}
\hline & ITEMS \\
\hline EP1 & Export volumen \\
EP2 & Export growth \\
\hline EP3 & Market share in international markets \\
EP4 & Degree of diversification (no of countries exporting to) \\
EP5 & Access to international markets \\
EP6 & Profitability of exports \\
EP7 & Profit margin of exports \\
EP8 & General satisfaction with exports \\
\hline
\end{tabular}

The selection of items was made following the literature on the subject, concentrating basically on the research carried out by Zou et al (1998), Sousa (2004), Jantunen et al (2008), Chugan et al (2014) and Chen et al (2016). 
Although plenty of scales have been traditionally developed to determine EP, two particular papers have been determinant for our investigation: Sousa (2004), who contributed to the research by summarizing the items and their frequency of use (see Table 4.2 on Chapter 4 for detailed information), and Chen et al (2016), who did the same for the last decade (see chapters 2 and 4 for details).

Taking that information as the basis for our scale, we finally revised the number of items and adapted them to our study, resulting in the eight items shown on Table 5.4.

Other scales developed in the literature are those of White et al (1998), Robertson and Cheety (2000), Rose and Shoham (2002), Balababnis and Katsikea (2003), Cadogan et al (2005). They can be considered as "classical scales", but they are still used in recent papers as the way to evaluate Export Performance has not changed much in the last two decades.

\subsubsection{Management (MN)}

The Management construct ( $M$ in the EMSP model) pretends to evaluate the development of firm capabilities through knowledge, particularly within the management function of the company. Management is supposed to be affected by the environment, especially in international surroundings, and that is the reason to evaluate the way the management team has adapted its skills to that situation.

By using a new seven point Likert scale, we asked the respondents to evaluate the performance of their companies in the acquisition of management capabilities compared to their main competitors, being 1 much worse, and 7 much better.

The items to be evaluated (see Table 5.5) were related to skills on general management, marketing, language, computer and IT, or team management. Experience in international markets, the provision of a general overview of the company, or the orientation towards exports were also items to be considered. 
Table 5.5. Management

\begin{tabular}{ll}
\hline \multicolumn{1}{|c}{ ITEMS } \\
\hline MN1 & General management skills \\
MN2 & Marketing skills \\
MN3 & Language skills \\
MN4 & Computer and IT skills \\
MN5 & Experience in international markets \\
MN6 & General overview of the company \\
MN7 & Export orientation \\
MN8 & Ability to facilitate communication \\
MN9 & Ability to manage teams \\
\hline
\end{tabular}

The items for the management scale have been developed on the basis of two different approaches: on one hand the research on firm capabilities, developed by Parnell et al (2015), Morgan and Katsikeas (2012), Song et al (2008), Desarbo et al (2005), Conant et al (1990), where management is one of the key concepts (along with marketing and technology capabilities), and on the other hand the classical theory developed by authors like Lages and Montgomery (2005), Stötinger and Holmüller (2001), Contractor et al (2005) or Fernandez and Alegre (2015).

\subsubsection{Strategy (MS, OM, NT)}

The strategy construct, which plays an intermediate role in the model, is influenced by management and environment and, at the same time, has an effect on the export performance of the company. It is a complex variable that can be analyzed from three different points of view: the long term strategic marketing policy, the operational marketing policy which is carried out through marketing mix actions (product, price, promotion and place), and the marketing activity resulting from the incorporation of new technologies to the process.

As a consequence, six different scales (MS, PD, PC, PM, PL, NT) with a total of 54 items will be developed, providing plenty of information to the empirical research. Additionally, one more scale (CS) will be considered as a part of the descriptive analysis in order to determine the competitive strategy of the company and the contribution of marketing to the overall process. 
A) Marketing Strategy (MS)

The Marketing Strategy construct is based on the opinion provided by the interviewees when asked to evaluate the performance of their company regarding different components of the marketing strategy in comparison to their competitors. Once more, a Likert scale was introduced, being 1 much worse and 7 much better.

Table 5.6. Marketing Strategy (MS)

\begin{tabular}{cl}
\hline & ITEMS \\
\hline MS1 & Knowledge of customers \\
MS2 & Knowledge of competitors \\
MS3 & Planning of marketing activities \\
MS4 & Integration of marketing activities \\
MS5 & Skill to segment and target markets \\
MS6 & Development of market research programs \\
MS7 & Relationships with channel members (agents, distributors ...) \\
MS8 & Development of CSR programs (environment/ethical policies) \\
MS9 & Ability to retain customers \\
MS10 & Effectiveness of the after-sales service \\
MS11 & Effectiveness of the sales team \\
\hline
\end{tabular}

Plenty of scales have been developed for this subject, but we have focused on the capabilities approach and the empirical research carried out by authors like Parnell et al (2015), Morgan and Katsikeas (2012), Song et al (2008), Desarbo et al (2005), Conant et al (1990), Murray et al (2001) and Leonidou et al (2002), who analyzed the marketing strategy disaggregating this variable in two conceptions: marketing and market linking.

The first one is totally related to the long term marketing strategy, and the second one, totally in accordance with the relationship marketing theory developed in Chapter 3 , was used to introduce this concept in our scales. In the case of MS (see Table 5.6), items like MS1 to MS6 comply with the first conception (marketing) and items like M7 to M10 adapt to the second one (market linking). 
B) Operational Marketing (OM)

If the MS construct is associated to the strategic component of marketing, the operational aspect (OM) is directly linked to the marketing mix strategy of the company, which has been traditionally carried out through the development of product, price, promotion and place policies. In our model, this second construct (OM) has an influence on the first one (MS), as short term decisions have an impact on the long term marketing strategy of the firm.

Operational marketing, in our case was measured through the use of scales for each marketing mix component (PD, PC, PM, PL), and managers were asked to evaluate a series of statements related to these components. Their reply could vary from 1: strongly disagree to 7: strongly agree (see Tables 5.7 to 5.10 for more details).

Table 5.7. Product (PD)

\begin{tabular}{ll}
\hline & ITEMS \\
\hline PD1 & We adapt the product to customer needs \\
\hline PD2 & We offer a wide range of products \\
PD3 & We invest in product quality \\
PD4 & We invest in product brand name \\
PD5 & We invest in product design \\
PD6 & We invest in product innovation \\
PD7 & We provide a high level of customer service \\
PD8 & We pretend to differentiate our product from the competition \\
\hline
\end{tabular}

Table 5.8. Price (PC)

\begin{tabular}{ll}
\hline & ITEMS \\
\hline PC1 & Our price strategy is adapted depending on the market \\
PC2 & We follow a high-price strategy \\
PC3 & We offer very competitive prices \\
PC4 & We keep high profit margins \\
PC5 & We control the final price of the product \\
PC6 & Prices are stablished according to product costs \\
PC7 & Frequent promotions and price discounts are carried out \\
PC8 & We provide credit to our customers \\
\hline
\end{tabular}


Table 5.9. Promotion (PM)

\begin{tabular}{ll}
\hline & ITEMS \\
\hline PM1 & Our communication policy is adapted depending on the market \\
\hline PM2 & We carry out promotion exhibitions \\
PM3 & We visit our customers regularly \\
PM4 & We promote through media \\
PM5 & We have our own catalogues \\
PM6 & We carry out mailshots regularly \\
PM7 & The website is adapted to foreign markets \\
PM8 & We take advantage of social networks \\
PM9 & We use the language of every foreign country \\
\hline
\end{tabular}

Table 5.10. Place (PL)

\begin{tabular}{ll}
\hline & ITEMS \\
\hline PL1 & Our distribution strategy is adapted depending on the market \\
PL2 & We support the chosen channel in every country \\
PL3 & We use agents \\
PL4 & We use distributors \\
PL5 & We have commercial subsidiaries \\
PL6 & We have production subsidiaries \\
PL7 & We sell directly to the final customer \\
PL8 & We sell through the Internet in foreign countries \\
PL9 & We take care of our delivery dates \\
\hline
\end{tabular}

The basis for the construction of these scales has been the research carried out by Leonidou et al (2002) where they develop the items for the marketing mix policy (see Table 4.1 on Chapter 4).

The marketing mix construct (considered either in the form of an aggregate, or as separate variables describing the 4Ps) has been considered as the key element of operational marketing throughout the years. However, modern approaches consider it is not sufficient to determine the operational marketing strategy to its full extent.

This is the basic reason to consider complimentary bibliography and to analyze the construct from other sides, mainly relationship marketing and new technologies approaches. In this way, authors like Parnell et al (2015), Morgan and Katsikeas (2012), Song et al (2008), Desarbo et al (2005), Conant et al (1990), Murray et al (2011), which have been previously cited, have developed scales that focus on the existence of long term relationships with customers and members of the distribution channels. 
Items like PD7, PC8, PM3, PL2, PL3 or PL4 take the relationship component into consideration.

However, we enclose detailed information of the bibliography for every component of the Operational Marketing construct (see Table 5.11).

Table 5.11. Bibliography for Operational Marketing (OM) scales

\begin{tabular}{|c|c|c|}
\hline & CONSTRUCT & BIBLIOGRAPHY \\
\hline \multirow{4}{*}{$\begin{array}{l}\text { Operational } \\
\text { Marketing } \\
\text { (OM) } \\
\text { Strategy }\end{array}$} & Product (PD) & $\begin{array}{l}\text { Leonidou et al (2002), Ayan and Percin (2005), } \\
\text { Boehe and Cruz (2010), Katsikeas et al } \\
\text { (1996), Lages et al (2009), Zou et al (2003) }\end{array}$ \\
\hline & Price $(P C)$ & $\begin{array}{l}\text { Leonidou et al (2002), Ayan and Percin (2005), } \\
\text { Lages and Montgomery (2005), Sousa and } \\
\text { Bradley (2008), Zou et al (2003), Cavusgil and } \\
\text { Zou (1994) }\end{array}$ \\
\hline & Promotion (PM) & $\begin{array}{l}\text { Leonidou et al (2002), Ayan and Percin (2005), } \\
\text { Zou et al (2003) }\end{array}$ \\
\hline & Place (PL) & $\begin{array}{l}\text { Leonidou et al (2002), Ayan and Percin (2005), } \\
\text { Brouthers et al (2009), Karelakis et al (2008), } \\
\text { Lages, Lages and Lages (2005), Lages, Silva and } \\
\text { Styles (2009), Singh and Chugan (2013), Ural } \\
\text { (2009) }\end{array}$ \\
\hline & & \\
\hline
\end{tabular}

Source: Developed by the author 
C) New Technologies (NT)

The development of new technologies and their incorporation to the marketing strategy and to the overall structure of the company has also been considered from two different point of views: on one hand, the contribution to the development of relationships (mainly customer relationships), and on the other the contribution to the firm capabilities.

This has led us to the conception of a specific construct that considers the effect of new technologies on the marketing strategy, and therefore, on the final export performance of the company (see Table 5.12).

The scale considered the opinion of the respondent when asked to evaluate the performance of the company regarding the use of New Technologies compared to its main competitors. The replies offered 7 alternatives, being 1 much worse and 7 much better.

Table 5.12. New Technologies (NT)

\begin{tabular}{ll}
\hline & ITEMS \\
\hline NT1 & Promotion and communication of new products \\
NT2 & Provision of online catalogues to customers \\
NT3 & Answer to customer queries (availability, order status ...) \\
NT4 & Enabling salespeople online access to product, price ... information \\
NT5 & Enabling salespeople/customer online transmission of orders \\
NT6 & Providing online support to distributors/dealers \\
NT7 & Gathering market infor on customers, competitors and industry \\
NT8 & Use of website visitor information for marketing and prospecting \\
NT9 & Improvement of comm. in managing operations and team projects \\
\hline
\end{tabular}

Regarding the previous research considered for the construction of this scale, we focused on the paper by Prasad et al (2001). Other scales considered in the process were those of Vilaseca-Requena et al (2007), Moen et al (2008), Asikhia (2009), Moon and Jain (2007), Sinkovics et al (2013), Kevin and Johnsen (2011), apart from the technology scales developed on the firm capabilities perspective developed by Parnell et al (2015), Morgan and Katsikeas (2012), or Song et al (2008). 
D) Competitive Strategy (CS)

Although the effect of the competitive strategy is not considered in the Structural Equations Model (SEM) process, one additional question was introduced in the questionnaire to determine the importance of different policies on the company.

The competitive strategy is considered on the descriptive analyses and will contribute to the explanation of the model.

The way to consider the competitive strategy was through one simple question with five different alternatives. The respondent had to select the policy that best fits the competitive strategy followed by the company in foreign markets (see Table 5.13).

Table 5.13. Competitive Strategy (CS)

\section{ITEMS}

Marketing differentiation: we specialize in new marketing techniques, brand

CS1 development, control over distribution, competitive pricing ...

CS2 Segmentation differentiation: we offer specialized products to specific customers Innovation differentiation: we focus on the development of new products and

CS3 technologies

Products/services differentiation: we concentrate on the quality of products and

CS4 services (efficiency and service)

CS5 No specific strategy

The bibliography used for the construct was basically the one developed by Camisón et al (2007), based on Porter $(1980,85)$ and Robinson and Pearce (1988). Other contributions came from Lado et al (2004), Namiki (1988), and Denis (1990). 


\subsubsection{Environment (ENV)}

Once the internal factors have been analyzed and quantified, it is time to concentrate on the external elements affecting the export performance of the company. As specified when developing the theoretical support of the construct, all the attention has been paid to the international environment, as we are determining a model for a particular sector -the fashion sector in the Spanish market-, where all the companies are affected by similar conditions. The environment construct (see table 5.14) will help us to establish the influence of the "E" in the EMSP model of internationalization.

The way to evaluate the effect of the environment was by asking the interviewees to evaluate the importance of different items when determining which international markets to enter. A seven point Likert scale was considered with the following legend: (1: low importance ... 7: high importance).

Table 5.14. Environment (ENV)

\section{ITEMS}

ENV1 Possibility to keep high profit margins

ENV2 Ability to detect customer needs

ENV3 Market stability (few technological, social or political changes)

ENV4 Similarities in political and legal terms

ENV5 Similarities in marketing policies

Regarding the literature for the construction of the Environment scale, the following papers were considered: White et al (1998), Baldauf et al (2000), Green et al (2008), Alvarez (2004), Chugan and Singh (2014), Chen et al (2016).

The effect of cultural similarities, physic and psychic distance, or perceptions on political and legal terms is present in most of the scales. Other items like the existence of tariffs or non-tariff barriers were not finally considered because their effect is not so important in the sector and a big proportion of their exports are focused on the European Union were tariffs are inexistent. 


\subsubsection{Details of the interviewee}

In order to provide more information about the respondents of the questionnaire, we introduced two simple questions to determine both their sex and their position in the company. This information was only used on the descriptive analyses and not included in the final variables of the model (see Tables 5.15 and 5.16).

Table 5.15. Sex of the interviewee

\begin{tabular}{l}
\hline Sex \\
\hline Male \\
Female \\
\hline
\end{tabular}

Table 5.16. Position in the company

\begin{tabular}{l}
\hline Position \\
\hline General Manager \\
Export/Mktg \\
manager \\
Technician \\
Others \\
\hline
\end{tabular}

\subsection{CONCLUSIONS}

This chapter pretends to define the basis for the construction of the questionnaire, which is the fundamental tool for the empirical analysis carried out in this thesis. The objective of the questionnaire is to determine the characteristics of the exporting companies in the fashion sector in Spain.

To do so, we have concentrated on a series of constructs that have been developed in accordance with the variables previously defined.

The first part of the questionnaire refers to the internal factors of the organisation, paying special attention to the Export Performance, Management and Marketing 
Strategy constructs. Additionally, information about the characteristics of the company is also requested in order to determine the descriptive analysis of the sample.

A second part describes the items for the analysis of the environment, which is an external variable that affects the internal factors of the company, but cannot be controlled.

And finally, a third part considers basic information about the respondents.

However, although detailed information on the items from every variable has been provided in this chapter, the final questionnaire which has been sent to the companies in the sample, is included in a separate annex at the end of this document.

Next chapter will focus on the empirical analysis of the information which was obtained from the questionnaires. 


\section{CHAPTER 6. ANALYSIS}

\subsection{INTRODUCTION}

The objective of this chapter is to present the analysis of the model, focusing on two basic concepts: the descriptive analysis, and the analysis of the dimensionality, reliability and validity of the model.

The first part pretends to offer detailed information of the exporting companies included in the selected sample. We already know they all belong to the fashion and design sector in Spain, but information on their size, experience in the market, sales figures , number of countries exporting to, ... will also be necessary.

The second part, on the other hand, develops the statistical analysis of the variables included in the EMSP model of internationalization. In this context, the statistical analysis and the testing of the hypotheses in the model were carried out through the Structural Equation Modelling (SEM) system using the EQS 6.2 for Windows software (Bentler, 1995) and IBM SPSS 20 Statistics.

Structural equation models, also called simultaneous equation models, are multivariate regression models. That means that some variables in an SEM may have an influence on the rest of variables, either directly or throughout other intermediaries determining a multiple causal relationship. 
Another important fact is that structural equation models include both unobservable exogenous and endogenous variables, as well as unobservable disturbances.

Structural equation models are also called LISREL models, which is, such the acronym for linear structural relations, as the first widely used software for the estimation of these kind of structures (Jöreskog, 1973).

\subsection{DESCRIPTIVE ANALYSIS}

The descriptive analysis will focus on four different aspects of the investigation: firm characteristics, interviewees characteristics, competitive strategy of the selected companies, and the constructs of the model.

\subsubsection{Firm Characteristics}

If we start by analyzing the geographical distribution of the sample for this investigation (Table 6.1), we can observe that the biggest number of companies (70.27\%) are located in the "Valencian community" (Comunidad Valenciana) region, which is the region around Valencia, in the east of Spain. This is so mainly for two reasons:

1) The Valencian Community (formed by Castellón, Valencia and Alicante) is one of the most important exporting areas in the country, together with Catalonia (Cataluña) and Madrid.

2) The sectors considered in the investigation (details can be found in Table 6.2) present a very active role in the local economy and, even in some cases, most of the production is carried out in this area.

Other areas of importance are Murcia (also in the Eastern Region), as well as Catalonia (Cataluña) and Madrid. 
Table 6.1. Geographical distribution

\begin{tabular}{lccc}
\hline & Frequency & Percent & Cum. Percent \\
\hline C.Valenciana & 52 & 70.27 & 70.27 \\
\hline Murcia & 7 & 9.46 & 79.73 \\
Cataluña & 7 & 9.46 & 89.19 \\
Madrid & 4 & 5.41 & 94.59 \\
Andalucía & 1 & 1.35 & 95.95 \\
Baleares & 1 & 1.35 & 97.30 \\
\hline La Rioja & 1 & 1.35 & 98.65 \\
\hline País Vasco & 1 & 1.35 & 100.00 \\
\hline TOTAL & $\mathbf{7 4}$ & $\mathbf{1 0 0 . 0 0}$ & \\
\hline
\end{tabular}

Regarding the sectors distribution (Table 6.2), home decoration (mainly home textiles) and footwear are the sectors in the study with a bigger number of companies $(68.92 \%$ of the sample in total). The rest of activities, always related to fashion and design are clothing and complements on one hand, and furniture on the other.

The study has considered two groups within the production of high "added value" products, which are: home decoration (textiles, furniture, illumination ...) and fashion (footwear, clothing, complements ...).

Table 6.2. Sectors distribution

\begin{tabular}{lccc}
\hline & Frequency & Percent & Cum. Percent \\
\hline Home & 28 & 37.84 & 37.84 \\
Footwear & 23 & 31.08 & 68.92 \\
Clothing & 8 & 10.81 & 79.73 \\
Furniture & 7 & 9.46 & 89.19 \\
Complements & 3 & 4.05 & 93.24 \\
Others & 5 & 6.76 & 100.00 \\
\hline TOTAL & $\mathbf{7 4}$ & $\mathbf{1 0 0 . 0 0}$ & \\
\hline
\end{tabular}

If we go though the total turnover figures $(€)$ of the firms represented in the sample (Table 6.3 ), we can observe that a $68.92 \%$ of them can be considered as small companies, with sales figures below 10 million $€$. A $25.68 \%$ could be classified as medium size companies, with sales figures between 10 and 50 million $€$. And only a $5.41 \%$ of them could be seen as big companies. 
Attending to these figures, we can conclude that over a $90 \%$ of the companies in this study are SMEs, even if they sell abroad, something which is in accordance with the structure of the productive sector in Spain, as it is formed by SMEs in its vast majority. A $25.68 \%$ of them could even be defined as micro-companies, as their sales figure is below 2 million $€$.

The average turnover of the companies in the sample is 18.3 million $€$.

Table 6.3. Total turnover $(€)$

\begin{tabular}{lccc}
\hline & Frequency & Percent & $\begin{array}{c}\text { Cum. } \\
\text { Percent }\end{array}$ \\
\hline$\leq 2,000,000$ & 19 & 25.68 & 25.68 \\
$2,000,001-5,000,000$ & 23 & 31.08 & 56.76 \\
$5,001,000-10,000,000$ & 9 & 12.16 & 68.92 \\
$10,000,001-50,000,000$ & 19 & 25.68 & 94.59 \\
$>50,000,000$ & 4 & 5.41 & 100.00 \\
\hline TOTAL & $\mathbf{7 4}$ & $\mathbf{1 0 0 . 0 0}$ & \\
\hline
\end{tabular}

Similar conclusions can be reached when considering the number of employees per company (Table 6.4 ) as a $75.68 \%$ of the companies employ less than 50 workers (small companies), and over a $90 \%$ of them can be considered as SMEs, employing less than 200 workers.

Table 6.4. Total number of employees

\begin{tabular}{lccc}
\hline & Frequency & Percent & Cum. Percent \\
\hline$\leq 20$ & 32 & 43.24 & 43.24 \\
$21-50$ & 24 & 32.43 & 75.68 \\
$51-100$ & 6 & 8.11 & 83.78 \\
$101-200$ & 5 & 6.76 & 90.54 \\
$>200$ & 7 & 9.46 & 100.00 \\
\hline TOTAL & $\mathbf{7 4}$ & $\mathbf{1 0 0 . 0 0}$ & \\
\hline
\end{tabular}

When analyzing the number of years the companies have been operating in the market (table 6.5), we find that the most frequent interval is $31-40$ years $(22.97 \%)$, followed by the $11-20$ years interval (21.62\%) and the $21-30$ years interval (18.92\%). 
In total, the average number of years is 29.19 , leading us to the assumption that the exporting fashion and design sector in Spain is quite mature.

Table 6.5. Years of experience

\begin{tabular}{lccc}
\hline & Frequency & Percent & Cum. Percent \\
\hline$\leq 10$ & 10 & 13.51 & 13.51 \\
$11-20$ & 16 & 21.62 & 35.14 \\
$21-30$ & 14 & 18.92 & 54.05 \\
$31-40$ & 17 & 22.97 & 77.03 \\
$41-50$ & 7 & 9.46 & 86.49 \\
$>50$ & 10 & 13.51 & 100.00 \\
\hline TOTAL & $\mathbf{7 4}$ & $\mathbf{1 0 0 . 0 0}$ & \\
\hline
\end{tabular}

The next item to be considered is the number of years in the export venture (Table 6.6), with the following results: the most frequent interval is $11-15$ years with no big differences regarding other intervals.

If we concentrate on mean values, the average number of years in the export venture amounts to 18.47 years, a figure which is quite under the total number of years in the market (29.19). That leads us to the conclusion that, generally speaking, the companies in the fashion and design sector cannot be considered as "born globals". Instead, they are closer to the Uppsala model described on chapter 2, where companies start operating in local markets and only after they get sufficient experience, do they get involved in the exporting process.

Table 6.6. Number of years in export venture

\begin{tabular}{lccc}
\hline & Frequency & Percent & Cum. Percent \\
\hline$\leq 5$ & 10 & 13.51 & 13.51 \\
$6-10$ & 9 & 12.16 & 25.68 \\
$11-15$ & 14 & 18.92 & 44.59 \\
$16-20$ & 11 & 14.86 & 59.46 \\
$21-25$ & 12 & 16.22 & 75.68 \\
$26-30$ & 10 & 13.51 & 89.19 \\
\hline 30 & 8 & 10.81 & 100.00 \\
\hline TOTAL & $\mathbf{7 4}$ & $\mathbf{1 0 0 . 0 0}$ & \\
\hline
\end{tabular}


With an average of 25.6, the number of countries exporting to (Table 6.7), present higher frequency rates in lower intervals. In this way, a $32.43 \%$ of companies export to less than 10 different countries, over a $50 \%$ export to $11-50$ countries, and only a $14.86 \%$ export to over 50 countries.

Table 6.7. Number of countries exporting to

\begin{tabular}{lccc}
\hline & Frequency & Percent & Cum. Percent \\
\hline$\leq 5$ & 11 & 14.86 & 14.86 \\
$6-10$ & 13 & 17.57 & 32.43 \\
$11-20$ & 19 & 25.68 & 58.11 \\
$21-50$ & 20 & 27.03 & 85.14 \\
$>50$ & 11 & 14.86 & 100.00 \\
\hline TOTAL & $\mathbf{7 4}$ & $\mathbf{1 0 0 . 0 0}$ & \\
\hline
\end{tabular}

If we introduce dynamic tables, Table 6.8 shows the relation between the experience developed by companies (number of years in exports) and the numbers of countries they are exporting to. We can see that companies with a bigger experience in exports sell to a bigger number of different countries. $78.95 \%$ of the companies with less than 10 years in exports sell their products to less than 20 different countries. This percentage goes down as years of experience increase (76\% in the case of 11-20 years of experience, $31.8 \%$ in the $21-30$ years interval, and $25 \%$ in the $31-40$ years interval).

Table 6.8. Relation between Years in Exports and N. of countries exporting to.

\begin{tabular}{lcccccc}
\hline \multicolumn{7}{c}{ N. of countries exporting to } \\
\hline $\begin{array}{c}\text { Years in } \\
\text { Exports }\end{array}$ & $1-20$ & $21-40$ & $41-60$ & $61-80$ & $81-100$ & Total \\
\hline $1-10$ & 15 & 3 & 1 & & & 19 \\
$11-20$ & 19 & 5 & 1 & & & 25 \\
$21-30$ & 7 & 7 & 6 & 2 & & 22 \\
\hline $31-40$ & 2 & 1 & 2 & 2 & 1 & 8 \\
\hline Total & 43 & 16 & 10 & 4 & 1 & 74 \\
\hline
\end{tabular}


As a conclusion, we can appreciate that the number of countries where companies are exporting to, is directly proportional to the number of years of experience, something with comes to support the theory behind gradualist models.

The next factor to be analyzed, with an average value of $54.66 \%$, is export intensity, which is considered as the exports / total sales ratio. The distribution, which can be seen in detail on Table 6.9, determines that approximately a third of the companies present a $61-80 \%$ export intensity, being the $\leq 20 \%$ and $>80 \%$ intervals the ones with lower frequency rates.

We should also note, that, when referring to exports throughout this thesis, sales to other countries in the European Union are also included -especially in terms of marketing- as different foreign countries (even if they belong to the EU) present certain peculiarities which make them different to the domestic market where the company has traditionally developed its operations.

Table 6.9. Export intensity (\%)

\begin{tabular}{lccc}
\hline & Frequency & Percent & Cum. Percent \\
\hline$\leq 20$ & 12 & 16.22 & 16.22 \\
$21-40$ & 13 & 17.57 & 33.78 \\
$41-60$ & 15 & 20.27 & 54.05 \\
$61-80$ & 25 & 33.78 & 87.84 \\
$>80$ & 9 & 12.16 & 100.00 \\
\hline TOTAL & $\mathbf{7 4}$ & $\mathbf{1 0 0 . 0 0}$ & \\
\hline
\end{tabular}

The final ratio to be considered is the relation between exports to the EU and total exports, with an average result of $53.18 \%$.

Full details can be appreciated in table 6.10 , but we can conclude that over $50 \%$ of the sales to foreign countries are made within the European Union. 
Table 6.10. Exports to EU / Total Exports (\%)

\begin{tabular}{lccc}
\hline & Frequency & Percent & Cum. Percent \\
\hline$\leq 20$ & 13 & 17.57 & 17.57 \\
$21-40$ & 4 & 5.41 & 22.97 \\
$41-60$ & 30 & 40.54 & 63.51 \\
$61-80$ & 21 & 28.38 & 91.89 \\
$>80$ & 6 & 8.11 & 100.00 \\
\hline TOTAL & $\mathbf{7 4}$ & $\mathbf{1 0 0 . 0 0}$ & \\
\hline
\end{tabular}

On the other hand, if we consider the relation between the experience of the company in international markets and the exports to EU / Total Exports ratio through dynamic tables (see Table 6.11), similar percentages are obtained in all cases (around $60 \%$ of all companies, no matter the experience in exports, sell more than $60 \%$ of their goods in the European Union).

Table 6.11. Relation between Years in Exports and Exports to EU/Total Exports.

\begin{tabular}{ccccccc}
\hline \multicolumn{7}{c}{ Exports to EU / Total Exports (\%) } \\
\hline Years in Exports & $0-19$ & $20-39$ & $40-59$ & $60-79$ & $80-100$ & Total \\
\hline $1-10$ & 6 & & 2 & 6 & 5 & 19 \\
$11-20$ & 4 & 1 & 4 & 13 & 3 & 25 \\
$21-30$ & 1 & 2 & 10 & 9 & & 22 \\
$31-40$ & & 1 & 2 & 5 & & 8 \\
\hline Total & 11 & 4 & 18 & 33 & 8 & 74 \\
\hline
\end{tabular}

The fact of being part of an economic union with no tariffs and similar regulations, makes companies concentrate their internationalization efforts in this area. The European Union, with 28 member states is one of the three biggest commercial areas in the planet and an important part of its exchanges remains in the area.

Consequently, Spanish firms in the fashion sector tend to increase the number of countries exporting to, but within the boundaries of the European Union, in most cases. This fact is in accordance with the statistics shown on chapter 2 (Internationalization background) where a $40 \%$ of Spanish exports were focused on just four European 
countries. The development of export business in far-away countries is still a pending subject for Spanish SMEs.

This conclusion is also in accordance with the Uppsala model where companies start their international venture by exporting to closer countries with bigger similarities, and expand their activities to far away markets once they have acquired the necessary experience.

\subsubsection{Interviewees characteristics}

Regarding the characteristics of the respondents, two simple questions were introduced (sex and position in the company), offering the following results:

The analysis of the sex item (Table 6.12 ) concluded that $75.68 \%$ of the respondents were men and the remaining $24.32 \%$ were women. Consequently, the equilibrium is far to be reached, and this finding comes to confirm that the number of men operating in positions of responsibility in Spanish companies is still quite superior to the number of women in the same positions.

Table 6.12. Sex of the interviewee

\begin{tabular}{lccc}
\hline & Frequency & Percent & $\begin{array}{c}\text { Cum. } \\
\text { Percent }\end{array}$ \\
\hline Male & 56 & 75.68 & 75.68 \\
Female & 18 & 24.32 & 100.00 \\
\hline TOTAL & $\mathbf{7 4}$ & $\mathbf{1 0 0 . 0 0}$ & \\
\hline
\end{tabular}

On the other hand, considering the "position in the company" item (table 6.13), we can find that $29.73 \%$ of the questionnaires were filled in by the general manager of the company, a $35.14 \%$ of them were filled in by the export/marketing manager, $18.92 \%$ by technicians in the export/marketing department, and the remaining $16.22 \%$ by other positions. 
Table 6.13. Position of the interviewee

\begin{tabular}{lccc}
\hline & Frequency & Percent & $\begin{array}{c}\text { Cum. } \\
\text { Percent }\end{array}$ \\
\hline General Manager & 22 & 29.73 & 29.73 \\
Export/Mktg & & & \\
manager & 26 & 35.14 & 64.86 \\
Technician & 14 & 18.92 & 83.78 \\
Others & 12 & 16.22 & 100.00 \\
\hline TOTAL & $\mathbf{7 4}$ & $\mathbf{1 0 0 , 0 0}$ & \\
\hline
\end{tabular}

\subsubsection{Competitive Strategy}

The analysis of the competitive strategy (Table 6.14) has not been analyzed in this study as a construct, but as an item that will provide information about the importance of marketing and other components in the competitive strategy of the company.

The competitive strategy of the company can be classified attending to the theoretical model developed by Porter and attends to five different options:

1. Marketing differentiation: the company specializes in new marketing techniques, brand development, control over distribution, competitive pricing ...

2. Segmentation differentiation: the company offers specialized products to specific customers.

3. Innovation differentiation: the company focus is placed on the development of new products and technologies.

4. Products/services differentiation: the company concentrates on the quality of products and services (efficiency and service).

5. The company has not developed a specific strategy.

The conclusions obtained from the survey is that only a $25.14 \%$ of the companies relate their competitive strategy to marketing in one way (marketing differentiation) or the other (segmentation differentiation). 
An additional $13.51 \%$ of the companies develop an innovation differentiation strategy, a $36.49 \%$ of them have introduced a differentiation policy through the development of new products/services, and a remaining $14.86 \%$ of companies do not consider a specific strategy.

Table 6.14. Competitive strategy

\begin{tabular}{lccc}
\hline & Frequency & Percent & $\begin{array}{c}\text { Cum. } \\
\text { Percent }\end{array}$ \\
\hline Marketing differentiation & 21 & 28.38 & 28.38 \\
Segmentation differentiation & 5 & 6.76 & 35.14 \\
Innovation differentiation & 10 & 13.51 & 48.65 \\
$\begin{array}{l}\text { Products/services } \\
\text { differentiation }\end{array}$ & 27 & 36.49 & 85.14 \\
No specific strategy & 11 & 14.86 & 100.00 \\
\hline TOTAL & $\mathbf{7 4}$ & $\mathbf{1 0 0 , 0 0}$ & \\
\hline
\end{tabular}

\subsubsection{Constructs of the model}

In this section of the descriptive analysis, we will focus on the results obtained from the statistical scrutiny of the constructs of the model. In order to get a better comprehension of the enclosed information, we should remember that all constructs have been measured through a 7 point Likert scale, which means that all the results will be referred to such a scale.

To start with, the analysis of the export performance construct (Table 6.15) shows that the managers of the selected companies are quite satisfied with the evolution of exports, presenting the highest mean of all items (5.12, corresponding to 7.3 in a decimal scale).

Export volume, export growth and the profitability of exports also present a good result, being "market share in international markets" the item showing the lowest result (4.41), but still far from a medium punctuation of 3.5 . 
Table 6.15. Export Performance

\begin{tabular}{clcc}
\hline & ITEMS & MEAN & STD. DEV. \\
\hline EP1 & Export volumen & 5.07 & 1.32 \\
EP2 & Export growth & 4.93 & 1.19 \\
\hline EP3 & Market share in international markets & 4.51 & 1.56 \\
& Degree of diversification (no of countries exporting & & \\
EP4 & to) & 4.81 & 1.44 \\
EP5 & Access to international markets & 4.70 & 1.43 \\
EP6 & Profitability of exports & 4.92 & 1.08 \\
EP7 & Profit margin of exports & 4.73 & 1.02 \\
EP8 & General satisfaction with exports & 5.12 & 1.28 \\
\hline
\end{tabular}

Regarding management (Table 6.16), mean values are also high, with 3 items (language skills, computer and IT skills and export orientation) presenting the highest values. The ability to manage teams and to facilitate communication, on the contrary show the poorest results, but always above a medium punctuation of 3.5 .

We can conclude from this analysis that the managers of exporting companies are well trained in most of the subjects, providing experience in international markets and a general overview of the company. However, the skills to be reinforced are related to the management of teams, communication and marketing.

Table 6.16. Management

\begin{tabular}{llcc}
\hline & ITEMS & MEAN & STD. DEV. \\
\hline MN1 & General management skills & 5.08 & 0.93 \\
MN2 & Marketing skills & 5.01 & 1.12 \\
MN3 & Language skills & 5.39 & 1.20 \\
MN4 & Computer and IT skills & 5.35 & 1.16 \\
MN5 & Experience in international markets & 5.24 & 1.04 \\
MN6 & General overview of the company & 5.19 & 0.97 \\
MN7 & Export orientation & 5.34 & 1.26 \\
MN8 & Ability to facilitate communication & 4.85 & 1.09 \\
\hline MN9 & Ability to manage teams & 4.74 & 1.06 \\
\hline
\end{tabular}

As per marketing strategy (Table 6.17), the items presenting the highest values are the effectiveness of the after-sales service and the sales team (two questions which are crucial to the marketing activity), as well as the knowledge of customers and competitors. 
Two of the items which are directly related to relational marketing policies (relationships with channel members and the development of CSR programs) also reach high values.

On the contrary, the items associated to the planning of marketing activities (segmentation skills and the development of market research programs) present the lowest mean values, but still positive.

Table 6.17. Marketing Strategy

\begin{tabular}{clcc}
\hline & ITEMS & MEAN & STD. DEV. \\
\hline MS1 & Knowledge of customers & 5.22 & 0.93 \\
MS2 & Knowledge of competitors & 5.26 & 0.91 \\
\hline MS3 & Planning of marketing activities & 4.69 & 1.12 \\
MS4 & Integration of marketing activities & 4.28 & 1.07 \\
MS5 & Skill to segment and target markets & 4.81 & 1.00 \\
MS6 & Development of market research programs & 4.58 & 1.27 \\
MS7 & Relat. with channel members (agents, distributors ...) & 5.11 & 0.94 \\
MS8 & Devel. of CSR programs (environment/ethical policies) & 5.22 & 1.16 \\
MS9 & Ability to retain customers & 5.24 & 0.90 \\
MS10 & Effectiveness of the after-sales service & 5.32 & 0.88 \\
MS11 & Effectiveness of the sales team & 5.26 & 0.92 \\
\hline
\end{tabular}

As already specified in previous chapters, the marketing strategy can be approached from two perspectives: the strategic way and the operational way. The former is determined by the MS construct, and the latter is developed through the use of marketing mix policies.

The operational marketing strategy will be analyzed as follows through the development of four specific constructs related to Product, Price, Promotion and Place.

Starting with Product (Table 6.18), all items reach high positions, with the investment in product quality at the top. Other important items are the differentiation of products from the competition, the provision of a high level customer service, and the adaptation of the product to customer needs depending on the market. Product design and product innovation are also important to the respondents. 
It can be concluded that the development of adequate product policies is important to the companies represented in the survey.

Table 6.18. Operational marketing: Product

\begin{tabular}{llcc}
\hline & ITEMS & MEAN & STD. DEV. \\
\hline PD1 & We adapt the product to customer needs & 5.38 & 1.07 \\
PD2 & We offer a wide range of products & 5.36 & 1.08 \\
PD3 & We invest in product quality & 5.78 & 0.94 \\
PD4 & We invest in product brand name & 5.18 & 1.14 \\
PD5 & We invest in product design & 5.20 & 1.22 \\
PD6 & We invest in product innovation & 5.05 & 1.20 \\
PD7 & We provide a high level of customer service & 5.47 & 0.85 \\
& We pretend to differentiate our product from the & & \\
PD8 & competition & 5.50 & 1.08 \\
\hline
\end{tabular}

Price policies (Table 6.19), on the other hand, present more diverse results with "the adaptation of price strategies depending on the market" item presenting the highest mean value. High-price strategies also seem to be important, and prices are established according to product costs in plenty of cases, but promotion and price discounts present very discreet mean values, slightly exceeding the medium value of 3.5.

Table 6.19. Operational marketing: Price

\begin{tabular}{llrc}
\hline & ITEMS & MEAN & STD. DEV. \\
\hline & Our price strategy is adapted depending on the & & \\
PC1 & market & 5.36 & 0.88 \\
PC2 & We follow a high-price strategy & 4.51 & 1.34 \\
PC3 & We offer very competitive prices & 4.30 & 1.18 \\
PC4 & We keep high profit margins & 4.24 & 1.20 \\
PC5 & We control the final price of the product & 4.36 & 1.30 \\
PC6 & Prices are established according to product costs & 4.88 & 0.96 \\
& Frequent promotions and price discounts are carried & & \\
PC7 & out & 3.74 & 1.23 \\
\hline PC8 & We provide credit to our customers & 4.42 & 1.40 \\
\hline
\end{tabular}

Promotion policies are fundamental to the marketing mix policies and to the contribution of the final performance of the company. Diverse results are also shown in detail on Table 6.20, but we are able to conclude that the use of the language in 
every country, the attendance of exhibitions and the regular visit of customers are the most important items to the interviewees. On the other hand, although communication policies are adapted depending on the market, the items showing the lowest results are the promotion through media and social networks.

Even though the use of new technologies in marketing policies will be analyzed in a separate construct later on, we can now observe that digital marketing strategies are not one of the priorities for SMEs at the moment.

Table 6.20. Operational marketing: Promotion

\begin{tabular}{llrc}
\hline & ITEMS & MEAN & STD. DEV. \\
\hline & Our communication policy is adapted depending on & & \\
PM1 & the market & 4.95 & 1.05 \\
PM2 & We carry out promotion in exhibitions & 5.15 & 1.52 \\
PM3 & We visit our customers regularly & 4.62 & 1.36 \\
PM4 & We promote through media & 3.70 & 1.59 \\
PM5 & We have our own catalogues & 4.77 & 1.60 \\
PM6 & We carry out mailshots regularly & 4.16 & 1.39 \\
PM7 & The website is adapted to foreign markets & 4.80 & 1.48 \\
PM8 & We take advantage of social networks & 3.64 & 1.66 \\
PM9 & We use the language of every foreign country & 5.46 & 1.38 \\
\hline
\end{tabular}

In order to conclude the marketing mix policy analysis, the results for the Place construct are displayed on Table 6.21.

When considering the existence of commercial and production subsidiaries, mean values can be found below 3.5. This confirms that most exporting SMEs consider the internationalization process as an export activity from the origin, and only a few have established subsidiaries in other countries.

On the opposite, the items related to the distribution policy scoring high mean levels are the use of agents and distributors, which are fundamental in the development of the channel. Taking care of delivery times and the adaptation of the distribution strategy to every foreign market present the highest values.

Regarding the use of the Internet to sell in foreign countries, an intermediate value of 3.55 can be appreciated, with high levels of standard deviation, which shows (once 
again and in accordance with the results obtained from the promotion policy construct) that digital marketing techniques still have "a long way to go".

Table 6.21. Operational marketing: Place

\begin{tabular}{llrc}
\hline & ITEMS & MEAN & STD. DEV. \\
\hline & Our distribution strategy is adapted depending on the & & \\
PL1 & market & 5.15 & 1.17 \\
PL2 & We support the chosen channel in every country & 4.96 & 1.15 \\
\hline PL3 & We use agents & 5.42 & 1.11 \\
PL4 & We use distributors & 4.92 & 1.39 \\
\hline PL5 & We have commercial subsidiaries & 2.64 & 1.94 \\
PL6 & We have production subsidiaries & 2.27 & 1.75 \\
PL7 & We sell directly to the final customer & 4.03 & 1.73 \\
PL8 & We sell through the Internet in foreign countries & 3.55 & 1.82 \\
\hline PL9 & We take care of our delivery dates & 5.73 & 0.86 \\
\hline
\end{tabular}

Despite the findings in previous operational marketing constructs, companies tend to consider the use of new technologies in their relations with customers and channel members (Table 6.22). The lowest mean values correspond once more to the incorporation of new technologies into communication and management operations, although they are still important.

The highest positions correspond to the provision of online catalogues to customer and the answer to customer queries (with 5.50 and 5.51 mean values).

Table 6.22. New Technologies

\begin{tabular}{|c|c|c|c|}
\hline & ITEMS & MEAN & $\begin{array}{l}\text { STD. } \\
\text { DEV. }\end{array}$ \\
\hline NT1 & Promotion and communication of new products & 5.24 & 1.04 \\
\hline NT2 & Provision of online catalogues to customers & 5.50 & 1.09 \\
\hline NT3 & $\begin{array}{l}\text { Answer to customer queries (availability. order } \\
\text { status ...) }\end{array}$ & 5.61 & 0.86 \\
\hline NT4 & $\begin{array}{l}\text { Enabling salespeople online access to product. price ... } \\
\text { information }\end{array}$ & 4.99 & 1.00 \\
\hline NT5 & $\begin{array}{l}\text { Enabling salespeople/customer online transmission of } \\
\text { orders }\end{array}$ & 5.01 & 1.09 \\
\hline NT6 & Providing online support to distributors/dealers & 4.66 & 1.35 \\
\hline NT7 & $\begin{array}{l}\text { Gathering market related information on customers. } \\
\text { competitors and industry }\end{array}$ & 4.72 & 1.12 \\
\hline NT8 & Use of website visitor information for marketing and & 4.47 & 1.44 \\
\hline
\end{tabular}


prospecting

Improvement of communication and coordination in

NT9 managing operations and team projects

$4.43 \quad 1.09$

Finally, the environment construct (Table 6.23) presents a higher mean value (5.32) in "the ability to detect customer needs" item. On the other hand, factors like similarities in marketing polities or political and legal terms could be considered of lower importance, but still very representative. The possibility to keep profit margins and foreign market stability (showing in-between values) are the remaining factors for this construct.

Table 6.23. Environment

\begin{tabular}{llcc}
\hline & ITEMS & MEAN & STD. DEV. \\
\hline ENV1 & Possibility to keep high profit margins & 4.73 & 1.29 \\
ENV2 & Ability to detect customer needs & 5.32 & 1.02 \\
& Market stability (few technological. social or political & & \\
ENV3 & changes) & 4.99 & 1.12 \\
ENV4 & Similarities in political and legal terms & 4.45 & 1.20 \\
ENV5 & Similarities in marketing policies & 4.34 & 0.93 \\
\hline
\end{tabular}

\subsection{DIMENSIONALITY, RELIABILITY AND VALIDITY OF THE MODEL}

The next step in the empirical analysis is focused on testing the different hypotheses of the theoretical model which were developed in the first part of this thesis. To do so, we will follow the two step approach developed by Anderson and Gerbing (1988).

The first step pretends to confirm the quality of the scales through a confirmatory factor analysis (CFA) that will eliminate non-significant items. This will determine the dimensionality, reliability and validity of the scales providing a more effective measuring method.

At a second stage, we will concentrate on testing the causal relations of the conceptual model in order to determine the hypotheses that will be accepted or rejected. 
In our case, the analysis will start with the study of the operative marketing variables (product, price, promotion and distribution) which have been measured through a series of 34 items. These items determine a common dimension, which is the marketing mix policy of the company, a key construct with an influence on the final export marketing strategy.

According to the literature, a combination of items with a same objective can be considered as "composite measures" (Bandalos and Finney, 2001; Bou-LLusar et al 2009; Landis et al 2000; Little et al, 2002; Bagozzi and Edwards, 1998; McCallum et al, 1999) that will be subjected to confirmatory factor analysis (CFA) together with the rest of the items and scales in the study, so that they can be validated.

The use of composite measures (also known as item parcelling), is to be considered in our analysis for two reasons:

1) It is appropriate to meet the normal distribution assumption of maximum likelihood estimation.

2) It reduces the number of variances and covariances to be estimated, something which reduces the impact of sampling error on the estimation process.

As a consequence, once the marketing mix variables (Product, Price, Promotion and Place) have been analyzed as a composite measure and a CFA has been carried out (Table 6.24), 14 of the original 34 items are missing and a new variable (OM: Operational marketing), that will be integrated in the final model, is attained.

The criteria to discard not significant items, are established from a double perspective: on one hand factor loadings must be superior to 0.6 , and on the other $t$-values must be above 1.96 . 
Table 6.24. CFA for the Operational Marketing (OM) item parceling

\begin{tabular}{llcc} 
& & factor & \\
loading & t value \\
\hline PD1 & We adapt the product to customer needs & $0.43^{*}$ & 3.75 \\
PD2 & We offer a wide range of products & $0.54^{*}$ & 5.27 \\
\hline PD3 & We invest in product quality & 0.70 & 7.88 \\
PD4 & We invest in product brand name & 0.82 & 8.98 \\
PD5 & We invest in product design & 0.82 & 11.40 \\
PD6 & We invest in product innovation & 0.91 & 11.41 \\
\hline PD7 & We provide a high level of customer service & $0.58^{*}$ & 5.79 \\
& We pretend to differentiate our product from the & & \\
PD8 & competition & 0.74 & 6.35 \\
\hline
\end{tabular}

\begin{tabular}{llcc}
\hline & PRICE & $\begin{array}{c}\text { factor } \\
\text { loading }\end{array}$ & t value \\
\hline PC1 & Our price strategy is adapted depending on the market & $0.27^{*}$ & $1.76^{*}$ \\
PC2 & We follow a high-price strategy & 0.83 & 12.54 \\
\hline PC3 & We offer very competitive prices & $0.21^{*}$ & $1.53^{*}$ \\
PC4 & We keep high profit margins & 0.82 & 12.57 \\
PC5 & We control the final price of the product & 0.76 & 14.64 \\
PC6 & Prices are established according to product costs & $0.18^{*}$ & $1.32^{*}$ \\
& Frequent promotions and price discounts are carried & & \\
PC7 & out & $0.05^{*}$ & $0.33^{*}$ \\
PC8 & We provide credit to our customers & $0.44^{*}$ & 3.90 \\
\hline
\end{tabular}

\begin{tabular}{llcc}
\hline PROMOTION & $\begin{array}{c}\text { factor } \\
\text { loading }\end{array}$ & t value \\
\hline PM1 & Our communication policy is adapted depending on the & & \\
PM2 & We carry out promotion exhibitions & 0.68 & 2.61 \\
PM3 & We visit our customers regularly & 0.73 & 2.70 \\
PM4 & We promote through media & 0.70 & 2.57 \\
PM5 & We have our own catalogues & 0.79 & 2.64 \\
PM6 & We carry out mailshots regularly & 0.76 & 2.42 \\
PM7 & The website is adapted to foreign markets & 0.70 & 2.59 \\
PM8 & We take advantage of social networks & 0.72 & 2.67 \\
PM9 & We use the language of every foreign country & 0.83 & 2.64 \\
\hline
\end{tabular}




\begin{tabular}{llcc}
\hline & PLACE & $\begin{array}{c}\text { factor } \\
\text { loading }\end{array}$ & t value \\
\hline & Our distribution strategy is adapted depending on the & & \\
PL1 & market & 0.80 & 6.96 \\
\hline PL2 & We support the chosen channel in every country & 0.81 & 7.56 \\
\hline PL3 & We use agents & $0.46^{*}$ & 3.52 \\
PL4 & We use distributors & $0.48^{*}$ & 4.83 \\
PL5 & We have commercial subsidiaries & $0.59^{*}$ & 5.50 \\
PL6 & We have production subsidiaries & $0.45^{*}$ & 4.14 \\
PL7 & We sell directly to the final customer & $0.37^{*}$ & 3.73 \\
PL8 & We sell through the Internet in foreign countries & 0.62 & 23.49 \\
PL9 & We take care of our delivery dates & $0.46^{*}$ & 2.92 \\
\hline
\end{tabular}

$\left({ }^{*}\right)$ not significant items (factor loading $<0.6$ or $t$ value $<1.96$ )

If we check every variable separately, we can reach the following conclusions:

PRODUCT

According to confirmatory factor analysis, the items considered as not significant for the model are: "we adapt the product to customer needs", "we offer a wide range of products", and "we provide a high level of customer service".

That means that 5 items (instead of the previous 8 ) will remain to define the contribution of the product to the operational marketing variable.

We can see that the remaining items are all related to the particular features of the product (quality, brand name, design, innovation, and the way it is different to the competition).

PRICE

When analyzing the contribution of the price variable to the model, only 3 items are kept: "we follow a high-price strategy", we keep high profit margins" and "we control the final price of the product".

That means that the items related to price discounts, costs analysis or even credit policies to customers, take a second place and the strategy is focused on offering high value added products, rather than being competitive on prices. 
PROMOTION

It is remarkable that all items in the promotion component of the marketing mix policy are significant to the model, something which comes to confirm the importance to the companies in the sample of an adequate promotion policy and the way it is adapted to international markets.

PLACE

Regarding the place component, we can conclude after running the confirmatory factor analysis that the contribution to the model comes basically from the way companies support and adapt the distribution channels in every country, and not so much from the way the distribution policy is developed (hiring agents or distributors, setting up subsidiaries ...).

This is quite reasonable, on the other hand, if we remember that over a $50 \%$ of the sales to foreign countries are located within the EU, where plenty of the operations can be carried out from the origin.

As a result, the number of items to describe the place policy within the operational marketing policy will be reduced from 9 to just 3 of them.

After the items which are not significant enough (factor loadings $<0.60$ and $t$ values <1.96) have been eliminated from the OM measuring scales, we will carry on with the analysis of the dimensionality, reliability and validity of this variable (Table 6.25). The new construct will be composed of four dimensions (PD, PC, PM and PL) and a total of 20 items.

Table 6.25. Analysis of the dimensionality, reliability and validity of OM

\begin{tabular}{llcc}
\hline & PRODUCT (CR=0.90; AVE=0.69) & $\begin{array}{c}\text { factor } \\
\text { loading }\end{array}$ & t value \\
\hline PD3 & We invest in product quality & 0.65 & 3.04 \\
PD4 & We invest in product brand name & 0.85 & 3.73 \\
PD5 & We invest in product design & 0.82 & 3.48 \\
PD6 & We invest in product innovation & 0.90 & 3.69 \\
& We pretend to differentiate our product from the & & \\
PD8 & competition & 0.73 & 3.24 \\
\hline
\end{tabular}




\begin{tabular}{llcc} 
& & factor & \\
& PRICE (CR=0.85; AVE=0.69) & loading & t value \\
\hline PC2 & We follow a high-price strategy & 0.77 & 5.32 \\
PC4 & We keep high profit margins & 0.83 & 6.69 \\
PC5 & We control the final price of the product & 0.81 & 6.34 \\
\hline
\end{tabular}

\begin{tabular}{llcc}
\hline & PROMOTION (CR=0.91; AVE=0.62) & $\begin{array}{c}\text { factor } \\
\text { loading }\end{array}$ & t value \\
\hline PM1 & Our communication policy is adpted depending on the & & \\
PM2 & We carry out promotion exhibitions & 0.69 & 6.37 \\
PM3 & We visit our customers regularly & 0.72 & 7.26 \\
PM4 & We promote through media & 0.69 & 6.43 \\
PM5 & We have our own catalogues & 0.80 & 9.91 \\
PM6 & We carry out mailshots regularly & 0.77 & 7.55 \\
PM7 & The website is adapted to foreign markets & 0.70 & 7.52 \\
PM8 & We take advantage of social networks & 0.73 & 6.16 \\
\hline PM9 & We use the language of every foreign country & 0.82 & 11.02 \\
\hline
\end{tabular}

\begin{tabular}{llcc} 
& PLACE (CR=0.86; AVE=0.71) & $\begin{array}{c}\text { factor } \\
\text { loading }\end{array}$ & t value \\
\hline & Our distribution strategy is adapted depending on the & & \\
PL1 & market & 0.87 & 2.22 \\
PL2 & We support the chosen channel in every country & 0.89 & 2.56 \\
PL8 & We sell through the Internet in foreign countries & 0.68 & 2.62 \\
\hline
\end{tabular}

CR: Composite reliability; AVE: Average variance extracted

Fit of the model: Chi-Squared $=88.1363$; Degrees of freedom $(D F)=160 ; p=0.0635214$

$\mathrm{CFI}=0.928 ; \mathrm{MNFI}=0.917 ; \mathrm{RMSEA}=0.052$

As observed in Table 6.25, the probability related to with Chi-Squared reaches a value which is higher than $0.05(0.0635214)$, confirming an overall appropriate fit of the scale (Jöreskog and Sörbom, 1996). Besides, CFI and MNFI are close to the unity and RMSEA is close to zero.

On the other hand, the convergent validity is proven in two ways: through the significant (>0.5) factor loadings (Bagozzi, 1980; Bagozzi and Yi, 1988; Hair et al, 1998) 
and through an average variance extracted (AVE) for each factor higher than 0.5 (Fornell and Larcker, 1981).

The reliability of the scale is demonstrated when the composite reliability indexes (CR) of each dimension is higher than 0.6 (Bagozzi and $\mathrm{Yi}, 1988$ ), something that occurs in our model.

And finally, the discriminant validity of the OM construct (Table 6.26) is confirmed because the estimated correlation between the factors of the construct (values below the diagonal) is lower than the square root of the AVE between each pair of factors (values on the diagonal). This proves that "the construct shares more variance with its indicators than with other constructs of the model" (Fornell and Larcker, 1981).

Table 6.26. Discriminant validity of the scales associated to OM

\begin{tabular}{|l|c|c|c|c|}
\hline & PRODUCT & PRICE & PROMOTION & PLACE \\
\hline PRODUCT & 0.83 & & & \\
\hline PRICE & 0.56 & 0.83 & & \\
\hline PROMOTION & 0.64 & 0.57 & 0.79 & \\
\hline PLACE & 0.59 & 0.64 & 0.66 & 0.84 \\
\hline
\end{tabular}

Below the diagonal: estimated correlation between the factors

Diagonal: square root of AVE

Once the new OM construct has been created and validated according to the literature on the subject (Bandalos and Finney, 2001; Bou-Llusar et al, 2009; Landis et al, 2000), a new analysis of the dimensionality, reliability and validity of the final model (the EMSP model, as described on Chapter 4) will be carried out, showing the results on Table 6.27 . 
Table 6.27. Dimensionality, reliability and validity of the EMSP model.

\begin{tabular}{llcc}
\hline & EXPORT PERFORMANCE (CR=0.96; AVE=0.89) & $\begin{array}{c}\text { factor } \\
\text { loading }\end{array}$ & t value \\
\hline EP1 & Export volume & 0.86 & 4.13 \\
EP2 & Export growth & 0.88 & 6.13 \\
\hline EP3 & Market share in international markets & 0.88 & 4.58 \\
EP4 & Degree of diversification (no of countries exporting to) & 0.85 & 4.68 \\
\hline EP5 & Access to international markets & 0.89 & 4.94 \\
EP6 & Profitability of exports & 0.88 & 6.48 \\
\hline EP7 & Profit margin of exports & 0.84 & 6.59 \\
EP8 & General satisfaction with exports & 0.93 & 4.64 \\
\hline
\end{tabular}

\begin{tabular}{llcc}
\hline & MANAGEMENT (CR=0.94; AVE=0.84) & $\begin{array}{c}\text { factor } \\
\text { loading }\end{array}$ & t value \\
\hline MN1 & General management skills & 0.79 & 6.48 \\
MN2 & Marketing skills & 0.85 & 6.00 \\
\hline MN3 & Language skills & 0.87 & 6.03 \\
MN4 & Computer and IT skills & 0.80 & 5.05 \\
MN5 & Experience in international markets & 0.74 & 5.97 \\
MN6 & General overview of the company & 0.78 & 6.43 \\
MN7 & Export orientation & 0.85 & 4.80 \\
MN8 & Ability to facilitate communication & 0.78 & 5.78 \\
\hline MN9 & Ability to manage teams & 0.76 & 6.04 \\
\hline
\end{tabular}

\begin{tabular}{clcc}
\hline & MARKETING STRATEGY (CR=0.93; AVE=0.79) & $\begin{array}{c}\text { factor } \\
\text { loading }\end{array}$ & t value \\
\hline MS1 & Knowledge of customers & 0.75 & 3.05 \\
MS2 & Knowledge of competitors & 0.71 & 6.63 \\
\hline MS3 & Planning of marketing activities & 0.85 & 5.56 \\
MS4 & Integration of marketing activities & 0.62 & 6.64 \\
MS5 & Skill to segment and target markets & 0.83 & 4.69 \\
MS6 & Development of market research programs & 0.77 & 6.37 \\
& Relationships with channel members (agents. & & \\
MS7 & distributors ...) & 0.74 & 5.05 \\
& Development of CSR programs (environment/ethical & & \\
MS8 & policies) & 0.81 & 6.01 \\
\hline MS9 & Ability to retain customers & 0.58 & 7.97 \\
MS10 & Effectiveness of the after-sales service & 0.68 & 7.58 \\
MS11 & Effectiveness of the sales team & 0.79 & 5.97 \\
\hline
\end{tabular}




\begin{tabular}{llcc}
\hline & NEW TECHNOLOGIES (CR=0.93; AVE=0.81) & $\begin{array}{c}\text { factor } \\
\text { loading }\end{array}$ & t value \\
\hline NT1 & Promotion and communication of new products & 0.76 & 5.96 \\
NT2 & Provision of online catalogues to customers & 0.80 & 6.14 \\
\hline NT3 & $\begin{array}{l}\text { Answer to customer queries (availability. order status ...) } \\
\text { Enabling salespeople online access to product. price ... }\end{array}$ & 0.74 & 5.94 \\
NT4 & $\begin{array}{l}\text { information } \\
\text { NT5 }\end{array} \quad \begin{array}{l}\text { Enabling salespeople/customer online transmission of } \\
\text { orders }\end{array}$ & 0.73 & 7.40 \\
NT6 & $\begin{array}{l}\text { Providing online support to distributors/dealers } \\
\text { NT7 }\end{array} \quad \begin{array}{l}\text { Gathering market info on customers. competitors and } \\
\text { industry }\end{array}$ & 0.71 & 3.85 \\
NT8 & $\begin{array}{l}\text { Use of website visitor information for marketing and } \\
\text { prospecting }\end{array}$ & 0.79 & 4.11 \\
\hline & $\begin{array}{l}\text { Improvement of comm. in managing operations and } \\
\text { NT9 }\end{array}$ team projects & 0.75 & 4.53 \\
\hline
\end{tabular}

\begin{tabular}{llcc}
\hline & ENVIRONMENT (CR=0.86; AVE=0.79) & $\begin{array}{c}\text { factor } \\
\text { loading }\end{array}$ & t value \\
\hline ENV1 & Possibility to keep high profit margins & 0.71 & 3.77 \\
ENV2 & Ability to detect customer needs & 0.85 & 3.77 \\
& Market stability (few technological. social or political & & \\
ENV3 & changes) & 0.68 & 4.40 \\
ENV4 & Similarities in political and legal terms & 0.69 & 5.31 \\
ENV5 & Similarities in marketing policies & 0.75 & 6.70 \\
\hline
\end{tabular}

\begin{tabular}{clccc}
\hline & OPERATIONAL MARKETING (CR=0.90; AVE=0.86) & $\begin{array}{c}\text { factor } \\
\text { loading }\end{array}$ & t value \\
\hline PD & Product & 0.85 & 4.53 \\
PC & Price & 0.72 & 4.66 \\
PM & Promotion & 0.91 & 4.17 \\
PL & Place & 0.83 & 3.02 \\
\hline
\end{tabular}

CR: Composite reliability; AVE: Average variance extracted

Fit of the model: Chi-Squared=1030.3513; Degrees of freedom (DF) $=968 ; p=0.0803358$

$\mathrm{CFI}=0.898 ; \mathrm{MNFI}=0.891 ; \mathrm{RMSEA}=0.061$

We can observe that all items present adequate factor loadings and $t$ values, which means that none of them need to be removed from the model according to the confirmatory factor analysis (CFA). 
Continuing with the process, the steps to check the validity of the EMSP model and the values to be considered will be exactly the same to the ones in the validation process of the OM construct.

Consequently, once more, the probability related to Chi-Squared reaches a value which is higher than $0.05(0.803358)$, confirming an overall appropriate fit of the scale (Jöreskog and Sörbom, 1996). Besides, CFI and MNFI are close to the unity and RMSEA is close to zero.

Regarding the convergent validity of the model, factor loadings are all superior to 0.5 (Bagozzi, 1980; Bagozzi and Yi, 1988; Hair et al, 1998) and the average variance extracted (AVE) for each factor is higher than 0.5 (Fornell and Larcker, 1981), meeting the requirements for the confirmation.

The reliability of the scale is also demonstrated because the composite reliability index (CR) of each dimension is higher than 0.6 (Bagozzi and Yi, 1988).

And finally, the discriminant validity of the EMSP model (Table 6.28) is confirmed because the estimated correlation between the factors of the construct (values below the diagonal) is lower than the square root of the AVE between each pair of factors (values on the diagonal)." (Fornell and Larcker, 1981).

Table 6.28. Discriminant validity of the scales associated to the EMSP model

\begin{tabular}{|c|c|c|c|c|c|c|}
\hline & EP & MN & MS & NT & ENV & OM \\
\hline EP & 0.89 & & & & & \\
\hline MN & 0.60 & 0.84 & & & & \\
\hline MS & 0.56 & 0.63 & 0.79 & & & \\
\hline NT & 0.59 & 0.70 & 0.66 & 0.81 & & \\
\hline ENV & 0.62 & 0.62 & 0.67 & 0.69 & 0.79 & \\
\hline OM & 0.63 & 0.61 & 0.65 & 0.66 & 0.73 & 0.86 \\
\hline
\end{tabular}

Below the diagonal: estimated correlation between the factors

Diagonal: square root of AVE 
The final model (see fig. 6.1) with the causal relationships determined by the hypotheses, results as follows:

Fig. 6.1. EMSP model of internationalization with causal relationships

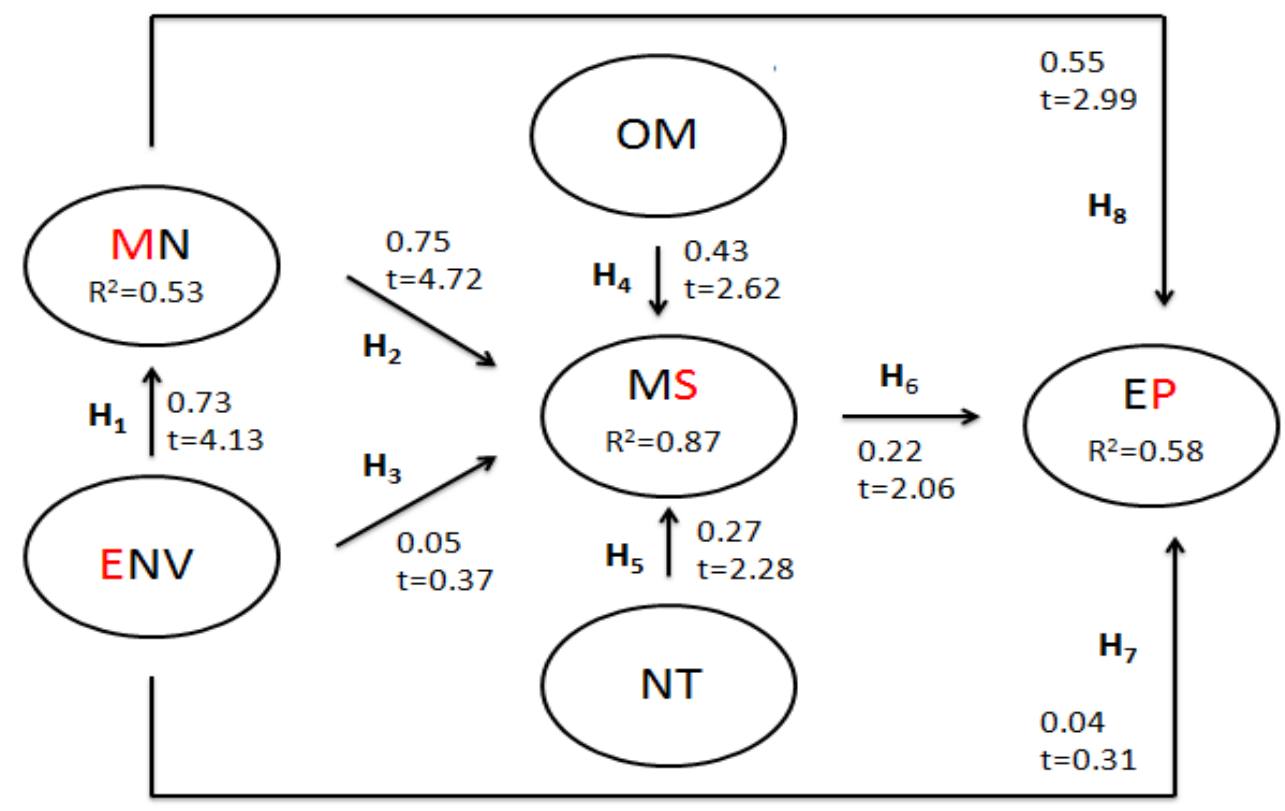

Source: Developed by the author

\subsection{DETERMINATION OF CAUSAL RELATIONSHIPS}

The final stage of the analysis will focus on the way the hypotheses of the EMSP model are tested and how the definitive causal relationship between variables is established (see Table 6.29.)

Table 6.29. Causal relationships of the model

\begin{tabular}{clccl}
\hline Hypotheses & \multicolumn{1}{c}{ Path } & Parameter & t value & \multicolumn{1}{c}{ Result } \\
\hline H1 & ENV $\rightarrow$ MN & 0.73 & 4.13 & Supported \\
H2 & MN $\rightarrow$ MS & 0.75 & 4.72 & Supported \\
H3 & ENV $\rightarrow$ MS & 0.05 & $0.37^{*}$ & Not supported \\
H4 & OM $\rightarrow$ MS & 0.43 & 2.62 & Supported \\
H5 & NT $\rightarrow$ MS & 0.27 & 2.28 & Supported \\
H6 & MS $\rightarrow$ EP & 0.22 & 2.06 & Supported \\
H7 & ENV $\rightarrow$ EP & 0.04 & $0.31^{*}$ & Not supported \\
H8 & MN $\rightarrow$ EP & 0.55 & 2.99 & Supported \\
\hline
\end{tabular}

Source: Developed by the author 
$(*)$ not significant hypothesis (t value<1.96)

Fit of the model: Chi-Squared=1043.1869; Degrees of freedom (DF) $=975 ; p=0.0636862$ $\mathrm{CFI}=0.901 ; \mathrm{MNFI}=0.872 ; \mathrm{RMSEA}=0.051$

As in previous cases, the probability associated to Chi-Squared $(0.0636862)$ is higher than 0.05, CFI and MNFI values are close to the unity and RMSEA is close to zero, confirming the validity of the model.

We can see from the empirical analysis that $\mathrm{H} 1, \mathrm{H} 2, \mathrm{H} 4, \mathrm{H} 5, \mathrm{H} 6$ and $\mathrm{H} 8$ are supported, while H3 and H7 (t-value < 1.96) are not supported. However, a deep analysis is provided below.

\subsubsection{The effect of the environment}

The effect of the environment in our model was determined in three different ways:

1) $\mathrm{H}_{1}$ focused on the relationship between environment and management .

2) $\mathrm{H}_{3}$ analyzed the link between environment and marketing strategy.

3) $\mathrm{H}_{7}$ considered the direct influence on the export performance.

As we can see on Table 6.30 only $\mathrm{H}_{1}$ is accepted, while $\mathrm{H}_{3}$ and $\mathrm{H}_{7}$ are both rejected. The empirical analysis leads us to the conclusion that the relationship between the environment and the intermediate and final variables is not a direct one. Instead, the environment affects the way the firm is managed, and this will have a later effect on other variables (marketing strategy and export performance).

Table 6.30. Causal relationships for the Environment variable

\begin{tabular}{ccccl}
\hline Hypotheses & \multicolumn{1}{c}{ Path } & Parameter & t value & \multicolumn{1}{c}{ Result } \\
\hline H1 & ENV $\rightarrow$ MN & 0.73 & 4.13 & Supported \\
H3 & ENV $\rightarrow$ MS & 0.05 & $0.37^{*}$ & Not supported \\
H7 & ENV $\rightarrow$ EP & 0.04 & $0.31^{*}$ & Not supported \\
\hline
\end{tabular}

Source: Developed by the author 
This result, on the other hand, is totally consistent with the theory developed in previous models - mainly the one proposed by Katsikeas et al (2000)- where the environment was considered as a background variable which had an effect on organizational and managerial factors. These factors would, at the time, play a fundamental role in the determination of the marketing strategy, an intervening variable that finally affected the final export performance of the company (the outcome variable).

Other authors like Leonidou et al (2002), Gemünden (1991), Holzmüller and Kasper (1991), Axinn (1994), da Rocha and Christensen (1994) also took part in the development of the basic theory for similar models where the environment and internal factors affected an intermediate variable (marketing strategy) before a final effect could be appreciated on the export performance of the company. Later on, the reviews by Chugan and Singh (2014) or Chen et al (2016) also contributed to the stream that supports the conclusions from our empirical analysis on the environment construct.

\subsubsection{The effect of management}

The management variable plays a fundamental role in our analysis, as it is confirmed to affect the export performance of the company in two ways:

1) directly $\left(\mathrm{H}_{8}\right.$ is accepted).

2) indirectly $\left(\mathrm{H}_{2}\right.$, which is also proven to be supported, shows the relationship between management and marketing strategy).

Table 6.31. Causal relationships for the Management variable

\begin{tabular}{ccccc}
\hline Hypotheses & Path & Parameter & t value & Result \\
\hline $\mathrm{H} 2$ & $\mathrm{MN} \rightarrow \mathrm{MS}$ & 0.75 & 4.72 & Supported \\
$\mathrm{H} 8$ & $\mathrm{MN} \rightarrow \mathrm{EP}$ & 0.55 & 2.99 & Supported \\
\hline
\end{tabular}

Source: Developed by the author 
There is wide bibliography to support these two hypotheses. On one hand, the research developed in the case of the environment construct can also be applied to the case of management, as managers can be considered an input for the marketing strategy (the intermediate variable that will result in the final performance of the export venture).

On the other hand, authors like Zou and Stan (1998), Sousa et al (2008), Axinn and Thach (1990), Cavusgil and Zou (1994), Singer and Czinkota (1994), Gençturk and Kotabe (2001), Ayan and Percin (2005), and Shamsuddoha and Ali (2006), among others, support the positive relationship between the manager's commitment towards export and the export performance of the company. Managers are supposed to develop the necessary changes to adapt the organization to the new international environment, and this affects every single functional part of it. When a manager is committed to the internationalization of the firm, the effect is clear on the export marketing strategy and on the final performance.

Additionally, other scholars like Drucker (1993), Lages and Montgomery (2005) or Sousa et al (2008) state that knowledge creates sustainable competitive advantage, and this is the key to support the fact that well trained managers, with experience and skills in subjects like marketing and international environments, are fundamental to the development of an appropriate export marketing strategy that will result in a better performance.

\subsubsection{The effect of strategy}

The marketing strategy construct is another key element in the EMSP model of internationalization. As an intermediary variable, it is affected by the management and the environment (only in an indirect way in the second case). But not only that, as the MS construct is also determined by two more variables: Operational marketing and the incorporation of new technologies. 
In this context, the causal relationships for the Marketing Strategy variable were established as follows:

1) $\mathrm{H}_{4}$ (which is accepted) determines the effect of the operational marketing policies on the marketing strategy.

2) $\mathrm{H}_{3}$ (also accepted) analyzes the influence of new technologies in the development of a marketing strategy.

3) $\mathrm{H}_{6}$ (also supported) establishes the link between the long term marketing strategy of the company and the export performance of the company.

Table 6.32. Causal relationships for the Marketing Strategy variable

\begin{tabular}{ccccc}
\hline Hypotheses & \multicolumn{1}{c}{ Path } & Parameter & t value & Result \\
\hline H4 & OM $\rightarrow$ MS & 0.43 & 2.62 & Supported \\
H5 & NT $\rightarrow$ MS & 0.27 & 2.28 & Supported \\
H6 & MS $\rightarrow$ EP & 0.22 & 2.06 & Supported \\
\hline
\end{tabular}

Source: Developed by the author

There is plenty of theory to determine the important contribution of the marketing mix policies to the final marketing strategy of the company (as described on $\mathrm{H}_{4}$ ). In this way, a whole chapter in this thesis (chapter 3) has been devoted to the development of different marketing approaches. Although traditional marketing mix policies are no longer seen as the only marketing tool by many authors - especially in the services sector- , they still play a fundamental role when analyzed from different perspectives. In our case, two new approaches were considered: relationship marketing and the incorporation of the internet to the process.

Empirical research has determined the importance of operational marketing policies through authors like Chugan and Singh (2014), Sousa et al (2008), Cavusgil and Zou (1994), Koh (1991), Katsikeas et al (1996), Shoham (1996), Ayan and Percin (2005), and especially Leonidou et al (2002) which was fundamental to the development of our marketing mix scales. 
Besides, when incorporating relationship marketing processes to the model through the adaptation of marketing linking capabilities theories to our marketing mix scales, more scholars contribute to the support of these causal relationships with papers like those of Murray et al (2009), Zou et al (2003), Morgan et al (2009), Martin and Javalgi (2015), Wilden et al (2015), Vorhies and Harker (2000), Chen et al (2013).

Regarding the influence of new technologies in the development of the marketing strategy (described on $\mathrm{H}_{3}$ ), a positive relationship was found through the statistical analysis of our model. The incorporation of new technologies, and the internet in particular, to the marketing and relational functions of the company contributes to the development of additional capabilities that are incorporated to the export performance through the marketing strategy.

Researchers like Prasad et al (2001), Song et al (2008), Day (1994), Karavdic and Gregory (2005), Asikhia (2009), Mathews et al (2016), Gregory et al (2007), Oh et al (2012), Sinkovics et al (2013) or Bianchi and Mathews (2016) come to confirm the relationship between new technologies and marketing technologies because, according to them, "IT capabilities facilitate internal communication" and that leads to a superior performance of the company.

New technologies also promote the reinforcement of the classical theory from scholars like Kohli and Jaworski (1990), and Narver and Slater (1990), who stated that a firm should be able to get information from the market and spread it throughout the organization. In this context, ITs contribute to boost both processes.

Finally, the link between the long term marketing strategy of the company and the export performance of the company (described on $\mathrm{H}_{6}$ ) has also been proved in our model. This relationship has been widely recognized throughout the literature regarding the determinants of export performance.

Ever since the theoretical models proposed by Cavusgil and Zou (1994), Katsikeas et al (2000), Leonidou et al (2002) or Morgan et al (2004) among others, the marketing strategy construct has been considered as an intermediary variable that is affected by other inputs and, at the same time, is directly linked to the export performance of the 
company (the final dependent variable in the EMSP model of internationalization). Later reviews like the ones from Chugan and Singh (2014) or Chen et al (2016) point in the same direction.

This casual relationship, however, does not present higher loading factors in the case of our study due to the competitive strategy carried out by the companies represented in the sample. If we go back to the descriptive analysis, we can check that only a $35.14 \%$ of the companies linked their competitive strategy to marketing in one way (marketing differentiation) or the other (segmentation differentiation), with a high percentage (14.86\%) not considering any specific strategy at all.

In this context, we can conclude that the development of strategic planning and marketing related strategies are still a pending subject in Spanish SMEs.

\subsection{CONCLUSIONS}

Although the final conclusions of this thesis will be exposed on the following chapter, we can now introduce some of the most remarkable findings from the empirical analysis.

In the first place, the descriptive analysis comes to confirm our impressions regarding the characteristics of the fashion sector in Spain. In this way, most of the companies are SMEs and have developed their exports mainly in close foreign markets (the European Union).

Despite the situation, managers are satisfied with the evolution of exports in general, and consider the performance of their companies regarding the acquisition of management capabilities as quite positive, leaving a margin to the improvement of communication and management abilities.

Regarding the use of new technologies, most of the companies incorporate the Internet to promotion and communication services, but the pending subject is the use 
of new technologies to obtain market information and prospecting (the analysis of big data).

Another aspect to be considered is that a big number of companies do not follow any specific competitive advantage (nearly $15 \%$ ), and only a $35.14 \%$ focus on marketing policies.

Finally, the analysis of hypotheses takes us to the conclusion that the environment affects the model, but only in an indirect way (through the internal factors of the company). Management skills, on the other hand, constitute a fundamental input, as it is related to export performance both directly as through the implementation of the marketing strategy. The overall marketing strategy, at the time, is conditioned by the development of marketing mix. 


\section{CHAPTER 7. CONCLUSIONS AND LIMITATIONS}

\subsection{INTRODUCTION}

The final chapter of this thesis analyzes the conclusions of the investigation from different angles. Firstly, a previous consideration is made in order to introduce the characteristics of the companies considered in the sample and the way they predetermine the model. Secondly, the focus is placed on the theoretical analysis of the approaches behind the EMSP model of internationalization and their application to our study. And finally, the results of the empirical research will provide the causal relationships of the variables considered and the most important conclusions of this thesis.

A second part will focus on the limitations of the model and will introduce a series of remarks that might be useful for future investigations.

\subsection{PREVIOUS CONSIDERATIONS}

The investigation of the causes and determinant factors in the internationalization of companies has been a subject of major interest at all times. This has led to a vast number of theoretical streams and empirical research techniques with different measuring scales and variables. 
However, a common trend in the literature is the consideration of export performance as the final dependent variable. As determined in chapter 2, a considerable part of researchers have dedicated part of their investigations to determine how all kinds of internal and external variables interact in a certain model that pretends to quantify the effect on the efficiency of an exporting company (represented by the aforementioned export performance construct).

In the case of this thesis, the starting point for the research has been the identification of the major theoretical streams (developed on chapters 2 and 3) in order to determine a final model that would offer an explanation to the behaviour of exporting companies in the fashion and design sector in Spain.

Organizations in this industry present certain peculiarities. If we attend to their size, for example, most of them are relatively small, and present in many cases the structure of SMEs or micro companies (it is convenient to remind that $90 \%$ of the companies in the study could be categorised in the first group, and over a $25 \%$ of them in the second).

The fact of presenting a reduced size, makes these companies difficult to access and develop a certain number of capabilities like the incorporation of technology to all their processes, the possibility to innovate or to obtain better financing conditions. In some cases, these activities, which are fundamental for the development of the company, are outsourced through technological institutes and other similar organizations which are promoted by the same industry.

However, presenting a reduced structure (over $75 \%$ of them employ less than 50 operators and over $40 \%$ less than 20 ), does not always result in negative implications. Smaller companies are more flexible and adapt to changes much more easily. These characteristics are taking SMEs to consider the option to carry out marketing policies as a way to develop internal capabilities and improve their efficiency. Marketing, contrary to other inputs like technology or innovation, is difficult to outsource and has to be considered from an internal point of view. Getting to know what the customer really needs, and implementing the necessary changes to adapt the structure of the 
company to new processes, can be seen as a kind of innovation, and is easier to do in SMEs.

So, going back to our theoretical model, due to the huge number of approaches that could be taken into consideration, a decision had to be made, and the final result was playing the focus on marketing, because of the idiosyncrasy of the companies considered in the sample.

Taking marketing as a reference meant that additional research had to be provided in order to define the new approaches behind this field of knowledge. That was made on chapter 3, taking us to the conclusions that marketing mix is still a very important tool to determine the export marketing strategy, but not the only one. If we want to develop an effective operational marketing strategy, traditional approaches should be combined with other visions like relational marketing and the incorporation of new technologies to the marketing process.

\subsection{THE THEORETICAL BACKGROUND BEHIND THE EMSP MODEL}

As shown on chapter 1 , the theory behind the determinant factors of the performance in an exporting company implies the consideration of different disciplines which are interconnected: internationalization, management, strategy and marketing.

\subsubsection{Internationalization approaches}

Regarding internationalization, two different stages can be noticed: a first conception of the internationalization process from the macroeconomic point of view (research was based on countries and multinational companies), and a second one which places the centre of attention on SMEs and the factors that influence their internationalization processes. 
As the real interest of this thesis is focused on the study of SMEs and not so much on macroeconomic issues, we will concentrate on the approaches affecting the characteristics of the companies in our sample.

One of the biggest inputs for this thesis came from the study of the determinants of export performance, which is still a subject of major interest at present and has been analyzed for over thirty years. The most important contributions come from the literature reviews carried out by Aaby and Slater (1989), Zou And Stan (1998), Leonidou et al (2002), Sousa et al (2008), Chugan and Singh (2014), and Chen et al (2016), among others.

The conclusion is that export performance is affected by both internal and external factors. External factors come from the environment and are difficult to control by the company and its managers. On the contrary, internal factors are controlled and developed within the company and have a direct effect on the efficiency of the company. Internal factors are related to one of the most influential theories, the Resource Based View (RBV) and the later Dynamic Capabilities (DC) approach, which have contributed in great manner to the analysis and definition of these variables.

A detailed list of internal variables is displayed on table 2.3 from chapter 2 , but they can be summarized in the following categories: firm characteristics (size, age, experience ...), management characteristics (experience, orientation towards exports ....) and export marketing strategy (strategic and operational).

However, the internationalization processes of the company and the definition of variables can be considered from a diverse number of theoretical approaches. A description of the ones which have an influence on our model, are detailed below.

A) Gradualist models

Gradualist models, which are in fact an extension of the product life cycle by Vernon, were developed by authors like Johanson and Vahlne, from the Nordic school, and can 
be addressed in two ways: the Uppsala model (U-Model), and the Innovation model (IModel).

In fact, both models share the belief that internationalization processes start by entering close markets and gradually expand to more distant countries, once the company has developed the necessary knowledge through experience. Internationalization is a gradual process which is related to knowledge and experience in the case of the Uppsala model or to innovation in the case of the I-Model.

In our case, gradualist models (contrary to the Born Global theory) reflect the reality of most Spanish firms in the sector we are analyzing. Fashion is not a product that is ready to consume in the same way in every place. On the contrary, it must be adapted in most cases. That means that companies should be able to know the reality of every foreign market before they make important decisions. Consequently, entering new markets in the case of this sector tends to be a gradualist process as well. Companies start by exporting their products to close countries where the needs and likes of consumers are quite similar, and only after a while, are they ready to concentrate on other export ventures.

Chapter 6 describes in full detail the characteristics of the selected sample. Subjects like geographical distribution, activity sector or export intensity are considered, and will help the reader to have an approximate idea of the idiosyncrasy of the Spanish companies in the fashion sector.

B) Resource Based View (RBV) and Dynamic Capabilities (DC)

As already specified, these two approaches are fundamental to the definition of our model. The theory behind them was supported by authors like Barney (1991), Prahalad and Hamel (1990), Nelson (1991), Penrose (1959), Teece, Pisano and Shuen (1997) or Wernerfelt (1984). The RBV estates that companies possess "a unique combination of valuable tangible and intangible resources, and it is precisely these resources and capabilities that determine the company's competitive advantage" and, as a final result, its performance. 
When extended to dynamic markets, RBV gives way to a new conception, known as Dynamic Capabilities (DC). Resources turn into capabilities in order to explain the way firms develop competitive advantage in situations of quick and unpredictable change.

The implication for our model is the definition of the internal factors which are supposed to affect the final export performance of the company. In this context, two constructs, associated to intangible capabilities, are taken into consideration: the characteristics of Management (MN) and the Marketing Strategy (MS), which are presented in detail on chapter 5 .

Firm characteristics, which can also be considered as capabilities, are introduced in the questionnaire for the empirical research, but are not included in the final model, as they have played an important role within the descriptive analysis of the sample and have provided useful information about the way these companies behave (see chapter 6 for detailed information).

C) Other theories

It is difficult to establish a separating line when analyzing different disciplines, as they can be influenced by the same or very similar theories.

This is the case of Relational (Network) approaches that stand for the creation of network relations that will have a positive result on the final performance of the company. Companies start by developing these networks in domestic markets and will be replicated in foreign markets later on. However, relational theories present a very important influence in our model when considered from the marketing point of view.

International entrepreneurship and Knowledge Based View perspectives present a similar case, as they can be applied both to the fields of internationalization and management. These streams place entrepreneurship in the centre of the internationalization strategy, as the human factor is determinant to the final performance of the company and an effective manager must be able to detect new opportunities in foreign countries. 
The same happens with contingency theory approaches and other gradualist models like the organization learning theory. They have an influence in our model through the determinant role of the management construct which will be analyzed hereunder.

\subsubsection{Management approaches}

As the results of the empirical analysis have come to confirm, the role of the management construct is fundamental to our model.

Management has been approached from many different perspectives through the years and the theory has evolved to integrate individual characteristics based on knowledge and the development of human resources in empirical models.

In this context, the RBV determines that the competitive advantage of exporting companies come from the development of internal capabilities, with knowledge capabilities playing a fundamental role. This approach resulted in other theories like the KBV (Knowledge based view) and international entrepreneurship models, which can be considered as the basic background for the development of the management construct in our EMSP model of internationalization.

The literature on the subject is characterized for a change in the general perspective of the RBV, moving from "firm capabilities" to individual levels. Knowledge, and not information, is the basis for innovation. Besides, cooperation with partners in foreign markets makes exporting companies more efficient, and connects us to the field of relational marketing techniques.

Finally, a common trend to develop human resources is appreciated in the evolution of theoretical research. The traditional models with a clear division of labour and the establishment of rigid relationships among workers and managers have led to a new concept of management where relations are considered horizontally and not vertically, and the motivational factors is determinant to get a higher productivity from the human factor that will finally revert in the performance of the company. 
Approaches like the Contingency theory determine that different strategies may be successful in similar organizations because, when managers make decisions they consider the situation in a particular moment, and, consequently, there is not one best way to achieve high levels of performance. This is consistent with the dynamic capabilities approach, which introduced the constant changes in the environment as an influential factor in the determination of the company's tangible and intangible resources and capabilities.

In our particular case, the descriptive analyses of the management construct takes us to the conclusion that managers from exporting companies in the fashion sector in Spain are generally well trained, with skills in marketing, IT and languages. They also provide a general overview of the company and are orientated towards exports. On the other hand, there is still a margin to improve the ability to manage teams and promote communication within the company, although the general perception on these subjects is above 4 in a seven point scale.

\subsubsection{Strategy approaches}

The strategy construct is analyzed from two different angles in this thesis: the general competitive strategy of the company, and the export marketing strategy.

The first one is considered on the descriptive analysis and is crucial to determine the importance of marketing strategies within the general competitive strategy of the company. Contrary to the marketing strategy (MS) construct, it is not considered in the final empirical model because the central point of this investigation is determining the effect of marketing strategies on the final export performance of the company, and other sources of competitive advantage are left aside.

The theory behind the determination of the competitive strategy scales in the EMSP model of internationally comes basically from Porter $(1980,1985)$ and all the subsequent developments. 
Porter determines there are three generic strategies for a company: overall cost leadership, differentiation by providing superior quality or service, and focusing on certain specific market niches. This has been the basis for the development of complementary scales, leading us to the final one considered in this thesis, as specified on chapter 5.

The final conclusions obtained from the analysis of our model is that only a $25.14 \%$ of the companies relate their competitive strategy to marketing in one way (marketing differentiation) or the other (segmentation differentiation). An additional $13.51 \%$ of the companies develop an innovation differentiation strategy, a $36.49 \%$ of them have introduced a differentiation policy through the development of new products/services, and a remaining $14.86 \%$ of companies do not consider a specific strategy.

Porter also introduced the concept of value chain, which is still considered as the basis of strategic management thought. The value chain is the way to analyze all the activities carried out by the company, as the way they interact is very important to determine its competitive advantage. Value activities will create added value for customers and will result in a better performance. Consequently, by controlling the whole value chain, the company will be able to improve its competitive advantage in the market.

Finally, a very important part of Porter's theory is how the competitive position of the firm can be affected by the five forces that influence the market: "industry rivalry (existing competition in the industry), bargaining power of buyers, bargaining power of suppliers, threat of new entrants and threat of substitutes"

With the study of these forces, Porter introduces the effect of the environment on the general strategy of the company. This is a concept which definitely has an effect in our model and is considered from this and other perspectives. The way a company detects the peculiarities of foreign markets and adapts the strategy to them, is a key factor to the evolution of the export performance of the company.

In our case, the analysis of the environment construct is considered from two perspectives: the way the company is able to establish high margins in foreign 
countries because of lower competition levels, and the way the company is able to detect and adapt to the peculiarities of these external markets (see construct details on chapters 5 and 6$)$.

\subsubsection{Marketing approaches}

The development of the Marketing Strategy (MS) variable considers there are two different ways to incorporate marketing to the model, which is by separating strategic components from operational ones.

Operational marketing mix policies will determine the long term marketing strategy of the company, that will also be affected by the incorporation of new technologies to the process.

There are plenty of theoretical developments related to the evolution of marketing research. The most important for us, without any kind of doubt, is the transition from product to services based marketing policies.

The traditional conception of marketing (Drucker 1954; Levitt 1960, McKitterick 1957, McCarthy 1960; Kotler 1967), kept the attention on customers and the way to satisfy their needs, introducing the marketing mix concept (product, price, promotion and place) which is still active today.

However, that vision of marketing was considered as too simplistic by other researchers. They thought that new approaches would provide solutions to the changing environment and would analyze the problem from a new "services" perspective. Marketing mix policies should, therefore, be complemented with other instruments depending on the new line of thought to be considered.

The most important theoretical approaches that had an effect on the construction of our model are considered down below. 
A) Market Orientation (MO)

"A business that increases its market orientation will improve its market performance" That is one of the postulates introduced by authors like Slater and Narver (1990) or Jaworski and Kohli (1993).

According to Narver and Slater, a proper market orientation strategy develops the actions to obtain a higher value for customers and, consequently, a superior performance in time, which is the source for "sustainable competitive advantage".

It is important to analyze the needs of our customers and to know the strengths and weaknesses of our competitors in order to create that additional value. There is a need to know the market, to obtain information and disseminate it through the organization.

Our model pretends to evaluate the way companies are market orientated through the introduction of certain items in the marketing strategy construct, which refers to the strategic component of the marketing policy. As a result, Spanish companies tend to develop an appropriate knowledge of customer and competitors and should improve their ability to segment and target markets or the development of market research programs, along with the planning of marketing activities.

B) Relationship Marketing (RM) and Network Analysis.

The Market Orientation theory led to the development of Relationship Marketing techniques, which are fundamental to our empirical model.

The literature (Berry, 1983; Sheth and Parvatiyar, 2000; Gummesson, 1994a, 1994b, 2002; Payne and Frow, 2005) states that communication should be in the centre of the marketing strategy, and long term relationships between firms and customers should be built. 
By creating long term relationships with customers, which are based on questions like trust and commitment, consumers will be identified with a company's philosophy and will buy from them and not from other competitors.

Something very similar happens in the Network approach, where the focus is placed on the construction of relationship networks with customers, providers or agents from the selected distribution channels.

As already specified in chapters 5 and 6 , the RM approach plays an important role in the determination of scales, with the introduction of items such in the MS construct as in the OM construct (mainly in product, promotion and distribution policies). Items like the development of CSR programs or the relationship with channel members constitute a clear example.

On the other hand, the managers from the companies in the sample, are conscious of the importance of such policies, showing high punctuations for these items.

C) RVB and the incorporation of New Technologies

There is not much more to say about the importance of the RVB and the DC approaches along this investigation. These two approaches, which were already considered from the internationalization point of view, are also present when determining the theoretical background behind the marketing strategy construct.

When associating the RVB to marketing, relational assets and intellectual marketbased assets are considered as fundamental to increase the performance of exporting companies. But one more intangible should be considered: the incorporation of new technologies to the operational marketing strategy.

Although the use of the internet has been developed in the literature as an independent discipline (see chapter 3 for details), we have considered it from the dynamic capabilities point of view. In this context, scales were introduced to determine the extent to which marketing activities are affected by new technologies. 
The conclusions are that new technologies are incorporated to promotion activities and provision of information, but not so much to promote communication in management operations or to gather information about the market. Consequently, there is still a margin for the development of online marketing policies.

D) Marketing 4.0

The Marketing 4.0 approach introduced by Kotler is a consequence of relational theories and present many points in common. According to Kotler, marketing has evolved from a product-based perspective (1.0) to a customer-oriented era (2.0), a values-driven era (3.0), and a final stage based on big data and ITs (4.0). In a world of great confusion, consumers look for companies which develop social, economic and environmental programs with certain vision and values. Consequently, CSR programs take a special importance.

The implications in the model are basically the same as those for the relational marketing approach, as the development of CSR programs was considered from the strategic marketing point of view.

\subsection{THE EMPIRICAL RESEARCH}

Once the theoretical approaches were analyzed and the variables affecting the export performance of the companies in our case were defined (go to chapter 4 for full details), could we finally determine the final model.

The EMSP model of internationalization is characterized by the combination of different internal (MN, OM, NT, MS) and external variables (ENV) that are supposed to have an effect on the final dependent variable which is the export performance of the company (EP). 
The environment is the only external variable that cannot be controlled by the company, but has an effect on it. The model pretends to show the way it can determine management characteristics, the marketing strategy and the export performance of the company.

Management, at the time, can be influenced by the environment and is supposed to have an effect on the marketing strategy of the company and the final export performance.

And finally, the marketing strategy is a central variable which is conditioned by a series of factors from the marketing side (operating marketing strategies and the use of new technologies), as well as the environment and management characteristics.

Due to the importance of the marketing discipline along this thesis, an important part of the questionnaire (see chapter 5 for complete details) is dedicated to the questions referred to scales analyzing operational marketing strategies (which are based on the application of marketing mix policies), strategic marketing policies, and the way new technologies are incorporated to the marketing function.

The consequences were that the constructs for the product, price, promotion and distribution (place) policies could be analyzed separately and integrated in the final model through an item parcelling process which would generate a new construct known as OM (operational marketing strategy). The process could be carried out because all these four variables presented a similar behaviour as they are the constituents of the classical way to understand marketing.

The OM variable, however, will not finally act on its own, as operational marketing policies are supposed to have an effect on the long term marketing strategy of the company, which is also conditioned by the use of new technologies.

The conclusions from a first confirmatory factor analysis were that 14 items out of a total of 34 were discarded, resulting in the final OM variable that would integrate the marketing mix policy of the companies in the sample. The resulting construct showed that not all policies contributed to the model in the same way, as 3 items out of 8 were 
removed from the product policy variable, 5 out of 8 from the price policy, 6 out of 9 from the distribution policy and all 9 items from the promotion policy remained.

As a consequence, the OM construct was finally integrated by 20 items, corresponding to: promotion (9 items), product (5), price (3) and place (3). For full details of the process, go to chapter 6 .

A second confirmatory analysis showed that there was no need to remove any more items from any of the variables integrating the model.

The final conclusions regarding the causal relationships that define the role of each variable in the model are enclosed hereafter.

\subsubsection{The effect of the environment}

The empirical analysis shows that only $H_{1}$ is accepted, while $H_{3}$ and $H_{7}$ are both rejected. That means that the environment does not have a direct effect on the marketing strategy or the final export performance of the company.

On the contrary, the environment affects management characteristics, and these are supposed to have a later effect on the marketing strategy and the export performance.

This is quite logical, as the conditions of the environment in foreign countries will have to be interpreted by managers in order to adapt the company to the new circumstances. The characteristics of these markets will also determine the abilities and skills of the management team. These are all facts analyzed in the papers by Leonidou et al (2002), Gemünden (1991), Holzmüller and Kasper (1991), Axinn (1994), da Rocha and Christensen (1994), Katsikeas et al (2000), Chugan and Singh (2014) or Chen et al (2016).

In our case, the management construct was composed of items like experience in international markets, export orientation, language skills or marketing abilities, which are highly determined by the markets where the company is operating, that is the environment. 
The way managers adapt their skills and the overall and marketing strategies to the conditions of these markets, will result in a higher or lower export performance.

\subsubsection{The effect of management}

Such $\mathrm{H}_{8}$ as $\mathrm{H}_{2}$ are accepted, which implies that management characteristics affect the export performance of the company both directly and indirectly (management determines the marketing strategy of the company, and this has an effect on the export performance).

A key element in the internationalization process of any company is the degree of commitment towards exports, because it is proven to have a clear effect on the export marketing strategy and on the firm's performance, as stated by scholar like Zou and Stan (1998), Sousa et al (2008), Axinn and Thach (1990), Cavusgil and Zou (1994), Singer and Czinkota (1994), Gençturk and Kotabe (2001), Ayan and Percin (2005), and Shamsuddoha and Ali (2006).

Additionally, RBV and KBV are in total accordance with these results as they consider knowledge as one of the most important intangible capabilities within a company and a way to create "sustainable competitive advantage". Well trained managers are seen as a source of innovation and a way to adapt the company to the changes in the environment, with the subsequent positive effect on the efficiency of the company.

\subsubsection{The effect of strategy}

Apart from management characteristics, there are other two variables that have an effect on the Marketing Strategy (MS) of the company: Operational Marketing Strategy (OM) and New Technologies (NT). Besides, the role of MS as an intermediary variable determines that it is also related in a positive way to export performance. In this way, $\mathrm{H}_{4}, \mathrm{H}_{5}$ and $\mathrm{H}_{6}$ are supported. 
Traditional marketing mix policies are the basis of the OM construct (Chugan and Singh, 2014; Sousa et al, 2008; Cavusgil and Zou, 1994; Koh, 1991; Katsikeas et al, 1996; Shoham, 1996; Ayan and Percin, 2005; Leonidou et al, 2002), and still a very important marketing tool, although not the only one. That is the reason why additional approaches in the form of relationship marketing and new technologies were considered.

One of the conclusions from our investigation is that promotion and product policies contribute to the model in a bigger way than price or place policies. The items in the scale where the focus was placed on particular effects of pricing or distribution were finally discarded and special attention was paid to the establishment of high margins and high prices, the support to distribution channels or the consideration of the Internet as a new distribution and sales channel, something in accordance with the new approaches.

Relationship management (marketing linking constructs) and new technologies are also considered by the RVB as a way to determine a competitive advantage. In our model, the incorporation of new technologies to the marketing strategy contributes to the development of additional capabilities.

The effect of the marketing strategy of the company on the export performance has also been proved in our model, although it depends, in great manner, on the competitive strategy adopted by the company. Only a $35 \%$ of the companies in our sample link their final strategy to marketing, with nearly a $15 \%$ which do not take any strategy into consideration.

As a final conclusion, these figures reflect that there is still a margin for companies to increase the contribution of marketing to their final strategy. The planification of international marketing activities or the development of market research programs, were items that could still improve their values in the proposed scales. 


\subsection{LIMITATIONS AND FUTURE RESEARCH}

According to authors like Sousa et al (2008), Leonidou et al (2010), and Chugan and Singh (2014), there has been an important change in the characteristics of the investigations on the determinants of the export performance. As a consequence, the latest research studies show that:

- The number of studies from other countries apart from the USA have increased. Researchers from areas like Europe or Asia are providing new evidence based on the empirical research carried out in their countries.

- The size of the company is also an important issue, and consequently, most of the studies have concentrated on SMEs.

- Marketing approaches are playing an important role, as market orientation is considered as a key determinant of export performance and a way to adapt the company to the external environment, which also affects its performance.

- There is still a need to develop theoretical models as most of the empirical research considers not only one, but different approaches, and there is not a common perception of the discipline. Plenty of scales and measuring variables are considered depending on every particular case.

- The way the investigation is carried out has changed: samples are now bigger, the use of control and moderating variables has increased, and the level of statistical sophistication has improved.

As determined by the literature, the analysis of the factors that affect the performance of exporting companies is a subject of increasing interest in areas like Europe and Asia. In this context, the author would like to contribute his grain of sand by introducing the EMSP model to explain the behaviour of the exporting companies in the fashion sector in Spain. 
To do so, different theoretical approaches had to be considered and scales adapted to the characteristics of this sector, composed in its vast majority by small and medium enterprises, something which is in line with the trends in the academic world.

It is difficult to analyze the problem from all sides, so decisions had to be made, and finally, due to the characteristics of the sector, the best option was to consider the way new marketing approaches affected the behaviour of these companies. As already stated, small companies may outsource some specific processes, but not the marketing strategy, as it is a fundamental way to adapt the company to the changing environment.

Up to now, the construction of the model is quite in accordance with the evolution of the literature, but the investigation also presents a certain number of limitations.

The first one is the difficulty to compare these results with those from other investigations. As mentioned before, the big amount of models and measuring variables makes it difficult to find meeting points and the lack of resources makes it difficult to develop the investigation in more than one country. It would have been interesting to find if conclusions from the same sector in different markets were similar. In fact, not many papers have gone in this direction.

A second inconvenience was the size of the sample, which was conditioned by the size of the sector of study. When the Universe of a determined sector of companies is limited, finding an appropriate number of companies answering a questionnaire is not always easy, and plenty of personal contacts had to be made in order to get the necessary information.

Taking all these factors into consideration, the author would like to introduce some remarks for future investigations.

As already noted, there is a lack of studies comparing the behaviour of exporting companies in different markets. Germany, for instance, has a similar structure to Spain in many ways: their economy is based on exports (although their exports to GDP ratio is higher, as determined on the introduction chapter) and most of the sectors are composed of SMEs, with important regional clusters. An investigation comparing the 
behaviour of exporting companies in both economies would be of interest and important conclusions might be obtained.

Another question to be considered is the use of moderating variables, as moderators represent a way to validate casual relationships and to offer an explanation for inconsistent results. A determined relationship, for example, could be significant in a context and non-significant in another one depending on the considered moderating variable (Chen et al, 2013). This has not been a subject of major research interest in the last decades and, in fact, only three variables have been studied as moderators: firm size, international experience and environment turbulence.

Finally, the fact of considering marketing as the main determinant of competitive advantage, has taken us to discard other factors, like those related to the development of new technology and the innovation of all kind of processes in the company, which could also be considered as inputs for future investigations. 


\section{BIBLIOGRAPHY}

Aaby, N. E., \& Slater, S. F. (1989). Management influences on export performance: a review of the empirical literature 1978-1988. International marketing review, 6(4).

Achrol, R. S. (1997). Changes in the theory of interorganizational relations in marketing: Toward a network paradigm. Journal of the academy of marketing science, 25(1), 56-71.

Achrol, R. S., \& Kotler, P. (1999). Marketing in the network economy. The Journal of Marketing, 146-163.

Akyol, A., \& Akehurst, G. (2003). An investigation of export performance variations related to corporate export market orientation. European Business Review, 15(1), 5-19.

Alguezaui, S., \& Filieri, R. (2014). A knowledge-based view of the extending enterprise for enhancing a collaborative innovation advantage. International Journal of Agile Systems and Management, 7(2), 116-131.

Ali, W., Frynas, J. G., \& Mahmood, Z. (2017). Determinants of corporate social responsibility (CSR) disclosure in developed and developing countries: a literature review. Corporate Social Responsibility and Environmental Management.

Alonso Rodríguez, J. A., \& Donoso Donoso, V. (2000). Modelización del comportamiento de la empresa exportadora española. Información Comercial Española, (788), 35-58. 
Alvarez, R. (2004). Sources of export success in small-and medium-sized enterprises: the impact of public programs. International Business Review, 13(3), 383-400.

Alvarez, S. A., \& Busenitz, L. W. (2001). The entrepreneurship of resource-based theory. Journal of management, 27(6), 755-775.

Andersen, O. (1993). On the internationalization process of firms: A critical analysis. Journal of international business studies, 24(2), 209-231.

Anderson, J. C., \& Gerbing, D. W. (1988). Structural equation modeling in practice: A review and recommended two-step approach. Psychological bulletin, 103(3), 411.

Andersson, S. (2000). The internationalization of the firm from an entrepreneurial perspective. International Studies of Management \& Organization, 30(1), 63-92.

Ansoff, H. I. (1965). Corporate strategy: An analytic approach to business policy for growth and expansion. McGraw-Hill Companies.

Antoncic, B., \& Hisrich, R. D. (2001). An integrative conceptual model. Journal of Euromarketing, 9(2), 17-35.

Antonietti, R., \& Marzucchi, A. (2014). Green tangible investment strategies and export performance: A firm-level investigation. Ecological Economics, 108, 150-161.

Anwar, S., \& Nguyen, L. P. (2011). Foreign direct investment and export spillovers: Evidence from Vietnam. International Business Review, 20(2), 177-193.

ASIKHIA, O. U. (2009). The mediating role of e-marketing on the consequences of market orientation in Nigerian firms. International Journal of Business and Information, 4(2).

Asseraf, Y., \& Shoham, A. (2014). 3 The impact of strategic orientations on export marketing strategy: new classification and typology. Research Handbook on Export Marketing, 60. 
Atilgan, E., Aksoy, S., \& Akinci, S. (2005). Determinants of the brand equity: A verification approach in the beverage industry in Turkey. Marketing intelligence \& planning, 23(3), 237-248.

Aulakh, P. S., \& Johansson, J. K. (1997). Global Marketing: Foreign Entry, Local Marketing, and Global Management.

Axinn, C. N., \& Thach, S. V. (1990). Linking export performance to the marketing practices of machine tool exporters. Advances in International Marketing,4(1), 113133.

Axinn, C. N. (1994). Introduction: international perspectives on export marketing. Advances in international marketing, 6.

Ayal, I., \& Zif, J. (1979). Market expansion strategies in multinational marketing. The Journal of Marketing, 84-94.

Ayan, T. Y., \& Percin, S. (2005). A Structural Analysis of the Determinants of Export Performance: Evidence from Turkey. Innovative Marketing, 1(2), 106-118.

Bagozzi, R. P. (1980). Causal models in marketing. Wiley.

Bagozzi, R. P., \& Yi, Y. (1988). On the evaluation of structural equation models. Journal of the academy of marketing science, 16(1), 74-94.

Bagozzi, R. P., \& Edwards, J. R. (1998). A general approach for representing constructs in organizational research. Organizational research methods, 1(1), 45-87.

Balabanis, G. I., \& Katsikea, E. S. (2003). Being an entrepreneurial exporter: does it pay?. International Business Review, 12(2), 233-252.

Baldauf, A., Cravens, D. W., \& Wagner, U. (2000). Examining determinants of export performance in small open economies. Journal of World Business, 35(1), 61-79. 
Balodi, K. (2014). Strategic orientation and organizational forms: an integrative framework. European Business Review, 26(2), 188-203.

Bandalos, D. L., \& Finney, S. J. (2001). Item parceling issues in structural equation modeling. New developments and techniques in structural equation modeling, 269, V296.

Barney, J. (1991). Firm resources and sustained competitive advantage.Journal of management, 17(1), 99-120.

Barney, J. B. (2000). Firm resources and sustained competitive advantage. Advances in Strategic Management, 17(1), 203-227.

Barney, J., Wright, M., \& Ketchen, D. J. (2001). The resource-based view of the firm: Ten years after 1991. Journal of management, 27(6), 625-641.

Barney, J. B., \& Hesterly, W. (2015). Strategic management and competitive advantage concepts and cases. Pearson.

Beise-Zee, R., \& Rammer, C. (2006). Local user-producer interaction in innovation and export performance of firms. Small Business Economics, 27(2-3), 207-222.

Bentler, P. M. (1995). EQS structural equations program manual. Multivariate software.

Berry, L. L. (1983). Relationship marketing. American Marketing Association.

Berry, L. L. (2000). Cultivating service brand equity. Journal of the Academy of marketing Science, 28(1), 128-137.

Bertrand, O. (2011). What goes around, comes around: Effects of offshore outsourcing on the export performance of firms. Journal of International Business Studies, 42(2), 334-344.

Bianchi, C., \& Mathews, S. (2016). Internet marketing and export market growth in Chile. Journal of Business Research, 69(2), 426-434. 
Bilkey, W. J., \& Tesar, G. (1977). The export behavior of smaller-sized Wisconsin manufacturing firms. Journal of international business studies, 8(1), 93-98.

Bilkey, W. J. (1978). An attempted integration of the literature on the export behavior of firms. journal of international Business studies, 9(1), 33-46.

Birkinshaw, J., Morrison, A., \& Hulland, J. (1995). Structural and competitive determinants of a global integration strategy. Strategic Management Journal,16(8), 637-655.

Boehe, D. M., \& Cruz, L. B. (2010). Corporate social responsibility, product differentiation strategy and export performance. Journal of Business ethics, 91(2), 325346.

Bonner, K., \& McGuinness, S. (2007). Assessing the impact of marketing assistance on the export performance of Northern Ireland SMEs. International Review of Applied Economics, 21(3), 361-379.

Boso, N., Story, V. M., Cadogan, J. W., Micevski, M., \& Kadic-Maglajlic, S. (2013). Firm innovativeness and export performance: Environmental, networking, and structural contingencies. Journal of Marketing Research, 21(4), 62-87.

Bou-Llusar, J. C., Escrig-Tena, A. B., Roca-Puig, V., \& Beltrán-Martín, I. (2009). An empirical assessment of the EFQM Excellence Model: Evaluation as a TQM framework relative to the MBNQA Model. Journal of Operations Management, 27(1), 1-22.

Boulding, W., \& Christen, M. (2001). Sustainable Pioneering Advantage?: Profit Implications of the Entry Timing Decision. WORKING PAPERS-INSEAD R AND D.

Bouncken, R. B., Schuessler, F., \& Kraus, S. (2015). The Theoretical Embedding Of Born Globals: Challenging Existing Internationalization Theories. The International Business \& Economics Research Journal (Online), 14(1), 39. 
Bowman, D., \& Gatignon, H. (1995). Determinants of competitor response time to a new product introduction. Journal of Marketing Research, 42-53.

Bowman, C., \& Ambrosini, V. (2003). How the resource-based and the dynamic capability views of the firm inform corporate-level strategy. British journal of management, 14(4), 289-303.

Brakus, J. J., Schmitt, B. H., \& Zarantonello, L. (2009). Brand experience: what is it? How is it measured? Does it affect loyalty?. Journal of marketing,73(3), 52-68.

Brouthers, L. E., \& Xu, K. (2002). Product stereotypes, strategy and performance satisfaction: The case of Chinese exporters. Journal of International Business Studies, 33(4), 657-677.

Brouthers, L. E., Nakos, G., Hadjimarcou, J., \& Brouthers, K. D. (2009). Key factors for successful export performance for small firms. Journal of International Marketing, 17(3), 21-38.

Brown, T. E., Davidsson, P., \& Wiklund, J. (2001). An operationalization of Stevenson's conceptualization of entrepreneurship as opportunity-based firm behavior. Strategic management journal, 22(10), 953-968.

Buckley, P. J. (1989). The limits of explanation: Testing the internalization theory of the multinationial enterprise. Journal of international business studies,19(2), 181-193.

Buckley, P. J. y Brooke, MZ (1992). International Business Studies. An Overview". Blackwell, Oxford.

Buckley, P. J., \& Casson, M. C. (1998). Analyzing foreign market entry strategies: Extending the internalization approach. Journal of international business studies, 29(3), 539-561. 
Cadogan, J. W., Diamantopoulos, A., \& Siguaw, J. A. (2002a). Export market-oriented activities: Their antecedents and performance consequences. Journal of International Business Studies, 33(3), 615-626.

Cadogan, J. W., Sundqvist, S., Salminen, R. T., \& Puumalainen, K. (2002b). Marketoriented behavior: Comparing service with product exporters. European journal of marketing, 36(9/10), 1076-1102.

Cadogan, J. W., Cui, C. C., \& Kwok Yeung Li, E. (2003). Export market-oriented behavior and export performance: The moderating roles of competitive intensity and technological turbulence. International marketing review, 20(5), 493-513.

Cadogan, J. W., Sundqvist, S., Salminen, R. T., \& Puumalainen, K. (2005). Export marketing, interfunctional interactions, and performance consequences. Journal of the Academy of Marketing Science, 33(4), 520-535.

Cadogan, J. W., Sundqvist, S., Puumalainen, K., \& Salminen, R. T. (2012). Strategic flexibilities and export performance: The moderating roles of export market-oriented behavior and the export environment. European Journal of Marketing, 46(10), 14181452.

Camisón Zornoza, C., Garrigós Simón, F. J., \& Palacios Marqués, D. (2007). Estrategias competitivas y desempeño empresarial: estudio comparativo de los modelos de Robinson \& Pearce y Miles \& Snow en el sector hotelero español. Investigaciones Europeas de dirección y economía de la empresa, 13(3).

Campbell-Hunt, C. (2000). What have we learned about generic competitive strategy? A meta-analysis. Strategic Management Journal, 21(2), 127-154.

Carneiro, J., Rocha, A. D., \& Silva, J. F. D. (2011). Determinants of export performance: a study of large Brazilian manufacturing firms. BAR-Brazilian Administration Review, 8(2), 107-132. 
Carroll, A. B. (1991). The pyramid of corporate social responsibility: Toward the moral management of organizational stakeholders. Business horizons, 34(4), 39-48.

Caves, R. E. (1971). International corporations: The industrial economics of foreign investment. Economica, 38(149), 1-27.

Caves, R. E. (1982). Multinational enterprise and economic analysis. Cambridge university press.

Cavusgil, S. T. (1980). On the internationalization process of firms. European research, 8(6), 273-281.

Cavusgil, S. T., \& Zou, S. (1994). Marketing strategy-performance relationship: an investigation of the empirical link in export market ventures. The Journal of Marketing, $1-21$.

Chad, P. (2014). Organizational change within charities: improved performance via introduction of market orientation and other strategic orientations. International Review on Public and Nonprofit Marketing, 11(1), 89-113.

Chen, Y. C., Li, P. C., \& Arnold, T. J. (2013). Effects of collaborative communication on the development of market-relating capabilities and relational performance metrics in industrial markets. Industrial Marketing Management, 42(8), 1181-1191.

Chen, Y., Tang, G., Jin, J., Li, J., \& Paillé, P. (2015). Linking market orientation and environmental performance: The influence of environmental strategy, employee's environmental involvement, and environmental product quality.Journal of Business Ethics, 127(2), 479-500.

Chen, J., Chen, J., Sousa, C. M., Sousa, C. M., He, X., \& He, X. (2016). The determinants of export performance: a review of the literature 2006-2014. International Marketing Review, 33(5), 626-670. 
Chetty, S. K., \& Hamilton, R. T. (1993). Firm-level determinants of export performance: a meta-analysis. International Marketing Review, 10(3).

Chetty, S. K. (1999). Dimensions of internationalisation of manufacturing firms in the apparel industry. European Journal of Marketing, 33(1/2), 121-142.

Chugan, P. K. (1998). Factors affecting the inter-firm variations in export performance: a case of Indian autoparts industry. The Indian Journal of Economics, 79(312), 45-64.

Chugan, P. K., \& Singh, S. (2014). Taxonomy for firm-level determinants of export performance. Universal Journal of Industrial and Business Management,2(1), 6-12.

Conant, J. S., Mokwa, M. P., \& Varadarajan, P. R. (1990). Strategic types, distinctive marketing competencies and organizational performance: a multiple measures-based study. Strategic management journal, 11(5), 365-383.

Conner, K. R. (1991). A historical comparison of resource-based theory and five schools of thought within industrial organization economics: do we have a new theory of the firm?. Journal of management, 17(1), 121-154.

Constantinides, E. (2006). The marketing mix revisited: towards the 21st century marketing. Journal of marketing management, 22(3-4), 407-438.

Constantinides, E. (2014). Foundations of social media marketing. Procedia-Social and behavioral sciences, $148,40-57$.

Contractor, F. J., Hsu, C. C., \& Kundu, S. K. (2005). Explaining export performance: a comparative study of international new ventures in Indian and Taiwanese software industry. MIR: Management International Review, 83-110.

Craig, C. S., \& Douglas, S. P. (2000). Configural advantage in global markets.Journal of international Marketing, 8(1), 6-26. 
Cronin Jr, J. J., \& Taylor, S. A. (1992). Measuring service quality: a reexamination and extension. The journal of marketing, 55-68.

Czinkota, M. R., \& Ronkainen, I. A. (2013). International marketing. Cengage Learning.

Czinkota, M., \& Ronkainen, I. (Eds.). (2011). The future of global business: a reader. Routledge.

Dacin, M., Goodstein, J., \& Richard Scott, W. (2002). Institutional theory and institutional change: Introduction to the special research forum. Academy of management journal, 45(1), 45-56.

Da Rocha, A., \& Christensen, C. H. (1994). The export experience of a developing country: a review of empirical studies of export behavior and the performance of Brazilian firms. Advances in international marketing, 6(1), 111-142.

Daszkiewicz, N., \& Wach, K. (2012). Internationalization of SMEs: Context, Models and Implementation. N. Daszkiewicz \& K. Wach, Internationalization of SMEs. Context, Models and Implementation, Gdańsk University of Technology Publishers.

Day George, S. (1990). Market Driven Strategy.

Day, G. S. (1994). The capabilities of market-driven organizations. the Journal of Marketing, 37-52.

Day, G. S. (1997). Maintaining the competitive edge: Creating and sustaining advantages in dynamic competitive environments. Wharton on dynamic competitive strategy, 48-75.

Dean, J. W., \& Bowen, D. E. (1994). Management theory and total quality: improving research and practice through theory development. Academy of management review, 19(3), 392-418. 
Dean, D. L., Mengüç, B., \& Myers, C. P. (2000). Revisiting Firm Characteristics, Strategy, and Export Performance Relationship:: A Survey of the Literature and an Investigation of New Zealand Small Manufacturing Firms. Industrial Marketing Management, 29(5), 461-477.

Denis, J. E. (1990). Une synthèse de la recherche sur le comportement des firmes à l'exportation.

DeSarbo, W. S., Anthony Di Benedetto, C., Song, M., \& Sinha, I. (2005). Revisiting the Miles and Snow strategic framework: uncovering interrelationships between strategic types, capabilities, environmental uncertainty, and firm performance. Strategic Management Journal, 26(1), 47-74.

Devece, C., Llopis-Albert, C., \& Palacios-Marqués, D. (2017). Market orientation, organizational performance, and the mediating role of crowdsourcing in knowledge-based firms. Psychology \& Marketing, 34(12), 1127-1134.

Dhanaraj, C., \& Beamish, P. W. (2003). A resource-based approach to the study of export performance. Journal of small business management, 41(3), 242-261.

Diamantopoulos, A., \& Schlegelmilch, B. B. (1994). Linking export manpower to export performance: a canonical regression analysis of European and US data. Advances in international marketing, 6, 161-181.

Doole, I., \& Lowe, R. (2008). International marketing strategy: analysis, development and implementation. Cengage Learning EMEA.

Drucker, P. F. (1954). The Practice of Management.

Drucker, P. (1993). F.(1993). Post-capitalist society.

Duncan, T., \& Moriarty, S. E. (1998). A communication-based marketing model for managing relationships. The Journal of marketing, 1-13. 
Dunning, J. H. (1980). Toward an eclectic theory of international production: Some empirical tests. Journal of international business studies, 11(1), 9-31.

Dunning, J. H. (1981). International Production and the Multinational Enterprise (RLE International Business). Routledge.

Durmuşoğlu, S. S., Apfelthaler, G., Nayir, D. Z., Alvarez, R., \& Mughan, T. (2012). The effect of government-designed export promotion service use on small and mediumsized enterprise goal achievement: A multidimensional view of export performance. Industrial marketing management, 41(4), 680-691.

Eberhard, M., \& Craig, J. (2013). The evolving role of organisational and personal networks in international market venturing. Journal of World Business, 48(3), 385-397.

Eden, L., Dai, L., \& Li, D. (2010). International Business, International Management, and International Strategy: What's in a Name?. International Studies of Management \& Organization, 40(4), 54-68.

Eisenhardt, K. M., \& Martin, J. A. (2000). Dynamic capabilities: what are they?. Strategic management journal, 1105-1121.

El-Gohary, H. (2010). E-Marketing-A literature Review from a Small Businesses perspective. International Journal of Business and Social Science, 1(1).

Ellis, P. D. (2007). Distance, dependence and diversity of markets: effects on market orientation. Journal of International Business Studies, 38(3), 374-386.

Fahey, L. (1999). Competitors: outwitting, outmaneuvering, and outperforming. University of Texas Press.

Fang, S. R., Chang, E., Ou, C. C., \& Chou, C. H. (2014). Internal market orientation, market capabilities and learning orientation. European Journal of Marketing, 48(1/2), 170-192. 
Farquhar, P. H. (1989). Managing brand equity. Marketing research, 1(3).

Fernández-Mesa, A., \& Alegre, J. (2015). Entrepreneurial orientation and export intensity: Examining the interplay of organizational learning and innovation. International Business Review, 24(1), 148-156.

Fernández, Z., \& Nieto, M. J. (2006). Impact of ownership on the international involvement of SMEs. Journal of international business studies, 37(3), 340-351.

Fiedler, F. E. (2006). The Contingency model: H Theory of Leadership Effectiveness. Small Groups: Key Readings, 369.

Fillis, I. (2001). Small firm internationalisation: an investigative survey and future research directions. Management decision, 39(9), 767-783.

Flint, D. J. (2004). Strategic marketing in global supply chains: Four challenges. Industrial marketing management, 33(1), 45-50.

Fornell, C., \& Larcker, D. F. (1981). Evaluating structural equation models with unobservable variables and measurement error. Journal of marketing research, 39-50.

Francis, J., \& Collins-Dodd, C. (2000). The impact of firms' export orientation on the export performance of high-tech small and medium-sized enterprises. Journal of International Marketing, 8(3), 84-103.

Francis, J., \& Collins-Dodd, C. (2004). Impact of export promotion programs on firm competencies, strategies and performance: The case of Canadian high-technology SMEs. International Marketing Review, 21(4/5), 474-495.

Freeman, J., Styles, C., \& Lawley, M. (2012). Does firm location make a difference to the export performance of SMEs?. International Marketing Review, 29(1), 88-113. 
Friedman, M. (2007). The social responsibility of business is to increase its profits. In Corporate ethics and corporate governance (pp. 173-178). Springer, Berlin, Heidelberg.

Frow, P. E., \& Payne, A. F. (2009). Customer relationship management: a strategic perspective. Journal of Business Market Management, 3(1), 7-27.

Gadenne, D. L., Kennedy, J., \& McKeiver, C. (2009). An empirical study of environmental awareness and practices in SMEs. Journal of Business Ethics,84(1), 4563.

Gao, G. Y., Murray, J. Y., Kotabe, M., \& Lu, J. (2010). A “strategy tripod" perspective on export behaviors: Evidence from domestic and foreign firms based in an emerging economy. Journal of International Business Studies, 41(3), 377-396.

Gashi, P., Hashi, I., \& Pugh, G. (2014). Export behaviour of SMEs in transition countries. Small Business Economics, 42(2), 407-435.

Gemunden, H. G. (1991). Success factors of export marketing: A meta-analytic critique of the empirical studies. New perspectives on international marketing, Routledge, London, 33-62.

Gençtürk, E. F., \& Kotabe, M. (2001). The effect of export assistance program usage on export performance: a contingency explanation.Journal of International Marketing, 9(2), 51-72.

Gertner, R. K., Gertner, D., \& Guthery, D. (2007). The implications of export performance measurement for the significance of the determinants of export performance: an empirical investigation of Brazilian firms. Journal of Global Marketing, 20(1), 21-38.

Girma, S., Gong, Y., \& Görg, H. (2009). What determines innovation activity in Chinese state-owned enterprises? The role of foreign direct investment. World Development, 37(4), 866-873. 
Grant, R. M. (1991). The resource-based theory of competitive advantage: implications for strategy formulation. California management review, 33(3), 114-135.

Grant, R. M. (1996). Prospering in dynamically-competitive environments: Organizational capability as knowledge integration. Organization science, 7(4), 375-387.

Green, K. M., Covin, J. G., \& Slevin, D. P. (2008). Exploring the relationship between strategic reactiveness and entrepreneurial orientation: The role of structure-style fit. Journal of Business Venturing, 23(3), 356-383.

Green, K. W., Whitten, D., \& Inman, R. A. (2012). Aligning marketing strategies throughout the supply chain to enhance performance. Industrial Marketing Management, 41(6), 1008-1018.

Gregory, G., Karavdic, M., \& Zou, S. (2007). The effects of e-commerce drivers on export marketing strategy. Journal of International Marketing, 15(02), 30-57.

Grönroos, C. (1984). A service quality model and its marketing implications. European Journal of marketing, 18(4), 36-44.

Grönroos, C. (1990). Service management and marketing: managing the moments of truth in service competition. Jossey-Bass.

Grönroos, C., \& Voima, P. (2013). Critical service logic: making sense of value creation and co-creation. Journal of the Academy of Marketing Science, 41(2), 133-150.

Gummesson, E. (1994a). Broadening and specifying relationship marketing.AsiaAustralia Marketing Journal, 2(1), 31-43.

Gummesson, E. (1994b). Making relationship marketing operational.International Journal of service industry management, 5(5), 5-20.

Gummesson, E. (2002). Relationship marketing and a new economy: it's time for deprogramming. Journal of Services Marketing, 16(7), 585-589. 
Guo, C. (2002). Market orientation and business performance: A framework for service organizations. European Journal of Marketing, 36(9/10), 1154-1163.

Hair, J. F., Black, W. C., Babin, B. J., Anderson, R. E., \& Tatham, R. L. (1998). Multivariate data analysis (Vol. 5, No. 3, pp. 207-219). Upper Saddle River, NJ: Prentice hall.

Haji-Basri, M. (2012). Marketing research contemporary themes and trends.Marketing Research, 4(5).

Hambrick, D. C. (1983). Some tests of the effectiveness and functional attributes of Miles and Snow's strategic types. Academy of Management journal, 26(1), 5-26.

Hanson, W., \& Kalyanam, K. (2007). Principles of Internet marketing. South-Western College Publishing.

Harrigan, K. R. (1983). Research methodologies for contingency approaches to business strategy. Academy of Management Review, 8(3), 398-405.

Hart, S., \& Tzokas, N. (1999). The impact of marketing research activity on SME export performance: evidence from the UK. Journal of small business management, 37(2), 63.

Hauser, J. R., \& Clausing, D. (1988). The house of quality. Harvard business review, 66(3).

Hecksher, E., \& Ohlin, B. (1933). Interregional and international trade.

Heenan, D. A., \& Perlmutter, H. V. (1979). Multinational organizational development: A social architectural approach. Reading.

Helfat, C. E. (1997). Know-how and asset complementarity and dynamic capability accumulation: The case of R\&D. Strategic management journal, 339-360.

Hennart, J. F. (2001). Theories of the multinational enterprise. The Oxford handbook of international business, 127-149. 
Higón, D., \& Driffield, N. (2011). Exporting and innovation performance: Analysis of the annual Small Business Survey in the UK. International Small Business Journal, 29(1), 424.

Hill, C. W. (2004). Global business today. Irwin/McGraw-Hill.

Hofstede, G. (1980). Motivation, leadership, and organization: do American theories apply abroad?. Organizational dynamics, 9(1), 42-63.

Hofstede, G. (1983). The cultural relativity of organizational practices and theories. Journal of international business studies, 14(2), 75-89.

Hofstede, G., Neuijen, B., Ohayv, D. D., \& Sanders, G. (1990). Measuring organizational cultures: A qualitative and quantitative study across twenty cases. Administrative science quarterly, 286-316.

Holzmüller, H. H., \& Kasper, H. (1991). On a theory of export performance: Personal and organizational determinants of export trade activities observed in small and medium-sized firms. MIR: Management International Review, 45-70.

Hoque, Z. (2004). A contingency model of the association between strategy, environmental uncertainty and performance measurement: impact on organizational performance. International Business Review, 13(4), 485-502.

Hortinha, P., Lages, C., \& Filipe Lages, L. (2011). The trade-off between customer and technology orientations: impact on innovation capabilities and export performance. Journal of International Marketing, 19(3), 36-58.

Hultman, M., Katsikeas, C. S., \& Robson, M. J. (2011). Export promotion strategy and performance: the role of international experience. Journal of International Marketing, 19(4), 17-39.

Hunt, S. D., \& Morgan, R. M. (1995). The comparative advantage theory of competition. The Journal of Marketing, 1-15. 
Hunt, S. D. (2000). A general theory of competition. Thousands Oaks.

Huotari, K., \& Hamari, J. (2012, October). Defining gamification: a service marketing perspective. In Proceeding of the 16th International Academic MindTrek Conference (pp. 17-22). ACM.

Hussey, D. (2002). Company analysis: determining strategic capability. Strategic change, 11(1), 43-52.

Hymer, S. (1976). The international operations of national firms: A study of direct foreign investment (Vol. 14, pp. 139-155). Cambridge, MA: MIT press.

Ibeh, K. I. (2003). On the internal drivers of export performance among Nigerian firms: empirical findings and implications. Management decision, 41(3), 217-225.

Jain, S. C. (1989). Standardization of international marketing strategy: some research hypotheses. The Journal of Marketing, 70-79.

Jain, S. K., \& Gupta, G. (2004). Measuring service quality: SERVQUAL vs. SERVPERF scales. Vikalpa, 29(2), 25-37.

Jantunen, A., Nummela, N., Puumalainen, K., \& Saarenketo, S. (2008). Strategic orientations of born globals-Do they really matter?. Journal of world business, 43(2), 158-170.

Jaworski, B. J., \& Kohli, A. K. (1993). Market orientation: antecedents and consequences. The Journal of marketing, 53-70.

Jaworski, B. J., \& Kohli, A. K. (2017). Conducting field-based, discovery-oriented research: lessons from our market orientation research experience. AMS Review, 7(12), 4-12.

Johanson, J., \& Wiedersheim-Paul, F. (1975). The internationalization of the firm-four swedish cases 1. Journal of management studies, 12(3), 305-323. 
Johanson, J., \& Vahlne, J. E. (1977). The internationalization process of the firm -a model of knowledge development and increasing foreign market commitments. Journal of international business studies, 8(1), 23-32.

Johanson, J., \& Vahlne, J. E. (1990). The mechanism of internationalisation. International marketing review, 7(4).

JOHANSON, J. (1993). MATTSSON, Lars-Gunnar. Internationalization in industrial system: a network approach. Strategies in global competition, 468-486.

Johanson, J., \& Vahlne, J. E. (2003). Business relationship learning and commitment in the internationalization process. Journal of international entrepreneurship, 1(1), 83101.

Johanson, J., \& Vahlne, J. E. (2009). The Uppsala internationalization process model revisited: From liability of foreignness to liability of outsidership. Journal of international business studies, 40(9), 1411-1431.

Jöreskog, K. G. (1973). Analysis of covariance structures. In Multivariate Analysis-III (pp. 263-285).

Joreskog, K. G., \& Sorbom, D. L. I. S. R. E. L. LISREL 8: User's Reference Guide 1996. Scientific Software International, Chicago.

Julien, P. A., \& Ramangalahy, C. (2003). Competitive strategy and performance of exporting SMEs: An empirical investigation of the impact of their export information search and competencies. Entrepreneurship Theory and Practice, 27(3), 227-245.

Kalinic, I., \& Forza, C. (2012). Rapid internationalization of traditional SMEs: Between gradualist models and born globals. International Business Review,21(4), 694-707.

Kaplan, A. M. (2012). If you love something, let it go mobile: Mobile marketing and mobile social media 4x4. Business horizons, 55(2), 129-139. 
Karavdic, M., \& Gregory, G. (2005). Integrating e-commerce into existing export marketing theories: A contingency model. Marketing Theory, 5(1), 75-104.

Karelakis, C., Mattas, K., \& Chryssochoidis, G. (2008). Greek wine firms: Determinants of export performance. Agribusiness, 24(2), 275-297.

Katsikeas, C. S., Piercy, N. F., \& Ioannidis, C. (1996). Determinants of export performance in a European context. European journal of Marketing, 30(6), 6-35.

Katsikeas, C. S., Leonidou, L. C., \& Morgan, N. A. (2000). Firm-level export performance assessment: review, evaluation, and development.Journal of the Academy of Marketing Science, 28(4), 493-511.

Katsikeas, C. S., Samiee, S., \& Theodosiou, M. (2006). Strategy fit and performance consequences of international marketing standardization. Strategic management journal, 27(9), 867-890.

Keegan WJ. Global marketing management. Upper Saddle River, NJ: Prentice-Hall, 1995

Keegan, W. J., \& Schlegelmilch, B. B. (2001). Global marketing management: A European perspective. Pearson education.

Kevin Tseng, K. M., \& Johnsen, R. E. (2011). Internationalisation and the internet in UK manufacturing SMEs. Journal of Small Business and Enterprise Development, 18(3), 571-593.

Knight, G. A., \& Cavusgil, S. T. (2004). Innovation, organizational capabilities, and the born-global firm. Journal of International Business Studies, 35(2), 124-141.

Kogut, B., \& Zander, U. (1992). Knowledge of the firm, combinative capabilities, and the replication of technology. Organization science, 3(3), 383-397. 
Koh, A. C. (1991). Relationships among organisational characteristics, marketing strategy and export performance. International marketing review, 8(3).

Kohli, A. K., \& Jaworski, B. J. (1990). Market orientation: the construct, research propositions, and managerial implications. The Journal of Marketing, 1-18.

Kohli, A. K., Jaworski, B. J., \& Kumar, A. (1993). MARKOR: a measure of market orientation. Journal of Marketing research, 467-477.

Kotler, Philip (1967), Marketing Management Analysis, Planning, and Control.

Englewood Cliffs, NJ: Prentice Hall.

Kotler, P., Kartajaya, H., \& Setiawan, I. (2010). Marketing 3.0: From products to customers to the human spirit. John Wiley \& Sons.

Kotler, P., Kartajaya, H., \& Setiawan, I. (2016). Marketing 4.0: Moving from traditional to digital. John Wiley \& Sons.

Kozlenkova, I. V., Samaha, S. A., \& Palmatier, R. W. (2014). Resource-based theory in marketing. Journal of the Academy of Marketing Science, 42(1), 1-21.

Kwok, A. C. (2014). The evolution of management theories: A literature review. Nang Yan Business Journal, 3(1), 28-40.

Lado, N., Martínez-Ros, E., \& Valenzuela, A. (2004). Identifying successful marketing strategies by export regional destination. International marketing review, 21(6), 573597.

Lages, C., Lages, C. R., \& Lages, L. F. (2005). The RELQUAL scale: a measure of relationship quality in export market ventures. Journal of business research,58(8), 1040-1048.

Lages, L.F., \& Montgomery, D. B. (2005). The relationship between export assistance and performance improvement in Portuguese export ventures: An empirical test of the 
mediating role of pricing strategy adaptation. European Journal of marketing, 39(7/8), 755-784.

Lages, L. F., Jap, S. D., \& Griffith, D. A. (2008). The role of past performance in export ventures: a short-term reactive approach. Journal of International Business Studies, 39(2), 304-325.

Lages, L. F., Silva, G., \& Styles, C. (2009). Relationship capabilities, quality, and innovation as determinants of export performance. Journal of International Marketing, 17(4), 47-70.

Landis, R. S., Beal, D. J., \& Tesluk, P. E. (2000). A comparison of approaches to forming composite measures in structural equation models. Organizational Research Methods, 3(2), 186-207.

Lee, N., Broderick, A. J., \& Chamberlain, L. (2007). What is 'neuromarketing'? A discussion and agenda for future research. International Journal of Psychophysiology, 63(2), 199-204.

Lee, S. H., Beamish, P. W., Lee, H. U., \& Park, J. H. (2009). Strategic choice during economic crisis: Domestic market position, organizational capabilities and export flexibility. Journal of World Business, 44(1), 1-15.

Lehmann, D. R. (2005). Journal evolution and the development of marketing.Journal of Public Policy \& Marketing, 24(1), 137-142.

Leonidou, L. C., \& Katsikeas, C. S. (1996). The export development process: an integrative review of empirical models. Journal of international business studies, 27(3), 517-551.

Leonidou, L. C., Katsikeas, C. S., \& Piercy, N. F. (1998). Identifying managerial influences on exporting: past research and future directions. Journal of International Marketing, 74-102. 
Leonidou, L. C., Katsikeas, C. S., \& Samiee, S. (2002). Marketing strategy determinants of export performance: a meta-analysis. Journal of Business research, 55(1), 51-67.

Leonidou, L. C., Katsikeas, C. S., Palihawadana, D., \& Spyropoulou, S. (2007). An analytical review of the factors stimulating smaller firms to export: Implications for policy-makers. International Marketing Review, 24(6), 735-770.

Leonidou, L. C., Katsikeas, C. S., \& Coudounaris, D. N. (2010). Five decades of business research into exporting: A bibliographic analysis. Journal of International Management, 16(1), 78-91.

Levitt, T. (1960). Marketing myopia. Harvard business review, 38(4), 24-47.

Levitt, T. (1993). The globalization of markets. Readings in international business: a decision approach, 249.

Levy, D. (1994). Chaos theory and strategy: Theory, application, and managerial implications. Strategic management journal, 15(S2), 167-178.

Line, N. D., \& Runyan, R. C. (2012). Hospitality marketing research: Recent trends and future directions. International Journal of Hospitality Management,31(2), 477-488.

Ling-Yee, L., \& Ogunmokun, G. O. (2001). Effect of export financing resources and supply-chain skills on export competitive advantages: implications for superior export performance. Journal of World Business, 36(3), 260-279.

Ling-Yee, L. (2004). An examination of the foreign market knowledge of exporting firms based in the People's Republic of China: Its determinants and effect on export intensity. Industrial Marketing Management, 33(7), 561-572.

LiPuma, J. A., Newbert, S. L., \& Doh, J. P. (2013). The effect of institutional quality on firm export performance in emerging economies: a contingency model of firm age and size. Small Business Economics, 40(4), 817-841. 
Little, T. D., Cunningham, W. A., Shahar, G., \& Widaman, K. F. (2002). To parcel or not to parcel: Exploring the question, weighing the merits. Structural equation modeling, 9(2), 151-173.

Lynch, R. (2009). Strategic management. England: Pearson Education Limited

Magnusson, P., Westjohn, S. A., Semenov, A. V., Randrianasolo, A. A., \& Zdravkovic, S. (2013). The role of cultural intelligence in marketing adaptation and export performance. Journal of Marketing Research, 21(4), 44-61.

Marandu, E. E. (1996). Impact of export promotion on export performance: a Tanzanian study. Journal of Global Marketing, 9(1-2), 9-40.

Marshall, Alfred (1927), Principles of Economics, (1890). Reprint, London: Macmillan

Martin, S. L., \& Javalgi, R. R. G. (2016). Entrepreneurial orientation, marketing capabilities and performance: the moderating role of competitive intensity on Latin American International new ventures. Journal of Business Research, 69(6), 2040-2051.

Martínez Mora, C. (1997). Causas de la internacionalización de las empresas: un estudio aplicado a pequeñas y medianas empresas de la provincia de Alicante.

Mathews, S., Bianchi, C., Perks, K. J., Healy, M., \& Wickramasekera, R. (2016). Internet marketing capabilities and international market growth. International Business Review, 25(4), 820-830.

MacCallum, R. C., Widaman, K. F., Zhang, S., \& Hong, S. (1999). Sample size in factor analysis. Psychological methods, 4(1), 84.

McCarthy, E. J. (1960). Basic marketing: a managerial approach. Homewood, IL: Richard D. Irwin. Inc., 1979McCarthyBasic Marketing: A Managerial Approach1979.

McDaniel, S. W., \& Kolari, J. W. (1987). Marketing strategy implications of the Miles and Snow strategic typology. The Journal of Marketing, 19-30. 
McDougall, P. P., Shane, S., \& Oviatt, B. M. (1994). Explaining the formation of international new ventures: The limits of theories from international business research. Journal of business venturing, 9(6), 469-487.

McDougall, P. P., \& Oviatt, B. M. (2000a). International entrepreneurship: the intersection of two research paths. Academy of management Journal, 43(5), 902-906.

McDougall, P. P., \& Oviatt, B. M. (2000b). International entrepreneurship literature in the 1990s and directions for future research. Entrepreneurship,2000, 291-320.

McGregor, D. (1960). Theory X and theory Y. Organization theory, 358, 374.

McKitterick, J. B. (1957). What is the marketing management concept. Chicago, IL.

Mejri, K., \& Umemoto, K. (2010). Small-and medium-sized enterprise internationalization: Towards the knowledge-based model. Journal of International Entrepreneurship, 8(2), 156-167.

Mele, C., \& Colurcio, M. (2006). The evolving path of TQM: towards business excellence and stakeholder value. International Journal of Quality \& Reliability Management, 23(5), 464-489.

Mele, C. (2007). The synergic relationship between TQM and marketing in creating customer value. Managing Service Quality: An International Journal,17(3), 240-258.

Miles, R. E., Snow, C. C., Meyer, A. D., \& Coleman, H. J. (1978). Organizational strategy, structure, and process. Academy of management review, 3(3), 546-562.

Mill, J. S. (1848). Principles of Political Economy With Some of Their Applications to Social Philosophy. 1857. George Routledge and Sons, Manchester.

Mintzberg, H. (1988). Generic strategies: toward a comprehensive framework. Advances in strategic management, 5(1), 1-67. 
Mitchell, W. (1991). Dual clocks: Entry order influences on incumbent and newcomer market share and survival when specialized assets retain their value. Strategic Management Journal, 12(2), 85-100.

Moen, $\varnothing$., Koed Madsen, T., \& Aspelund, A. (2008). The importance of the internet in international business-to-business markets. International Marketing Review, 25(5), 487-503.

Moon, B. J., \& Jain, S. C. (2007). Determinants and outcomes of internet marketing activities of exporting firms. Journal of Global Marketing, 20(4), 55-71.

Morgan, R. M., \& Hunt, S. D. (1994). The commitment-trust theory of relationship marketing. The journal of marketing, 20-38.

Morgan, N. A., Kaleka, A., \& Katsikeas, C. S. (2004). Antecedents of export venture performance: A theoretical model and empirical assessment. Journal of marketing, 68(1), 90-108.

Morgan, N. A., Vorhies, D. W., \& Mason, C. H. (2009). Market orientation, marketing capabilities, and firm performance. Strategic Management Journal, 30(8), 909-920.

Morgan, N. A., Katsikeas, C. S., \& Vorhies, D. W. (2012). Export marketing strategy implementation, export marketing capabilities, and export venture performance. Journal of the Academy of Marketing Science, 40(2), 271-289.

Morgan, N. A., Feng, H., \& Whitler, K. A. (2018). Marketing Capabilities in International Marketing. Journal of International Marketing.

Morin, C. (2011). Neuromarketing: the new science of consumer behavior.Society, 48(2), 131-135.

Mtigwe, B. (2006). Theoretical milestones in international business: The journey to international entrepreneurship theory. Journal of International Entrepreneurship, 4(1), $5-25$. 
Mudalige, D. M., \& Ismail, N. A. (2014). The effect of entrepreneurial orientation and brand orientation on SME internationalization and performance: A conceptual framework. International Postgraduate Business Journal.

Murphy, E. R., Illes, J., \& Reiner, P. B. (2008). Neuroethics of neuromarketing.Journal of Consumer Behaviour, 7(4-5), 293-302.

Murray, J. Y., Gao, G. Y., \& Kotabe, M. (2011). Market orientation and performance of export ventures: the process through marketing capabilities and competitive advantages. Journal of the Academy of Marketing Science, 39(2), 252-269.

Nadler, D., Tushman, M., \& Nadler, M. B. (1997). Competing by design: The power of organizational architecture. Oxford University Press.

Namiki, N. (1988). Export strategy for small business. Journal of Small Business Management, 26(2), 32.

Narver, J. C., \& Slater, S. F. (1990). The effect of a market orientation on business profitability. The Journal of marketing, 20-35.

Nelson, R. R. (1991). Why do firms differ, and how does it matter?. Strategic management journal, 12(S2), 61-74.

Ngai, E. W. (2003). Internet marketing research (1987-2000): a literature review and classification. European Journal of Marketing, 37(1/2), 24-49.

Normann, R., \& Ramirez, R. (1993). From value chain to value constellation.Harvard business review, 71(4), 65-77.

O'Cass, A., \& Julian, C. (2003). Examining firm and environmental influences on export marketing mix strategy and export performance of Australian exporters. European journal of marketing, 37(3/4), 366-384. 
Oh, H., Kim, B. Y., \& Shin, J. H. (2004). Hospitality and tourism marketing: recent developments in research and future directions. International Journal of Hospitality Management, 23(5), 425-447.

Oh, L. B., Teo, H. H., \& Sambamurthy, V. (2012). The effects of retail channel integration through the use of information technologies on firm performance. Journal of Operations Management, 30(5), 368-381.

Ohmae, K. (1989). Managing in a borderless world. Harvard Business Review,67(3), 152-161.

Okpara, J. O. (2009). Strategic choices, export orientation and export performance of SMEs in Nigeria. Management Decision, 47(8), 1281-1299.

Orlitzky, M., Siegel, D. S., \& Waldman, D. A. (2011). Strategic corporate social responsibility and environmental sustainability. Business \& society, 50(1), 6-27.

Pan, Y., \& Tse, D. K. (2000). The Hierarchical Model of Market Entry Modes.Journal of International Business Studies, 31(4), 535-554.

Pandza, K., \& Thorpe, R. (2009). Creative search and strategic sense-making: missing dimensions in the concept of dynamic capabilities. British Journal of Management, 20(s1), S118-S131.

Parasuraman, A., Zeithaml, V. A., \& Berry, L. L. (1985). A conceptual model of service quality and its implications for future research. the Journal of Marketing, 41-50.

Parasuraman, A., Zeithaml, V. A., \& Berry, L. L. (1988). Servqual. Journal of retailing, 64(1), 12-40.

Parnell, J. A., Long, Z., \& Lester, D. (2015). Competitive strategy, capabilities and uncertainty in small and medium sized enterprises (SMEs) in China and the United States. Management Decision, 53(2), 402-431. 
Payne, A., \& Frow, P. (2005). A strategic framework for customer relationship management. Journal of marketing, 69(4), 167-176.

Payne, A. F., Storbacka, K., \& Frow, P. (2008). Managing the co-creation of value. Journal of the academy of marketing science, 36(1), 83-96.

Payne, A., \& Frow, P. (2017). Relationship marketing: looking backwards towards the future. Journal of Services Marketing, 31(1), 11-15.

Pena, A. I. P., Jamilena, D. M. F., \& Molina, M. Á. R. (2012). Validation of a market orientation adoption scale in rural tourism enterprises. Relationship between the characteristics of the enterprise and extent of market orientation adoption. International Journal of Hospitality Management, 31(1), 139-151.

Peng, M. W., Wang, D. Y., \& Jiang, Y. (2008). An institution-based view of international business strategy: A focus on emerging economies. Journal of international business studies, 39(5), 920-936.

Penrose, E. T. (1959). The Theory of the Growth of the FirmWiley. New York.

Piercy, N. F., \& Cravens, D. W. (1995). The network paradigm and the marketing organization: developing a new management agenda. European Journal of Marketing, 29(3), 7-34.

Pine, B. J., \& Gilmore, J. H. (1999). The experience economy: work is theatre \& every business a stage. Harvard Business Press.

Porter, M. E. (1980). Competitive strategy: techniques for analyzing industries and competitors.

Porter, M. E. (1985). Competitive advantage: creating and sustaining superior performance. 1985. New York: FreePress. 
Porter, M. E. (1986). Changing patterns of international competition. California management review, 28(2), 9-40.

Porter, M. E. (1990). The competitive advantage of nations. Harvard business review, 68(2), 73-93.

Prahalad, C. K., \& Hamel, G. (1990). Core competency concept. Harvard Business Review, 64.

Prasad, V. K., Ramamurthy, K., \& Naidu, G. M. (2001). The influence of internetmarketing integration on marketing competencies and export performance. Journal of International Marketing, 9(4), 82-110.

Qader, I. K. A., \& Omar, A. B. (2013). The evolution of experiential marketing: Effects of brand experience among the millennial generation. International Journal of Academic Research in Business and Social Sciences, 3(7), 331.

Ramaswami, S. N., Srivastava, R. K., \& Bhargava, M. (2009). Market-based capabilities and financial performance of firms: insights into marketing's contribution to firm value. Journal of the Academy of Marketing Science, 37(2), 97-116.

Rangone, A. (1999). A resource-based approach to strategy analysis in small-medium sized enterprises. Small Business Economics, 12(3), 233-248.

Raymond, L., \& St-Pierre, J. (2013). Strategic capability configurations for the internationalization of SMEs: A study in equifinality. International Small Business Journal, 31(1), 82-102.

Reid, S. D. (1981). The decision-maker and export entry and expansion.Journal of international business studies, 12(2), 101-112.

Rialp, A., Rialp, J., Urbano, D., \& Vaillant, Y. (2005). The born-global phenomenon: A comparative case study research. Journal of International Entrepreneurship, 3(2), 133171. 
Ricardo, D. (1817). On foreign trade. Principles of political economy and taxation.

Ricci, L. A., \& Trionfetti, F. (2012). Productivity, Networks, and Export Performance: Evidence from a Cross-country Firm Dataset. Review of International Economics, 20(3), $552-562$.

Robertson, C., \& Chetty, S. K. (2000). A contingency-based approach to understanding export performance. International Business Review, 9(2), 211-235.

Robinson, R. B., \& Pearce, J. A. (1988). Planned patterns of strategic behavior and their relationship to business-unit performance. Strategic management journal, 9(1), 43-60.

Root, F. R. (1994). Entry strategies for international markets. Jossey-Bass.

Rose, G. M., \& Shoham, A. (2002). Export performance and market orientation: Establishing an empirical link. Journal of Business Research, 55(3), 217-225.

Roth, K., Schweiger, D. M., \& Morrison, A. J. (1991). Global strategy implementation at the business unit level: Operational capabilities and administrative mechanisms. Journal of International Business Studies, 22(3), 369-402.

Ruekert, R. W. (1992). Developing a market orientation: an organizational strategy perspective. International journal of research in marketing, 9(3), 225-245.

Ruiz-Ortega, M. J., \& García-Villaverde, P. M. (2008). Capabilities and competitive tactics influences on performance: Implications of the moment of entry. Journal of Business Research, 61(4), 332-345.

Ruzzier, M., Hisrich, R. D., \& Antoncic, B. (2006). SME internationalization research: past, present, and future. Journal of small business and enterprise development, 13(4), 476-497. 
Saleh, M. A. H. (2016). Themes and Topics of Research in Marketing: A Content Analysis of the Articles Published in Three Marketing Journals. International Journal of Business Administration, 7(1), p12.

Same, S., \& Larimo, J. (2012, May). Marketing theory: Experience marketing and experiential marketing. In 7th International Scienti fi c Conference Business and Management-2012, in Vilnius, Lithuania.

Samiee, S., \& Roth, K. (1992). The influence of global marketing standardization on performance. The Journal of Marketing, 1-17.

Santos-Vijande, M. L., López-Sánchez, J. Á., \& Trespalacios, J. A. (2012). How organizational learning affects a firm's flexibility, competitive strategy, and performance. Journal of Business Research, 65(8), 1079-1089.

Saravanakumar, M., \& SuganthaLakshmi, T. (2012). Social media marketing. Life Science Journal, 9(4), 4444-4451.

Schmitt, B. H. (2000). Experiential marketing: How to get customers to sense, feel, think, act, relate. Simon and Schuster.

Schmitt, B. H., Brakus, J., \& Zarantonello, L. (2014). The current state and future of brand experience. Journal of Brand Management, 21(9), 727-733.

Schumacher, R. (2012). Adam Smith's theory of absolute advantage and the use of doxography in the history of economics. Erasmus Journal for Philosophy and Economics, 5(2), 54-80.

Schumpeter, J. A. (1934). The Theory of Economic Development: An Inquiry into Profits, Capital, Credit, Interest and the Business Cycle. Trans. Redvers Opie. Cambridge, MA: Harvard University Press.

Schumpeter, J. A. (2013). Capitalism, socialism and democracy. Routledge. 
Shafei, R., \& Zohdi, M. (2014). Relational capabilities in market orientation to improvement of performance outcomes in SMEs. International Journal of Business Performance Management, 15(4), 295-315.

Shamsie, J., Phelps, C., \& Kuperman, J. (2004). Better late than never: A study of late entrants in household electrical equipment. Strategic Management Journal, 25(1), 6984.

Shamsuddoha, A. K., \& Yunus Ali, M. (2006). Mediated effects of export promotion programs on firm export performance. Asia Pacific Journal of Marketing and Logistics, 18(2), 93-110.

Shaw, A. (1912), "Some Problems in Market Distribution," Quarterly Journal of Economics, 12 (August), 703-765.

Sheth, J., \& Parvatiyar, A. (2000). Relationship Marketing in Consumer Markets: antecedents and consequences. Sheth, J. and.

Shoham, A. (1996). Marketing-mix standardization: determinants of export performance. Journal of global marketing, 10(2), 53-73.

Singer, T. O., \& Czinkota, M. R. (1994). Factors associated with effective use of export assistance. Journal of International Marketing, 53-71.

Singh, D. A. (2009). Export performance of emerging market firms. International Business Review, 18(4), 321-330.

Sinkovics, N., Sinkovics, R. R., \& "Bryan" Jean, R. J. (2013). The internet as an alternative path to internationalization?. International Marketing Review, 30(2), 130155.

Smith, K. G., Guthrie, J. P., \& Chen, M. J. (1986, August). Miles and Snow's Typology of Strategy, Organizational Size and Organizational Performance. In Academy of 
Management proceedings (Vol. 1986, No. 1, pp. 45-49). Briarcliff Manor, NY 10510: Academy of Management.

Smith, A. (1904), An Inquiry into the Nature and Causes of the Wealth of Nations, (1776). Reprint, London: Printed for W. Strahan and T. Cadell.

Snow, C. C., \& Hrebiniak, L. G. (1980). Strategy, distinctive competence, and organizational performance. Administrative Science Quarterly, 317-336.

Song, X. M., \& Parry, M. E. (1997a). A cross-national comparative study of new product development processes: Japan and the United States. The Journal of Marketing, 1-18.

Song, X. M., \& Parry, M. E. (1997b). The determinants of Japanese new product successes. Journal of Marketing Research, 64-76.

Song, M., Nason, R. W., \& Di Benedetto, C. A. (2008). Distinctive marketing and information technology capabilities and strategic types: A cross-national investigation. Journal of International Marketing, 16(1), 4-38.

Sousa, C. M. (2004). Export performance measurement: an evaluation of the empirical research in the literature. Academy of marketing science review,2004, 1.

Sousa, C. M., Martínez-López, F. J., \& Coelho, F. (2008). The determinants of export performance: A review of the research in the literature between 1998 and 2005. International Journal of Management Reviews, 10(4), 343-374.

Sousa, C. M., \& Bradley, F. (2008). Antecedents of international pricing adaptation and export performance. Journal of world business, 43(3), 307-320.

Sousa, C. M., \& Lengler, J. (2009). Psychic distance, marketing strategy and performance in export ventures of Brazilian firms. Journal of Marketing Management, 25(5-6), 591-610. 
Sousa, C. M., \& Novello, S. (2014). The influence of distributor support and price adaptation on the export performance of small and medium-sized enterprises. International Small Business Journal, 32(4), 359-385.

Srivastava, R. K., Shervani, T. A., \& Fahey, L. (1998). Market-based assets and shareholder value: A framework for analysis. The Journal of Marketing, 2-18.

Srivastava, R. K., Shervani, T. A., \& Fahey, L. (1999). Marketing, business processes, and shareholder value: An organizationally embedded view of marketing activities and the discipline of marketing. The Journal of Marketing, 168-179.

Srivastava, R. K., Fahey, L., \& Christensen, H. K. (2001). The resource-based view and marketing: The role of market-based assets in gaining competitive advantage. Journal of management, 27(6), 777-802.

Stevenson, H. H. (1983). A perspective on entrepreneurship (Vol. 13). Cambridge, Massachusetts: Harvard Business School.

Stöttinger, B., \& Holzmüller, H. H. (2001). Cross-national stability of an export performance model-a comparative study of Austria and the US. MIR: Management International Review, 7-28.

Teece, D. J., Pisano, G., \& Shuen, A. (1997). Dynamic capabilities and strategic management. Strategic management journal, 509-533.

Theodosiou, M., Kehagias, J., \& Katsikea, E. (2012). Strategic orientations, marketing capabilities and firm performance: An empirical investigation in the context of frontline managers in service organizations. Industrial Marketing Management, 41(7), 1058-1070.

Thirkell, P. C., \& Dau, R. (1998). Export performance: success determinants for New Zealand manufacturing exporters. European Journal of marketing, 32(9/10), 813-829. 
Tookey, D. A. (1964). Factors associated with success in exporting. Journal of management Studies, 1(1), 48-66.

Ural, T. (2009). The effects of relationship quality on export performance: A classification of small and medium-sized Turkish exporting firms operating in single export-market ventures. European Journal of Marketing , 43(1/2), 139-168.

Varadarajan, R. (2010). Strategic marketing and marketing strategy: domain, definition, fundamental issues and foundational premises. Journal of the Academy of Marketing Science, 38(2), 119-140.

Vargo, S. L., \& Lusch, R. F. (2004). Evolving to a new dominant logic for marketing. Journal of marketing, 68(1), 1-17.

Vargo, S. L., \& Lusch, R. F. (2008a). From goods to service (s): Divergences and convergences of logics. Industrial Marketing Management, 37(3), 254-259.

Vargo, S. L., \& Lusch, R. F. (2008b). Service-dominant logic: continuing the evolution. Journal of the Academy of marketing Science, 36(1), 1-10.

Vargo, S. L., \& Lusch, R. F. (2016). Institutions and axioms: an extension and update of service-dominant logic. Journal of the Academy of Marketing Science, 44(1), 5-23.

Vernon, R. (1966). International investment and international trade in the product cycle. The quarterly journal of economics, 190-207.

Vilaseca-Requena, J., Torrent-Sellens, J., \& Jiménez-Zarco, A. I. (2007). ICT use in marketing as innovation success factor: Enhancing cooperation in new product development processes. European Journal of Innovation Management, 10(2), 268-288.

Vivas López, S. (2005). Competitive advantage and strategy formulation: The key role of dynamic capabilities. Management decision, 43(5), 661-669. 
Vivek, S. D., Beatty, S. E., \& Morgan, R. M. (2012). Customer engagement: Exploring customer relationships beyond purchase.Journal of marketing theory and practice, $20(2), 122-146$.

Vorhies, D. W., \& Harker, M. (2000). The Capabilities and Performance Advantages of Market-Driven Firms: An Empirical Investigation. Australian journal of management, 25(2), 145-171.

Vorhies, D. W., \& Morgan, N. A. (2005). Benchmarking marketing capabilities for sustainable competitive advantage. Journal of marketing, 69(1), 80-94.

Wang, C. H., Chen, K. Y., \& Chen, S. C. (2012). Total quality management, market orientation and hotel performance: The moderating effects of external environmental factors. International Journal of Hospitality Management, 31(1), 119-129.

Webster Jr, F. E. (1992). The changing role of marketing in the corporation. The Journal of Marketing, 1-17.

Webster, F. E. (1994). Market-driven management: using the new marketing concept to create a customer-oriented company (Vol. 21). John Wiley \& Sons.

Wei, Y. S., Samiee, S., \& Lee, R. P. (2014). The influence of organic organizational cultures, market responsiveness, and product strategy on firm performance in an emerging market. Journal of the Academy of Marketing Science, 42(1), 49-70.

Wei, Z., Zhao, J., \& Zhang, C. (2014). Organizational ambidexterity, market orientation, and firm performance. Journal of Engineering and Technology Management, 33, 134153.

Wengel, J., \& Rodriguez, E. (2006). SME export performance in Indonesia after the crisis. Small Business Economics, 26(1), 25-37.

Wernerfelt, B. (1984). A resource-based view of the firm. Strategic management journal, 5(2), 171-180. 
Wernerfelt, B. (1995). The resource-based view of the firm: Ten years after. Strategic management journal, 16(3), 171-174.

White,S. D., Griffith, D. A., Ryans, J. K., \& Jr. (1998). Measuring export performance in service industries. International Marketing Review, 15(3), 188-204.

White, C. L., Nielsen, A. E., \& Valentini, C. (2017). CSR research in the apparel industry: A quantitative and qualitative review of existing literature. Corporate Social Responsibility and Environmental Management, 24(5), 382-394.

Wilden, R., \& Gudergan, S. P. (2015). The impact of dynamic capabilities on operational marketing and technological capabilities: investigating the role of environmental turbulence. Journal of the Academy of Marketing Science, 43(2), 181-199.

Wolff, J. A., \& Pett, T. L. (2000). Internationalization of small firms: An examination of export competitive patterns, firm size, and export performance. Journal of Small Business Management, 38(2), 34.

Wu, L. Y. (2006). Resources, dynamic capabilities and performance in a dynamic environment: Perceptions in Taiwanese IT enterprises. Information \& Management, 43(4), 447-454.

Yadav, M. S. (2010). The decline of conceptual articles and implications for knowledge development. Journal of Marketing, 74(1), 1-19.

Yeoh, P. L. (2000). Information acquisition activities: A study of global start-up exporting companies. Journal of International Marketing , 8(3), 36-60.

Yi, J., Wang, C., \& Kafouros, M. (2013). The effects of innovative capabilities on exporting: Do institutional forces matter?. International Business Review, 22(2), 392406.

Yip, G. S. (1989). Global Strategy... In A World Of Nations?. MIT Sloan Management Review, 31(1), 29. 
Yip, G. S. (1995). Instructor's Manual: Total Global Strategy: Managing for Worldwide Competitive Advantage. Prentice Hall.

Yüksel, i̇. (2012). Developing a multi-criteria decision making model for PESTEL analysis. International Journal of Business and Management, 7(24), 52.

Zeithaml, V. A., Parasuraman, A., \& Berry, L. L. (1985). Problems and strategies in services marketing. The Journal of Marketing, 33-46.

Zeithaml, V. A. (1988). Consumer perceptions of price, quality, and value: a means-end model and synthesis of evidence. The Journal of marketing, 2-22.

Zerbini, F. (2017). CSR initiatives as market signals: A review and research agenda. Journal of Business Ethics, 146(1), 1-23.

Zeriti, A., Robson, M. J., Spyropoulou, S., \& Leonidou, C. N. (2014). Sustainable export marketing strategy fit and performance. Journal of International Marketing, 22(4), 4466.

Zhang, C., Cavusgil, S. T., \& Roath, A. S. (2003). Manufacturer governance of foreign distributor relationships: do relational norms enhance competitiveness in the export market?. Journal of International Business Studies, 34(6), 550-566.

Zhu, Z., Zhao, J., \& Jin, X. (2013). A typology of net-enabled organisational capabilities for digital competitive advantage: the case study of travel and hospitality industry in China. International Journal of Networking and Virtual Organisations 11, 12(1), 56-69.

Zou, S., \& Tamer Cavusgil, S. (1996). Global strategy: a review and an integrated conceptual framework. European Journal of Marketing, 30(1), 52-69.

Zou, S., \& Stan, S. (1998). The determinants of export performance: a review of the empirical literature between 1987 and 1997. International Marketing Review, 15(5), 333-356. 
Zou, S., Taylor, C. R., \& Osland, G. E. (1998). The EXPERF scale: a cross-national generalized export performance measure. Journal of international Marketing, 37-58.

Zou, S., \& Cavusgil, S. T. (2002). The GMS: A broad conceptualization of global marketing strategy and its effect on firm performance. Journal of marketing, 66(4), 4056.

Zou, S., Fang, E., \& Zhao, S. (2003). The effect of export marketing capabilities on export performance: an investigation of Chinese exporters. Journal of International marketing, 11(4), 32-55. 


\section{ANNEX I. QUESTIONNAIRE}

This Annex includes the questionnaire that was sent to the companies in the sample. See details as follows:

\section{GENERAL INFORMATION OF THE COMPANY}

\begin{tabular}{|l|l|}
\hline Corporate name & \\
\hline City & $\begin{array}{l}\square \text { Home } \\
\square \text { Clothing industry } \\
\square \text { Footwear } \\
\square \text { Complements } \\
\text { Province / Area }\end{array}$ \\
\hline Fashion sector & Others \\
\hline Total turnover (€) & Number of employees \\
\hline Year of establishment & \\
\hline N. of years in export venture & \\
\hline N. of countries selling to & \\
\hline Export intensity: exports / total sales (\%) & \\
\hline Exports to EU / Total exports (\%) & \\
\hline
\end{tabular}




\section{EXPORT PERFORMANCE OF THE COMPANY}

Please specify your level of satisfaction with the international activity of your company in the last 3 years (1: very unsatisfied ..... 7: very satisfied)

Very unsatisfied

very satisfied

\begin{tabular}{|l|c|c|c|c|c|c|c|}
\hline Exports volume & 1 & 2 & 3 & 4 & 5 & 6 & 7 \\
\hline Exports growth & 1 & 2 & 3 & 4 & 5 & 6 & 7 \\
\hline Market share in international markets & 1 & 2 & 3 & 4 & 5 & 6 & 7 \\
\hline Degree of diversification (no of countries exporting to) & 1 & 2 & 3 & 4 & 5 & 6 & 7 \\
\hline Access to international markets & 1 & 2 & 3 & 4 & 5 & 6 & 7 \\
\hline Profitability of exports & 1 & 2 & 3 & 4 & 5 & 6 & 7 \\
\hline Profit margin of exports & 1 & 2 & 3 & 4 & 5 & 6 & 7 \\
\hline General satisfaction with exports & 1 & 2 & 3 & 4 & 5 & 6 & 7 \\
\hline
\end{tabular}

\section{MANAGEMENT}

Please evaluate the performance of your company regarding the acquisition of management capabilities compared to your main competitors.

much worse

much better

\begin{tabular}{|l|c|c|c|c|c|c|c|}
\hline General management skills & 1 & 2 & 3 & 4 & 5 & 6 & 7 \\
\hline Marketing skills & 1 & 2 & 3 & 4 & 5 & 6 & 7 \\
\hline Language skills & 1 & 2 & 3 & 4 & 5 & 6 & 7 \\
\hline Computer and IT skills & 1 & 2 & 3 & 4 & 5 & 6 & 7 \\
\hline Experience in international markets & 1 & 2 & 3 & 4 & 5 & 6 & 7 \\
\hline General overview of the company & 1 & 2 & 3 & 4 & 5 & 6 & 7 \\
\hline Export orientation & 1 & 2 & 3 & 4 & 5 & 6 & 7 \\
\hline Ability to facilitate communication & 1 & 2 & 3 & 4 & 5 & 6 & 7 \\
\hline Ability to manage teams & 1 & 2 & 3 & 4 & 5 & 6 & 7 \\
\hline
\end{tabular}




\section{MARKETING STRATEGY}

Please evaluate the performance of your company regarding the following components of the marketing strategy:

much worse

much better

\begin{tabular}{|l|c|c|c|c|c|c|c|}
\hline Knowledge of customers & 1 & 2 & 3 & 4 & 5 & 6 & 7 \\
\hline Knowledge of competitors & 1 & 2 & 3 & 4 & 5 & 6 & 7 \\
\hline Planning of marketing activities & 1 & 2 & 3 & 4 & 5 & 6 & 7 \\
\hline Integration of marketing activities & 1 & 2 & 3 & 4 & 5 & 6 & 7 \\
\hline Skill to segment and target markets & 1 & 2 & 3 & 4 & 5 & 6 & 7 \\
\hline Development of market research programs & 1 & 2 & 3 & 4 & 5 & 6 & 7 \\
\hline Relationships with channel members (agents/distributors ...) & 1 & 2 & 3 & 4 & 5 & 6 & 7 \\
\hline Development of CSR programs (environment/ethical policies) & 1 & 2 & 3 & 4 & 5 & 6 & 7 \\
\hline Ability to retain customers & 1 & 2 & 3 & 4 & 5 & 6 & 7 \\
\hline Effectiveness of the after-sales service & 1 & 2 & 3 & 4 & 5 & 6 & 7 \\
\hline Effectiveness of the sales team & 1 & 2 & 3 & 4 & 5 & 6 & 7 \\
\hline
\end{tabular}

PRODUCT

Regarding your product strategy in international markets, please specify your degree of agreement or disagreement for every statement.

strongly disagree strongly agree

\begin{tabular}{|l|c|c|c|c|c|c|c|}
\hline We adapt the product to customer needs & 1 & 2 & 3 & 4 & 5 & 6 & 7 \\
\hline We offer a wide range of products & 1 & 2 & 3 & 4 & 5 & 6 & 7 \\
\hline We invest in product quality & 1 & 2 & 3 & 4 & 5 & 6 & 7 \\
\hline We invest in product brand name & 1 & 2 & 3 & 4 & 5 & 6 & 7 \\
\hline We invest in product design & 1 & 2 & 3 & 4 & 5 & 6 & 7 \\
\hline We invest in product innovation & 1 & 2 & 3 & 4 & 5 & 6 & 7 \\
\hline We provide a high level of customer service & 1 & 2 & 3 & 4 & 5 & 6 & 7 \\
\hline We pretend to differentiate our product from the competition & 1 & 2 & 3 & 4 & 5 & 6 & 7 \\
\hline
\end{tabular}


PRICE

Regarding your price strategy in international markets, please specify your degree of agreement or disagreement for every statement.

strongly disagree strongly agree

\begin{tabular}{|l|c|c|c|c|c|c|c|}
\hline Our price strategy is adapted depending on the market & 1 & 2 & 3 & 4 & 5 & 6 & 7 \\
\hline We follow a high-price strategy & 1 & 2 & 3 & 4 & 5 & 6 & 7 \\
\hline We offer very competitive prices & 1 & 2 & 3 & 4 & 5 & 6 & 7 \\
\hline We keep high profit margins & 1 & 2 & 3 & 4 & 5 & 6 & 7 \\
\hline We control the final price of the product & 1 & 2 & 3 & 4 & 5 & 6 & 7 \\
\hline Prices are established according to product costs & 1 & 2 & 3 & 4 & 5 & 6 & 7 \\
\hline Frequent promotions and price discounts are carried out & 1 & 2 & 3 & 4 & 5 & 6 & 7 \\
\hline We provide credit to our customers & 1 & 2 & 3 & 4 & 5 & 6 & 7 \\
\hline
\end{tabular}

\section{PROMOTION}

Regarding your promotion strategy in international markets, please specify your degree of agreement or disagreement for every statement.

strongly disagree strongly agree

\begin{tabular}{|l|c|c|c|c|c|c|c|}
\hline Our communication policy is adapted depending on the market & 1 & 2 & 3 & 4 & 5 & 6 & 7 \\
\hline We carry out promotion in exhibitions & 1 & 2 & 3 & 4 & 5 & 6 & 7 \\
\hline We visit our customers regularly & 1 & 2 & 3 & 4 & 5 & 6 & 7 \\
\hline We promote through media & 1 & 2 & 3 & 4 & 5 & 6 & 7 \\
\hline We have our own catalogues & 1 & 2 & 3 & 4 & 5 & 6 & 7 \\
\hline We carry out mailshots regularly & 1 & 2 & 3 & 4 & 5 & 6 & 7 \\
\hline The website is adapted to foreign markets & 1 & 2 & 3 & 4 & 5 & 6 & 7 \\
\hline We take advantage of social networks & 1 & 2 & 3 & 4 & 5 & 6 & 7 \\
\hline We use the language of every foreign country & 1 & 2 & 3 & 4 & 5 & 6 & 7 \\
\hline
\end{tabular}




\section{PLACE / DISTRIBUTION}

Regarding your distribution strategy in international markets, please specify your degree of agreement or disagreement for every statement.

strongly disagree

strongly agree

\begin{tabular}{|l|c|c|c|c|c|c|c|}
\hline Our distribution strategy is adapted depending on the market & 1 & 2 & 3 & 4 & 5 & 6 & 7 \\
\hline We support the chosen channel in every country & 1 & 2 & 3 & 4 & 5 & 6 & 7 \\
\hline We use agents & 1 & 2 & 3 & 4 & 5 & 6 & 7 \\
\hline We use distributors & 1 & 2 & 3 & 4 & 5 & 6 & 7 \\
\hline We have commercial subsidiaries & 1 & 2 & 3 & 4 & 5 & 6 & 7 \\
\hline We have production subsidiaries & 1 & 2 & 3 & 4 & 5 & 6 & 7 \\
\hline We sell directly to the final customer & 1 & 2 & 3 & 4 & 5 & 6 & 7 \\
\hline We sell through the Internet & 1 & 2 & 3 & 4 & 5 & 6 & 7 \\
\hline We take care of our delivery dates & 1 & 2 & 3 & 4 & 5 & 6 & 7 \\
\hline
\end{tabular}

\section{NEW TECHNOLOGIES}

Please evaluate the performance of your company regarding the use of New Technologies in the following policies compared to your main competitors.

\begin{tabular}{|l|c|c|c|c|c|c|c|}
\hline Promotion and communication of new products/services & 1 & 2 & 3 & 4 & 5 & 6 & 7 \\
\hline Provision of online catalogues to customers & 1 & 2 & 3 & 4 & 5 & 6 & 7 \\
\hline Answer to customer queries (availability, order status ...) & 1 & 2 & 3 & 4 & 5 & 6 & 7 \\
\hline Enabling salespeople online access to product, price ... information & 1 & 2 & 3 & 4 & 5 & 6 & 7 \\
\hline Enabling salespeople/customer online transmission of orders & 1 & 2 & 3 & 4 & 5 & 6 & 7 \\
\hline Providing online support to distributors/dealers & 1 & 2 & 3 & 4 & 5 & 6 & 7 \\
\hline Gathering market related information on customers, competitors & 1 & 2 & 3 & 4 & 5 & 6 & 7 \\
and industry & & & & & & 7 \\
\hline Use of website visitor information for marketing and prospecting & 1 & 2 & 3 & 4 & 5 & 6 & 7 \\
\hline $\begin{array}{l}\text { Improvement of communication and coordination in managing } \\
\text { operations and team projects }\end{array}$ & 1 & 2 & 3 & 4 & 5 & 6 & 7 \\
\hline
\end{tabular}


COMPETITIVE STRATEGY

Please select the policy that best fits the competitive strategy followed by your company in foreign markets.

\begin{tabular}{|l|l|}
\hline & $\begin{array}{l}\text { Marketing differentiation: we specialize in new marketing techniques, brand development, control } \\
\text { over distribution, competitive pricing ... }\end{array}$ \\
\hline \begin{tabular}{l} 
Segmentation differentiation: we offer specialized products to specific customers \\
\hline Innovation differentiation: we focus on the development of new products and technologies
\end{tabular} \\
\hline $\begin{array}{l}\text { Products/services differentiation: we concentrate on the quality of products and services } \\
\text { (efficiency and service) }\end{array}$ \\
\hline \begin{tabular}{l} 
No specific strategy \\
\hline
\end{tabular}
\end{tabular}

\section{ENVIRONMENT}

Please evaluate the importance of the following characteristics when determining which international markets to enter. (1: low importance ...... 7: high importance)

\begin{tabular}{|l|c|c|c|c|c|c|c|}
\multicolumn{1}{c}{} & \multicolumn{7}{c|}{ low importance } \\
\hline Possibility to keep high profit margins & 1 & 2 & 3 & 4 & 5 & 6 & 7 \\
\hline Ability to detect consumer needs & 1 & 2 & 3 & 4 & 5 & 6 & 7 \\
\hline Market stability (few technological, social or political changes) & 1 & 2 & 3 & 4 & 5 & 6 & 7 \\
\hline Similarities in political and legal terms & 1 & 2 & 3 & 4 & 5 & 6 & 7 \\
\hline Similarities in marketing policies & 1 & 2 & 3 & 4 & 5 & 6 & 7 \\
\hline
\end{tabular}

